INFX Guide:

DEPARTMENT OF ENERGY

BILATERAL AGREEMENTS FOR

COOPERATION IN THE FIELD OF

RADIOACTIVE WASTE MANAGEMENT

(INFX: International Information Exchange)

Prepared for the U.S. Department of Energy

under Contract DE-AC06-76RLO 1830

Pacific Northwest Laboratory

Operated for the U.S. Department of Energy

- by Battelle Memorial Institute

* Baftelle 
JuTy 31,1985

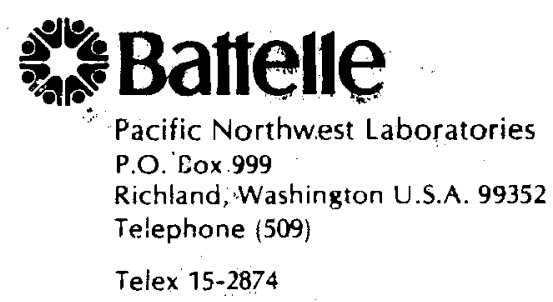

DISTRIBUTION

PNL-3774, Rev. 5, MINFX Guide; Department of Energy Biliateral Agreements For Cooperation in the Fielo of Radioactive haste Management"

This is the fifth revision of a document originally issued in November 1981 under the title INEX Guide: Summary of U. S. ROE Plans and Policies for International Cooperation in the Fisld of Baciloactive Waste Manageneut: It replaces PNL-3774, Rev. 4, which should be completely discarded.

Please contact our of fice $(509-375-3878)$ if you hise any questions. Sincerely,

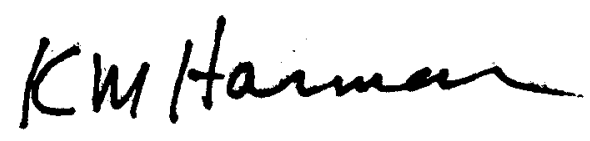

K. M. Harmon

International Program Support Office

$\mathrm{KMH} / \mathrm{aj}$

Enclosure 
INFX GUIDE :

DEPARTMENT OF ENERGY BILATERAL AGREEMENTS

FOR COOPERATION IN THE FIELD OF RADIOACTIVE WASTE MANAGEMENT

(INFX: INTERNATIONAL INFORMATION EXCHANGE)

Compiled by

K. M. Harmon

L. T. Lakey

I. W. Leigh

A. G. Jeffs

Issued November 1981

Latest Revision Ju1y 1985

Prepared for

the U. S. Department of Energy

under Contract DE-AC06-76RLO 1830

Pacific Northwest Laboratory

Richland, WA 99352 


\section{DISCLAIMER}

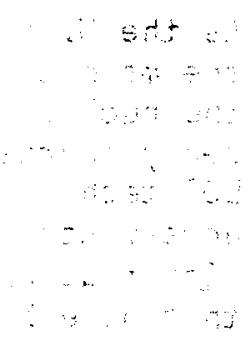

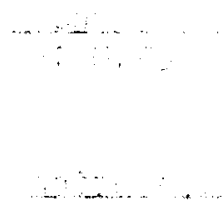

$\cdot$

This report was prepared as an account of work sponsored by an agency of the United States Government. Neither the United States Government nor any agency thereof, nor any of their employees, makes any warranty, express or implied, or assumes any legal liability or responsibility for the accuracy, completeness, or usefulness of any information, apparatus, product, or process disclosed, or represents that its use would not infringe privately owned rights. 'Reference herein to any specific commercial product, process, or service by trade name, trademark, manufacturer, or otherwise, does not necessarily constitute or imply its endorsement, recommendation, or favoring by the United States Government or any agency thereof. The views and opinions of authors expressed herein do not necessarily state or reflect those of the United States Government or any agency thereof.

\section{PACIFIC NORTHWEST LABORATORY operated by \\ BATTELLE \\ for the \\ UNITED STATES DEPARTMENT OF ENERGY \\ under Contract DE-AC06-76RLO 1830}

\begin{tabular}{|c|c|}
\hline \multicolumn{2}{|c|}{ Printed in the United States of America } \\
\hline \multicolumn{2}{|c|}{ Available from } \\
\hline \multirow{2}{*}{\multicolumn{2}{|c|}{$\begin{array}{l}\text { National Technical Information Service } \\
\text { United States Department of Commerce }\end{array}$}} \\
\hline & \\
\hline & \\
\hline \multicolumn{2}{|c|}{$\begin{array}{l}5285 \text { Port Royal Road } \\
\text { Springfield, Virginia } 22161\end{array}$} \\
\hline \multirow{2}{*}{\multicolumn{2}{|c|}{$\begin{array}{l}\text { NTIS Price Codes } \\
\text { Microfiche A01 }\end{array}$}} \\
\hline & \\
\hline \multicolumn{2}{|c|}{ Printed Copy } \\
\hline & Price \\
\hline Pages & Codes \\
\hline $001-025$ & $\mathrm{~A} 02$ \\
\hline $026-050$ & $\mathrm{~A} 03$ \\
\hline 051.075 & $\mathrm{AO4}$ \\
\hline $076-100$ & A05 \\
\hline $101-125$ & $A 06$ \\
\hline $126-150$ & $\mathrm{~A} 07$ \\
\hline $151-175$ & $A 08$ \\
\hline $176-200$ & $A 09$ \\
\hline $201-225$ & $A 010$ \\
\hline $226-250$ & A011 \\
\hline $251-275$ & $\mathrm{~A} 012$ \\
\hline $276-300$ & A013 \\
\hline
\end{tabular}
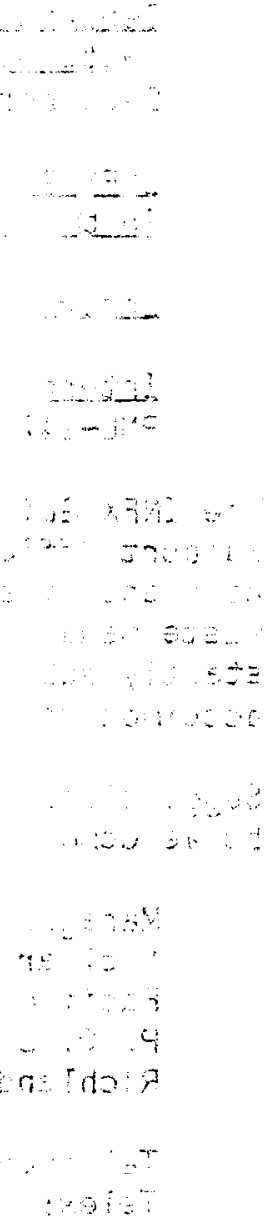
As the U. S. Department of Energy (DOE) and DOE contractors have increased the magnitude and scope of their cooperative activities with other nations in the nuclear fuel cycle and waste management field, a need has developed for ready sources of information concerning foreign waste management programs, DOE technology exchange policies, bilateral fuel cycle and waste management agreements and $\mathrm{pl}$ ans and activities to implement those agreements. The INFX (International Information Exchange) Guide is one of a series of documents that have been prepared to provide that information:

Department of Energy, Office of Radioactive Waste Management, International Waste Management Activities: Evaluation and Plans, issued by OCRWM in December 1984;

INEX Guide: Department of Energy Bilateral Agreements for Cooperation in the Field of Radioactive Waste Management, PNL-3774, Rev. 5, July 1985;

International Fuel Cycle Fact Book, PNL-3594, Rev. 5, January 1985;

International Source Book: Nuclear Fuel Cycle Research and Development, PNL-2478, Rev. 2, 1982 (undergoes periodic updating).

The INFX Guide has been compiled under the charter of PNL's International Support Office (IPSO) to maintain for DOE a center to collect, organize, evaluate and disseminate information on foreign and international radioactive waste management programs. Because the information in this document is constantly subject to change, the document is assembled in loose-leaf form to accommodate frequent updates.

Suggestions that would improve the usefulness or accuracy of this guide will be welcomed and should be submitted to:

Manager, International Program Support Office Nuclear Fuel Cycle and Waste Management Program Office Pacific Northwest Laboratory

P. O. Box 999

Richl and, WA 99352

Telephone/FTS: (509) $375-2758$ or $375-3878$

Telex: $\quad 15-2874$ 


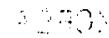

$\therefore$

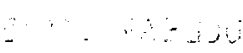

$\cdots$ 


\section{IABLE OF CONIENTS}

INTRODUCTION . . . . . . . . . . . . . . . . . . .

BILATERAL ACTIVITIES

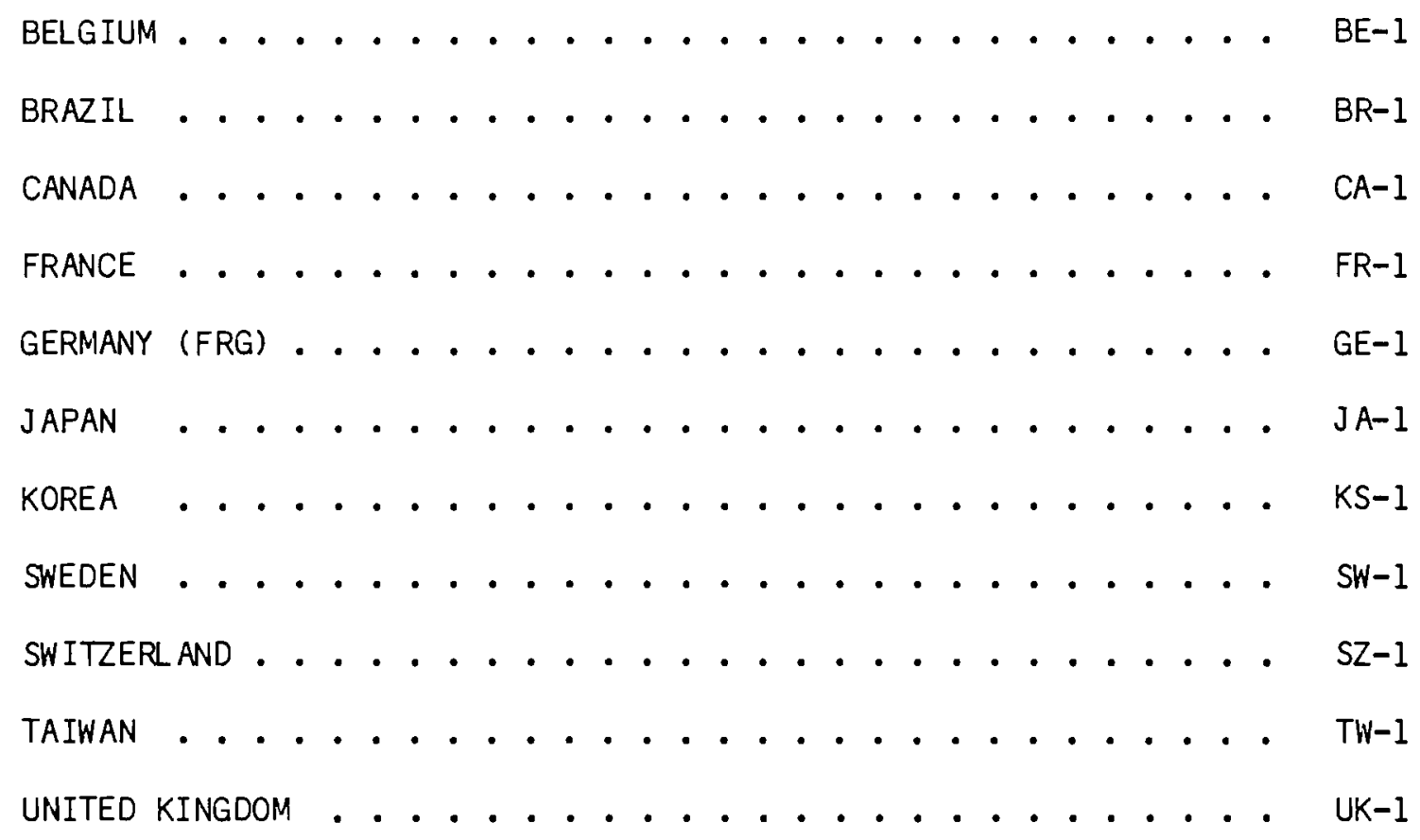

INTERNATIONAL ACTIVITIES

EUROPEAN ATOMIC ENERGY COMMUNITY (CEC) . . . . . . . . . CEC-1 OECD/NUCLEAR ENERGY AGENCY (NEA) . . . . . . . . . . NEA-1

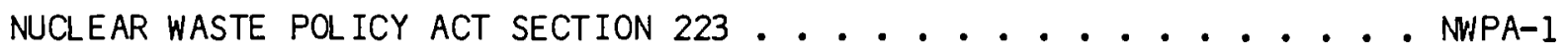
APPENDIX A - DOE INFX POLICIES . . . . . . . . . . . . A-I

APPENDIX B - ESTABL ISHING AGREEMENTS . . . . . . . . . . . . B-l APPENDIX C - REPORT DISTRIBUTION . . . . . . . . . . . . C C-1 APPENDIX D - FOREIGN VISITORS AND TRAVEL . . . . . . . . . . D-I 


\section{INTRODUCTION}

A significant feature of United States nuclear waste management and fuel cycle policy is the continuing national commitment to participate in cooperative international R\&D programs. This commitment was reaffirmed in a statement to the press by the President July 16, 1981, which said in part: "The United States will cooperate with other nations in the peaceful uses of nuclear energy, including civil nuclear programs to meet their energy security needs, under a regime of adequate safeguards and controls . . . The United States will support IAEA programs and other international cooperative efforts in the areas of nuclear safety and environmentally sound nuclear waste management." The Department of State underscored the administration's stand in a statement by James L. Buckley August 10, 1981, "I would like to encourage the Department of Energy to support efforts taking place in important industrial countries to solve some of the problems generic to nuclear electricity generation. This is particularly true for our partners in the Organization for Economic Cooperation and Development . . ." The Congress and the Administration once again affirmed to policy in the Nuclear Waste Policy Act (NWPA) of 1982 by requiring the Department of Energy and the Nuclear Regulatory Commission to offer non-nuclear weapon states their cooperation and technical assistance in alleviating problems that may develop from accumulation of spent nuclear fuel in excess of storage capabilities.

The current general policy for international cooperation in the fuel cycle and waste management field is aimed at:

1) supporting the U.S. domestic energy program through the acquisition of information about foreign energy technologies and R\&D programs and their results;

2) providing support for U.S. foreign policy objectives through international cooperation in the energy information field; and

3) achieving, to the extent possible, a reasonable balance of benefits between the parties.

In support of this policy, the U.S. Department of Energy:

1) sponsors active support of the OECD/Nuclear Energy Agency (NEA) and participation in International Atomic Energy Agency (IAEA) activities. These two organizations depend to a major extent upon technical experts from their Member States for preparation of technical reports and safety guidance documents and for contributions to workshops, seminars, and symposia. DOE representatives participate in such efforts, either in part or entirely, at DOE expense. The NEA al so sponsors projects, e.g., the multilateral in situ tests at the Stripa mine in Sweden and the International Radionuclide Sorption Information Retrieval System (ISIRS) Project; 
2) is significantly increasing the level of U.S. effort to implement formal bilateral agreements to exchange waste fuel cycle management technology and cooperate in other ways. These activities include U.S. participation in foreign projects, the exchange of personnel and the exchange of information;

3) encourages DOE contractors to host visitors from non-agreement nations at DOE sites and exchange technical information.

The INFX Guide is a compilation of a) DOE's bilateral agreements for cooperation in the radioactive waste management field, b) Section 223 of the NWPA and c) reports of the most recent bilateral program review/evaluation meetings. Appendices that provide guidance for establishing new agreements, arranging for foreign travel, and foreign distribution of DOE waste management reports are also included.

At present, the U.S. has bilateral agreements with Belgium, Canada, the Commission of European Communities (CEC), France, Germany (FRG), Japan, Sweden, Switzerland and the United Kingdom for cooperation in the fuel cycle/waste management area, has agreements with Brazil and Spain for scientific and technical cooperation that could include exchange of waste management information, and has responded to requests from several other countries for assistance under Section 223 of the NWPA.

The status of DOE's bilateral agreements is summarized below.

1. Belgium. The agreement between DOE and the Belgian Nuclear Energy Research Center (CEN/SCK) at Mol was instituted January 19, 1981 and currently extends to 1989 . The technical scope includes waste processing, retrievable and terminal storage, and environmental effects.

2. Brazil. In preliminary discussions in the spring of 1983, Brazilian representatives expressed their interest in receiving technical help from the U.S. in the waste management area. The report of the Working Group (on nuclear cooperation) is included in the Brazil section.

3. Canada. The agreement between DOE and Atomic Energy of Canada Limited (AECL) was instituted in 1976 and covers waste processing, waste storage (retrievable and terminal), and environmental effects. The cooperative program is currently focused on Canada's Underground Research Laboratory (URL) at whiteshe11, with DOE providing technical support. The cooperative geologic program is managed through DOE-AECL review meetings, held approximately annually, and through U.S. participation in URL project planning meetings.

4. CEC. A DOE-CEC cooperative agreement was signed in October 1982. At present, it covers deep geologic isolation technology and studies of waste form properties, but may be extended to other waste management topics. Initial emphasis in implementation is on MCC-related activities. 
5. Federal Republic of Germany. The agreement between DOE and the German Ministry of Science and Technology (BMFT) has been in effect since 1974 and covers virtually all aspects of waste management technology. At present, the principal emphasis is on exchange of technology for conditioning high-level and TRU wastes, on remedial action programs and on geologic isolation. Under the basic agreement, DOE and BMFT have instituted several implementing agreements. The cooperative program is managed through annual review meetings, held alternately in the U.S. and Germany.

6. France. A DOE-CEA cooperative agreement was signed in 1983. The French are primarily interested in gaining access to U.S. geologic waste isolation technology but are willing to provide information concerning their waste treatment R\&D in exchange.

7. Japan. The Power Reactor and Nuclear Fuel Development Corporation (PNC) of Japan and DOE have been exchanging LMFBR technology under a formal agreement since 1968. In 1.981, two new DOE/PNC working groups were established under the LMFBR agreement--one for waste management and one for FBR fuel reprocessing. The two working groups have held preliminary meetings, and specific cooperative activities are in progress.

8. Spain. An agreement for scientific and technological cooperation was established between the governments of Spain and the U.S. in 1982. Specific fields were not defined.

9. Sweden. An agreement between DOE and the Swedish Nuclear Fuel and Waste Management Company (SKB) was instituted in 1977, covering waste storage in deep geologic formations. In addition to an active information exchange program, DOE supported a three-year series of field tests in the Stripa mine in Sweden (1977-1980) and is currently participating in an NEA in situ test program at Stripa.

10. Switzerland. National Cooperative for the Storage of Radioactive Waste (NAGRA) and DOE signed an agreement for cooperation in the field of waste management in 1985. The emphasis will be on crystalline rock repository development.

11. United Kingdom. Waste management technology exchange between DOE and the United Kingdom Atomic Energy Authority (UKAEA) occurs under an LMFBR cooperative agreement dating from 1976. Several working group meetings have been held in the area of TRU waste conditioning, and technical exchanges have occurred in other areas. Consideration is being given to a separate waste management exchange agreement. 




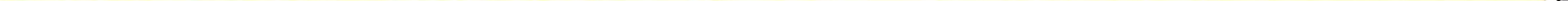




\section{BELGIUM (BE)}

BLANKET AGREEMENT (Attachment BE-1)

Parties: $\quad$ US/DOE; Belgium/Nuclear Research Center at Mol (CEN/SCK)

Term: January 19, 1981 to January 19,1989

Technical Scope: Waste processing technology; retrievable and terminal waste storage; environmental effects

\section{SUBSIDIARY AGREEMENTS}

None

\section{STATUS/PLANNING REPORTS}

Summary of Bilateral Agreement Meeting--US, 03/85 (Attachment BE-2)

\section{ADMINISTRATION}

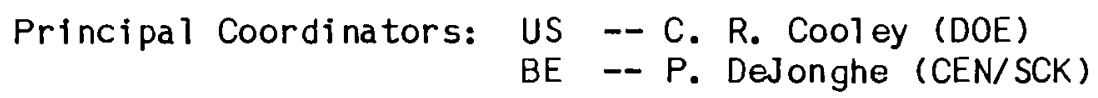

Document Exchange: see Appendix C 


\section{(ivi)}

Department of Energy

Washington, D.C. 20585

January 3, 1985

\section{Mr. S. Amelinckx}

Director General

Center for the Study of Nuclear Energy of Belgium

B-2400 Mol, Belgium

Dear Mr. Amelinckx,

The Agreement between the UNITED STATES DEPARTMENT OF ENERGY and the Belgian CENTRE D'ETUDE DE L'ENERGIE NUCLEAIRE / STUDIECENTRUM VOOR KERNENERGIE in the field of RADIOACTIVE WASTE MANAGEMENT, which entered into force on January 19, 1981, is due to expire on January 19,1985 .

The visits and exchanges that have taken place under this Agreement have been of value to both sides, and we anticipate that the planned future prograns of both our organizations in the field of radioactive waste management offer the potential of continued mutual benefit.

I therefore am pleased to propose on behalf of the United States Department of Energy that this letter and your favorable reply shall have the effect of extending the Agreement between our organizations in the field of radioactive waste management until January $19,1989$.

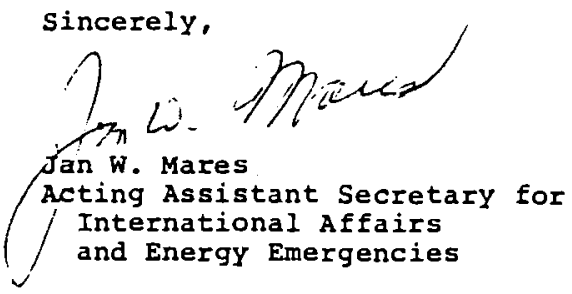

STUDIECENTAUM VOOR KEANENEAGIE S.C.K./C.E.N.

INSTELLING VAN OPENBAAA NUT

in duplicate is :

LABOAA TOAY OI the S.C.K.IC.E.N.

Bosereang 200 B-2400 MOL

Tolox : 31922

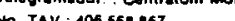

Mr.Jan W. MARES

Ang Assistant Secretary for Interat Ional Affalrs and Energy Emergencies Deparcment of Energy

MOL. January 22,1985

SA/gu

Dear Mr.Mares,

I acknowledge recelpt of your letter of January 3 , concerning the extension of the agreement between the Daited States Department of Energy and the Belgian Centre d'Etude de l'Energle Nuclealre/studecentru voor Kernenergle, in the fleld of Radioactive Haste Management. which entered into force on January 19, 1981. We sincerely thank you for your willingness to extend the agreement for a new period of 4 years, expiring on January 19,1989 .

I am convinced that, taking into account the importance of the subject of radioactive waste management and the existence of aubltious programmes, both parties will draw maxinum benefit from the extended collaboration.

According to the terms of your letter, we consider that the present reply has the effect of extending the Agreement between our organizations in the fleld of radioactlve waste management.

Yours sincerely,

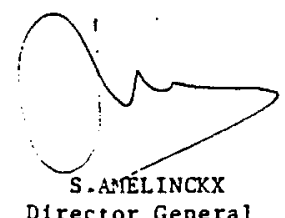

D1rector General 
Agreement between the

UNITED STATES DEPARTMENT OF ENERGY and the Belgian

\section{CENTRE D'ETUDE DE L'ENERGIE NUCLEAIRE} STUDIECENTRUM VOOR KERNENEFGIE in the field of

RADIOACTIVE WASTE MANAGEMENT
The United States Department of Energy (DoE) and the Belgian Centre d'Etude de I'Energie Nucléaire/Studiecentrum voor Kernenergie (CEN/SCK), hereinafter called the Parties:

sharing non-proliferation objectives and consequently having a mutual interest in the development of radioactive waste management techniques in such a manner as not to contribute to the proliferation of nuclear weapons;

recognizing the advantages of sharing information derived from their respective experiences and capabilities:

noting the respective statutory authority of DoE and CEN/SCK to disseminate information related to nuclear energy; and

desiring to ençage in specific cooperative arrangements to exchange a broad rance of information concerning radioaciive waste management; that includes the alternatives of disposal of separated waste products and the disposal of spent fuel:

have agreed as follows:
1. The objective of cooperation under this Agreement is to establish, for the mutual benefit of the Parties, a reasonably balanced exchange of technolc gy in the field of radioactive waste management.

2. The parties agree to use their best efforts to balance and maximize the exchange of information under this Agreement, subject to the provisions of Article 13.

3. The Parties agree to use their good offices to facilitate activities under this Agreement. particularly those involving exchange, visits or assignment of personnel, recognizing that there are established requirements and procedures governing such visits and assignments to facilities of the respective Parties, including contractor facilities, and recognizing that such requirements and procedures are not affected by this Agreement.

4. The Parties agree to establish jointly any detailed procedures required to carry out this Agreement. All situations not specifically covered in this Agreement shall be settled by mutual agreement of the Parties and shall be governed by the basic principle of equivalent benefit to both Parties.

5. In the course of implementing this Agreement, the parties may exchange safeguards technology as applicable to the areas of cooperation, listed in Article 2

\section{ARTICLE 2}

The areas of cooperation in radioactive waste management technology covered by this Agreement may include

1. Terminal Storage in Geological Formations

a. Characterization of $\mathrm{G}$ eologic Formations

b. Development and Testing of Facilities

c. Safety A:sessment and Public Acceptance Matters

2. Tectinology of Retrievable Storage

a. Design Verification of Canister Storage

b. Retrievahility Design in Geologic Repositories

c. Storage of Plutonium Contaminated Waste

3. Waste Processing Technology

a. High Level Waste Solidification

b. Fuel Hardware and Hulls

c. Interriedicte and Low Level Liquid Waste

d. Contaminated Solid Waste

(1) Combustibles

(2) Non-combustitles 
e. Airborne Waste

(1) Particulates and lodine

(2) Noble Gases

(3) Tritium. Including its Separation from Water

(4) Carbon-14

\section{Environmental Effects}

a. Assessment Methodology

b. Burial Ground Waste Migration Models

Other areas of cooperation may be added by mutual agreement.

\section{ARTICLE 3}

Cooperation in accordance with this Agreement may include but is not limited to the following forms :

1. Exchange of scientists, engineers and other specialists for participation in agreed research, development, analysis, design and experimental activities conducted in scientific centers, laboratories, engineering officas and other facilities of each of the Parties or its contractors for agreed periods. Each such exchange of staff shall be the subject of a separate attachment agreement between the Parties.

2. Exchange of samples, materials, instruments and components for testing.

3. Exchange of scientific and technical information, and results and methods of research and development.

4. The organization of seminars and other meetings on specific agreed topics concerning the fields of technology listed in Article 2. Such seminars shall normally be held alternately in the United States and in Belgium.

5. Shor visits by specialist teams or individuals to the research and development facilities of the other Party.

6. The use by one Party of the facilities owned or operated by the other Party. Such use of facilities shall be the subject of Subsidiary Agreements between the Parties, and may be subject to commercial terms and conditions.

7. Joint projects in which the Parties agree to share the work and/or costs Each such joint project shall be the subject of a Subsidiary Agrceiment between the Paries.

Other forms of ccoperation may be agreed to by the Parties and approved by the Joint Commintes (Article 4).

\section{ARTICLE 4}

1. To supervise the execution of this Agreement, a Joint DoE-CEN/SCK Committee in the Field of Radioactive Waste Management shall be established. This Committee shall meet each year alternately in the United States and Belgium, or at other agreed times and places. The Head of the Delegation of the Receiving Party shall act as Chaisman during meetings of the Com. mittee.

2. At its meetings, the Joint Committee shall evaluate the status of cooperation under this Agreement. This evaluation shall include a comprehensive review of each Party's radioactive waste management program status and plans, an assessment of the balance of exchanges in the various areas of cooperation listed in Article 2, and a consideration of measures required to correct any imbalances. In addition, the Joint Committee shall consider and act on any major new proposals for cooperation.

3. For periods between meetings of the Joint Committee, each Party shall designate one person to act on its behalf in all matters concerning cooperation under this Agreement.

4. Day to day management of the cooperation in each of the areas listed in Article 2 shall be carried ou: by Correspondents appointed by the persons designated under paragraph 3 of this Article.

\section{ARTICLE 5}

Where it is decided a cooperative program or project under this Agreement should be subject to a formalized Subsidiary Agreement executed by both Parties, the Subsidiary Agreement should be attached as an annex to this Agreement and should address all detailed provisions for implementation, including such matters as patents, exchange of equipment, and information disclosure specific to the particular program or project.

\section{ARTICLE 6}

1. General

The Parties support the widest possible dissemination of information provided or exchanged under this Agreement, subject to the need to protect proprieta.

$r y$ information exchanged hereunder, and to the Provisions of Article 8 .

2. Use of Proprielary Information

A. Definitions as used in this Agreement :

(i) The term "informotion" means scientific or technical data, results or methods of reseaich and development, and any other information such as cost evaluations intenced to be provided or exchanged under this Agreement; 
(ii) The term "proprietary information" means information which con. tains trade secrets or commercial or financial information which is privileged or confidential, and may only include such information which :

a) has been held in confidence by its owner;

b) is of a type which is customarily held in confidence by its owner

entities (including the receiving Party) except on the basis that it be held in confidence; and

d) is not otherwise available to the receiving Party from another source without restriction on its further dissemination.

\section{B. Procedures}

(i) A Party receiving proprietary information pursuant to this Agreemen shall respect the privileged nature thereof. Any document which contains proprietary information shall be clearly marked with the following (or substantially similar) restrictive legend :

"This document contains proprietary information furnished in confidence under an Agreement dated ................. between the United States Department of Energy and the Belgian Centre d'Etude de l'Energie Nucléaire/Studiecentrum voor Kernenergie (CEN/SCK) and shall not be disseminated outside these organizations, their contractors, licensees and the concerned departments and agencies of the Governments of the US and Belgium without the prior approval of ................

This notice shall be marked on any reproduction hereof, in whole or in part. These limitations shall automatically terminate when this information is disclosed by the owner without restriction."

(ii) Proprietary information received in confidence under this figreement may be disseminated by the receiving Party to

a) persons within or employed by the receiving Party, and concerned Government departments and Government agencies in the country of the receiving Party:

b) prime or subcontractors of the receiving Party located within the geographical limits of the receiving F'arty's nation, for use only within the framework of their contracts with the receiving Party in work relating to the subject ma'ter of the proprietary information;

c) organizations licensed by the receiving Party for use only within the terms of such licenses:

provided that any proprietary information so disseminated shall be pursuant to an agreement of confidentiality and shall be marked with a restrictive $1-g$ and substantially identical to that appearing in subparagraph $2.6(i)$ ibove.

(iii) With the prior written consent of the Party providing proprictary information unoer this Agreement, the receiving Party may dissemi. nate such proprietary information more widely than otherwise permitted in the foregoing subsection (ii). The Parties shall cooperate with each other in developing procedures for requesting and oblaining approval for such wider dissemination, and each Party will grant such approval to the extent permitted by its national policies, regulations and laws.

C. Each Party shall exercise its best efforts to ensure that proprietary information received by it under this Agreement is controlled as provided herein. If one of the Parties becomes aware that it will be, or may reasonably be expected to become, unable to meet the non-dissemination provisions of this Article, it shall immediately inform the other Party. The Parties shall thereafter consult to define an appropriate course of action.

D. Information arising from seminars and other meetings arranged under this Agreement and information arising from the attachments of staft, use of facilities and joint projects shall be treated by the Parties according to the principles specified in this Article; provided, however, no proprietary information orally communicated shall be subject to the limited disclosure requirements of this Agreement unless the individual communicating such information places the recipient on notice as to the proprietary character of the information communicated.

E. Nothing contained in this Agreement shall preclude the use or dissemination of information received by a Party other than pursuant to this Agreement.

\section{ARTICLE 7}

Information transmitted by one Party to the other Party under this Agreement shall be accurate to the best knowledge and belief of the Transmitting Party, but the Transmitting Party does not warrant the suitability of the information trans. mitted for any particular use or application by the Receiving Party or by any third Party. Information developed jointly by the Parties shall be accurate to the best knowledge and belief of both Parties. Neither Party warrants the accuracy of the jointly developed information or its suitability for any particular use or application by either Party or by any third Party.

\section{ARTICLE 8}

1. With respect to any invention or discovery made or conceived in the course of or under this Agreement :

a) If made or conceived by personnel of one Party (the Assigning Party) or its contractors while assigned to the other Party (Recipient Party) or its contractors, in connection with exchanges of scientists, engineers and other specialists:

(1) The Recipient Party shall acquire all right, title and interest in and to any such invention or discovery in its own country and in third countries, subjcct to a non-exclusive, irrevocable, royalty-free license in all such counties to the Assigning Party, with the right 10 grant sublicenses, under any such invention or discovery and any patent application. patent or other protection relating thereto. 
(2) The Assigning Party shall acquire all right, title and interest in and to any such invention or discovery in its own country. subject to a non exclusive, irrevocable, royalty-free license to the Recipient Party, with the right to grant sublicenses, under any such invention or discovery and any patent application, patent or other protection relating thereto.

b. If made or conceived by a Party or its contractors as a direct result of employing information which has been communicated to it under this Agreement by the other Party or its contractors or communicated during seminars or other joint meetings, the Party making the invention shall acquire all right, title and interest in and to such invention or discovery in all countries, subject to a grant to. the other Party of a royalty-free. non-exclusive, irrevocable ficense with the right to grant sublicenses in and to any such invention or discovery and any patent application, patent or other protection relating thereto, in all countries.

c. With regard to other specific forms of cooperation, including loans or exchanges of materials. instruments and equipment or special joint research projects, the Parties shall provide for appropriate distribution of rights to inventions or discoveries resulting from such cooperation. In general, however, each Party should normally own the rights to such inventions or discoveries in its own country with a non exclusive, irrevocable, royalty-free license to the other Party, and the rights to such inventions or discoveries in other countries should be agreed by the Parties on an equitable basis.

2. Neither Party shall discriminate against citizens of the country of the other Party with respect 10 granting any license or sublicense under any invention or discovery pursuant to paragraph 1 above.

3. Each Party shall assume the responsibility to pay awards or compensation required to be paid to its own nationals according to its own laws.

\section{ARTICLE 9}

1. Whenever an exchange of staff is contemplated under this Agreement, each Party shall ensure that qualified staff are selected for attachment to the other Party.

2. Each such attachment of staff shall be the subject of a separate attachment agreement between the Parties.

3. Each Party shall be responsible for the salaries, insurance and allowances to be paid to its staff.

4. Each Party shall pay for the travel and living expenses of its staft while on attachment to the host Pariy unless othen:ise agreed.
5. The host establishment shall arrange for comparable accomodations for the other Party's staff and their families on a mutually agreeable reciprocal basis.

6. Each Party shall provide all necessary assistance to the attached staff land their families) of the other Party as regards administrative formalities (trave arrangements, etc.).

7. The staff of each Party shall conform to the general and special rules of work and safety regulations in force at the host establishment, or as agreed in sepa rate attachment of staff agreements.

\section{ARTICLE 10}

1. By mutual agreement the sending Party may provide equipment to be utilized in joint projects and experiments. In such cases the sending Party shall supply as soon as possible a detailed list of the equipment to be provided together with the relevant specifications and technical and informational documentation.

2. The equipment and necessary spare parts supplied by the sending Party for use in joint projects and experiments shall remain its property and shall be returned to the sending Party upon completion of the joint project or experiment, unless o therwise agreed.

3. The above-mentioned equipment shall be brought into operation at the hos establishment only by mutual agreement between the Parties or between their senior representatives at the host establishment.

4. The host establishment shall provide the necessary premises for the equipment and will provide for electrical power, water, gas, etc., in accordance with technical requirements which shall be as mutually agreed upon.

5. The responsibility and expenses for the transport of equipment and materials from the United States by plane or ship to an authorized port of entry in Belgium convenient to the ultimate destination, and return, and also responsibility for their safekeeping and insurance en route shall rest with DoE.

6. The responsibility and expenses for the transport of equipment and materials from Belgium by plane or ship to an authorized pon of entry in the United States convenient to the ultimate destination, and return, and also responsibility for their safekeeping and insurance en route shall rest with CEN/SCK.

7. The equipment provided by the sending Party for carrying out joint projects will be considered to be scientific, not having a commercial character, for the purposes of designation and impor Vexport declarations.

8. The receiving Party shall be responsible for safekeeping and insurance en route from the authorized port of entry to the ultimate destination and return. 


\section{ARTICLE 11}

Both Parties agree th at the following provisions shall apply concerning compensation for damages incurred during the implementation of joint projects. It is understood that such compensation will be in accordance with the laws of the country on whose territory damages will have been incurred, except as otherwise provided.

\section{First and Second Party Damages}

a. Each Party shall alone be responsible for payment of compensation for damages suffered by its staff regardless of where the damages have been incurred, and will not bring suit or lodge any other claims against the other Party for damages to its property, except as noted in paragraphs 1.b. and 1.c.

b. If the damage suffered by the staff of one of the Parties is due to the gross negligence or intentional misconduct of the staff of the other Party, the latter shall reimburse the former an agreed to sum of monies which the former would be obliged to pay to the person or persons suffering the damages.

c. If damages to the property of one Party are due to the gross negligence or intentional misconduct of the staff of the other Party, the latter shall compensate the former for the damages suffered.

\section{Third Party Damages}

a. Defective Equipment

Damages caused to the staff or property of a Third Party by defective equipment of a Party will be compensated for by the Party to which the equipment belongs, except as noted in paragraph $2 . c$.

b. By Staff

Damages caused to the staff or property of a Third Party by the staff of a Party will be compensated for by the Party in whose territory the damages occurred, except as noted in paragraph 2.c.

c. Gross Negligence or Intentional Misconduct

If damages referred to in paragraphs 2.a. and 2.b. were due to the gross negligence or intentional misconduct of the staff of a Party, that Party will bear the financial responsibility in regard to the Third Party.

d. Damage by Third Party

In the event of damage of any kind caused by a Third Party to the staff or property of one or both of the Parties, each of these, upon the request of the other Party will render it aid in the corroboration of claims on the Third Party.

e. Resolution or Qucstions

The Party on whose territory the damage was incurred will, in consulta. tion with the other Party, take upon itself the resolution, with the Third Party, of all questions connected with the determination of the causes, extent and necessity for compensation for damages incurred. Any such resolution shall have the concurrence of the other Party. Aiter determin. ing the extent of the damages, both farties will decide bctwen them selves, the questions relating to compensation for domanes incurref.
3. In the event of any dispute between the two Parties, a Committee shall be appointed by the Parties, with equal representation. The conclusions of the Committee will be presented to DoE and CEN/SCK who will review the conclusions and arrive at a mutual agreement concerning final disposition.

4. The foregoing provisions of this Article shall have no applicability to damages caused by a nuclear incident, as defined by the laws of the Parties. Compensation for damage caused by such a nuclear incident shall be in accordance with the laws of the Paries.

5. Definitions

a. "Staff" of a Party means the employees of the Party. its contractors and subcontractors performing services under this Agreement, and employees of these contractors and subcontractors performing services under this Agreement.

b. "Equipment" or "Property" of a Party means the equipment or property owned by that Party, or by the contractor and subcontractors of that Party who perform services in connection with joint projects under this Agreement.

\section{ARTICLE 12}

1. The provisions of this Agreement shall not affect the rights or duties of the Parties under other agreements or arrangements. This Agreement also in no way precludes commercial firms or other legally constituted enterprises in each of the tivo countries from engaging in commercial dealings in accordance with applicable laws of each country; nor does it preclude the Parties from engaging in activities with other governments or persons, exœpt that "proprietary information" shall have limited dissemination as set forth in Article 6 of this Agreement.

2. DoE shall act as the point of coordination for contracts and arrangements involving US commercial firms when such firms or enterprises act on behalf of the US Government under terms of this Agreement. CEN/SCK shall act as the point of coordination for contracts and arrangements involving Belgian commercial firms when such firms or enterprises act on behalf of or under contract to the Belgian Government under the terms of this Agreement. It is understood that all such contracts and arrangements shall conform with applicable laws and regulations under which each Party operates.

\section{ARTICLE 13}

Cooperation under this Agrecment shall be in accordance with the laws of the respective countries and the regulations of the respective Parties. All questions related to the Agreement arising during its term shall be settled by the Parties by mutual agreement. 


\section{ARTICLE 14}

Except when otherwise specifically agreed, all costs resulting from cooperation under this Agreement shall be borne by the Party that incurs them. It is understood that the ability of the Parties to carry out their obligations is subject to the availability of appropriated funds.

\section{ARTICLE 15}

The Parties agree to engage in discussions, at an appropriate time, with the com mon purpose of seeking a multinational approach to the treatment and/or terminal storage of radioactive waste and, if found to be an acceptable further step. to undertake jointly funded projects.

\section{ARTICLE 16}

1. This Agreement shall enter into force upon the later date of signature by a Party, shall continue for a four-year period, and may be extended or amended by mutual consent. The implementation of, and progress under, this Agre ment may be subject to annual review by the Paries.

2. This Agreement may be terminated at any time at the discretion of either Party, upon six month's advance notification in writing by the Party seeking to terminate the Agreement. Such termination shall be without prejudice to the rights which may have accrued under this Agreement to either Party up to the date of such termination.

3. In the event that, during the period of this Agreement, the nature of eithe Party's radioactive waste management program should change substantially, whether this be by expansion, reduction, transformation or amalgamation of major elements with the radioactive waste management programs of a third Party, either Party to this Agreement shall have the right to request revisions in the scope and/or terms of this Agreement.
4. All joint efforts and experiments not completed at the termination of this Agreement shall be continued until their completion under terms of this Agreement.

Done in duplicate,

For the UNITED STATES

DEPARTEMENT OF ENERGY

Name

Date

For the Belgian CENTRE D'ETUDE DE L'ENERGIE NUCLEAIREI

STUDIECENTRUA VOOR KERN

ENERGIE

Dale 7/1/1981 - 

MEETING OF CEN/SCK, MOL, BELGIUM AND U.S. DEPARTMENT OF ENERGY REPRESENTATIVES ON WASTE MANAGEMENT, MARCH $25,1985$.

Nuclear EnergY Research Center (CEN/SCK) (Belgiun) and U.S. DOE representatives met to discuss plans for cooperation under the bilateral agreement on waste management. The meeting was held in Washington, D.C. at DOE Headquarters on March 25, 1985. Attendees from CEN/SCK included Paul DeJonghe and Pierre Tonon of CEN/SCK. DOE attendees included R. Purple, C. Cooley, J. Fiore, J. Coleman, R. Coleman, and J. Epstein. J. Strahl attended from Weston.

The discussion during the meeting provided an exchange of information on the CEN/SCR programs and the DOE programs in spent fuel storage, geologic disposal, waste treatment, and low level waste disposal. [See attached minutes.] It was agreed that informal contacts should be encouraged and maintained as a mechanism to identify specific areas of future cooperation.

It was agreed that a meeting of the joint committee, as required by the bilateral agreement, should be held later this year.

The group concluded that there is a basis for continuing further exchanges and that coordinators should be appointed who would organize the forthcoming exchange meeting. Paul DeJonghe, CEN/SCK, and C. Cooley, DOE, will serve as the coordinators pending establishment of official appointments. The coordinators will develop the agenda and schedule for the meeting of the joint comittee. The suggested topics for the next meeting are: waste treatment. geologic disposal, testing of geologic media and associated performance assessment, and waste form/package testing. 




\section{BRAZIL (BR)}

\section{WORKING GROUP IN NUCLEAR COOPERATION}

Parties:

US/Department of State; Brazilian Ministry of External Affairs

Term: Indefinite

Technical Scope:

Identify specific areas for mutually beneficial cooperation in the nuclear field

SUBSIDIARY AGREEMENTS

None

\section{STATUS/PLANNING REPORTS}

Brazil-US Working Group on Nuclear Energy: Final Report --US, 08/83 (Attachment BR-1) 
The Working Group on Nuclear Cooperation was one of five separate working groups established by the decision of Presidents Joao Figueiredo and Ronald Reagan in December of 1982. The Governments of Brazil and the United States established a Joint Working Group on Nuclear Energy with the purpose to renew their positive relationship in the nuclear field and to identify specific areas in which this mutually beneficial cooperation can be actively pursued, consistent with each nation's national laws, policies and programs.

BRAZIL-U.S. WORKING GROUP ON NUCLEAR ENERGY

FINAL REPORT
2. The Nuclear Working Group was jointly chaired by Ambassador Carlos Augusto de Proenca Rosa of Brazil's Ministry of External Relations and Ambassador Richard $T$. Kennedy of the United states Department of State. An important dimension of the Working Group's activity was the opportunity for officials in the various governmental organizations having responsibility for nuclear matters to meet and exchange views with officials of corresponding organizations in the other nation. This broad representation included the following agencies on the Brazilian side: Ministry of External Relations; Ministry of Mines and Energy; the National Security Council Staff; National Nuclear Energy Commission (CNEN); NUCLEBRAS S.A.. On the United States side, the following agencies were represented: Department of State; Department of Energy; Arms Control and Disarmament Agency; and Nuclear Regulatory Commission. (List of Participants in Annex I). 
3. Brazil and the United States have developed extensive cooperation in the field of nuclear technology for over two decades. In 1965 the two countries entered in to an Agreement for Cooperation in the Civil Uses of Atomic EnergYi and a revised agreement for thirty years was concluded in 1972. In addition to exchanges on the experimental and research aspects of nuclear science and technology, this cooperation has included the construction of Brazil's Angra I nuclear power reactor. However, the range of these cooperative nuclear activities was narrowed as a result of legislation adopted by the United states in 1978 .

4. The Nuclear Working Group held two separate sessions. The first was conducted May 9-10, 1983 in Brasilia; the second took place August $8-10$ in Washington. These meetings were conducted in a very positive atmosphere, and information concerning the respective nuclear programs and policies of each country was exchanged. Also, officials of each country had an opportunity to visit major nuclear facilities in Brazil and the United states to obtain a first-hand view of each nation's scientific, technical and inoustrial program for utilizing nuclear energy.

5. During the two sessions, the Working Group, following previously agreed agendas (enclosed as Annex II), exchanged views on three main areas of mutual interest:
(A) An overview of the Brazilian and U.S. nuclear power programs, their present role and prospects in the context of the global energy situation in both countries;

(B) Pending issues in the nuclear bilateral relations and prospects for new areas of cooperation;

(C) The role and $v$ iews of both countries concerning multilateral fora and in regard to international nuclear trade and cooperation in the nuclear area.

\section{A - ROLE OF NUCLEAR ENERGY IN BRAZIL AND IN THE UNITED STATES}

6. At the first session, the Working Group undertook an overview of both Brazilian and U.S. nuclear power programs. The Brazilian delegation showed how geographical and population. distribution characteristics had molded energy planning in Brazil. Detailed comments were offered on energy production and consumption in Brazil and how nuclear power constitutes one important link in bridging the gap between the two. The Brazilian global energy situation was presented to show the relation of nuclear power to other sources such as hyoropower, coal and biomass. The Brazilian delegation presented in detail the staqes of developmert of the fuel cycle being implemented

BR-1.2 
within the Brazilian nuclear power program. The delegation stressed the major role played by nuclear energy towards both energy security and technological development. On the occasion, the peaceful, civilian and non-proliferating nature of the Brazilian nuclear power program was reiterated.

7. The United States side indicated that, since the foundation of the Atoms for Peace program in the 1950's, the United state has sought to foster the peaceful uses of nuclear energy both in its own country and in other nations. The United States side also emphasized that nuclear power not only makes a significant contribution to the current national energy supply (about 12.3 percent of the total), it meets over half the electric power requirements in certain regions on the country. By the early $1990^{\circ} \mathrm{s}$, when plants now under construction come intc operation, nuclear power is expected to supply some 20 percent of the total electricity demand. Thus, the united States maintains the world's largest nuclear power program; at present involving a commitment to 144 reactors, of which 80 are in operation, 60 under construction and 5 on order.

8. This exchange of information and views on both the Brazilian and American nuclear power programs constituted the basis of all ensuing work in this forum. It also confirmed the importance being placed by both countries on the role nuclear energy plays in the global energy context of both Brazil and the United States.

\section{B - BILATERAL NUCLEAR RELATIONS}

\section{B-1 Expanding Nuclear Cooperation}

9. In this connection, both delegations expressed their understanding that the future cooperation will continue to be developed within the framework of the "Agreement for cooperation Between the Government of the Federative Republic of Brazil and the Government of the United States of America Concerning Civil Uses of Atomic Energy", concluded in Washington, D.C. on July 17, 1972. The two delegations stressed the importance of this Agreement as a valid and valuable instrument to regulate the bilateral nuclear cooperation.

10. The bilateral nuclear relations were dealt with in a detailed and comprehensive way. Notwithstanding the fact that the objectives set for the Working Group did not include any negotiating mandate, as a result of a frank and cordial atmosphere prevalent in the meetings, it was possible to agree upon several proposals for concrete measures and actions. On one hand, such proposals were aimed at solving pending problems in the bilateral field which had hampered in the past a better 
dialogue in the nuclear sphere between the two countries. On the other hand, apart from dealing with the past, the working Group was also capable of setting the course for new avenues for cooperation in the future.

11. The following seven subjects were identified as the initial basis for renewed Brazilian/United States nuclear cooperation.

(1) Expanded exchange of nuclear safety information between Brazil's National Nuclear Energy Commission (CNEN) and the United States' Nuclear Regulatory Comission (NRC).

(2) Participation of Brazilian scientists and engineers through CNEN in the program for developing reduced enrichment uranium fuels for use in research and test reactors currently being conducted by the united states Department of Energy's Argonne National Laboratory.

(3) Cooperative activities in the area of spent fuel management (storage and/or disposal).

(4) Cooperative activities in aspects of research and development of advanced extended burn-up light water reactor fuel.
(5) Cooperative activities in the storage and disposal of radioactive waste.

(6) Contacts between U.S. institutions and CNEN on current activities on probabilistic risk assessment.

(7) Cooperation between Brazilian and U.S. officials in preparedness training for nuclear emergencies.

12. Several specific actions arising out of previous contacts between Brazil and U.S. are already under way in some of the above mentioned fields.

13. The working Group also explored the possibilities for cooperation in additional areas. One such example concerns the possible interest in U.S. reprocessing of U.S.-supplied research reactor fuel. Another example concerns participation in the Loss of fluid Test (LOFT) program.

\section{B-2 Resolving Nuclear Issues}

14. The question of the fuel supply to Angra I reactor was discussed. Both parties agreed that the Furnas/DOE contract should be suspended indefinitely, so that the resort by the Brazilian utility to a third party supplier will not raise any problems in terms of contractual penalties. 
15. Another pending problem in the bilateral relations discussed at the Working Group concerned the possibility of reworking damaged U.S.-supplied fuel elements at the IPEN research reactor. Between the two sessions, the subject was pursued through an exchange of letters. During the Washington meeting of the Working Group, the Brazilian delegation forwarded the technical data requested by the American side so that both parties could agree on the procedure to repair the said material. The Brazilian delegation accepted the offer to have an American expert visit Brazil to advise on that effort.

\section{C - MULTILATERAL ISSUES}

16. A comprehensive review was undertaken of the present role of the International Atomic Energy Agency and its prospects. Special attention was given to the issues to be discussed at the forthcoming IAEA General conference and to the work of sub-groups such as IPS and CAS. A review was also undertaken of the preparations for the United Nations Conference on the Peaceful Ușes of Nuclear Energy (PUNE).

17. Both Brazil and the United states strongly support the International Atomic Energy Agency (IAEA) as the central focus for participation in international nuclear matters. The IAEA conducts two activities of fundamental importance: a program of technical assistance for nuclear development and an indispensable system of safeguards to assure the peaceful uses of nuclear energy. The two sides expressed their determination to continue efforts to support and strengthen the agency in both these important functions.

18. A detailed exchange of views concerning the international commitments to peaceful use nuclear energy was undertaken by both delegations. In this respect, the Treaty of Tlatelolco was mentioned. The Brazilian delegation stressed that, pending the fulfillment of all the conditions for the enforcement of the Treaty, Brazil commits itself to it according to the canons of International Law, not to perform any act which defeats the objects and purposes of the Treaty, to which there corresponds the guarantee that the other signatories will do likewise.

The United states also emphasized its commitment to the Tlatelolco Treaty regime, as evidenced by its adherence to both Protocols applicable to states outside the treaty zone. For its part, the United States affirmed the desirability of achieving universal adherence to the Nuclear Non-Proliferation Treaty. While reiterating the Brazilian position in favor of the peaceful uses of nuclear energy, the Brazilian side reaffirmed its long-standing reservations about the NPT, due to its discriminatory nature. BR- 1.5 
19. Regarding international trade and cooperation in the nuclear field, a detailed presentation was given by the two delegations concerning their cooperation regimes and export control systems to ensure that exported material, equipment and technology is only used for peaceful purposes.

D. CONCLUSION

20. In conclusion, both delegations agreed that the objectives set forth for the Brazil-U.S. Working Group on Nuclear Energy were fully attained in accordance with the directives established by Presidents Joao Figueiredo and Ronald Reagan. In fact, not only was the Working Group able to successfully set the ground for solutions to problems that in the past had hampered the dialogue in the nuclear field between the two countries, but also could define concrete fields for further enhancing the bilateral cooperation. The two sides agreed on continuing their renewed dialogue on nuclear matters and that more frequent contacts on these issues could be useful for both parties. These achievements were made possible by the frankness and cordiality which characterized the sessions of the Brazil-U.S. Working Group on Nuclear Energy and which

reflected the guidance provided by Minister Ramiro Saraiva Guerreiro and Secretary of State George Shultz.

Carlos Augusto de Proenca Rosa Head of Economic Department Ministry of External Relations Government of Brazil
Richard T. Kennedy Ambassador-at-Large Government of the United States of America
Washington, D.C. August 10, 1983 



\section{CANADA (CA)}

BLANKET AGREEMENT (Attachment CA-1)

Parties: $\quad$ US/DOE; Canada/Atomic Energy of Canada Limited (AECL)

Term:

September 8, 1976 to August 25, 1987

Technical Scope: Waste processing technology; retrievable and terminal waste storage; environmental effects

\section{SUBSIDIARY AGREEMENTS}

None

\section{STATUS/PLANNING REPORTS}

Record of Program Review Meeting, Whiteshe11, CA, 07/83 (Attachment CA-2)

(Report of the 12/84 meeting $w i 11$ be supplied later)

\section{ADMINISTRATION}

Principal Coordinators: US -- C. R. Cooley (DOE)
CA - R. B. Lyon (AECL-Whiteshe11)

Document Exchange: $\quad$ See Appendix C 
BETWEEN:

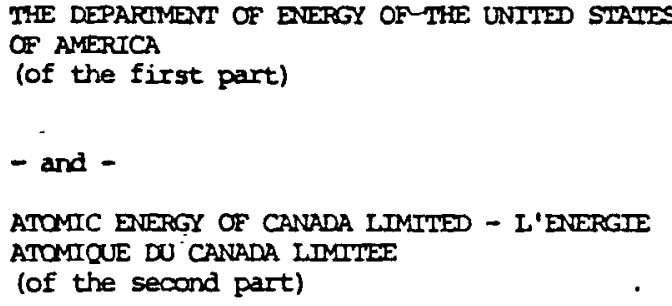

ATOMIC ENERGY OF CANADA ITMITED - L'ENERGIE ATOMIOUE DU CANADA LIMITEE (of the second part)

RESPECTING: "COOPERATYON IN RADIOACTIVE WASTE MANAGEMENT"
The fields of cooperation covered by this Agreenent may include:

1. Preparation and packaging of radioactive wastes.

2. Decontamination and decomissioning.

3. Surface and subsurface storage.

4. Caracterization of geologic formations.

5. Disposal in geologic formations.

6. Transportation requirements.

7. Operational considerations.

8. Environmental and safety considerations.

9. Public acceptance issues.

Other fields of cooperation may be added by mutual written agreement.

\section{FORMS OF OOOPERATION}

Atomic Energy of Canada Limited - L'Energie atomique du Canada, Limitee (AECL) hereinafter referred to as the Parties, wish to enter into an agreenent for coperation in the area of radicactive waste management;

AND WHEREAS the Parties wish such arrangement to supersede the Memorandum of Understanding between the U.S. Energy Research and Development Adninistration (later DOE) and $A E C$ relating to information in the nuclear field, dated September 8, 1976 and extended by agreement of the two Parties;

1NOW THEREFORE the Parties agree as follows:

\section{OBTECTTVES OF COOPERATION}

Cooperation under this Agrement shall be directed towards a study of mutually agreed topics associated with the managenent of radioactive waste, and related activities of the suclear fuel cycle.
Cooperation in accordance with this Agreement may include, but is not limited to the following forms:

1. Exchange, on a current basis, of scientific and technical information, and results and methods of research and development.

2. Organization of, and participation in, seminars and other meetings on specific agreed topics in the fields listed in clause 2 .

3. Exchange of samples, materials, and equipment for testing.

4. Exchange of scientists, esgineers and other specialists for agreed periods for participation in agreed research, development, analysis, design and experimental activities conducted in research centers,

laboratories, engineering offices and other facilities and enterprises of each of the Parties or its contractors. Such exchanges of staff shall be in accordance with clause 8 of this Agreement. 
5. Joint projects in which the Parties agree to share the work and/or costs. Each such joint project shall be the subject of a separate agreement pursuant to clause 5 of this Agreement.

Other specific forms of cooperation may be added by mutual written agreement.

\section{MANAGAREN}

1. To supervise the execution of this Agreement, the Parties shall each name a Principal Coordinator. As deened necessary, the Principal Doordinators shall meet to evaluate the status of cooperation under this Agreement. This evaluation shall include a comprehensive review of each Farty's radioactive waste management program status and plans, an assessment of the balance of exchanges among the various fields of cooperation listed In clause 2, and a consideration of measures required to correct any imbalance. These meetings shall be held alternately in Canada and the United States.

2. The Principal Coordinators shall consider and act on any mor new proposals for cooperation. When such proposals involve a new field of cooperation, clause 2 of the Agreement shall be modified accordingly after assessment and agreement, in oriting, of the Principal Coordinators.

3. For day-to-day implementation of this Agreement, the Principal Coordinators shall each designate Technical Doordinators to oversee the cooperation under this Agreement. The Technical Coordinators shall agree on specific programs of cooperation in their respective fields as described in clause 2 within policy guidelines set by the Principal Coordinators. The Technical Coordinator or his designee shall be responsible for the working contacts betueen the Parties in his respective field of cooperation.

\section{SUBSIDIARY AGFERERENS}

With respect to each joint project of the type contemplated by clause 3.5, a Subsidiary Agreement shall be executed by the Parties. Each Subsidiary Agreement shall include detailed provisions for carrying out the cooperative program or project and shall cover, as appropriate, such matters as technical scope, exchange of proprietary information, management of the wopration, patents, exchange of equipment, total costs, cost sharing between the Parties, project schedule and information disclosure specific to the particular joint project. Clauses $6,7,8,12,13,14,15,16,17$ and 18 of this Agreement shall be applicable to any such Subsidiary Agreement, unless the Parties otherwise agree in writing in the Subsidiary Agreenent.

\section{FTNANCE}

Except when otherwise specifically agreed at the time, in writing. all costs resulting fran cooperation under this Afreement shall be borne by the Party that incurs them.

\section{DISCLAIMER}

Information transmitted by one Party to another Party under this Agreement shall be accurate to the best knowledge and belief of the transmitting Party, but the transmitting Party does not warrant the suitability of the information transmitted for any particular use or 
application by a recelving Party or by any third party. Information developed jointly by the Parties shall be accurate to the best knowledge and bellef of each Party. No Party warrants the accuracy of the folntly developed information or 1ts sultability for any particular use or application by a Party or by any third party.

\section{ASSIGGMENTS AND IXCHANGES OF PERSONNEI}

1. Each Party may, at its own expense, observe test activities and analytical work of the other Party. Such observation may be exercised by short term visits or by the attachment of staff, subject to the prior agreement of the receiving Party on each occasion.

2. Whenever an attachment of staff is contemplated under this Agreement, each Party shall ensure that qualified staff are selected for attachment to the other Party.

3. The Parties will prepare agreements for attachment as may be necessary in conjunction with work assignments under this Agreenent.

4. Each Party shall be responsible for the salaries, insurance, and allowances to be paid to its staff.

5. Each Party shall pay for the travel and living expenses of its staff while on attachment to the host Party unless otherwise agreed.

6. The host Party shall arrange for accormodations for the at tached staff (and their families) of the other Party on a mutually agreeable reciprocal basis.
7. The host Party shail provide all necessary assistance to the attached staff (and their familles) of the other Party regarding administrative formalities, such as travel arrangements, etc.

8. The staff of each Party shall conform to the general and special rules of work and safety regulations in force at the host establishment, or as agreed to in a separate staff attachment agreement.

9. The Party proposing an attachment shall notify the receiving Party of the name of the persons proposed for the attachment and shall provide such information respecting any of the said persons as may be required by the receiving Party.

\section{INFORMATION}

1. The Parties support the widest possible dissemination of information provided or exchanged under this Agreenent, subject to the ned to protect proprietary information and to the provisions of clauses 10 and 11.

Use of Proprietary Information

Definitions as used in this Agreement:

(i) The tem "information" means scientific or technical data, results or methods of research and development and any other information intended to be provided or exchanged under this Agreement; 
(ii) The term "proprietary information" means information which contains trade secrets or commercial or financial information which is privileged or confidential, and shall only include such information which:

a) has been held in confidence by its ouner;

b) is of a type atich is custamarily held in confidence by its owner:

c) has not been transnitted by the transmitting Party to other entities (including the receiving Party) except on the basis that it be held in confidence; and

d) is not otherwise available to the receiving Party fran another source without restriction on its further dissenination.

(i) A Party receiving proprietary information pursuant to this Agreement shall respect the privileged nature thereof. Any document which contains proprietary information shall be clearly marked by the providing Party with the following (or substantially similar) restrictive legend:

'This docament contains proprietary information furnished in confidence under an Agrement dated between the United States Department of Energy and Atomic Energy of Canada Limited and shall not be disseminated outside these organizations, their contractors, and the concerned departments, and agencies of Covernrents of the U.S. and Canada without prior approval of
This notice shall be marked on any reproduction hereof, in whole or in part. These Iimitations shall automatically terminate when this information is disclosed by the owner without restriction."

(ii) Proprietary infomation received in confidence under this Agreement may be disseminated by the receiving Party to:

a) persons within or enployed by the receiving Party, and other concerned Government departments and Government agencies in the country of the receiving Party; and

b) prime or subcontractors of the receiving Party located within the geographical limits of the receiving Party's nation, for use only within the franework of their contracts with the receiving Party in work relating to the subject matter of the proprietary information;

provided that any such proprietary information shall be disseminated on a need-to-know basis pursuant to an agreement of confidentiality, shall be marked with the restrictive legend substantially identical to that appearing in subparagraph 3(i) above, and shall not be used for commercial purposes without the consent of the originating Party. 
(1ii) With the prior written consent of the Party providing proprietary information under this Agreement, the receiving Party may disserninate such proprietary information more widely than otherwise permitted in the foregoing subsection (11). The Parties shall cooperate with each other in developing procedures for requesting and obtaining prior written consent for such wider dissemination, and each Party will grant such approval to the extent permitted by its policies, regulations and laus.

4. Each Party shail exercise its best efforts to ensure that proprietary information received by it under this Agreement shall be controlled as provided herein. If one of the Parties becones axare that it will be, or may reasonably be expected to become, unable to meet the non-dissenination provisions of this clause, it shall irmediately inform the other party.

The Parties shall thereafter consult to define an appropriate course of action.

5. Information arising from seminars and other meetings arranged under this Agreement and information arising from the attachments of staff, use of facilities and jolnt projects shall be trated by the Parties according to the principles specified in this clause; provided, however, no proprietary information orally cormunicated shall be subject to the limited disclosure requirements of this Agreement unless the individual cammunicating such information places the recipient on notice as to the proprietary character of the information cormunicated.
6. Nothing contained in this Agreement shall preclude the use or dissemination of information received by a Party through arrangements other than those provided for under this Agreement.

\section{INVETTIONS OR DISCOVERIES}

1. With respect to any invention or discovery made or conceived in tive course of or under this Agreenent:

a) If made or conceived by personnel of one Party (the Assigning Party) or its contractors while assigned to the other Party (Recipient Party) or its contractors in connection with exchanges of scientists, engineers and other specialists:

(1) The Recipient Party shall acquire all right, title and interest in and to any such invention or discovery in its own country and in third countries, subject to a non-exclusive, irrevocable, royalty-free license in all such countries to the Assigning Party, its Goverment, and its nationals designated by it, in and to any such invention or discovery and any patent application, patent or other protection relating thereto.

(2) The Assigning Party shall acquire all right, title and interest in and to any such invention or discovery in its own country, subject to a non-exclusive, irrevocable, royalty-free license to the Recipient 
Party, 1ts Goverment, and its nationals designated

by $1 t$, in and to any such Invention or discovery and any patent application, patent or other protection relating thereto.

b) If made or concelved by a party or its contractors as a direct result of employing information which has been communicated to it under this Agreement by the other Party or its contractors or comunicated during seminars or other joint meetings, the Party making the invention shall acquire all right, title, and interest in and to such invention or discovery in all countries, subject to a grant to the other Party, its Government, and its nationals designated by it, of a non-exclusive, irrevocable, rovalty-free license in all countries, in and to any such invention or discovery and any patent application, patent or other protection relating thereto.

c) With regard to exchange of samples, materials, instruments, and components for testing, the Recipient Party shall have the same rights as the Recipient Party as set forth in paragraph 1 a)(1) above and the Sending Party shall bave the same rights as the Assigning Party as set forth in paragraph 1 a)(2) above to any inventions or discoveries utich are improvements to such samples, materials, instruments or components.

d) With regard to other specific forms of cooperation pursuant to clause 3.5, the Parties shall provide for appropriate distribution of rights to inventions or discoveries resulting fran such cooperation. In general, however, each Party should nomally oun the rights to such Inventions or discoveries in its own country with a non-exclusive, irrevocable, royaltyfree license to the other Party, its Govermment, and its nationals designated by $i t$, and the rights to such inventions or discoveries in other countries should be agreed by the Parties on an equitable basis.

2.

Each Party shall take all necessary steps to provide the cooperation of inventors and authors for the purposes of carrying out the provisions of this Agreement.

3. Each party shall be responsible for payment of awards or compensation due citizens of its own country under its relevant legislation.

\section{OOPYRIGTIS}

Copyrights of the Parties or of cooperating organizations and persons shall be accorded treatment consistent with internationally recognized standards of protection. As to copyrights on materials within the scope of paragraph 1 of clause 9 owned or controlled by a Party, that Party shall make efforts to grant to the other Party a license to reproduce copyrighted material.

$$
\text { CA-1.6 }
$$




\section{EQUIPIENT}

Each Party agrees that in the event equipment is to be exchanged or supplied by one Party to the other Party, the following provisions shall apply covering the shipment and use of the equipment:

1. The sending Party shall supply as soon as possible a detailed list of the equipment to be provided together with the associated specifications and technical and informational documentation.

2. The equipment, spare parts, and documentation supplied by the sending Party shall remain the property of the sending Party and shall be returned to the sending Party upon campletion of the mutually agreed upon activity unless otherwise agreed.

3. The host establishment shall provide the necessary premises and shelter for the equipment, and shall provide for electric power, etc., in accordance with technical requirements which shall be as mutually agreed upon.

4. Responsibility for expenses, safekeeping and insurance during the transport of the material fran the original location in the country of the Sending Party to the place of entry in the country of the Receiving Party shall rest with the Sending Party. If the Sending Party elects to have the material returned, it shall be responsible for expenses, safekeeping, and insurance during the transport of the material from the original point of entry in the Country of the Receiving Party to the final destination in the country of the Sending Party.
5. Responsibility for expenses, safekeping, and insurance during the transport of the material from the place of entry in the country of the Receiving Party to the final destination in the country of the Receiving Party shall rest with the Receiving Party. If the Sending Party elects to have the material returned, the Receiving Party shall be responsible for expenses, safekeeping, and insurance during the transport of the material fram the final destination in the country of the Receiving Party to the original point of entry in the country of the Receiving Party.

6. The equipnent provided by the Sending Party for carrying out mutually agreed-upon activities shall be considered to be scientific, not having a commercial character.

\section{SAMPLES AND MATERIALS}

The Parties agree that in the event samples or materials are provided by one Party to the other Party, the following provisions shall apply with respect to the transportation and use of such samples and materials:

1. Unless otherurise agreed by the Parties prior to delivery, all samples and materials provided by the Sending Party to the Receiving Party shall become the property of the Receiving Party upon delivery, and shall not be returned to the Sending Party.

2. Where one Party requests that a sample or material be provided by the other Party, the Party making the request shall bear all costs and expenses associated with the transportation of the sample or material from the lncation of the Sending Party to the final destination. 
3. Each Party shall promptly disclose to the other Party all information arising from the examination or testing of samples or materials exchanged under this Agreement. The Parties agree that proprietary information as defined in clause 9.2 which was developed prior to or outside the scope of this Agreenent, shall remin proprietary even though it is contained in the results of an examination or testing of samples or materials. Such information shall be identified as proprietary information by the Party asserting its proprietary nature as soon as possible after disclosure of all information arising from the examination or testing is made to such Party and the other Party shall be imediately advised of that identification. All information identified as proprietary information shall be controlled as provided under clause 9.3.

It is further understood and agreed that one Party providing samples or materials to the other Party may also provide a partial or complete list of the types of information which will arise fram the examination or testing of such samplesor materials and wich is proprietary as defined in clause 9.2 and all such proprietary information is to be controlled as set out in clause 9.3 .

\section{APPROPRIATED FUNDS}

The ability of the Parties to carry out their obligations under this Agreement is subject to the availability of appropriated funds.

\section{LAIS AND REGULATIONS}

Cooperation under this Agreement shall be in accordance with the laws and regulations of the respective countries. All questions related to the Agreement arising during its term shall be settled by the Parties by mutual agreernent.

\section{LEGAL RESPONSIBILITY}

The Parties shall use all reasonable skill and care in carrying out their duties under this Agreement in accordance with all applicable laus and regulations.

Compensation for damages incurred during the implementation of this Agreement shall be in accordance with the applicable laws of the countries of the Parties.

\section{DURATION} that this Agreement may be amended or extended by written agreenent of each of the Parties. 
2. All joint efforts and experiments not completed at the expiration of this Agreement may be contimed until their completion under the terms of this Agreement.

3. In the event that, during the period of this Agreenent, the nature of either Party's radioactive waste management program should change substantially, whether this be by expansion, reduction or transformation, or by amalgamation of major elements with the radioactive waste managenent program of a third Party, either Party shall have the right to request revisions in the scope and terms of this Agreement.

\section{TERUINATION}

This Agreement and any annex hereunder may be teminated at any time at the discretion of either Party upon six months advance notification in writing by the Party seeking to teminate the Agreement or ansex. Such termination shall be without prejudice to the rights that may have accrued Appil
AECL. under this Agreement or annex to either Party up to the date of the temination. sinequente

DONE AT OTTAWA this 25th day of August 1982.

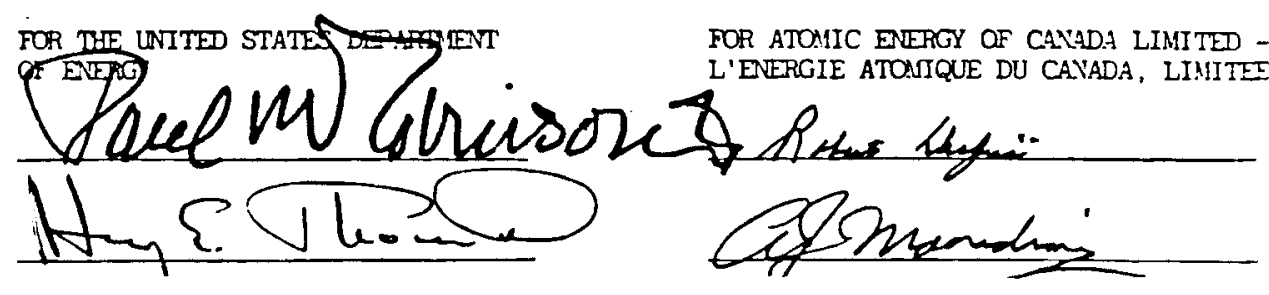

CA- 1.9 

FINDINGS/AGREEMENTS (Program Review Meeting, whiteshell, July 26-27, 1983).

1. Cooperation on subseabed should cont inue to be conducted through the Bedford Institute. Rummery prefers that cooperative arrangements be made without the transfer of dollars, if possible i e aree on items or without the transfer of dollars, if possible, .e., agree on items or most ly outside of Rummery's (AECL) review.

2. Arrangements will be made for AECL to obtain information on the NSTF data acquisition system. Their obtaining that system could save them much development time and money.

3. AECL is receptive to $R$. Lyon participation in a peer review team on performance assessment activities by the DOE projects.

4. AECL will provide comment on Materials Characterization Center procedures if requested.

5. Arrangements will be made for a visit by US storage team when requested.

6. Support of downhole experimental work will be maintained through USGS.

7. DOE will notify AECL on appropriate contacts for technical areas as soon as DOE reorganization and CPO contractor selection have been completed.

8. CPO is interested in the Atikokan hydrogeology study and will work directly with $A E C L$ on participation.

9. Participation in existing committees and review groups will continue on URL and on CPO test and design concepts.

10. Information on waste handling concepts and machine design can be supplied by Rockwell Hanford Company to AECL.

11. CPO will support reviews of URL by LBL, LLL of URL, etc.

\section{RECOMMENDATIONS}

1. Continued cooperation on the AECL program is highly beneficial to the US program. The AECL program is leading the US program in several areas specific to granite.

2. Specific participation in URL needs to be identified within the next year i.e., the specific experiments we are going to share, fund, etc., in URL.

3. CPO should take the lead in assuring that the one on one technical exchange is maintained even if the technical exchange is with a project other than crystalline rock.
4. The AECL approach to materials testing should be reviewed towards the end in $A E C L$ Test in return for SOme DOE sponsored work on materials in US facilities.

5. Because of the recognition of a possible need to conduct some larger scale testing in the future, $A E C L$ is willing to participate in a discussion on the merits of larger scale testing wich could be helpful to DOE planning the merits of larger scale this time they have no position on larger scale during the experiments. 



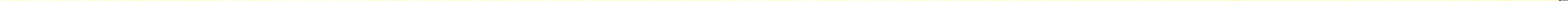




\section{ERANCE (FR)}

BLANKET AGREEMENT (Attachment FR-1)

Parties:

Term:

Technical Scope:
US/DOE; France/Atomic Energy Commission (CEA)

July 26,1983 to July 26,1988

Preparation, packaging, surface and subsurface storage of radioactive waste; characterization of geologic formations and geologic waste disposal;

transportation requi rements; D\&D

\section{SUBSIDIARY AGREEMENTS}

None

\section{STATUS/PLANNING REPORTS}

Excerpt from K. M. Harmon (PNL) travel report for Implementation of DOE/CEA Waste Management Blanket Agreement Meeting--Paris, 06/84 (Attachment FR-2)

\section{ADMINISTRATION}

Principal Coordinators: US -- C. R. Cooley (DOE)

$$
\text { FR -- J. Lefevre (CEA) }
$$

Document Exchange: See Appendix C 


\section{ORIBNAL}

\section{AGREEMENT}

between

THE UNITED STATES DEPARTMENT OF ENERGY

and

THE FRENCH COMMISSARIAT A L'ENERGIE ATOMIQUE

in the field of

RADIOACTIVE WASTE MANAGEMEN
WHEREAS

The UNITED STATES DEPARTMENT OF ENERGY (DOE) and THE FRENCH COMMISSARIAT A L'ENERGIE ATOMIQUE (CEA), herelnafter referred to as the Partles, have a mutual interest in the safe, effective and economic treatment, handling, 1solation, disposal and retrleval of cpent radioactive fuel and separated radioactive fuel and geparated radioactive waste products;

DOE and CEA belleve that a cooperative program of equitable sharing of their respective research and development data, technology and experfence ia the management of radioactive waste would be of mutual benef1t;

DOE and CEA recognize the contribution such research and development 1n radioactive waste management can make to protecting the in radioactive waste management can make to protecting the auclear energy

DOE and CEA act In certain areas related to radioactive waste management through their contractors, subsidiarles or associated Industrial firms;

DOE and CEA recognize the need to establish procedures for the protection of proprletary information.

It is the understanding of each Party that certaln Information is provided In confidence to the other Party, and that the undue dissemination thereof would be prejudicial to the interests of each Party and to prospects for future collaboration between DOE and CEA.

IT IS AGREED AS FOLLOWS

ARTICLE 1 - OBJECTIVES

1.1 The objective of this Agreement shall be to establish the basis for cooperation between the Parties in the fleld of radioactlve waste management of the nuclear fuel cycle.

1.2 As a flrst step, this Agreement provides for an exchange of general information between the Partles regarding the studes and research, development, demonstration and operational and research, development, demonstration and operat

1.3 Such exchange of Information will be governed by the proutstons of article 6 of this agreement.

1.4 Cooperation between the Parties shall be on the basts of mutual benefit, equality and reciprocity. 
ARTICLE 2 - AREAS OF COOPERATION

2.1 The areas of cooperation in the fleld of radioactive waste wanagement covered by this Agreement may include:

- Preparation and packaging of radioactive wastes

- Decontamination and decommissioning

- Surface and subsurface storage

- Characterization of geologic formations

- Disposal In geologie formations

- Transportation requirements

Other areas of cooperation may be added by mutual uritten agreement.

2.2 Information related to the above mentioned areas w111 be malnly assessed to cope with matters relative to:

- Operational considerations

- Eavironmental and public safety considerations

- Public acceptance 1ssues

ARTICLE 3 - FORMS OF COOPERATION

3.1 Cooperation under this Agreement may include, but is not 11mited to, the followiag forms:

a. Exchange, on a current basis, of sclentific and engineering information, and results and methods of research and development.

b. Organization of, and participation 1n, seminars or other meetings on specific agreed topics in the areas ilsted in Article 2.

c. Short visits by specialist teams or Individuals to the experimental and operational radioactive waste management facilities of the other Party, subject to the prior written agreement of the recelving Party.

3.2 Other forms of cooperation may be employed as outlined below, subject in each case to the execution of a separate agreement between the Parties pursuant to Article 4.

a. Attachment of the staff of one Party, its contractors or subsidlarles to the radioactive waste management facit1lites of the other Party, its contractors or subsidiarles for participation in agreed research, development, design, analysis or other experimental activities, and ongoing operations in the fleld of radioactive waste management.

b. Exchange of radioactive waste samples, materials and equipment for testing.

c. Jolnt projects in wh1ch the Partles agree to share the work and/or costs.

d. Other specific forms of cooperation.

ARTICLE 4 - IMPLEMENTING AGREEMENTS

4.1 If $1 t$ is declded that an attachwent of staff, an exchange of amples, materials or equipment, or a cooperative profect is to be established; or that an exchange of detalled technology and daca or of engleerlng lnforaction such as englneering drauings and specifications of full-scale components and of Industrial plant is to be undertaken; or that an exchange of under this procedures and experlence is to be undertaken implementing agreement between the Parties shall be executed.

4.2 Each 1mplement1ng agreement shall include all detalled provisions for carrylng out that activity, and shall cover such watters as technical scope, total costs, cost-shariag between the Parties, profect schedule, management of the cooperation, exchange of equipment, and provisions covering exchange of proprietary information, patents, and information disclosure specific to the particular profect. Activities under 1mplementing agreements may 1nvolve, as appropriate, associated firms or laboratories of the Parties or their contractors or subsidiarles.

ARTICLE 5 - MANAGEMENT

5.1 To supervise the execution of this Agreement, each Party shall name a Princlpal Coordinator. The Principal Coordinators shall normally meet each year alternately in the United States and In France, or at such other times and places as agreed.

5.2 At their meetings, the Principal Coordinators shall evaluate the status of cooperation under this Agreement. Th1s evaluation may include a review of each Party's radioactive waste past year's activities and accomplishments uader this Agreement, a review of the activities planned for the coming Agreement, a revlew of the activitles planned for the coming year withing each of the varlous areas of cooperation lisced In Artlcle 2, an assessment of the balances of exchanges under this Agreement within each of the areas of cooperation listed in Article 2, and a consideration of measures required to correct any 1mbalances. In addition, the Principal Coordinators shall consider and act on any major new proposals for cooperation. 
5.3 Day-to-day management of the cooperation under this Agreement shall be carried out by Technical Coordinators designated by the Principal Coordinators. The Technical Coordinators shall agree on specific detalls of cooperation in the technical areas 1isted In Article 2, with1n policy guidelines established by the Principal Coordinators. Each Technical Coordinator shall be responsible for working contacts betwee the Partles in his respective area of cooperation.

5.4 Implementing agreements executed pursuant to Article 4 for the performance of cooperative activities shall include

appropriate provisions for the management of such activities.

ARTICLE 6 - INFORMATION

6.1 The Parties support the videst possible dissemination of Information provided or exchanged under this Agreement. lnformation provided or exchanged under this Agreement, exchanged hereunder.

6.2 Information exchanged under this Agreement way be in either French or English.

6.3 Although th1s Agreement does not commit elther of the Parties to transmit to the other Party any information considered to be proprietary, the Parties recogalze that transmission of such proprietary 1nformation might prove useful to their collaboration, in which case the provisions of Sections 6.4 through 6.6 of this Agreement shall apply.

6.4 Definitions as used in this Article:

6.4.1 The term "Information" means sclentific or engineer1ag data, results or methods of research and development, operational expertise, and any other information latended to be provided or exchanged under this Agreement.

6.4.2 For the purposes of this ABreement, "Proprietary Information" ("Informations Privilégiées" in French) shall mean information of confidenclal nature such as trade secrets or commerclal or financial information which is privileged or confidenclal, and may only include such information which:

a) has been held in confidence by its owner;

b) Is of a type which is customartly held in confidence by 1 ts owner:

c) has not been transmltted by the transwitting Party to other entities (Including the recelving Party) except on the basis that it be held in confidence; and d) 1 s not otherwise avallable to the recelving Party from another source without restriction on 1 te further dissemination.

6.5 Procedures

6.5.1 A Party recelving Proprietary Information, as defined in Section 6.4.2, pursuant to th1s Agreement shall respect the privileged nature thereof. Any document which contalns Proprietary Information shall be clearly warked with the followlag (or substantially (1m1lar) restrictive legend:

-This document contains Proprietary Information furnished in confidence under an Agreement dated Detween the UNITED STATES DTRTMT OTONERGY and the FRENCH COMMISSARIAT Chall not be disseminated outside these organizations, their contractors, licensees and the concerned departments and agencles of the Governments of the U.S. and France without prior approval of

-Th1s notice shall be marked on any reproduction hereof, in whole or in part. These 11mitations shall automatically terminate when this information 1 disclosed by the owner without restriction.

6.5.2 Proprietary Information, as defined in Section 6.4.2 recelved in confidence under this Agreement may be disseminated by the recelving Party to:

a) persons within or employed by the recelving Party, and other concerned Government departments and Government agencles in the country of the recelving Party; and

b) prime or subcontractors of the recelving Party located withla the geographical limits of the recelving Party's nation, for use only within the framework of their contracts with the recelving Party in work relating to the subfect matter of the Proprletary Information;

provided, that any such Proprietary Information shall be disseminated on a need-to-know basis pursuant to an be desent of confldenciality and shall be marked with - restricrive legend substantially idencicel to that appearing in Section 6.5 .1 above.

6.5.3 With the prior witten consent of the Party providing Proprietary Information under this Agreemenc, the Informarton more widely than otherwise permitred in 
cooperate with each other in developing procedures for requesting and obtainting prior written consent for such wider dissemination, and each Party shall grant such approval to the extent permitted by its nactonal policles, regulations and laws.

6.6 Each Party shall exercise 1ts best efforts to ensure that Proprietary Information recelved by it under this Agreement Propretary inforato recelved by 1 te under this Agreent shall be controlled as provlded hereln. If one of the Partie becomes aware chat le will be, or may reasonably be expected chis Artele, te to a the nontlat chis Artele, 1t shall lomediacely lafom the other Party. thereafter consult to deflne an appropriate course of action.

6.7 Information arising from seminars and other meetings arranged under this Agreement shall be treated by the Parties accordin to the principles specified in this Article; provided,

however, Do Proprletary Information orally communicated shall be subject to the 11mited disclosure réquirements of this Agreement unless the Individual communicating such information places the reclplent on notlce as to the proprletary character of the information communicated.

6.8 Nothing contained in this Agreement shall preclude the use or dissecination of Information recelved by a Party other than p'irsuant to this Agreement.

ARTICLE 7 - DISCLAIMER

Information transoltted by one Party to the other Party under this Agreement shall be accurate to the best knowledge and bellef of the transaltring Party, but the transaltelng Party does not uarrant the aultabllity of the laforgatlon transulted for any partlcular application by the recelving Party or by any third Party.

\section{ARTICLE 8 - LIABILITIES}

The Parties shall use all reasonable skill and care in carrying out their duties under this Agreement in accordance with the laws and regulations of their respective countries.

8.2 Compensation for damages incurred during the course of and under this Agreesent shall be 1 in accordance with the applicable laws of the respective country of the Party concerned, except as provided in article 8.3.

8.3 The sending Party shall not be llable for damages of any nature, elther direct or 1nd1rect, to property or personnel of the recelving Party or to any third Party resulting from the use by the recelving Party of information provided under this Agreement.
ARTICLE 9 - LEGAL PROVISIONS

Each Party's activities under this Agreement shall be In accordance with its national laws and regulations. All questions related to the Agreement arising during 1 ts term shall be settled by the

Partles by mutual agreement.

ARTICLE 10 - FINANCIAL OBLIGATIONS

Except when otherwise specifically agreed in writing, all costs resulting from cooperation under this Agreement shall be borne by the Party that incurs them. It is understood that the the Party that lncurs the this Agreement are subject to the avallability of appropriated funds.

ARTICLE 11 - DURATION, AMENDMENT AND TERMINATION

11.1 Th1s Agreement shall enter 1nto force upon signature and, subject to bections $11.2,11.3$, and 11.4 , shall continue for a five (5) year period.

11.2 Th1s Agreement may be amended or extended by mutual written agreedent of the Parties.

11.3 Th1s Agreement may be terminated at any time at the discretion of elther Party, upon six (6) months advance notification in writing by the Party seeking to terminate the Agreement. Such termination shall be without prefudice to the rights uhich may have accrued under this Agreement to elther Party up to the date of such termination.

11.4 All joint efforts and experiments not completed at the explration or termination of this Agreement may be continued unt1l their completion under the terms of this Agreement.

Done in duplicate, in the Engllsh and French languages, each equally authentic, this 26 th day

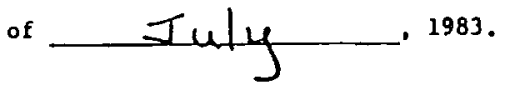

FOR TIE DEPARTIENT OF ENERCY OF THE UNITEP STATES OF AMERIC
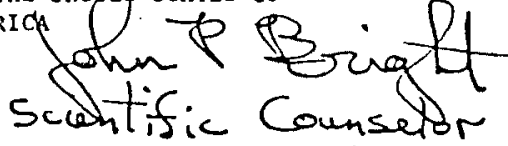$$
\text { us Embassy }
$$

FOR THE COIEISSARIAT A L'ESERG IE NTPMIQLE OF FRANCE

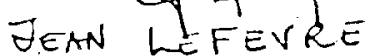
JEAN LEFEVRE

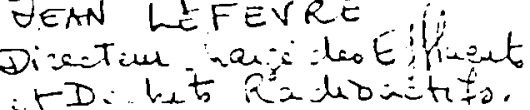

$\mathrm{FR}-1.4$ 


\section{FQREIGN TRAVEL REPORT}

(Excerpt from report by K. M. Harmon, PNL, June 1984)

Implementation of DOE/CEA Waste Management Blanket Agreement

June 15, 1984

Paris, France

\section{Highlights of Wrap-up Meeting - Eriday, June 15}

1. It was agreed that two implementing agreements should be developed, one for waste treatment and one for radioactive waste disposal. The purpose is to protect proprietary information and to cover exchange of personnel. Preliminary lists of topics and French technical contacts are as follows:

\section{Waste Treatment}

\section{Iopics}

- Incineration of $\alpha$ and $\beta, \gamma$ waste

- Melting

* Embedding; cementation

* Waste form characterization methodology

(all types of waste)

- LECALT - HLW form aging studies

- Stored waste retrieval

- Overpacks for HLW glass logs (ceramics, etc)

- Decontamination techniques

* TRU recovery

- Calcium/PuF reduction

- Removal of Am from Pu metal by volatilization

* Tritium recovery

\section{Contacts}

$\begin{array}{ll}\begin{array}{ll}\text { Sombret } \\ \text { Dubois }\end{array} & \text { (IRDI) } \\ \text { Pottier } & \text { (IRDI) } \\ \text { (IRDI) } \\ \text { Malet } & \text { (IRDI) } \\ \text { Sombret } & \\ \text { Al exandre } & \text { (IRDI) } \\ \text { Rolland } & \text { (DAM) } \\ & \\ \text { Giroux } & \text { (DAM) }\end{array}$

* These items can be discussed without an implementing agreement. Those items not marked with an asterick have French proprietary elements, and in-depth exchange must be covered by boiler plate which contains patent protection clauses, etc. 


\section{Radioactive Waste Disposal}

* Mill tailings

* Subseabed disposal

\section{Zettwoog (IPSN)}

Barbreau (IPSN)

Land-based repository development

Barthoux

(ANDRA)

(including LaManche activities)

* Site selection and characterization

- Performance assessment, including aging phenomena

- Repository design

* Radionuclide chemistry and transport

Billon

(IRDI)

- Silica plugging of granite fissures

- Correlation between surface fissures and subsurface fractures

* Backfilling

- Spent fuel disposal

Atabek

( IRDI )

Sugier

(DED)

2. It was agreed that workshops would be held during the next year on three topics:

- Waste form characterization methodology (contacts: P. Pottier/IRDI and M. Frei/DOE-RW). This will probably be held at Cadarache in October-November 1984.

- Repository site selection and characterization (contacts: A. Barthouz/ANDRA and a not-yet-selected DOE-RW representative)

- Plutonium recovery (contacts: Rolland/CEA-DAM and J. Dieckhoner/DOE-DP)

3. K. Klein (DOE-RW) will notify ANDRA within two weeks of the US contact for the workshop on repository site selection and characterization.

\footnotetext{
* These items can be discussed without an implementing agreement. Those items not marked with an asterick have French proprietary elements, and in-depth exchange must be covered by boiler plate which contains patent protection clauses, etc.
} 
4. S. Griffith (DOE-IE) will provide comments to LeNiger (DPIA) on existing drafts of implementing agreements by the end of June.

5. The CEA will transmit minutes of this meeting to DOE by mid-July. DOE will respond with comments and a list of DOE technical contacts within two weeks after receipt of the minutes.

6. A DOE/CEA meeting will be held approximately annually to review the waste management exchange activities and to plan for continued implementation. 



\section{GERMANY (FRG)}

BLANKET AGREEMENT (Attachment GE-1)

Parties: US/DOE; FRG/Federal Ministry for Research and Technology (BMFT)

Term: $\quad$ December 20, 1974 to December 31, 1989

Technical Scope: All areas of waste management

\section{SUBSIDIARY AGREEMENTS}

1. Transportation and storage--effects of intentional acts (Attachment GE-2)

2. Development of the Gas-Cooled Reactor (Attachment GE-3)

3. Experiments at the Asse salt mine (Attachment GE-4)

4. Methods of Treatment for Immobilization of High-Level Radioactive Waste (Attachment GE-5)

5. Amendments to Subsidiary Agreement No. 4 - Methods of Treatment for Immobilization of High-Level Radioactive Waste (Attachment GE-5A)

6. Temporary assignment of Dr. D. Strachen, PNL, to HMI (Attachment GE-6)

7. Research Related to Radioactive Material Transportation (draft; Attachment GE-7)

\section{STATUS/PLANNING REPORTS}

1. Summary record of US-DOE/FRG-BMFT Cooperative Program Planning and Review Meeting--US, 08/84 (Attachment GE-8)

2. Protocol for Second Spent Fuel Storage Information Exchange--US, 10/84 (Attachment GE-9) 


\section{ADMINISTRATION}

Principal Coordinators: US -- C. R. Cooley (DOE)

FRG -- R.-P. Randl (BMFT)

Document Exchange:

see Appendix C 


\section{TECHNICAL EXCHAYGE}

AND

COOPERATIVE ARRLYGENENT

BETWEEN

THE UNITED STATES ATOHIC ENERGY COMMISSION

AND

SHE FEDERAL MINISTRY FOR RESEARCH AND TECHNOLOCY

OF THE FEDERAL REPUBLIC OF GERMANY

IN THE FIELD OF MAVAGENENT OF RADIOACTIVE WASTES
The United States Atomic Energy Commission (AEC) and the Federal Ministry for Research and Technology (FNRT) of the Federal Republic of Germany, having a mutual interest in cooperation in the field of mangement of radioactive wastes hereby agree as follows:

Article 1

The subjects of cooperation are defined in Appendix "A", and can be modified or expanded, as may be mutually agreed.

\section{Article 2}

Both Parties will make available to each other information in the field of radioactive waste management which they have the right to disclose, either in their possession or available to them, from the technical areas described in Appendix "A".

\section{Article 3}

The information exchange will be reciprocal (balanced) and will be in the form of technical reports, experimental data, correspondence, visits, joint experts meetings, and such other means as the parties agree.

\section{Article 4}

The execution of joint programs and projects, or those programs and projects under which activities are divided between both parties, including tha use of test facilities and/or computer programs owned by either Party, will be agreed upon on a case-by-case basis. Longterm assignments of personnel can be accomodated on the same basis. 


\section{Article 5}

In general, information received pursuant to this Arrangement may be disseminated freely in the country of the recipient. However, privileged (private, proprietary, company confidential) information received by either Party under this Arrangement and bearing a restrictive designation may not, except as may be required by the laws of the respective Party, be publicly disseminated by the receiving Party without the prior written consent of the transmitting Party, but such information may be disseminated as follows:

(a) to persons within or employed directly by the recipient, and to other concerned government agencies:

(b) to prime or sub-contractors of the recipient Party for use only within the framework of its contract(s) with the respective Parties engaged in work relating to the subject matter of the information so disseminated;

provided that privileged information disseminated to any person under subparagraphs (a) and (b) above bear the marking "Not for dissemination outside recipient's organization without prior written approval of the (AEC or FMRT)". Each Party will use its best efforts to ensure that the dissemination of privileged information received under this Arrangement is controlled as prescribed herein.
Article 6

The information exchanged under this Arrangement shall be subject to the patent provisions in the Patent Addendum to this document.

\section{Article 7}

A coordinator will be designated by each Party, who will develop and control the arrangements and procedures for implementing the cooperation, in particular the effective exchange of information under this Arrangement. Approximately annually, the coordinators will organize joint working sessions at which the achievements, problems, effectiveness, future programs, etc., will be discussed with the objective of improving the cooperation.

\section{Article 8}

The application or use of any information exchnnged or transferred between the Parties under this Arrangement shall be the responsibility of the party receiving it, and the transmitting party does not warrant the suitability of such information for any particular use or application.

\section{Article 9}

Each Party will be prepared to the best of its ability, upon specific request, to advise the other on particular questions involving the topics of this Arrangement. 
It is the intent of both Parties to assure that a reasonably balanced exchange is achieved and maintair.ed.

\section{Article 11}

It is understood that the ability of the Parties to carry out their obligations is subject to the availability of appropriated funds.

\section{Article 12}

No provision has been made for reciprocal cost reimbursement between the Parties. Both parties shall bear. the costs incurred in their area of competence, including travel expenses and-subsistence allowances for their staff members and transport costs for apparatuses and other equipment transported under the cooperation program into the territory of the other Party in each case.

\section{Article 13}

This Arrangement shall also apply to Land Berlin, provided that the Government of the Federal Republic of Germany has not made a contrary declaration to the Government of the United States of America within three months from the date of entry into force of this Arrangement.

This Arrangement shall remain in operation for five (5) years after its effective date and may be extended by mutual agreement. However, the Arrangement may be terminated at any time, at the discretion of either Party, upon six months' advance written notification by the Party seeking to terminate, to the other Party.

\section{Article 15}

This Arrangement shall enter into force on the date of signature.

Done at Bonn in duplicate in the English and German languages, each equally authentic, this twentieth day of December, 1974

FOR THE UNITED STATES ATOMIC ENERCY COMNISSION

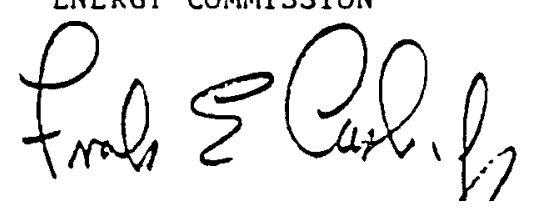

THE FEDERAL MINISTER FOR RESEARCH AND TECHNOLOGY OF THE FEDERAL REPUBLIC OF GERMANY

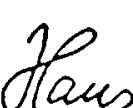

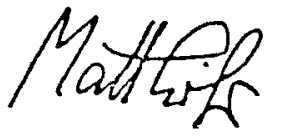




\section{APPENDIX "A"}

\section{Technical Scope}

AEC-FMrT Radioactive Waste Management Exchange *

1. Disposal of radioactive waste in salt deposits

a. Facility design and operation, including data on contamination of salt

b. Heat generation and dissipation

c. Rock mechanics studies

d. Safety considerations and cleanliness standards for casks

e. Geology and hydrology

f. Waste product criteria

g. Site criteria

h. Cost evaluation

* Initially the facilities involved in this exchange on the AEC side will be Oak Ridge Vational Laboratory (ORNL), Los Alamos Scientific Laboratory (LASL), Atgonne National

Alamos Scientific Laboratory (LASL), Atgonne National
Laboratory (AVL), Atlantic Richfield Hanford Co. (ARHCO), Battelle Memorial Institute'Pacific Northwest Laboratory' (BNill) and the waste management facilities at the Idaho Nationa Enginecring Laboracory (INEL), and those on the FYRT side will be Gesellschaft ruer lernforschung m.b.H ( $\mathrm{f} K$ ),

Gesellschaft fuer Sirahlen- und Umweleforschung m.b.H (GSF), Xernforschungsanlare Juelich G.m.b.H. ( $(\mathrm{FA} A$ ) and

Hahn-Meicner Insticut fuet Kernforschung G.m.b.it. (HMI). i. Records of repositories

j. Risk analysis

k. Monitoring and control

1. Public information and relations

2. Retricvable surface storage facilities

3. Waste management research and development

a. Solidification of high-level waste

b. Treatment and packaging of intermediate- and low-level waste

c. Incineration and incorporation in bitumen

d. Processes for removal and storage of noble gases and tritium in waste streams

e. Development of criteria for handling and storage of all classes of radioactive waste

f. Feasibility, safety and economic analysis for alternative long-term waste management methods adopted or under consideration

g. Processes and methods for the partitioning of high-level waste and for the extraction of selected nuclides

4. Waste from decommissioning of nuclear installations 
5. Operating aspects of storage or disposal of low- and intermediate

level wastes

a. Methods of minimizing initial generation

b. Current efforts on volume reduction, such as incineration and compaction

c. Current methods and limitations for packaging, handling and storage/disposal, including existing criteria

d. Currently identified categories requiring special or unique handling

\section{Transportation of radioactive waste}

a. Development of a transportation handing and shipping system for low-level waste

b. Design and approval of a high-level waste shipping package concept

c. Waste packaging technology

d. Safety evaluation techniques for waste packaging and transport systems, including a quantification of risk.
Aide Mewoire

The Federai ivinister for Research and Tecinology of the Federal Republic of Geruany, with regard to tice Technical Exchance and Cooperative Arrankement, which was signed by him and the United States ftomic Energy Comission this 20 th day of Decerioer 1774 , conveys his hope that the United States Atouic Energy Coraission will be prepared to enter into negotiations with the Federal jinister for Research and Tecrnolozy of the Federal kepubilic of Germiany for transfer to the European Cowmities as far as possible, those rights ard duties accruine to the Feceral Repubiic of Germany tinruagh this Arrangement in case an agreement covering tire sure subject is concilioed between the United States of fmerica and the Eurupean Comminities. 
AMENDMENT

to the

TECHNICAL EXCIIANGE AND COOPERATIVE ARRANGEMENT

of Decemb 32 20, 1974

in the field of

MANAGEMENT OF RADIOACTIVE WASTES

\section{WHEREAS}

The United States Department of Energy (and its predecessor the United States Atomic Energy Commission), and the Federal Ministry for Research and Technology (BMFT) of the Federal Republic of Germany, have exchanged research and development information in the field of Management of Radioactive wastes under the terms of an Arrangement between them that became effective on December 20, 1974 (hereinafter called the

"Arrangement"); and

\section{WHEREAS}

Responsibility for implementing the Arrangement on behalf of the United states is now vested by law in the United States Department of Energy (DOE); and

\section{WHEREAS}

DOE and BMFT share common nonproliferation objectives and consequently have mutual interests in further common development of radioactive waste management technology with a view to improving the use of nuclear technology while minimizing the risks of prolfferation:

\section{WHEREAS}

DOE and BMFT wish to continue and broaden the scope of their close and long-term cooperation in the field of radioactive waste management including the alternatives of disposal of separated waste products and the disposal of spent fuel under this Arrangement and in accordance with their respective treaties, national laws and regulations;

IT IS AGREED AS FOLLOWS

1. Areas of Cooperation

APPENDIX A (Technical Scope) of the Arrangement is deleted and replaced by the enclosed APPENDIX $A$.

2. Use and Disclosure of Information

Article 5 of the Arrangement is deleted and replaced by the enclosed APPENDIX $B$ to this Amendment.

3. Duration

The first sentence of Article 14 of the Arrangement is deleted and replaced by the following:

This Arrangement shall remain in force until December 31, 1984, and may be further extended by mutual agreement.

4. Additional Organizations

A new Article 16 is added as follows: 


\section{Article 16}

-The Partles agree that organizations in both the Federal Republic of Germany and the United states may participate in aspects of the cooperative activities under this Arrangement subject to mutual agreement of the Parties in writing and subject to all the terms and conditions of this Arrangement. *

\section{Entry into Force}

This Amendment shall enter into force upon signature.

Enclosures

Appendix A - Technical Scope

Appendix $B$ - Information Use and Disclosure

Done at Bonn in duplicate

in the English and German languages, each equally authentic, this $19^{\text {th }}$ day of Harch 1980

FOR THE UNITED STATES DEPARTIENT OF ENERGY

FOR THE FEDERAL MINISTER FOR RESEARCH AND TECHNOLOGY OF THE FEDERAL REPUBLIC OF GERMANY
APPENDIX A - TECHNICAL SCOPE

The technical areas of cooperation covered by this Arrangement may include:

1. Preparation of waste forms.

2. Decontamination and decommissioning.

3. Surface storage.

4. Characterization of geologic formations.

5. Disposal in geologic formations,

6. Transportation requirements.

7. Operational considerations.

8. Environmental and safety considerations.

9. Public acceptance issues.

Other areas of cooperation may be added by mutual agreement in writing.
Walter J. Stoessel, Jr.

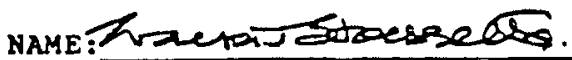

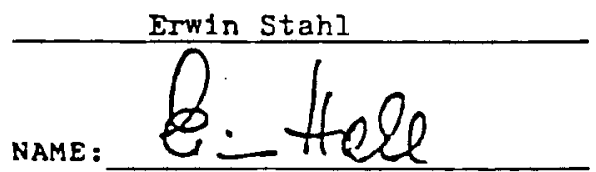

TITLE: Ambassador of the United States of America
TITLE : Parlamentarischer Staatsoekretar 
APPENDIX B - INFORHATION USE AND DISCLOSURE

1. General

The Parties support the widest possible dissemination of information provided or exchanged under this Arrangement, subject to the need to protect proprietary information developed prior to or outside the scope of joint activities conducted under this Airangement, and subject to the provisions of the Patent Addendum to this Arrangement.

2. Use of Proprietary Information

A. Definitions as used in this Arrangement:

(1) The term "information" includes scientific or technical data, results, or methods of research and development, and any other information intended to be provided or exchanged under this Arrangement.

(ii) The term "proprietary information" means information which contains trade secrets or commercial or financial information which is privileged or confidential, and may only include such information which:

(a) has been held in confidence by its owner;

(b) is of a type which is customarily held in confidence by its owner; (c) has not been transmitted by the transmitting Party to other entities lincluding the receiving Party) except on the basis that it be held in confidence; and

(d) is not otherwise available to the receiving Party without restriction on its further dissemination.

B. Procedures

(i) A Party receiving proprietary information pursuant to this Arrangement shall respect the privileged nature thereof. Any document which contains proprietary information shall be clearly marked with the following (or substantially similar) restrictive legend:

- This document contains proprietary information furnished in confidence under an Arrangement dated_between the United States Department of Energy and the Federal Minister for Research and Technology of the Federal Republic of Germany and shall not be disseminated outside these organizations, their contractors, licensees and the concerned departments of the Governments of the United States and the Federal Republic of Germany without the prior approval of:

- This notice shall be marked on any reproduction hereof, in whole or in part. These limitations shall automatically terminate when this information is disclosed by the owner without restriction." 
(11) Proprietary Information received in confidence under this Arrangement may be disseminated on a need-to-know basis by the receiving Party to:

(a) persons within or employed by the receiving Party, and to departments and agencies of the government of the receiving Party; and

(b) prime or subcontractors of the receiving Party located within or without the geographical limits of the receiving Party's legal jurisdiction, for use only within the framework of its contract(s) with the receiving Party in work relating to the subject matter of the proprietary information and provided that any proprietary information so disseminated shall be pursuant to an agreement of confidentiality and shall be marked with a restrictive legend substantially identical to that appearing in in sub-paragraph (i).

(iii) With the prior written consent of the Party providing proprietary information under this Arrangement, the receiving Party may disseminate such proprietary information more widely than otherwise permitted in sub-paragraph (i). The Parties will cooperate with each other in developing procedures for requesting and obtaining prior written consent for such wider dissemination, and each Party will use its best efforts to grant such approval to the extent permitted by its policies, regulations and laws.

c. Each Party will exercise its best efforts to ensure that proprietary information received by it under this Arrangement is controlled as provided herein. If one of the Parties becomes aware that it will be, or may reasonably be expected to become, unable to meet the confidentiality provisions of this Appendix, it will immediately inform the other Party. The Parties will thereafter consult to define an appropriate course of action.

D. Information arising from seminars and other meetings arranged under this Arrangement and information arising from the attachments of staff, use of facilities, and joint projects will be treated by the Parties according to the principles specified in this Appendix; provided, however, no proprietary information orally communicated will be subject to the limited disclosure requirements of this Arrangement unless the individual communicating such information places the recipient on notice as to the proprietary character of the information communicated and forthwith confirms the notice in writing. 
E. Nothing contained in this Arrangement will preclude the use or dissemination of information received by a Party through arrangements other than those provided for under this Arrangement. 


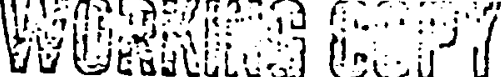

ANNEX TO BILATERAL AGREEHENT BETHEEN

USDOE/OSS and the FRB/BMFT

1. Scope

This annex to the bllateral exchange agreement between the Unlted States Department of Energy (DOE) and the Federal Republic of Germany (BMFT) contalns agreements and condtions for exchanges of Information relating to transportation and storage of nuclear fuel cycle materials. especially on effects of intentional acts.

\section{Definition}

\subsection{Materials}

This annex covers the commerclal nuclear materials, fncluding but not 1 imfted to spent reactor fuel, experimental waste, low level waste. and other waste generated by a reactor for power generation and materials from the front end of the nuclear fuel cycle. Including unrefined and processed ores and generated wastes.

\subsection{Transportation and Storage Programs}

Thts annex covers the transportation and storage prograns for nuclear materlals. Examples of posstble exchange 1 nclude analyses to determine the risk assessment of storlng and transporting nuclear materlals. experimental prograns to evaluate possible attacks on shipping and storage systems, evaluation. of storage and shipping systems in extreme environments possibly simulating extra severe accldents, and programs to evaluate the socloeconomic. Institutional. and organizational issues and pollcles assoctated with storage and transportation of nuclear materials.

\section{Annex Organtzation}

This annex has the following parts:

(a) Development of methods of, and channels for, exchanges of Information.

(b) Identification of specific areas for cooperation and exchanges of information are the following.

\section{Methods and Channels for Inforation Exchange}

Methods for exchanging Information wlll be established in accord ance with the usual methods defined in the bilateral agreement to which this annex is subordinated. Information exchanged can occur which this annex

(a) Metings between US and FRG personnel in which discusstion of programs and exchange of unclassifled materlal. studies, or data takes place.

(b) Visits to experimental sites to view experiments used to determine the result of intentional acts

\section{औरำ}

whtch may, by us standards, constftute classifted nformation.

(c) Exchange of offictal documents containing classifted Information.

Any exchange of the latter type information must be accomplish through offtclal USDOE/FRG channels. Exchanges of the type shown 1 $2 a$ and $2 b$ are accomplished by appropriate pre and post meeting docu mentation procedures. Information considered to be commerctal proprletary should not be exchanged under the terms of this agreeme

\subsection{Exchanges of Reports. Analyses, and Studies}

The reports, analyses, and studies assoctated with storage and transport of nuclear materials can be exchanged directly with transport of nuclear materials can be exchanged directiy

\subsection{Exchanges of Information on Experimental Programs}

This information can be exchanged in the same manner as report Detalls of environments. Initiating events such as accident simulatlons, possible attacks, and other effects can be exchanged through proper channels. Detatis of the resporse of shlpplng and storage systems to extreme environments. Including stmulated attacks can also be exchanged through proper channels. Detalls of the response of the nuclear materials themselves to yarlous environments can als be exchanged through the described channels.

Detalls of tests involying simulated attacks, package response and possible releases of materials are sensit tye and will be handle on an Individual basis through agreements reached between DOE/OSS and BMFT. The calculations of consequences or rlsks based on actua test data are also sensttive and will be handled on an Individual basis. This individual basis would include the agencles, laborator sponsors, and compantes involved, the klnds of experiments performe the data obtalned. and the possible conclusions reached.

\subsection{Exchanges of Visits}

This annex covers the possible exchange of yisits during parts of studies, experimental programs, and analyses. This annex does not ifmit vistes to pertods within a particular program duration. but also provides for pisits to include advisory and consultative roles in addition.

5. Identification of Specific Areas for Cooperation

5.1 US and FRG Programs

5.1.1 The USDOE, through Sandla Laboratorles is conducting an expe mental program to evaluate the impact of Intentional acts directed at transport containers for spent fuel and radioactive vaste contal 


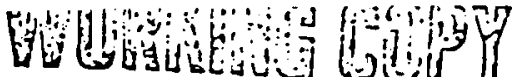

Th1s program will relate magnitude of the act with package damage release, and subsequent environmental impact. This progran is independent of simflar MRC program of more linited godis, but there is full communication between the programs. This annex shall also relate to technical exchanges with other US programs simflar in scope.

6.1.2 In the FRG, GNS developed, in cooperation with OWX and STEAG, a new systen of Type 8 packages, which can be used also for transport andor long term storage of irradiated fuel. In this frame, the consequences of terrorist attack on such casks with modern antitank weapons have to be examined. After theoretical approach, the effects are to be simulated with a number of experiments. After comparison of the theory with the results of the experiments, the additional exposure to the public will be calculated. If this additional exposure cannot be tolerated in the frame of existing guldeI ines and experlences. a concept of preventive measures and addtional protection has to be faund. This annex shall al so relate to technical exchanges with other FRG programs of siallar scope.

\subsection{Progran Detalls}

\subsection{Defintition of Damage}

\subsubsection{Selection of Attack Modes/Environments}

In collabortion with German authorltles and the correspondins organizations in the US, a range of possible modes of attack at the disposal of terrorlsts will be defined. Among these weapons, those will be selected for further examination, where the largest odage to casks can be expected.

\subsubsection{Experiments in the FRG}

Extensive experimental work is planned to find out the destructlon effects of the selected weapons on casks and frradiated fuel. For this purpose, experiments in the scale $1: 1$ will be executed. The experiments are bullt up in the following manner:

(a) simple experiments to find out the form of penetration through the cask wall.

(b) Advanced experiments to determine the mechanisms of fuel destruction and the total depth of penetration.

(c) Experiments on a simulated closed cask for determination of explosive energy transferred to the cask and the amount of material escaping from the cask. necessary number of scaled down models to be included in the US program.

\subsubsection{Evaluation of Experimental Results}

As a result of the experiments, it will be possible to assess penetration, descruction of contalnment, the type and anount of the destruction of the irradiated fuel and the anount and form of radiaactivematerlal. that wili escape from the cask. These baste data should be compared between US and FRG programs and harmontzed ulth the results of the US experiments.

\subsubsection{Calculation of the Additional Exposure to the Public as a Consequence of Terrorist At tack}

The additional exposure of the public as a consequence of terrorlst attack with weapons will be calculated, based on the results of 6.1.4. The calculation methods such as path-ways. transport, and dilution shall be discussed between the us and the FRG.

6.1.6 Participation at the Hot Experiment Planned in the US

GMS wlll channel its experfences into the preparation of the hot experiment planned in the US. Further participation, such as preparation of a GNS cask model. could be discussed.

\subsubsection{Preventive Measures}

If the calculation results in intolerable exposure to the pubIIc, preventive measures have to be examined. Posstble methods are:

(a) Additional technical protection of the cask.

(b) Administrative protective procedures.

\section{Tlme Schedule}

The GMS program is already underway in part. The same situatlon exists in the US. Therefore, a common program can be implemented in a relatively short delay. The experiments in Germany could be fintshed in about one yedr. Including the experiment on a closed cask. The evaluation could run in part parallel to the experiments, in part it wlll take three to six months additional time. An exact time schedule should be discussed between the us and the German partner.

All experiments wlll be executed without radtaactive material.

6.1.3 Experiments in the US

In the US, scaled down sections of cask walls (scale 1:3)

will be exposed to scaled intentional acts. GNS Hill prepare the 


\section{$12 / 22 / 76$}

AGREEMENT BETWEEN THE UNITED SOTATES ENERGY RESEARCH AND DEIELOPMENT ADMINISTRATION AND THE FEDERAL MINISTER FOR RESEARCH AND TECHNOLOGY OF THE FEDERAL REPUBLIC OF GERMANY IN THE FIELD OF GAS-COOLED REACTOR CONCEPTS AND TECHNOLOGY
The United States Energy Research and Development Administration (ERDA) and the Federal Minister for Research and Technology of the Federal Republic of Germany (BMFT), hereinafter called the. Parties;

having a mutual interest in developing the High Temperature Gas-Cooled Reactor (HTR) and the Gas-Cooled Fast Breeder Reactor (GCFR), both types of reactors hereinafter referred to as Gas-Cooled Reactors (GCR);

recognizing the important roles of both ERDA and BMFT in such research and development;

believing that the solution to problems of obtaining energy from the GCR should also provide for an amelioration of environmental problems;

believing that the introduction and utilization of gas-cooled reactors should provide needed energy options;

and recognizing the need to establish procedures governing the protection of privileged information provided in connection with activities under this Agreement;

have agreed as follows: 


\section{ARTICLE 1}

Cooperation between the Parties in the development of the GCR will be directed towards finding solutions to mutually agreed upon problems connected with the design, development, construction and operation of nuclear. power systems utilizing GCR's, and to exchange information developed during the resolution of these problems. This cooperation may include: exchange of expcrience and results of theoretical, experimental and conceptual design programs, and agreed upon research and development projects. This cooperation may also lead to joint planning, construction, operation and utilization of experimental and demonstration type facilities, as may be agreed in the future. Cooperation between the two Parties will be on the basis of mutual benefit, equality and reciprocity.

\section{ART ICLE 2}

The areas of cooperation in the development of GCR's covered by this Agreement may include:

1. Development of GCR technology including work on fuels, graphites, materials, fisgion product and coolant technology, primary circuit components, pressure vessel and thermal barrier technology and design, construction and operation of prototype and demonstration plants.
2. HTR fuel recycle technology including work on reprocessing, refabrication, waste treatment and disposal, recycle fuel-element performance, engineering and economic studies and the design, construction, operation and utilization of associated test, pilot plant, experimental and demonstration type facilities.

3. HTR steam cycle (HTR-SC) technology including all related RED work, components, design, construction and operation of test, prototype and demonstration facilities.

4. HTR direct cycle (IITR-DC) technology including work on the reactor and turbomachinery systems, fission product effects, reactor fuels, materials and components, design, construction and operation of test, prototype and demonstration facilities.

5. Very High Temperature Reactor and Process Heat (HTR-PH) technology including work on reactor fuels, materials, components, systems and chemical heat pipe technology, design, construction and operation of test, prototype and demonstration facilities.

6. Development of GCFR technology including related RED work, components, fuel fabrication and testing, design, construction and operation of test, prototype and demonstration facilities. 
7. Safety technology as it relates to all the gas-cooled reactor activities listed above.

8. Economic and environmental studies in the field of GCR's. Other areas of cooperation may be added by mutual agreement. ART ICLE 3

Cooperation in accordance with this Agreement may include but is not limited to the following forms:

1. Exchange of scientists, engineers and other specialists for participatior in agreed to research, development, analysis, design and experimental activities conducted in scientific centers, laboratories, engineering offices and reactor facilities of each of the Parties or its contractors for agreed upon periods.

2. Exchange of samples, materials, instruments and components for testing; and exchange of scientific and technical information and results and methods of research and development.

3. The organization of seminars and other meetings on agreed to topics covering basic problems of research and development in the areas enumerated in Article 2 , in a manner agreed to by the Joint Committee (Article 5).
4. Short visits by specialist teams or individuals to GCR facilities of the other Party.

Other specific forms of cooperation may be jointly agreed to by the Parties and approved by the Joint Committee (Articles 5 and 6 ).

\section{ART ICLE 4}

1. It is recognized by the Parties that there are organizational differences in their respective programs, and that BMFT may implement this Agreement through a GCR development company, which may also serve on behalf of BMFT as the focal point for communication and coordination for the ERDA/BMFT GCR research and technology exchange. ERDA may implement this Agreement, in whole or in part, through its contractors and subcontractors. In the event that any or all of the cooperative activities under this Agreement are implemented by a contractor, subcontractor or GCR development company, as contemplated above, such implementation shall in all respects be in accordance with the provisions of this Agreement. 
2. Entities of other countries which become participants in the GCR program of the Federal Republic of Germany may then participate in this Agreement on terms to be agreed by the Parties.

3. BMFT and ERDA agree that the French CEA has the option to join this Agreement on terms to be agreed upon by the Parties.

\section{$\underline{\text { ARTICLE } 5}$}

1. For the implementation of this Agreement, there is established a Joint ERDA/BMFT Committee on Cooperation in the Field of GCR's. This committee will implement, coordinate and review all aspects of this Agreement and, where necessary, make recommendations which each of the delegations will present to its Party covering specific means by which this Agreement shall be implemented.

2. The United States members of the Joint Committee shall be appointed by ERDA. The German members of the Joint Committee shall be appointed by BMFT. Each Party shall appoint the head of its delegation to the Joint Committee.
3. The Joint Committee will consist of ten members, five of which will be appointed by each of the Parties to this Agreement, meeting as agreed upon by the heads of the two delegations, at least once a year or at other times by agreement (alternately in the United States of America and in the Federal Republic of Germany) at an agreed to place. Each Party has the right to invite advisers as necessary. The head of the delegation of the receiving Party shall act as Chairman of the Joint Committee whenever it meets.

4. At least once a year, the Parties will provide the Joint Committee with a comprehensive review of GCR program status and plans which concern cooperation under this Agreement.

\section{ARTICLE 6}

1. Major new proposals for cooperation by either of the Parties would be reviewed, if deemed sufficiently important, by either the Joint Committee or by a joint ad hoc group appointed by the Joint Committee. 
2. Where a cooperative program or project under this Agreement necessitates a formalized specific memorandum of agreement executed by both Parties, the specific agreement should cover all detailed provisions for implementing that agreement, includirg such matters as patents, exchange of equipment and information disclosure specific to the particular program or project.

\section{ARTICLE 7}

1. The Parties will exchange, as agreed on a mutually beneficial basis, scientific and technical information, documents and results of research and development related to work carried out under this Agreement. Such information will be limited to that which they have the right to disclose, either in their possession or available to them, from the technical areas described in Article 2 .

2. Seminar proceedings and reports of joint programs carried out under this Agreement will be published as joint publications, as mutually agreed to by both Parties.
3. Both Parties agrec that information devaloped or cxchanged under this Agreement should be given wide distribution. Such information, except as noted in paragraphs 4 and 5 , may be made available to the public by either Party through customary channels and in accordance with normal procedures of the Parties.

4. It is recognized by both Parties that in the process of exchanging information, or in the process of other cooperation, the Parties may provide to each other "industrial property of a proprietary nature". Such property, including trade secrets, inventions, patent information and know-how, made available hereunder, but acquired by either Party prior to, or outside, the course of those activities, and which bears a restrictive designation, sha 11 be respected by the receiving Party and shall not be used for commercial purposes or made public without the consent of the transmitting rarty. Such property is defined as:

a. Of a type customarily held in confidence by commercial firms;

b. Not generally known or publicly available from other sources; 
c. Not having been made available previously by the transmitting Party or others without an agreement concerning its confidentiality; and

d. Not already in the possession of the receiving Party or its contractors.

\section{Recognizing that "industrial property of a proprietary} nature", as defined above, may be necessary for the conduct of a specific cooperative project or may be included in an exchange of information, such property shall be used only in the furtherance of GCR programs in the receiving country. Its dissemination will, unless otherwise mutually agreed upon, be limited as follows:

a. To individuals within or employed by the receiving party and to other concerned Government agencies and institutions of the receiving Party; and

b. To prime or subcontractors of the receiving Party for use only within the territory of the receiving Party and within the framework of their contract(s) with the respective Párty engaged in work relating to the subject natter of the information so disseminated; provided that the information disseminated to any person under subparagraphs $a$. or b. above shall bear a marking restricting dissemination outside the recipient's organization. Each Party will use its best efforts to ensure that the dissemination of information so marked is controlled as prescribed herein.

\section{ART ICLE 8}

The information exchanged under this Agreement shall be subject to the patent provisions in Article 10 .

\section{ART ICLE 9}

The application or use of any information exchanged or transferred between the Parties under this Agreement shall be the responsibilit: of the Party receiving it, and the transmitting Party does not warrant the suitability of such information for any particular use or application. 


\section{ARTICLE 10}

1. With respect to any invention or discovery made or conceived in the course of or under this Agreement, if not agreed upon otherwise (especially under Article 6):

a. If made or conceived by personnel of one Party (the Assigning Party) or its contractors while assigned to the other Party (Recipient Party) or its contractors, in connection with exchanges of scientists, engineers and other specialists:

(1) The Recipient Party will acquire all right, title and interest in and to any such invention, discovery, patent application, cr patent in its own country and in third countries; and

(2) The Assigning Party will acquire all right, title, and interest in and to any such invention, discovery, patent application, or patent in its own country.

b. If made or conceived by a Party or its contractors as a direct result of employing information which has been communicated to it under this Agreement by the other Party or its contractors or communicated during seminars or other joint meetings, the Party making the invention or discovery will acquire all right, title and interest in and to any such invention, discovery, patent application, or patent in all countries.

c. With regard to other specific forms of cooperation, including exchanges of materials, instruments and

2. The Party owning a patent covering any invention or discovery referred to in paragraph 1 above shall license the patent to nationals or licensees of the other Party upon request of such other Party on non-discriminatory terms and conditions. At the time of such a request, the other Party will be informed of all licenses already granted under such patent.

3. Each Party waives any and all claims against the other Party for compensation, royalty or award as regards any invention, discovery, patent application, or patent, made or conceived under this Agreement, and releases the other Party with respect to any and all such claims, including any claims under the provisions of the U.S. Atomic Energy Act of 1954, as amended, and the German Employees' Iluventions Law (Arbeitnchmererfindergesetz) of July 25, 1957 (BGBI, 1957, Part I, page 756), as 
equipment for special joint research projects, the Paztics shall provide for appropriate distribution of rights to inventions resulting from such cooperation. In general, however, each Party should normally determine the rights to such inventions in its own country, and the rights to such inventions and discoveries in other countries should be agreed upon by the Parties on a equitable basis.

d. It is understood that after the European Patent Conventions Uebereinkommen ueber die Erteilung europaeischer Patente, Uebereinkommen ueber das europaeische Patent fuer den Gemeinsamen Markt)

have come into force, either Party may request a modification of this paragraph 1 for the purpose of according equivalent rights as provided in subparagraphs l.a. - c. above under the European Patent Conventions.

\section{ARTICLE 11}

1. By mutual agreement the sending Party may provide equipment to be utilized in joint projects and experiments. In such cases the sending Party shall supply as soon as possible a detailed list of the equipment to be provided together with the relevant specifications and technical and informational documentațion.
2. The equipment and necessary spare parts supplied by the sending Party for use in joint projects and experiments shall remain its property and shall be returned to the sending Party upon completion of the joint project or experiment, unless otherwise agreed.

3. The above-mentioned equipment shall be brought into operation at the host establishment only by mutual agreement between the Parties or between their senior representatives at the host establishment.

4. The host establishment shall provide the necessary premises for the equipment and shall provide for electric power, water, gas, etc., in accordance with technical requirements which shall be mutually agreed upon.

5. The responsibility and expenses for the transport of equipment and materials from the United States of America by plane or ship to an authorized port of cntry in the Federal Republic of Germany convenient to the ultimate destination and return, and also responsibility for their safekeeping and insurance en route shall rest with ERDA. 
6. The responsibility and expenses for the transport of equipment and materials from the Federal Republic of Germany by plane or ship to an authorized port of entry in the United States of America convenient to the ultimate destination and return, and also responsibility for their safekeeping and insurance en route shall rest with the BNIFT.

7. The equipment provided by the sending Party for carrying out joint projects or experiments will be considered to be scientific, not having a commercial character.

\section{ART ICLE 12}

1. Each Party shall ensure the selection of adequate staff with the skills and competence necessary to conduct agreed upon joint projects. In carrying out such joint projects, selected staff of both Parties shall be attached to the host establishment.

2. Each Party shall be responsible for the salaries, insurance and allowances to be paid to its personnel.
3. Each Party shall pay for the travel and living expenses of its personnel when staying at the establishment of the host Party unless otherwise agreed.

4. The host establishment shall arrange for comparable accommodations for the other party's personnel and their families on a mutually agreeable reciprocal basis.

5. Each Party shall provide all necessary assistance to the specialists (and their families) of the other Party as regirds administrative formalities (travel arrangements, etc.).

6. The personnel of each Party shall conform to the general rules of work and sáfety regulations in force at the host establishment.

\section{ART ICLE 13}

Both Parties agree that the following provisions shall apply concerning compensation for damages incurred during the implementation of joint projects: It is understood that such compensation will be in accordance with the laws of the country on whose territory damages will have been incurred, except as otherwise provided. 
1. First and Second Party Damages

a. Each Party shall alone be responsible for payment of compensation for damages suffered by its staff regardless of where the damages have been incurred, and will not bring suit or lodge any other claims against the other Party for damages to its property, except as noted, in subfparagraphs $1 . b$ and $1 . c$.

b. If the damages suffered by the staff of one of the Parties are due to the gross negligence or intentional misconduct of the staff of the other Party, the latter shall reimburse the former an agreed to sum of money which the former would be obliged to pay to the person or persons suffering the damages.

c. If damages to the property of one Party are due to the gross negligence or intentional misconduct of the staff of the other Party, the latter shall compensate the former for the damages suffered.

\section{Third Party Damages}

a. Defective Equipment

Damages caused to the staff or property of a Third Party by defective equipment of a party will be compensated for by the Party to which the equipment belongs, except as noted in subparagraph 2.c.

b. By Staff

Damages caused to the staff or property of a Third Party by the staff of a Party will be compensated for by the Party in whose territory the damages occurred, except as noted in subparagraph 2.c.

c. Gross Negligence or Intentional Misconduct

If damages referred to in subparagraphs 2.a. and 2.b. were due to the gross negligence or intentional misconduct of the staff of a Party, that Party will bear the financial responsibility in regard to the Third Party.

d. Damages by Third Party

In the event of damages of any kind caused by a Third Party to the staff or property of one or both of the Parties, each of the two contracting Parties, 
upon the request of the other Party, will render the other aid in the corroboration of claims on the Third Party.

e. Resolution of Questions

The Party on whose territory the damages were incurred will, in consultation with the other Party, take upon itself the resolution, with the Third Party, of all questions connected with the determination of the causes, extent and necessity for compensation for damages incurred. Any such resolution shall have the concurrence of the other Party. After resolution of the mattcr, both Parties will decide, between themselves, the questions relating to compensation for damages incurred.

3. In the event of any dispute between the two Parties, a Committee shall be appointed by the Parties, with equal representation. The conclusions of the Committee will be presented to ERDA and BMFT who will review the conclusions and arrive at a mutual agreement concerning final disposition.
4. The foregoing provisions of this Article shall have no applicability to damages caused by a nuclear incident as defined by the laws of the Parties. Compensation for damage caused by such a nuclear incident shall be in accordance with the laws of the Parties.

5. Definitions

a. "Staff" of a Party means the Employees of the Party, its contractors and subcontractors performing services under this Agreement, and employees of these contractors and subcontractors performing services under this Agreement .

b. "Equipment" or "Property" of a Party means the equipment or property owned by that Party, or by the contractor and subcontractors of that Party who perform services in connection with joint projects under this Agreement.

\section{ARTICLE 14}

1. The provisions of this Agreement shall not affect the rights or duties of the Parties hereto under other agreements or arrangements. This Agreement also in no way precludes commercial firms or other legally constituted enterprises in each of the two countries from engaging in commercial 
dealings in accordance with the applicable laws of each country; nor does it preclude the parties from engaging in activities with other Governments or persons except that industrial property of a proprietary nature will have limited distribution as set forth in Article 7, paragraphs 4 and 5, of this Agreement. Moreover, it is expected that the present Agreement should facilitate industrial and commercial exchanges in the field of GCR between the firms of the countries of the Parties with a view to mutual benefits from such exchanges for both countries.

2. ERDA and BMFT will act as the point of coordination for contracts and arrangements between commercial firms of the United States of America and the Federal Republic of Germany when such firms act on behalf of their respective governments under the terms of this Agreement. It is understood that all such contracts and arrangements shall conform with applicable laws and regulations of the Parties. BMFT has a right to designate a GCR development company as stated in Article 4. ERDA has a right to implement this Agreement, in whole or in part, through its industrial contractors and subcontractors, as stated in Article 4.

\section{ART ICLE 15}

Cooperation under this Agreement shall be in accordance with laws and regulations of the respective countries. All questions related to the Agreement arising during its term shall be settled by the Parties by mutual agreement.

\section{ART ICLF: 16}

Each Party shall bear the costs of its participation in the activities under this Agreement. It is understood that the ability of the Parties to carry out their obligations is subject to the availability of appropriated funds.

\section{ART ICLE 17}

This Agreement shall also apply to Land Berlin, provided that the Government of the Federal Republic of Germany has not made a contrary declaration to the Government of the United States of America within three months from the date of entry into force of this Agreement. 
1. This igreement shall enter into force upon signature, shall continue for a ten-year period and shall be extendable by mutual consent. The implementation of, and progress under, this Agreement may be subject to annual review by the Parties.

2. This Agreement may be terminated at any time at the discretion of either Party, upon one year's advance notification in writing by the Party seeking to terminate the Agreement. Such termination shall be without prejudice to the rights which may have accrued under this Agreement to either Party up to the date of such termination.

3. In the event that during the period of this Agreement, the nature of either Party's GCR program should change substantially, whether this be by substantial expansion, reduction, transformation or amalgamation of major elements with the GCR Program of a Third Party, either Party shall have the right to request revisions in the scope and/or terms of this Agreement.

4. All joint efforts and experiments not completed at the termination of the Agreement will be continued with their completion under terms of this Agreement.

Done at

in duplicate in the English and German

languages, each text being equally authentic,

this $p i^{\text {th }}$ day of $[$ truary, 1977.

For The United States

Energy Research and

Development Administration
The Federal Minister for Research and Technology of the Federal Republic of Germany 

PROJECT AGREEMENT

BETWEEN

THE DEPARDMENT OF ENERGT OF THE UNITED STATES OF AMERICA

\section{AND}

THE FEDERAL MINISTER FOR RESEARCB AND TECHNOLOGY OF THE FEDERAI REPUBLIC OF GERMANY

POR THE CONDUCT OF EXPERDMENTS AT THE ASSE SALI MINE

Th1s Profect Agreement, hereinafter referred to as the Agreement, is entered into between the Department of Energy of the United States (DOE), and the Federal Minister for Research and Iechnology of the Federal Republic of Germany (BMFT), hereinafter referred to as the Partles, for the conduct of radioactive waste storage experimeges at the Asse Salt Mine in the State of Lower Saxony.

Th1s Agreement is entered 1nto as provided in Article 4 of the Technical Exchange and Cooperative Arrangement between the United States Atomic Energy Commission and the Federal Ministry for Research and Technology of the Federal Republic of Germany in the Field of Management of Radloactive Wastes of 20 December 1974 as amended on 19 March 1980 by the Parties.

\section{ARIICLE I - OBNECTIVES}

The objectives of cooperation under th1s Agreement are to:

1) obtain and analyze data on the migration of brine under the lafluence of heat and radiation;

2) obtain and ansigze data on the sutcability of test procedures and on the performance of test equipment;

3) obtain and analyze data on the performance of materials sultable for packag1ng radloactive wastes under the influence of heat, radiation and brine; and

4) obtain and analyze data on temperature and stress flelds associated Wth the mining of cavities in salt and with the emplacement of heat sources in salt.

\section{ARIICLE 2 - SCOPE}

1. To accomplish the odjectives of Article 1, a five-gear collaborative research and development profect, hereinafter referred to as the "Project," wil be undertaken concurrently by the Parties. The work wll be diplded Into two parts with DOE responsible for the conduct, principalis in the Dn1ted states, of one part (Part I) and BMFI responsible for the conduct, principally in the Federal Republic of Germany, of the other part (Part II).

2. The planning docments required to carry out the Project, together wth the responsibilities for their preparation, review, approval and execution, are listed in Table 1 which is appended to this Agreement. 
3. In Part I, DOE will be responsible for the following:

1) Design, fabrication, procurement and preshipment testing of four sets of mechanical equipment, exclusive of radioactive sources, to be 1nserted into the mine test holes. This equipment includes, but 18 not Ilmited to, sleeve assemblies, canisters, source support tubes, shleld plugs, borehole liners for source and guard heater locations and guard heaters.

2) Design, fabrication, procurement and preshipment tesțiog of a siagle Data Acquisition System (DAS) to be installed botb at the wine site on the surface and on the equipent installed in the test holes. This equipment lncludes all system components except for the following: the data link cable joining the surface equipment and the test hole equipment, the surface alarm and its wirlng to the mult1plexer and the electrical power supply.

3) Design, fabrication, procurement and preshipment testing of the Holsture Collection System (MCS) associated with the test holes. All 6ystem components will be provided except for the pressure tubing.

4) Prov1s10n of procedures and technical assistance relating to Installation, operation and maintenance of the above equipment and relating to operator training.

5) Provision of englneering services associated with (a) preparation and review of the documents listed in Table 1; (b) perfomance of the tasks contalned in approved documents as 11sted in Table 1;

(c) determination of site sultability through core sample analysis; and (d) field coordination as required in the $0 . S$. and the FRG.
6) Provision of office support 10 the O.S. for the BMFT Profect Leader or his designee during the equipment design, fabrication and presh1pwent test1ng efforts.

4. In Part II, BMT will be responsible for the following:

1) Making avallable to the Project the necessary surface and subsurface portions of the Asse Salt Mine 1dentified according to the Site Characteristics Requirements and the S1te Selection Hork Plan 11sted in Table 1.

2) Preparation of all required submittals and obtaining of all licenses necessary for conducting the Project at the Asse Salt Mine.

3) Conducting Mine excavation and experimental coring.

4) Design, fabrication, procurement, Installation and testing of all mechanical equl pment required to conduct and support the Project, other than that to be provided by DOE. This includes, but is not IIm1ted to, ang transportation casks; Installation casks; transfer equipwent; hot cell equipment; $11 \mathrm{fting}$ and handling equlpoent; recelving, storage, inspection, assembly, checkout and installation equiprent; radioactive sources and the equipwent or system required to waneurer the assembled radiation canister from the surface cask or hot cell to the test area and to insert each canlster into the test cav1ty. 'BMFT's equipment will be capable of reversing the procedure upon completion of the experiment or when any intermediate retrieval is required. 
EMFI w1ll al so provide design, fabrication, procurement, 1nstallation and testing of (a) all components of the nomal power and emergency power supply system required to dellver regulated single phase power to the terminels of each heater controller, and 1solated and filtered single phase power to duplex connector outlets in the vicinity of the Data Acquisition System; (b) the data line cable connecting the site modem to the surface modem in the Data Acquisition System and a surface alam activated by the Data Acquisition System; and (c) the pressure tubing interconnecting the test sites with the Molsture collection System.

5) Provision of engineering services associated with (a) preparation and review of the documents listed in Table 1; (b) performance of the tasks contained in approved documents as listed in Table 1; and (c) field coordination as required in the U.S. and the FRG.

6) Installation and maintenance of equipwent prorided by DOE as defined In Part I, above, and according to Article 6, paragraph 4, below.

7) Preparation and implementation of all operating and maintenance Instructions for the hot cell, the Asse Salt Mine Including the test site, and BMFT-procured equipont including the handling, transfer and Installation of that equipment.

8) Furnishtig all labor, lacluding supervision and management, required to excavate and prepare the test site, and required to Install, test, operate, and diswantle the test equipment and the test support equipent.
9) Provision of geological and geochemical services to evaluate and character1ze the salt in the proposed test site.

10) Assuming oversil responsib1lity for the developmeat and 1mplementation of all site emergency, training and post-test eraluation procedures.

11) Provision of field coordination in the FRG and the U.S.

12) Provision of offlce support for the DOE Project Leader or his designee during the preparation and experimentation periods.

13) Retent1on of records listed in Table 1.

5. Other responsibllities may be added to elther Part I, Part II or both by mutual written agreement.

\section{ARTICLE 3 - SCHEDULE MILESTONES AND REPORTING REQUIREMENTS}

1. A set of milestones will be developed and published by the Frofect Leaders during the first three months of the Project. These milestones will enable periodic assessment of progress and direction. Major milestones for the Project will Include:

1) The 1ssuance of a final Test Plan, which contains the deta1ls of the test objectives, planging and test hardware requirements.

2) The obtaining of licenses and permits.

3) The design, fabrication, testiag and delivery to the site of DOE-supplied equi pment.

4) The desiga, procurement, testing and delivery to the site of BMFT-supplied equi pment.

5) The 1ssuance of test results, analys1s and data documentation reports. 
2. It 15 ant1c1pated that the f1rst brine m1gration test will be 1n1tiated near the end of 1982. Tests wlll be conducted at each of the four test areas wthin the test site for approximately two (2) years, depending on data collected.

3. The Project Leader in each country will provide promptly to both Profect Coordinators brlef quarterly reports, wich will note the status of the Project with respect to schedules and milestones.

4. The two Project Leaders wlll jolntly prepare a detalled annual report describing the work done, results achieved and milestones completed.

5. The Profect Leaders will 1 ssue topical reports as mutually agreed and w11l issue a final report, which w1ll include test results and conclusions.

\section{ARTICLE 4 - MANAGERENT}

1. Each Party shall appolnt a Project Coordinator to act on 1ts behalf in all matters concerning cooperation and coordination under this Af reemeat. Overall responsibility for the Implementation of the Agreement will rest with the Project Coordinators.

2. The Project Coordinators shall jolntly approve, in writing, the Project schedule and work tasks, Including signiflcant changes thereto.

3. The Project Coordinators shall meet at least once a year at a mutually ggreed location.
4. Each Project Coordinator shall appoint a Project Leader to be responsible for the detalled management of 1 ts Part of the Project. Each Project Leader shall establish working contacts with the other Project Leader to assure compatibility of the work taking place under the two Parts of the Profect and to fac1litate coordination of technical exchanges between the Parties.

\section{ARTICLE 5 - FINANCE}

1. All costs resulting from cooperation under this Agreement shall be borne by the Party that 1ncurs thew.

2. Unless otherwlse agreed in wr1ting, no transfers of funds shall occur between the Parties.

\section{ARTICLE 6 - EQOIPMENT}

Each Party agrees that in the event equipment 1s to be exchanged or supplled by one Party to the other Party, the following provisions shall apply covering the shipment and use of the equipment:

1. The sending Party shall supply as soon as possible a deta1led list of the equipment to be provided rogether with the assoclated specifications and technical and 1nformational documentation.

2. The equipment, spare parts and documentation s"prlted by the sending Party shall remaln the property of the sending Party and shall be returned to the sending Party upon completion of the mutually agreed activity unless otherwse agreed. 
7. The equipwent provided by the sending Party for carrylag out mut lially agreed activities shall be considered to have a sclentifle, not a commercial character.

\section{ARTICLE 7 - EXCHANGE OF OBSERVERS AND ASSIGMENT OF PERSONNEL}

1. Each Party shall at 1 ts own expense have the right to observe the test activities and analgtical work of the other Party. Th1s right may be exercised by short term visits or by the attachment of staff subject to the prior agreement of the recelving Party on each occasion.

2. Whenever an exchange of staff is contemplated under this Agreement, each Party shall ensure that qualified staff are selected for attachent to the other Party.

3. The Parties will prepare attachent or other such agreements as may be necessary in confunction with work assigments under this Agreement.

4. Each Party shall be responsible for the calarles, Insurance and allowances to be pald to 1ts staff.

5. Each Party shall pay for the travel and living expenses of its staff whlle on attacheat to the host Party unless otherwse agreed.

6. The host Party shall arrange for comparable accomodations for the attached staff (and their families) of the other Party on a mutualy agreeable reciprocal basis.
3. The host establishmeat shall provide the necessary premises and shelter for the equipent and shall provide for electric power, vater, gas, etc. In accordance with technical requirements, which shall be as mutually agreed.

4. The equipent supplied by the sending Party shall be brought into operation at the host establishment only by mutual agreement between the Parties or between the1r sen1or representatives at the host establishment.

5. Regponsibility for expenses, safekeeplag and insurance during the transport of the equipment from the ordginal location in the country of the sending Party to the place of eatry in the country of the recelving Party shall rest with the sending Party. If the sending Party elects to have the equfpent returned, it shall be responsible for expenses, safekeping and Insurance en route from the place of entry in the country of the sending Party to the final destination in the country of the sending Party.

6. Responsibility for expenses, safekeeping and insurance during the transport of the equipment from the place of entry 1n the country of the recelving Party to the final destination in the coutry of the recelving Party shall rest with the recelving Party. If the sending Party elects to have the equipent returned, the recelving Party shall be responsible for expenses, safekeeplng and insurance en route from the place of departure in the country of the recelving Party to the place of entry in the country of the sending Party. 
7. The host Party shall provide all necessary assistance to the attached staff (and the1r famfles) of the other Party as regards administrative formaltites, such as travel arrangements, etc.

8. The ataff of each Party shall conform to the general and spectal rules of work and safety regulations in force at the host establishent, or as agreed in a ceparate staff atrachment agreement.

9. The Party proposing an attactment shall notify the recelving Party of the name of the person(s) proposed for the attachment and shall provide such 1 formation respecting the sald person(s) as may be required by the recelving Party.

\section{ARTICLE 8 - DISCLAIMER}

Information transmitted by one Party to the other Party under this Agreement ohall be accurate to the best knouledge and bellef of the transaltting Party, but the trangmitting Party does not warrant the suttabllity of the Information transmitted for any particular use or application by the receloing Party or by any third party. Information developed jointly by the Parties shall be accurate to the best koowledge and bellef of both Parties. Ne1ther Party warrants the accuracy of the jolntly developed information or 1ts sultab1l1ty for ang perticular we or application by either Party or by any third party.
1. The publication, distribution, handling, protection and owmership of Information and intellectual property, and rules and procedures related thereto not covered by this Agreement, shall be determined by the Parties by unaninity.

2. Subject to the restrictions apploing to patents, copyrights and proprletary 10formation, the Parties shall have the right to publish all Information provided to or arising from the Project. For the purpose of this Agreement, proprletary 1nformation will mean foformation which contalns trade secrets or commercial or financial information which is privileged or confidential and may only laclude such information which:

a) Bas been held in confidence by its owner;

b) Is of a type which is customarily held in confidence by 1 ts owner;

c) Bas not been trangmitted by the transmitting Party to other entities (1ncluding the recelving Party) except on the basis that it be held in confidence; and

d) Is not otherwse avallable to the recelving Party from another source without restriction on its further disemination.

3. It will be the responsibility of the Party providing inforiation to the Project to 1dentify information it furalshes which qualifies as proprletary Information under paragraph 2 of this Article 9 and ensure it is approprlately marked in accordance with paragraph 5 of this Article 9. The Party creating arising information which discloses or revealo proprietary Information shall also have the responsibility to so mark such information. 
Whenever proprietary information is orally communicated, the 1ndividus communicating such laformation shall place the reciplent on notice as to the proprletary aature of the information. The Parties will take all necessary measures in accordance with this Article, the laus of their respective coumtries and international law to protect proprietary information. If efther Party becomes aware that it will be, or way be reasonably expected to become, unable to meet the non-dissemination provisions of this article, it shall immediately notify the other Party.

4. Proprletary 1nformation provided to or arising from the Project work of one Party, which 1s transferred to the other Party, shall not be disseminated by the recelving Party except to:

(1) persons within or employed by the recelving Party and conceraed Government departments and agencies in the comtry of the Recelving Party having responsibilities related to the technology of the Project, and

(11) prime or subcontractors of the recelving Party located within the geographical limlts of the receloling Party's nation, for use only Wth1n the framework of their contracts with the recelving Party in work relating to the subject matter of the proprietary information; provided, however, that any proprletary information so disseminated shall be pursuant to an agreement of confidentlality and shall be marked in accordance Wh paragraph 5 of this Article 9.
5. Any document which contalns proprietary information shall be clearly marked with the following (or substantially simflar) restrictive legend: "Th1s document conta1ns proprietary 1nformation furnished 1n confidence under a Project Agreement dated

between the Unfted States Department of Energy and the Federal Minfster for Research and Technology of the Federal Republic of Germany, and shall not be disseminated or used except as provided for in the Project Agreement without the approval of Th1s notice shall be marked on any reproduction hereof, in whole or 1n part. These limitations shall automatically terminate when this information is disclosed by the owner whthout restriction."

6. The Partles will notify each other of any pre-existing proprletary 1nformation, or proprietary 1nformation developed 1ndependently of this Project, which will be used in the Project and which 1s necessary for the understanding of the Project results. Such Information shall not be exchanged except by mutual agreement of the Parties under the terms and conditions set forth in this Article 9.

7. In formation arising in the course of or woder the Project ("arising information") which does not disclose or reveal pre-existing proprietary 1nformation will be freely avallable to both Partles for use and dissemination. A Party possessing information regarding inventions on which patent protection 1s to be obtalned shall notify the other Party and thereafter such information shall not be published or publicly disclosed untll a patent application has been flled; provided, however, that this restriction on publication or 
disclosure shall not extend beyond six wonths from the date of aotice to the otber Party under this paragraph. Such information shall be appropriately marked to restrict publication or disclosure.

8. Reports contalaing arising information and information developed prior to or outside the Profect necessary for and used 1n the Project, Including proprietary 1nformation, wil be exchanged by the Parties and will cover the work performed by each Party under this Project.

9. Inventions made or concelved in the course of or under this Project ("arising Inventions") will be owned by BMFT in the Federal Republic of Germany and by DOE in the Dn1ted States. Each Party, 1ts Government and the nationals of its country designated by 1t, shall recelve a royalty-free, non-exclusive license in the other Party's country. In third counties, arlsing inventions shall be owned by the 1urenting Party. The Party owning an Invention in a third country shall grant to the other Party, its Goverrment, and the nationals of its country designated by $1 t$, a nod-exclusive, royalty-free license. Bowever, if the Party having the right to file a patent application in third countries does not wh to file in one or wore chird countries, that Party shall extend to the other Party the option to flle in one or more third coutries. If neither Party wishes to file in a third country, the 1nventing Party may dispose of the invention in ang manner it deems appropriate.
10. Each Party may take approprlate weasures necessary to protect copyrtghtable waterlal generated by 1 t under this Project. Coprrights obtalned wll be the property of that Party; provided, however, that the other Party may reproduce and distribute auch material, but wll not publish 1t. Wh a view to profit.

11. Each Party wil, Wthout prefudice to any r1ght of laventors or authors under its national laws, take all necesary steps to provide the cooperation of 1 ts authors and inventors required to carry out the provistons of this Article 9. Each Party wll assume the responsiblity to pay awards or compensation required to be pald to 1 ts employees according to the laws of its country.

\section{ARTICLE 10 - APPROPRIATED FUNDS}

The ability of the Parties to carry out their obligations lnder this Agreement 15 subject to the avallablitity of appropriated funds.

\section{ARTICLE 11 - LAWS AND REGULATIONS}

Cooperation under this Agreement shall be in accordance with the laws of the respective comtries and the regulations applicable to the respective Parties. All questions related to the Agreement arising during its term shall be settled by the Parties by mutual agreement.

ARTICLE 12 - LEGAL RESPONSIBILITY

1. The Parties shall use all reasonable skill and care in carrying out the15 dut les under this Agreement in accordance with all applicable laws and regulations. 
2. Compensation for damages incurred during the implementation of this Afreement shall be in accordance wth the applicable laws of the countries of the Parties.

\section{ARTICLE 13 - OTHER AGREEMENTS}

The provisions of this Agreement shall not affect the rights or duties of the Parties under other agreements or arrangements. This Agreement also in no way precludes comercial firms or other legally constitured enterprises in the countries of the Parties from engaging in comercial dealings in accordance whth the applicable laws of each country; nor does it preclude the Parties from engaging in activities with other goverments or persons.

\section{ARTICLE 14 - DURATION}

1. Th1s Agreement shall enter 1ato force upon signature, shall contioue in force for a flve-year perlod, and may be amended or extended by written agreement of the Parties.

2. All joint efforts and experiments not completed at the explration of this Agreement may be continued until their completion under the terms of this Agreement.

3. In the event that, during the perlod of th1s Agreement, the nature of either Party's radioactive waste managenen program should change substantially whether this be by substantial expansion, reduction, transformation or amalgamation of major elements with the radioactive waste management program of a third party, elther Party shall have the right to request revisions in the scope and/or terms of this Agreement.

\section{ARTICLE 15 - TERMINATION}

1. Th1s Agreement mag be terminated at ang t1me at the discretion of elther Party upon six months advance notification in witing by the Party seeking to terminate the Agreement. Such temination shall be Whout prefudice to the rights that mag have accrued under this Agreement to elther Party up to the date of the termination.

2. All jolnt efforts and experiments not completed at the termination of th1s Agreement mag be continued wril theit completion under the tems of the Agreement.

\section{ARTICLE 16 - LAND BERLIN}

Th1s Agreement shall also apply to Land Berlin, provided that the Government of the Federal Republic of Germany has not made a contrary declaration to the Goverment of the Dnited States of America within three months from the date of entry 1nto force of th1s Agreement.

Done at 1n duplicate in the English and German

languages, each equaliy authent1c, this day of October 1981.

FOR THE UNITED STATES DEPARTIENI OF ENERGY

Name : T1t1e: American Ambassader
FOR THE FEDERAL MINISTER FOR RESEARCH AND TECENOLOGT OF TEE FEDERAL REPUBLIC OF GERMANY

Name: centroun, as yed

T1tle: 


\section{Profect Plang1ag Documente}

Responsibllities for the preparation, revieu, approval and execution of plans for major activities under the Project are show below.

\section{Planglag Document}

\section{Preparation Revier}

Ste Characteristic Requirements

Selection of Potential Test Sites

Site Selection Work Plan Guidelines

Site Selection Work Plas

Excavation Methods

Experiment Core Characteristic Requirements

Experiment Corlng Methods

Experiment Core Testiag and QA Program Qverall QA Program Requirements

QA Procedures

Site Selection Test Results

Site Characterization Test Procedures

Deviation Not1ce DIsposition

Overall Experiment Tear Plan

Installation Frocedures (U.S. Supplled Equi poent)

Installation of FRG Supplied Equipent
Approval

$\begin{array}{rcc}\text { US } & \text { FRG } & \text { US } \\ \text { FRG } & \text { US } & \text { US/FRG } \\ \text { US } & \text { FRG } & \text { US } \\ \text { FRG } & \text { US } & \text { FRG } \\ \text { FRG } & \text { US } & \text { FRG } \\ \text { US } & \text { FRG } & \text { US } \\ \text { FRG } & \text { US } & \text { US } \\ \text { FRG } & \text { US } & \text { US } \\ \text { US } & \text { FRG } & \text { US } \\ \text { US/FRG } & \text { US } & \text { US } \\ \text { FRG } & \text { US } & \text { US } \\ \text { FRG } & \text { US } & \text { US } \\ \text { US/FRG } & \text { US/FRG } & \text { US/FRG } \\ \text { US } & \text { FRG } & \text { US/FRG } \\ \text { US } & \text { FRG } & \text { FRG } \\ & & \text { FRG } \\ \text { FRG } & \text { US } & \text { FR }\end{array}$

Execut1on

FRC

FRG

FRG

FRG

FRG

FRG

FRG

US/FRG

US/FRG

FRG

FRG

US/FRG

FRC

FRC

FRC

Preparat1on Revieu Approval

\section{Plana1ng Document}

Operating Procedures (1ncludes a decision matrix)

Emérgency Procedures (1ncludes a decision watrix)

Post-Test Evaluat1on Plan

Post-Test Eval uat1on Procedures

Operator Tralaing Procedures

Records Reteation

Pte-Test Geological FRG

Pre-Test Equitpment Assembly \& Install. FRG

Initial Operation

Operation

Post-Test Evaluat1on

Dafly Log of Mine Operations

Test Site Decommissioning Plan

FRG - Federal Republic of Germany, through BMFT or 1ts Designee.

US = United States of Amer1ca, through DOE or 1ts Designee. 
PROJECT AGREEMENT
BETWEEN
THE DEPARTMENT OF ENERGY OF THE UNITED STATES OF AMERICA
AND

THE FEDERAL MINISTER FOR RESEARCH AND TECHNOLOGY

OFEAL MINISTER FOR RESEARCH AND TECH
OF THE FEDERAL REPUBLIC OF GERMANY

ON METHODS OF TREATMENT FOR IMMOBILIZATION OF HIGH-LEVEL RADIOACTIVE WASTE

This Project Agreement is made between the Department of Energy of the United States of America ("DOE") and the Federal Minister for Research and Technology of the Federal Republic of Germany ("BMFT"), hereinafter the "Parties."

\section{ARTICLE 1 - OBJECTIVE}

1. The objective of cooperation under this Project Agreement is to undertake a joint experimental and analytical program for the development of processes for the treatment and immobilization of high-level radioactive waste and to use these processes for the fabrication of isotopic sources of radiation and heat (isotopic heat sources).

2. Cooperation under this Project Agreement shall constitute a joint project as contemplated by Article 4 of the DOE-BMFT Technical Exchange and Cooperative Arrangement in the Field of Management of Radioactive Wastes of December 20, 1974, as amended on March 19, 1980 (the "Waste Management Arrangement").

3. Articles 4, 7, 8,9,10,11, 13, and 16 of the Waste Management Arrangement are hereby incorporated by reference into this Project Agreement.

4. The execution of this Project Agreement is not intended to supersede or adversely affect the existing mutually-beneficial cooperation between DOE and BMFT, their contractors and associated organizations under the overall Waste Management Arrangement of 1974, and in particular that cooperation involving Pamela, West Valley, and Pacific Northwest Laboratory.

\section{ARTICLE 2 - PROGRAM}

A Joint Program (the "Program") designed to achieve the objectives of this Project Agreement is outlined below.

1. Exchange of information in the areas of design, development, construction, and operation of processes for the treatment and immobilization of highlevel radioactive waste, including such information from the Pamela, West Valley, and Pacific Northwest Laboratory facilities.

2. Research and development efforts on processes for the treatment and immobilization of high-level radioactive waste by means of fabrication of isotopic heat sources under radioactive conditions. Prior to the start of such fabrication, the parties shall agree in writing on the technical specifications for the isotopic heat sources. The Record of the DOE/BMFT Meeting on February 28, 1984 shall provide the intitial specifications and conditions for production, storage, and transportation of isotopic heat sources. Changes thereto shall be accomplished by exchange of letters between the Project Coordinators.

3. Assignment of staff of each Party or its contractors or associated organizations to the other Party or its contractors or associated firms to participate in the program. Each such assignment shall be the subject of a separate assignment agreement between the Parties, pursuant to Article 7 of this Project Agreement.

4. Short visits by specialist teams or individuals of one Party or its contractors or associated organizations to the other Party or its contractors or associated organizations, as mutually agreed and subject to the regulations of each party. 
5. Recording and exchange between the Parties of data and results arising from the Program.

6. Analyses of the experimental results, exchange of the results of such analyses, and exchange of conclusions derived from such results.

7. Preparation and exchange between the Parties of agreed reports during the Program, and preparation of a joint report at the end of the Program.

8. It is understood between the Parties that the tasks under the Program may be implemented by contractors of the Parties, such as GSF (Gesellschaft fuer Strahlen-und Umweltforschung mbH) and PNL (Pacific Northwest Laboratory).

ARTICLE 3 - RESPONSIBILITIES OF THE PARTIES

1. To meet the requirements of the Program, DOE shall at its own expense:

a. Make available the BMFT information which DOE has the right to disclose in the areas of design, development, construction, and operation of processes for the treatment and immobilization of high-level radioactive waste and on the use of such processes for the fabrication of isotopic heat sources.

b. Provide the facilities and equipment necessary for fabrication of isotopic heat sources.

c. Participate in the preparation of joint OOE-BMFT technical reports of results of activities and conclusions derived from such results under this Project Agreement.

d. Provide approximately $3 \times 10^{6} \mathrm{Ci}$ of Cesium-137 (Cs-137) and approximately $3 \times 10^{6} \mathrm{Ci}$ of Strontium-90 for use as the source of heat and radiation. On a best effort basis, DOE shall seek an additional $7 \times$ $10^{6} \mathrm{Cl}$ of $\mathrm{Cs}-137$ in order to meet the specifications and conditions for production of all the isotopic heat sources as stated in the Record of the DOE/BMFT Meeting on February 28, 1984.

e. Fabricate ten heat and radiation sources by incorporating the above radionuclides in a borosilicate-type glass matrix and encapsulating that matrix in steel canisters approximately $30 \mathrm{~cm}$ in diameter 10.0 .1 and $120 \mathrm{~cm}$ in length. The ten sources shall be fabricated with a nominal heat generation rate of 1,680 watts. In the event the additional $7 \times 10^{6} \mathrm{Cl}$ of $\mathrm{Cs}-137$ is obtained, two additional sets of ten canisters each shall be fabricated with nominal heat generation rates of 1,285 watts and 2,065 watts, respectively. OOE shall give BMFT one month's advance notification prior to beginning fabrication of the first isotopic heat source. DOE shall proceed with fabrication of the isotopic heat sources unless formally notified by BMFT to the contrary.

f. Provide and/or operate a canister storage, welding, decontamination, and gauging facilfty to prepare isotopic heat sources for shipment to the Federal Republic of Germany.

9. Make the isotopic heat sources available F.0.B. at DOE's Pacific Northwest Laboratory located at Richland, Washington, to BMFT for shipment to the Federal Republic of Germany.

h. Assign DOE or DOE contractor personnel to BMFT or BMFT's contractors or associated organizations as mutually agreed, to participate in the 
Program. Each such assignment shall be the subject of a separate assignment agreement between the Parties pursuant to Article 7 of this Profect Agreement.

2. To meet the requirements of the Program, BMFT shall at its own expense:

a. Make avallable to DOE information which BMFT has the right to disclose in the areas of design, development, construction and operation of processes for the treatment and immobilization of high-level radioactive waste, and on the use of such processes for the fabrication of isotopic heat sources.

b. Participate in the preparation of Joint DOE-BMFT technical reports of results of activities and conclusions derived from such results under this Project Agreement.

c. Provide DOE with suitable canisters and lids, compatible grappling devices, welding equipment, helium leak test equipment, and straightness and ovality gauges. Upon BMFT request, DOE shall provide welding equipment from its own sources at BMFT expense.

d. Assign BMFT or BMFT-contractor personnel to DOE or its contractors, as mutually agreed, to participate in the Program. Each such assignment shall be the subject of a separate assignment agreement between the Parties or their contractors pursuant to Article 7 of this Project Agreement.

e. Accept responsibility for the isotopic heat sources upon their being made available F.O.B. by DOE at DOE's Pacific Northwest Laboratory located at Richland, Washington. f. Upon acceptance of responsibility for the isotopic heat sources pursuant to Article 3.2.e, be responsible for their handling, storage, transportation, and insurance from point of origin at Richland, Hashington, to their ultimate destination in the Federal Republic of Germany.

9. Obtain all licenses or approvals necessary for transportation of the isotopic heat sources from Richland, Washington, to their ultimate destination in the Federal Republic of Germany.

h. Be responsible within the Federal Republic of Germany for the handling, storage, use, and disposal of the isotopic heat sources, unless the Parties mutually agree to some other course of action.

3. Each Party, at its own expense, shall have the right to observe and discuss activities of the other Party including BMFT's isotopic heat source test facilities. This right may be exercised by short-term visits or by the attachment of staff, subject to the prior agreement of the receiving party on each occasion.

4. In the event BMFT shall be unable, in BMFT's opinion, to obtain necessary licenses or approvals in its own country within a reasonable period of time, BMFT shall give written notification to DOE without delay. Upon receipt of such notification by DOE, the responsibilities of the Parties under this Agreement shall be changed as follows:

a. DOE's responsibilities 1 isted in Article 3.1.b., 3.1.d., 3.1.e., 3.1.f., and 3.1.g. shall thereupon cease;

b. BMFT's responsibilities 1 isted in Article 3.2.c., 3.2.e., 3.2.f., 3.2.g., and 3.2.h. shall thereupon cease; and 
c. BMFT's responsibilities listed in Article 5.1. and 5.2. and 5.4.

shall thereupon cease;

provided that termination costs, if any, shall remain the responsibility of BMFT.

5. If BMFT requests a later delivery than specified in the Record of the DOE/BMFT Meeting on February 28, 1984, then BMFT shall be responsible for the additional storage costs, if any. If $D O E$ requests a later delivery date than specified in the Record of the DDE/BMFT Meeting on February 28, 1984, then DOE shall be responsible for the additional storage costs, if any.

\section{ARTICLE 4 - MANAGEMENT}

Each Party shall appoint a Project Coordinator pursuant to Article 7 of the Waste Management Arrangement. For periods between meetings of the Project Coordinators, each Party shall appoint a Project Leader to act on its behalf on all matters concerning cooperation under this Project Agreement.

\section{ARTICLE 5 - FINANCIAL TERMS}

1. As $i$ ts part in defraying the incremental costs arising under the Program from the design and development of processes for the treatment and immobilization of high-level radioactive waste, and arising from the use of such processes for the fabrication of the first ten isotopic heat sources, BMFT shall provide to DOE the sum of US $\$ 4,900,000$ in accordance 'with procedures to be identified by DOE. The incremental cost of work to be performed by DOE under this Agreement shall not at any time exceed the advance received by DOE. Payments shall be made in accordance with the following schedule:

a. US $\$ 1,500,000$ within 60 days after this Project Agreement enters into force.

b. US $\$ 2,400,000$ within 120 days after this Project Agreement enters into force.

c. US $\$ 1,000,000$ within 180 days after this Project Agreement enters into force.

2. In the event the additional $7 \times 10^{6} \mathrm{Ci}$ of $\mathrm{Cs}-137$ to fabricate the additional 20 isotopic heat sources on a schedule that is mutually acceptable by both Parties is obtained, BMFT shall provide to DOE an additional amount, estimated in February 1984 to be $\$ 2,300,000$, as its part in defraying the additional incremental costs arising under the Program. The provision by DOE of such additional CS-137, and the provision by BMFT of such additional funds, shall be subject to written amendment to this Project Agreement, pursuant to Article 11.

3. In the event the Program outlined in Article 2, and the responsibilities of the Parties listed in Article 3, are to be modified to provide for additional activities, the financial terms in Article 5.1 and Article 5.2 may also be modified to reflect the additional responsibilities and contributions of each Party. Any such modification shall be the subject of a written amendment to this Project Agreement pursuant to Article 11.

4. Unless othenwise provided el sewhere in this Project Agreement, all costs arising from the conduct of the Program shall be borne by the Party that incurs them. 


\section{ARTICLE 6 - INFORMATION AND PATENTS}

1. The Parties shall exchange information which they have a right to disclose in the areas of design, development, construction, and operation of processes for the treatment and immobilization of high level radioactive waste and of the use of such processes for the fabrication of isotopic heat sources. The Parties shall also exchange information arising from activities set forth in Article 2, Paragraphs 5 through 7, of this Project Agreement.

2. The application or use of any information provided under or arising from this Project Agreement shall be the responsibility of the Party receiving $i t$, and the other Party does not warrant the suitability of such information for any particular use or application.

3. The information provided under or arising from this Project Agreement may be made available to the public by either Party through customary channels and in accordance with the nomal procedures of the Parties, subject to the provisions of Article 6.5 through Article 6.8 below.

4. Copyrights of either Party or of cooperating organizations shall be accorded treatment consistent with internationally recognized standards of protection.

5. Proprietary information shall not be exchanged, accepted for or utilized in the activities under this Project Agreement without the express written approval of the Parties. For the purposes of this Project Agreement, proprietary information shall mean information of a confidential nature acquired prior to or outside the scope of this Project Agreement such as trade secrets and know-how (for example, computer programs, design procedures and techniques, cherrical composition of materials, or manufacturing methods, processes, or treatments) which is appropriately marked, provided such information:

a. has been held in confidence by its owner;

b. is of a type which is customarily held in confidence by its owner;

c. has not been transmitted by the transmitting Party to other entities, including the receiving Party, except on the basis that it be held in confidence; and

d. is not otherwise avallable to the receiving Party from another source without restriction on $i$ ts further dissemination.

It shall be the responsibility of the Party supplying proprietary information to identify the information as such as to ensure that it is appropriately marked.

6. Inventions or discoveries made or conceived in the course of or under this Agreement (hereinafter referred to as "arising inventions") shall be identified by the inventing Party and shall be reported promptly to the other Party. Information regarding arising inventions on which patent protection is to be obtained shall not be published or publicly disclosed by the Parties until a patent application has been filed in either country of the Parties; provided, however, that this restriction on publication or disclosure shall not extend beyond six months from the date of reporting of the arising invention. It shall be the responsibility of the inventing Party to mark appropriately reports which disclose arising inventions that have not been appropriately protected by the filing of a patent application. 
7. Arising inventions shall be owned:

a. by BMFT in the Federal Republic of Germany, subject to a royal tyfree, non-exclusive, irrevocable license to DOE, its Government, and the nationals of its country designated by $i t$; and

b. by DOE in the United States and in third countries, subject to a royalty-free, non-exclusive, irrevocable license to BMFT, its Government, and the nationals of its country designated by $i t$.

8. Each Party shall, without prejudice to any rights of inventors or authors under its national laws, take all necessary steps to provide the cooperation from its inventors or authors required to carry out the provisions of this Article.

9. Each Party shall assume responsibility to pay awards or other compensation required to be paid to its own nationals according to its own laws.

\section{ARTICLE 7 - ASSIGMMENT OF STAFF}

1. Whenever an assignment of staff is contemplated under this Project Agreement, each Party shall ensure that qualified staff are selected for such assignment.

2. Each such assignment of staff shall be the subject of a separate assignment agreement between the parties or, when authorized by the parties, between their contractors or associated firms.

3. Each Party shall be responsible for the salaries, insurance and allowances to be paid to its staff.

4. Each Party shall pay for the travel and living expenses of its staff while assigned to the other Party, its contractors or associated firms, unless otherwise agreed.
5. Each Party shall arrange or do its best to arrange for comparable accommodations for the other Party's staff and their families on a mutually-agreeable reciprocal basis.

6. Each Party shall provide all necessary assistance to the assigned staff and their families as regards administrative formalities such as travel arrangements.

7. The assigned staff of each Party shall conform to the general and special rules of work and safety regulations in force at the host establishment, or as agreed in separate assignment agreements.

\section{ARTICLE 8 - EQUIPMENT}

1. In the event that equipment is to be exchanged or supplifed by one Party to the other Party under this Project Agreement, the loan or transfer of such equipment shall be the subject of a separate agreement.

2. The sending Party shall supply as soon as possible a detailed list of the equipment to be provided, together with the associated specifications and technical and other documentation.

3. Responsibllity for expenses, safekeeping, and insurance during transport of the equipment from its original location in the country of the sending Party to the final destination in the country of the receiving Party, and return, shall rest with the sending Party.

4. The equipment provided by the sending Party shall be considered to be scientific, not having a commercial character, and the receiving Party shall make a good faith effort to avoid the requirement for payment of import taxes on such equipment. 
5. It is understood that the equipment provided by one Party to the other Party shall remain the property of the receiving Party unless mutually agreed in advance to the contrary.

\section{ARTICLE 9 - DAMAGES}

Compensation for damages incurred during the implementation of this Agreement shall be in accordance with the applicable laws of the countries of the Parties.

ARTICLE 10 - GENERAL PROVISIONS

Cooperation under this Agreement shall be in accordance with the laws and regulations under which each Party operates. All questions related to this Agreement arising during its terms shall be settled by mutual agreement of the Parties.

ARTICLE 11 - FINAL PROVISIONS

1. This Project Agreement shall enter into force upon the later date of signature, and shall continue in force for a period of six years unless sooner terminated in accordance with Article 11.3 below.

2. This Project Agreement may be amended or extended at any time by written agreement of the Parties.

3. This Project Agreement may be terminated at any time upon six months advance notification in writing by either Party. Such termination shall be without prejudice to the rights which may have accrued to either Party up to the date of termination.

4. A1l joint efforts and experiments initiated but not completed at the expiration or termination of this Project Agreement may be continued as if this Project Agreement were still in effect.

5. This Project Agreement shall also apply to Land Berlin provided that the Government of the Federal Republic of Germany has not made a contrary declaration to the Government of the United States of America within three months of the date of entry into force of this Project Agreement.

Done in duplicate.

FOR THE DEPARTMENT OF ENERGY OF THE UNITED STATES OF AMERICA

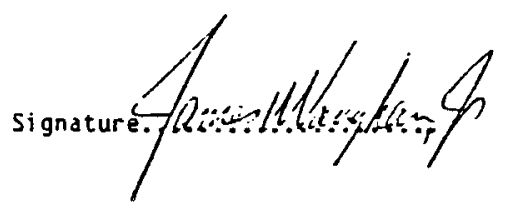

Name. James. W. Vaughan. Jr.....

Acting Assistant Secretary Title...for. Nuclear. Energy.....

Date.. November. $16.1984 . \ldots .$.
FOR THE FEDERAL MINISTER FOR RESEARCH AND TECHNOLOGY OF THE FEDERAL REPUBLIC OF GERMANY

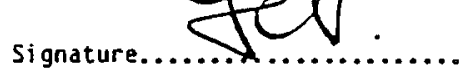

Name...DP...Günter. Leh.

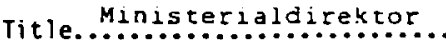

Date...November. $28.1984 . .$. 

MMENOMENTS TO
PROJECT AGREDMENT
BETWEEM

THE DEPARTMENT OF ENERGY OF THE UMITED STATES OF AMERICA

ANO

THE FEDERAL MIMISTER FOR RESE

OF THE FEDERAL REPUBLIC OF GERMAHY

ON METHODS OF TREATMENT FOR IMTOBILIZATION

OF HIGH-LEVEL RADYOACTIVE HASTE

The following articles replace or add to those contained in the original agreement stgned by J. W. Vaughan, Jr. on Moventer 16,1984 and 6. Lehr on Novenber
28,2984 . The additions to the original are underlined; the deletions are not shown.

Article 3.1.0

Provide approximately $7 \times 10^{6}$ if of Cesilum-137 (Cs-137) and approximately $4 \times 10^{6} \mathrm{C}$ of Strontium-90 for use as the source of heat and radiation as its best effort

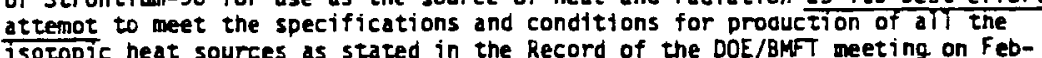

ruary 2B, 1984 .

Article 3.1.e

Fabricate thirty heat and radiation sources for shipment to the Federal Republic of Germany by incorporating the above radionuclides in a borosilicate-type gias matrix and encapsulating that atrix in steel canisters approximateiy $30 \mathrm{~cm}$ in diameter $(0.0$.) and $120 \mathrm{~cm}$ in length.

The nominal heat generation rates for these thirty sources shall be as follows:

\section{Set 1 - ten canisters at 1,680 watts each \\ Set 2 - ten canisters at 1,680 wates each \\ Set 3 - ten canisters at 2,065 watts each}

The nominal surface radiation dose rates for these thitry sources shall be as follows:

Set 1 - ten canisters at whstever dose rate results from the Sr-90 content required to obtain the nominai heat generation rate specifiec for Set i above

Set 2 - ten canisters at $5 \times 10^{5} \mathrm{R} / \mathrm{hr}$ each

Set 3 - ten canisters at $5 \times 10^{5} \mathrm{R} / \mathrm{hr}$ each

DOE shall give BMFT one month's advance notification prior to beginning

fabrication of th

notified by BMFT to the contrary.

\section{Article 3.1.f}

Provide can1ster szorage, heltum leak checkino, and decontamination equipment and operate chose tacificles coge ther with we icino ano gaugino eouidoment to be Republic of Eermany.

\section{Article 3.1 .9}

Make the thirty isotopic heat sources defined in Article 3.1.e above avallable F.8. at DOE's Pacific Northwest Laboratory located at Richianc, Hashington, to BMFT for shtpment to the Federal Republic of Germany.

Article 3.1.1 (new article)

Fabricate two instrumented heat and radiation sources, one "free-cooled" in air ana one "conzrol-cooled" in a furnace, using a feed composition with a heat

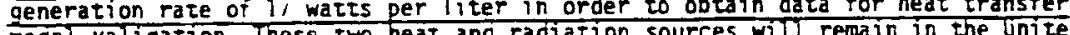

\section{Article 3.2.c}

Provide DOE with suitable cantsters and 1ids, compatible grappling devices, welding equipment, and stralghtness and ovality gauges. Upon BMFI request, DOE shall provide welding equtprent frem its on sources at aur expense.

\section{Article 3.2.e}

Accept responsfbility for the thirty 1sotopic heat sources upon their being made available F.O.B. by DOE at DOE'S Pactfic Northwest Laboratory located at Richland, Hashington.

Article 5.2

As tts part in defravina the 1ncremental costs arising during the fabrication of the acditional twenty isotodic neat sources for shipment tc the federal kepublic of Germany, the adational two isolodic neat sources for netit transter made valiation, and the helium leak cnecxing equipment for use ouring ciosure of the isotopic neat sources Detore snipment to the reoeral Repudic of Germany, BMFShail proviae to dot the aoditional sum of US $53,900,000$ in accordance with proceoures to be loentitiec by dot. As oescrided in article s.1, the incrementa cost of work to de pertormed by duscer this Aoreement snall not at anv with the following screaule,

c. US $\$ 1,900,000$ by July 1,1985

b. US $\$ 1,000.000$ by October 1,1985

c. US $\$ 1,000,000$ by Januar 1,1986 . 
Done in duplicate

For the Department of Energy

of the United States of America

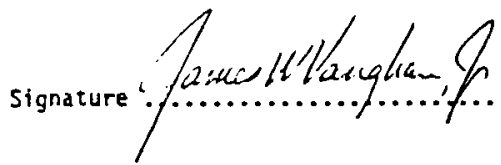

Mame ............................... Acting fissistant Secretary

Date June 26,1985
For the Federal Mininster for Research

and Technology of the Federal Republic

of Germany

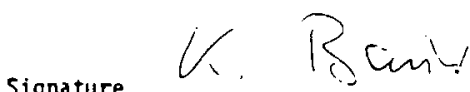

Dr K. Bauer, Deputy Director General

Name ...Dr...Gunțer. Lethr.

Title .M1n!sterialdisektor........

Date ...May...15...985. 
AGREEMENT BETWEEN

BATTELLE MEMORIAL INSTITUTE, PACIFIC NORTHWEST LABORATORY

and

HAHN-MEITNER INSTITUT FUER KERNFORSCHUNG B.T.b.H.

This AGREEMENT is entered into as of January, 1985 by and between Hahn-Meitner Institut fuer Kernforschung G.m.b.H. (hereinafter called HMI),
of the Federal Republic of Germany and Battelle Memorial Institute, Pacific Northwest Laboratory (hereinafter called PNL) of the United States of America, acting under contract DE-ACO6-76RLO 1830 with the United States of America as represented by the Department of Energy (hereinafter called DOE) (collectively called the parties):

WHEREAS, the United States of America and the Federal Republic of Germany, through their respective agencies the DOE and Federal Ministry for Research and Technology (FMRT) have entered into an agreement for Technical Exchang

WHEREAS, the parties are in the process of continuing said agreement and are also participating in a similar program with the European Atomic Energy Cormunity which was effective the 6 th day of 0ctober, 1982; and,

WHEREAS, HMI desires the assistance of Dr. Denis Strachan, a staff member of PNL; and,

WHEREAS, DOE agrees that the assignment of Dr. Strachan to HMI would further the intent of the above cited agreements.

THEREFORE, the parties hereby agree to the temporary assignment of Dr. Strachan to HMI in accordance with the cited agreements as follows:

1. Term: The term of this assignment shall be from February 1, 1985 to September 12, 1985 .

2. Purpose: Dr. Strachan is to continue working with HMI personnel in collaborative studies involving geochemical models/understanding of nuclear waste form leaching/repository interactions.

3. Limitations; Except as stated herein, any limitation applicable to one party shall be reciprocal.

4. Supervision and Control: Or. Strachan will remain a staff member of PNL for the duration of this assignment but will be subject to the work supervision of HMI to include applicable rules, regulations, and reasonable requirements of work conditions, such as, but not limited to, security, health and safety, hours of work and conduct.
5. Costs and Expenses:

a. HMI will pay the travel costs of Dr. Strachan and his family from Richland, Washington, to West Berlin and return.

b. PNL will pay salary, benefits, and living expenses to include subsistance.

6. Recall: HMI may request PNL to recall Or. Strachan at any time and PNL reserves the right to recall Dr. Strachan upon written notice. Any such recall shall terminate this agreement.

7. Information Use and Disclosure: The use and disclosure of information and proprietary information shall be as set forth in the DOE-FMRT agreement hereinbefore cited.

8. Indemnification:

a. Neither party shall be responsible for injury or damage to personnel or equipment of the other.

b. Nuclear: HMI hereby agrees to indemnify and hold harmless DOE, PNL and other parties and their officers, employees and agents from and against any claims in accordance with the provisions of The Act of December 23, 1959 "on the peaceful uses of atomic energy and protection against its hazards (Atomgesetz)," for loss of life, personal injury or deterioration of health caused to any person or for damage caused to property which arises out of or in connection with the assignment of Dr. Strachan.

9. Patents: With respect to any invention under this agreement, HMI and PNL agree that:

1. If made or conceived by personnel of one party (the assigning party) or its agents while assigned to the other party (the recipient party)

a. The recipient party shall acquire all right, title and interest in and to any such invention, discovery, patent application or patent in its own country and in third countries, subject to a nonexclusive, irrevocable, royaltyfree license to the assigning party, with the rignt to grant sublicenses for use in the production or utilization of special nuclear material or atomic energy.

b. The assigning party shall acquire all right, and interest in and to any such invention, discovery, patent application, or patent in its own country, subject to a nonexclusive, irrevocable, royalty-free license to the recipient party, with the right to grant sublicenses for use in the production
or utilization of special nuclear material or atomic energy. 
10. Modifications: No agreement or understanding for varying or extending this agreement shall be binding on either party unless made in writing thed by the duly

representatives of HMI or PNL.

11. Approval: This Agreement and any modification or amendments here to are subject to the written approval of DOE and shall not be binding until so approved.

IN WITNESS WHEREOF, the parties hereto have executed this Agreement as of the day and year first written above.

BATTELLE MEMORIAL INSTITUTE

Pacific Northwest Division

By

HAHN-MEITNER INSTITUT fuer KERNFORSCHUNG G.m.b.H.

By

APPROVED:

U.S. DEPARTMENT OF ENERGY

By 
Bllateral Arrangement on Cooperation and Technical Exchange Between the United States of America (USA) and the Federal Republic of
Germany (FRG) on Research Related to Radioactive Haterial Transportation

\section{Introduction}

Radioactive materials (RAM) are routinely transported in both domestic and international conterce as a result of nuclear activities within the USA and the FRG. Since regulations that govern radioactive material shipments have been historically developed in an international arena and since both the USA and the FRG have active research and development programs underway to evaluate the safety and of $f$ iciency of RAM transport; this arrangement on cooperation and technical exchange has been developed in order to enhance the ef fectiveness of activities within both countries. By coordinating research tasks to reduce redundancies and to provide a method of comparing data and information, each country will be able to expand its own data base and make more efficient use of available research funds.

\section{Basis for Arrangement}

This bilateral arrangement on cooperation and technical exchange between the USA and the FRG on research related to radioactive material transportation is within the scope of the amended Bilateral $A_{B}$ reement in the Field of Radioactive Waste management between the U S Department of Energy (DOE) (originally the U S Atomic Energy Commission) and the FRG Bundesministerium fur Forschung and Technologie (BMFT).

\section{Responsible Organizationg and Technical Contacts}

The organizations responsible for direction and approval of activities completed under this bilateral arrangement are the Department of Energy for the USA and the Bundesministerium fur Forschung and Technologies for the FRG.

In the FRG, the Bundesanstalt fur katerialprufung (BAM) has been assigned the responsibility by BHFT of being the technical contact for this arransement. The Transportation Technolosy Center (TIC) at Sandia Hational Laboratories (swL) has been assi

\section{Effective Period of Arrangement and Future outlook}

The effective period for initlal work to be completed under this arrangement on cooperation and technical exchange is January 1. 1985 through December 31, 1987. Thile this arrangement only covers activities during thi three year period, new tasks may be identified for cooperative research in future years. Upon agreement of the responsible organizations, this arrangement may be renewed to cover activities in years past 1987.
The costs of research activities or travel conducted under this arrangement will be the responsibility of each respective country. Ho transfer of funds between countries is expected. For the most part, this arrangement will result in greater efficiency, improved peer rovlew, and expanded information for activities that are currently funded or planned. Any additional funds that are needed by organizations in a given country are subject to the approval of the responsible, directing organization (DOE or BHFT) in each respective country.

\section{Personnel Exchanges}

A primary method of exchanging information and coordinating research activities will be through periodic exchanges of technical personnel. It is expected that technical representatives from each country will annually work at appropriate sites in the other country for a period of one to four weeks. In addition, representatives from each country may be assembled annually to review progress to date on research activities covered under this arrangement and to finalize the report for the previous period.

\section{Reports}

Informal letter reports will be distributed annually during the first two years of this arrangement. The jointly-prepared reports will provide a summary of activities in the nine research areas that have been completed during the previous year. A final report will be prepared and published at the end of 1987. All reports will be written in English and the final report will be published by the USA.

\section{Research Areas}

Research areas that are the focus of this bilateral arrangement are reviewed in this section. Potential topics to be emphasized by each country are also noted.

1. Cask Material Behavior

Materials are an important aspect of radioactive material packaging design. The use of ferritic steels and nodular cast irons for spent nuclear fuel casks is of particular interest to organizations in FRG. The exchange of material data, packaging design philosophy, and analysis
concepts for these applications is a major part of this activity.

\section{FRG Emphasis:}

Explaining approval basis for nodular cast iron in FRG and defining an intemationally acceptable approval basis

Establishing ferritic steel and nodular cast iron material data Evaluating standards and tests for qualification of ferritic and nodular cast iron materials. 


\section{USA Emphasis:}

- Establishing a fracture mechanics philosophy for cask materials. Joint Emphasis:

- Developing $Q / A$ and non-destructive test methods and their applicability for cask materials.

Developing acceptance criteria for cask materials

2. Computer Analysis Hethods

Computer analysis methods are extensively used to evaluate the performance of Type B packagings subjected to hypothetical accident conditions.

FRG Emphasis:

- Establishing guidelines for the acceptance of computer programs and analyses by regulatory agencies.

USA Emphasis:

Developing improved structural and thermal analysis methods for impact, puncture and thermal tests.

Joint Emphasis:

- Benchmarking of structural, thermal, shielding and criticality analysis techniques.

\section{Exchanging current experience on analysis methods.}

- Starting joint actions to implement accepted computer codes and pre/post processing techniques.

3. Testing Methods

Semi- and full-scale tests of transportation packagings are frequently conducted in both the USA and FRG. Improvements in test techniques and data evaluation are possible by sharing of experiences and research.

FRG Emphasis:

- Developing computer-aided testing (CAT) methods to verify instrumentation, calculate results, and format output.

USA Emphasis:

- Evaluating the effects of facillty parameters on fire testing.

\section{Joint Emphasis:}

- Exchanging test and scale modelling experience.

Developing acceptable test Q/A procedures. - Performing cooperative tests on prototypes to benchmark and evaluate
techniques.

4. Seals

The predicted performance of seals during normal and accident conditions is a major determinate in evaluating the ability of a packaging to satisfy containgent criteria.

FRG Emphasis:

- Developing qualification criteria for metal sealing systems.

- Documenting experience on the long-term behavior of metal sealing systems.

- Documenting lastomeric seal performance on storage and transport casks.

- Developing QA procedures for the manufacturing and use of metal and elastomeric seals.

USA Emphasis:

Establishing permeation rates of elastomeric materials for various gases at different temperatures.

Evaluating the performance of large diameter elastomeric and metal seals.

Joint Emphasis:

- Developing appropriate test procedures and methods for evaluating leak tightness of systems.

- Establishing a catalog or guide on typical sealing systems for casks with regard to required leak rates and long-term behavior.

5. Containment Evaluations

Radioactive material packagings have stringent leakage criteria that they mast meet during normal and following accident conditions. Understanding potential leakage phenomena through a containment boundary is a key aspect of packaging evaluations. 
FRG Emphasis:

- Establishing a correlation between volumetric leak tightness measurement and curie leak rates.

USA Emphasis:

- Developing methods to evaluate requirements for plutonium-bearing materials.

Evaluating the leakage of powders past elastomeric seals.

- Developing methods to measure 1 id movements during testing.

Joint Emphasis:

- Establishing consistent methods for containment evaluations.

6. Packaging Design Aids

Designs guides and standards are continuously being developed in both the USA and FRG to assist the designer in meeting the requirements of both

domestic and international regulations. Cooperation on these activities will lead to greater harmonization of national efforts.

\section{Joint Emphasis:}

- Developing consistent drafts of future standards.

- Coordinating input to revisions of IAEA Safety Series \#6, \#7 and \#37.

- Harmonizing QA procedures, manuals, and programs.

7. Waste Transportation Packagings

Numerous waste transportation packagings are being developed or used in the FRG and USA. Exchanges of information on these packagings will assist design programs in both countries.

FRG Emphasis:

- Presenting information on FRG radwaste package design criteria and the resultant packages.

USA Emphasis:

- Presenting information on USA radwaste package design criteria and the resultant packagings.

\section{Risk Analygis}

Risk analyses are important in preparing environmental assessments and selecting between maltiple policy options. Consistency and accuracy of results are important on an International scale in order to develop confidence in these techniques.

Joint Emphasis:

- Standardizing of assumptions and exposure models for rail, truck and barge transport.

- Benchmarking of analyses and comparing FRG/US/IAEA transport risk codes.

- Comparing of accident data and scenarios

Establishing consistent source term information derived from analysis/tests involving package failure thresholds.

- Comparing results of past analyses.

9. Data and information Exchange

USA and FRG will provide assistance to each other in the procurement of open and unclassified literature and data files that have been produced within each respective countries. Visual material to depict results of tests will be exchanged for possible use in preparation of informational materials. 
PROGRAM SCHEDULE

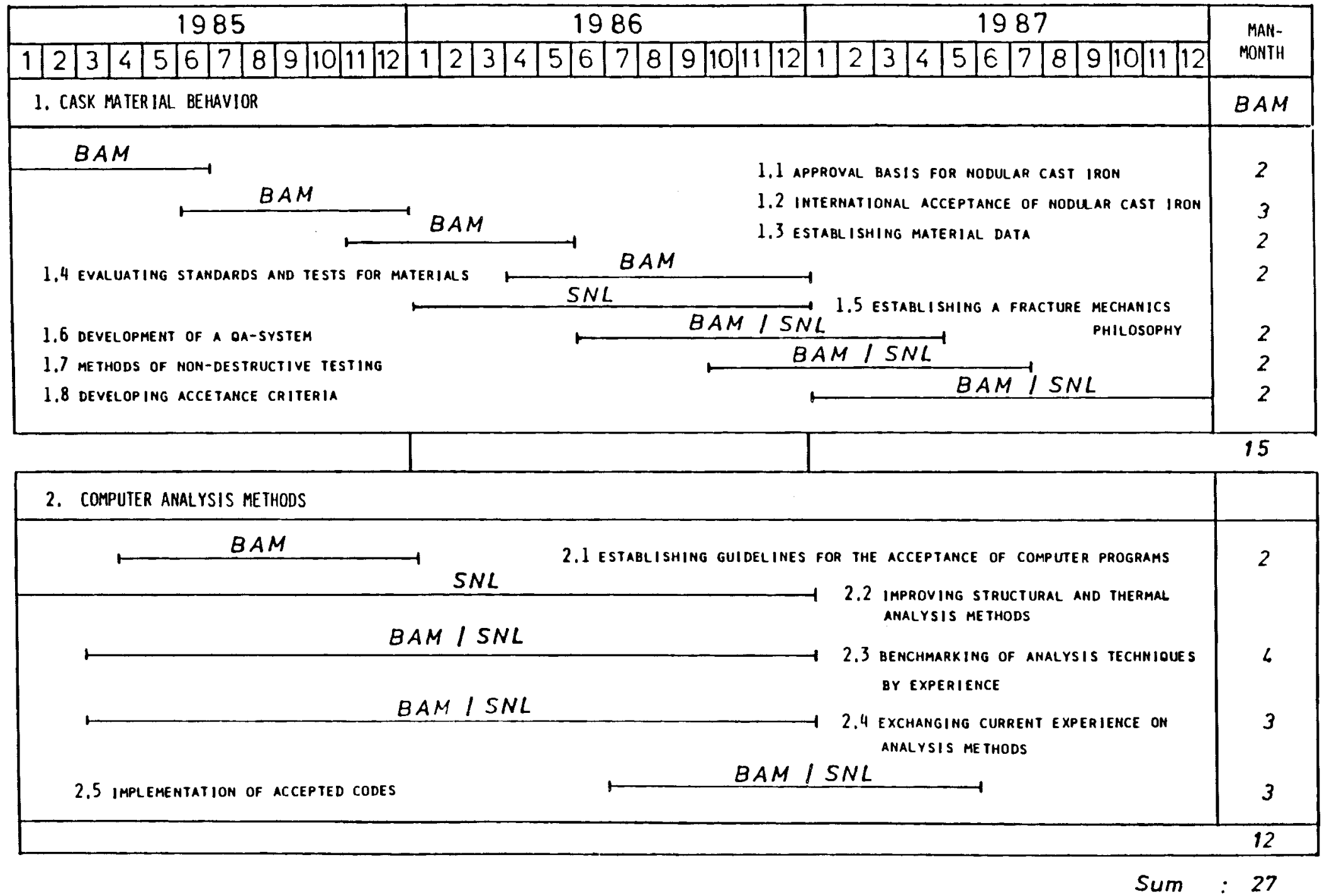

$\mathrm{GE}-7.4$ 


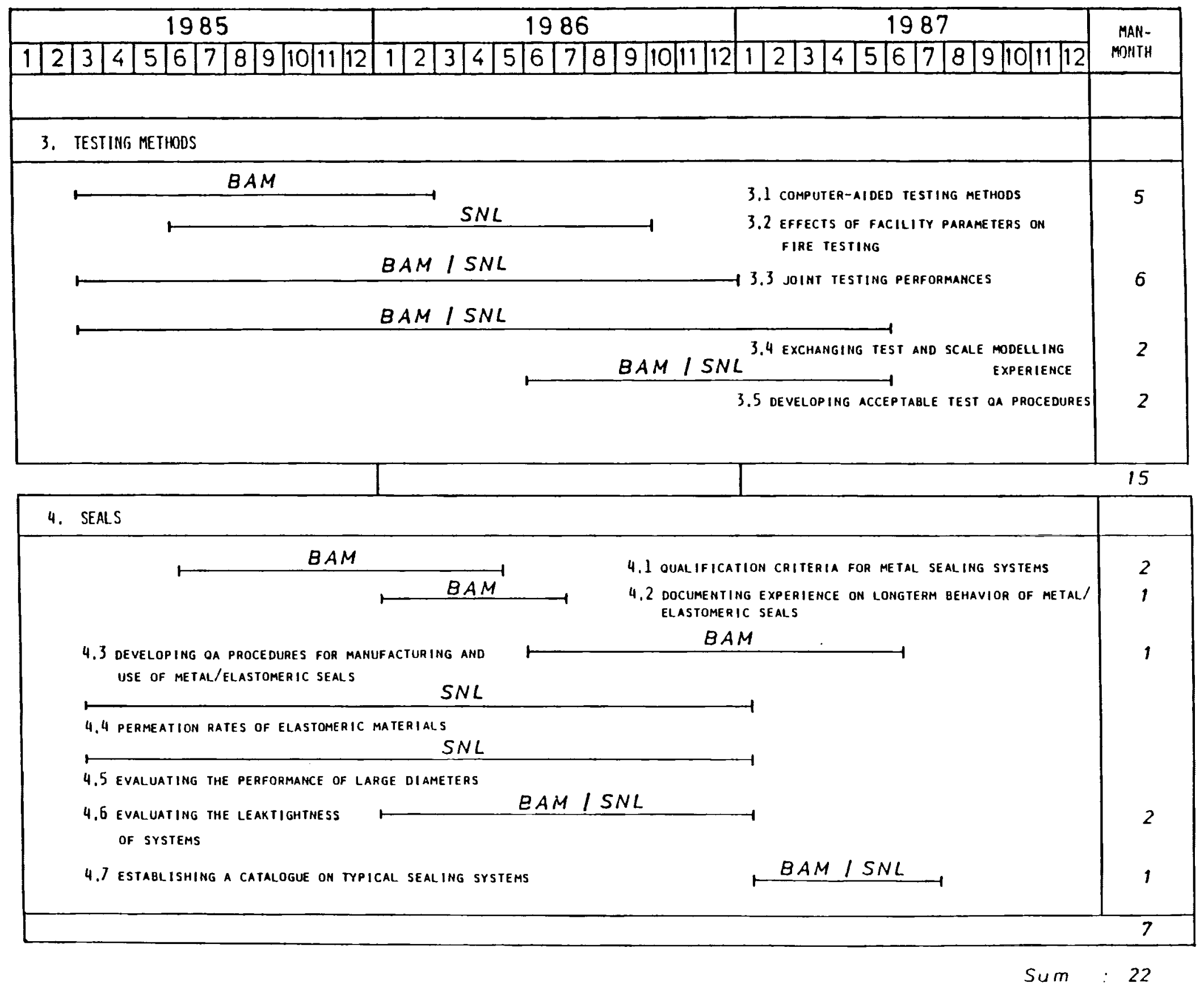




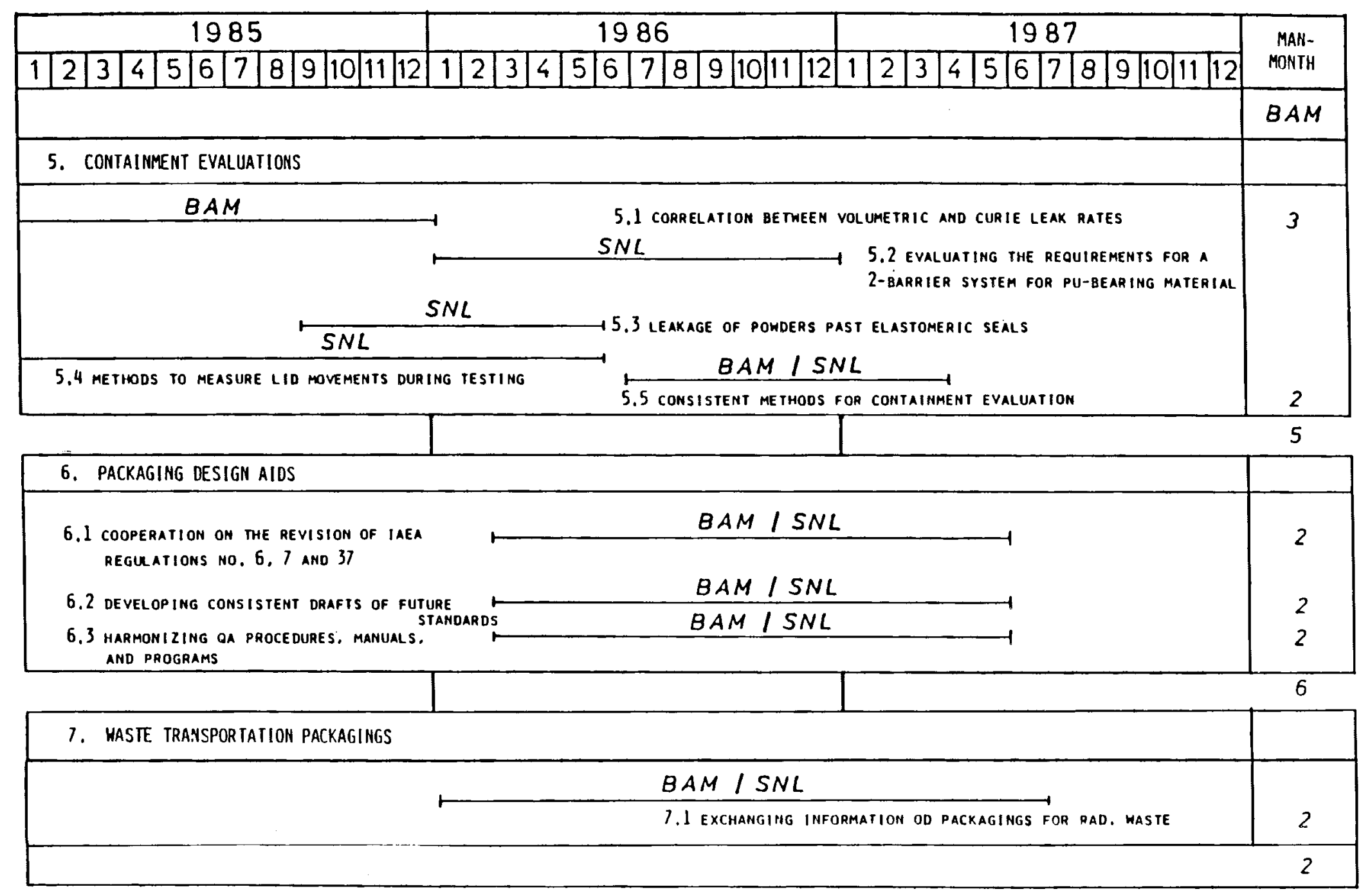




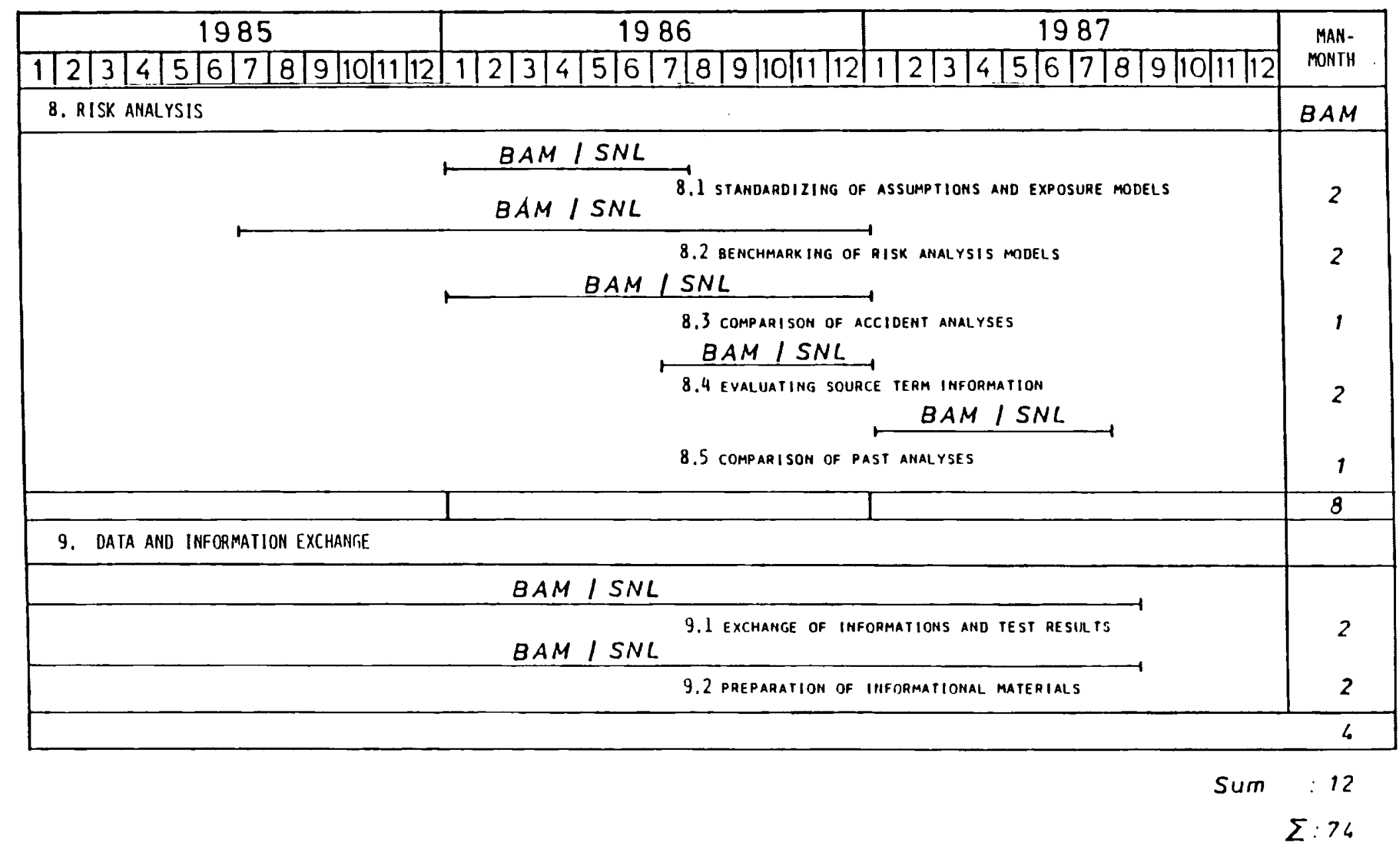





\section{US/DOE-FRG/BMFT WASTE MANAGEMENT COOPERATIVE}

\section{PROGRAM PLAMNING AND REVIEN MEETING}

August 30-3i, 1984

\section{SUMMARY}

\section{GENERAL}

It was agreed that the US DOE/BMFT Technical Exchange anc Cooperative Arrangement in the Field of Management of Radioactive wastes, which explres December 31 , 1984, would be renewed Ior ar: parties.

$$
\begin{aligned}
& \text { Contact: FRG - Reinhold Ollig - BMFT } \\
& \text { USA - Harold Jaffe - DOE-HQ/IE }
\end{aligned}
$$

\section{HIGH-LEVEL WASTE}

A new project agreement dealing with exchange of information on Methods of Treatment for Immobilization of Fission Products from High-Level Radioactive Wastes, and involving the manufacture of isotopic heat sources was discussed in detail. In order to meet both BMFT and DOE programmatic needs, both sides will make a concerted effort to prepare this Project Agreement by the end of September, 1984, or as soon thereafter as possible. Under the agreement. Pacific Northwest Laboratory will produce ten borosilicate glass logs containing $3 \times 10 E 6$ curies of Cs-137. Also, the DOE commitment to seex an additional $7 \times 10 E 6$ curies of Cs-137 to meer DOE/BMFT researcin and development needs on a prioricy basis was stressed.

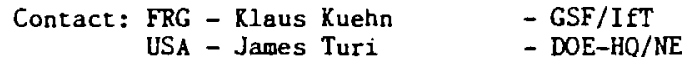

A number of vitrification production facilities - PAMELA, DWPF, WVDP, HWVP, WA-350, BRET - are now under design and/or construction in the FRG and USA. The main form of the HLW Technical Exchange Program for the next few years will be the exchange of visits and documents on these facilities. Included in the exchanges will be design information, experimental studies, and operational data. Two other important exchange areas will deal with quality assurance, other importanc exchange areas will deal with quality assuran safety, glass characterization, and repository acceptanct
testing. It is expected that in those exchanges the already testing. It is expected that in those exchanges the already extensive HLW bilateral exchange program will expand still
furtiner. It will involve PAMELA, KfK/INE, RFA, HMI, and DWK in the FRG with SRP, HWVP, PNL, ICPP, and WVDP in the USA. A detailed exchange program has been developed.

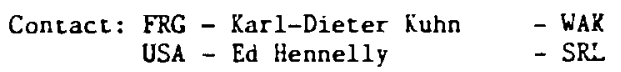

TRU WASTE

For alpha-bearing waste the focus of both countries' efforts has been alpha-bearing waste the focus of boch countries' efforts has forward touard final continuation of the US/FRG bilateral technical exchange is desire within the following subject areas: assay instrumentation, within the following subject areas: assay instrumentation, radionuclices, reduction in waste volumes, and systems planning aná analvsis.

The focus for informational transfer will be in the form of workshops and meetings. Workshops, in order of occurence, will be 1) Incinerator Design and Operational Períormance, 2) Radionuclide Migration Chemistry, 3) TRU Waste Form Product Specification and 4) Reduction in Final Waste Volumes. A future workshop is also being recommended for the area of decontamination and size reduction, and a meeting is being arranged on assay instrumentation.

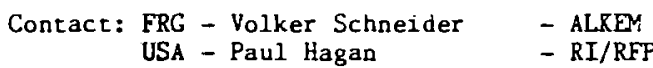

LOW-LEVEL WASTE

Activities for 1985 will concentrate on information exchange in the areas of:

I Waste Processing

- Volume Reduction

- Inplant and Mobile Treatment Systems

- Immobilization of Waste

- Waste Form Performance and Predictior

II Disposal and Storage Facilities - Requirements

- Performance Predicrion

III Decontamination Processes

IV In-Situ Waste Disposal for Special Wastes

Visits of US epresentatives to the FRG will be arranged in two areas; waste processing and disposal and storage facilities. Areas where workshops will be beneficial will be identified and arranged for $\mathbf{9 8 6}$. Maximum benefit will be made of appropriate TRU workshops planned for 1985.
Contact: FRG - Reinhard Kraemer
$-\mathrm{KfK}$
$-\mathrm{EGSG}$ 
GEOLOGICAL DISPOSAL

The Repositorv Working Group discussed continued informatior exchange through documents, visits, and workshops. A document exchange proceaure was agreed upon. Three worksnops are planned for FY-198j-one on rock mecnanics, one on backfill/sealing, an one on canister materials/corrosion. Specific objectives and other potential excnange topics were discussed in detail. Behavior of spent fuel in a repository environment should be considered as a furure exchange ropic. It was recognizeo that the brine migration tests at the ASSE Salt Mine as defined in the existing agreement should continue.

It is recognized that the activities at the Gorleben site are of interest to the US repository programs. It was agreed that the DBE and the Salt Repository Program Office would cooperate to establish an exchange of information and observers for shaft and repository construction activities of mutual interest.

The FRG empnasized their desire to have the US participate in the HLW experiment and the US agreed to continue to evaluate

potential participation. It was agreed that the next step would be a review by the US of the FRG HIW Test Plan and that the BMF and/or its contractors would review the Salt Repository Projec In-Sicu Test Plan. The FRG stressed their of fer to have the US perform experiments in the Asse Mine. The US agreed to continue to review potential activities and to continue discussions with the FRG.

$$
\begin{array}{cc}
\text { Contact: FRG - Rlaus Kuehn } & \text { - GSF/IfT } \\
\text { USA - Roger Wu } & - \text { DOE-SRPO } \\
\text { - Arlen Hunt } & - \text { DOE-WIPt }
\end{array}
$$

\section{DECONTAMINATION/DECOMMISSIONING}

This topic will be discussed on September 7, 1984, and the record of that meeting will be made part of the detailed minutes of this meeting.

Contacrs: FRG - Walter Diefentacher - RfK

$$
\text { USA - Clarence Miller - DOE-RL }
$$

SPETT FUEI. STORAGE

This topic will be discussed in October, 1984, and the record of that meeting will be made part of the detailed minutes of this meeting.

Contact: FRG - Joachim Fieisch

$$
\text { - DWK }
$$

USA - A. Burt Johnson

August 31,1984

Park City, Utah, USA

FEDERAL REPUBLIC OF GERMANY

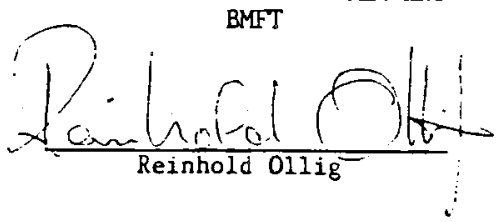

UNITED STATES OF AMERIC

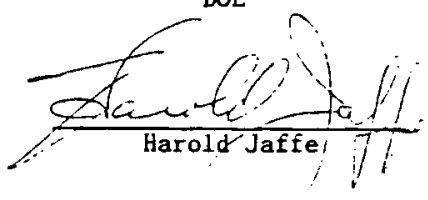




\section{AREAS OF INTEREST}

DECONTAMINATION AND DECOMMISSIONIMG

A number of decommissioning projects are uncerway or are being planned for the next few years in both the FRG and US. To aid in these efforts, continuacion of the IJS-DOE/FRG-BlifT bilateral technical exchange is desired.

Areas of common interest are:

- Unrestricted release criteria

- Measuring techniques and equipment for low-level and unrestricted release

- Waste processing, packaging and disposal

- Decontamination technioues

- Segmenting techniques for metal, concrete

- Volume reduction techniques

- Remote handling techniques

- Coatings, strippable, protective

The FRG interests in U.S. projects are related to:

- D\&D activities on comnercial reactors (to the extent that DOE can arrange)

- Shippingport Station Deconmissioning Project

- Waste Experimental Reduction Facility

The US interests in FRG projects are related to:

- Gundrenmingen D\&D

- Niederaichbach D\&D

- Asbestos removal techniques

- $F R-2$ D\&D

The near-term focus for informational transfer will be in the form of document exchanges and meetings. Future exchanges at the working level are anticipated. These eirect contacts between projects will be arranged with the assistance of the official FRG-BMFT and US-0OE technical contacts.

D\&D Program Coordinator: FRG - Rolf-Peter Randl BMF T

Technical Contact: FRG - Rolf-Peter Randl
USA - Edward G. Delaney DOE -HQ/NE FRG - Walter Diefenbacher J. J. Schreiber KFK DOE-RL (Surplus Facilities Management Progräml DOE-RL (Shippingport Station Decommissioning
Project officel

AGREEMENTS AND COMMITMENTS

Requested by FRG

1. Shippingport Decommissioning $P l$ an and General Electric contact

2. Readiness Review Document

3. Strippable coatings as decontamination agent

4. Small Portable Arc Saw remotely manipulated

5. List of status of commercial reactors in U.S.

Requested by U.S. DOE

1. Niederaichbach Safety Report (includes description of decommissioning plans

2. FR-2 Project list and description of metal cutting and

3. Report on high suction vacuum machine used for asbestos removal

4. FRG Trip Report (this visit)

5. Information on surface and piping measurement equipment and techniques
Action

Completed. During the meeting at Rrchland September 6, 1984, the U.S. Rrovided written instructions, "How to Plan" and General Electric contact.

Completed. Provided on September 6, 1984 by Rockwell.

Completed. During the meeting at Richland September 6, 1984, the U.S. provided brand name, manufacturer, location, and telephone number for "Alara Coat."

c. E. Miller will send as soon as documentation is completed and released (expected by end of October, 1984).

M. Widmayer $(D O E-[D)$ will provide as soon as available.

\section{Walter Diefenbacher will provide by October, 1984.}

Walter Oiefenbacher will pravide as requested.

Hans Viecenz will provide when completed (expected by December, 1984).

Walter Diefenbacher will provide by December, 1984.

Wolfgang Stang will provide by Octaber, 1984. 

Protocol for USA/FRG

Second Spent Fuel Storage Information Exchange

Held in Morris, Illinois \& Toronto, Canada

October $16-20,1984$

Toronto, Canada

October 20,1984
I INTRODUCTION

Based on the September 1982 agreement, USA and FRG representatives met for the second spent fuel storage information exchange involving the following itinerary and subjects:

- October 15, 16 General Electric Co. Morris Operation, Morris Illinois, to view the Cask Characterization Test and to discuss cask decay heat and thermal analysis (Agenda, Attachment A).

- October 19, 20* Toronto, Ontario - Canada, to discuss topics listed in Attachment $B$. The participants are listed in Attachment $C$.

On August $30 / 31,1983$ the US-DOE-FRG-BMFT

Waste Management Information Exchange Committee met in Park City. Utah. The protocol of that meeting directs that future plans

for the spent fuel storage information exchange should be decided during the october 19, 1984 meeting in Toronto. This protocol relates to the request in the Park City protocol.

II SUMMARY

A. Spent fuel storage technology developments in the USA and FRG since the last exchange were reviewed. In the USA, dry storage tests and demonstrations have emerged as a major part of the spent fuel storage $R$ \& $D$ program. Several rod consolidation initiatives

* On October 17, 18, the US and FRG delegates attended a spent fuel storage workshop in Toronto, sponsored by Ontario Hydro, assisted by EPRI. The workshop presentations and private discussions during the workshop are considered a part of the information exchange. 
also have developed or are in planning stages.

In the FRG metal cask demonstrations have been a major activity. Fuel behavior testing and modelling have proceeded to definitive states.

The USA review included contributions from programs sponsored by the Department of Energy (DOE), by the Electric Power Research Institute (EPRI), the Nuclear Regulatory Commission (NRC), and the Tennessee Valley Authority (TVA).

FRG program presentations were made by representatives from DWK, Kraftwerk Union (KWU), Gesell schaft fur Nuklear Service (gNS) and Transnuklear (TN).

Dry cask storage technology development in the FRG has included four demonstrations; two have been completed and evaluated; two are proceeding. Now the technology is entering the operational phase at Gorleben. The license for storage of spent fuel has been issued and arrival of the first cask is expected in the near Euture.

In the USA a cask characterization test is underway. Three electric utilities are proceeding with plans for at-reactor and/or federal site storage in metal or concrete casks.

In the areas of fuel behavior, FRG irradiated rod tests have been completed and evaluated at Ispra. Based on those results, post-pile creep experiments, stress corrosion cracking studies, and fuel assembly tests (KWO and CaSTOR), fuel modelling has confirmed the satisfactory behavior of LWR fuel in dry storage. The above results will be provided to the USA to support their dry storage licensing efforts.
Both US and FRG irradiated rod tests have demonstrated that cladding defects do not propagate during storage in inert gases. us tests also are addressing definition of satisfactory storage conditions in air.

In the USA, rod consolidation has proceeded through cold demonstrations to a hot demonstration of limited scope. Further larger-scale consolidation demonstrations are planned. Interest and discussion of dry storage of consolidated fuel in a cask have developed.

Wet storage surveillance is continuing at a low level in the USA. The formal FRG wet storage program has recently been completed.

\section{I CONCLUSIONS}

There was a concensus of the participants that the second spent fuel storage meetings and G.E. Morris visit were beneficial. The $F R G$ basic dry storage and $R$ \& $D$ programs are phasing down, while the AFR storage phase is emerging. Further improvements with respect to. cask technology, e.g. casks with larger capacity and with capability to store fuel with higher burnups are being introduced.

In the USA some dry storage $R \& D$ programs are continuing. A demonstration phase is developing, with the operational phase still in the fucure. Rod consolidation is a significant developing concept in the USA and has some interest in the FRG. The participants agreed that there is a sufficient basis to continue the spent fuel storage information exchange, as agreed on the revised program (Attachement D). 
The participants agreed that the next exchange meeting should be held in Germany on or about October 1985, coinciding with completion of cask and fuel behavior evaluations and the early operating experience at Gorleben.

IV US AND FRG REQUESTS

1. All requests for spent fuel storage information will be channeled through the designated spent fuel storage information exchange co-ordinators for USA and FRG.

2. The FRG requests that all publications which include data from FRG cask tests be reviewed by appropriate FRG (DWK) representatives prior to publication.

3. The USA will make available to FRG cask thermal and shielding analysis codes when they have been qualified.

4. Cask Characterization test results will be made available to the FRG.

5. Exchange of scientists and/or technicians will be encouraged, including US staff wishing to observe cask operations; joint discussions by FRG and US code evaluators and fuel integrity investigators.

6. Lists of reports are included (Attachments $E$ and F). The countries agree to provide copies of reports requested.
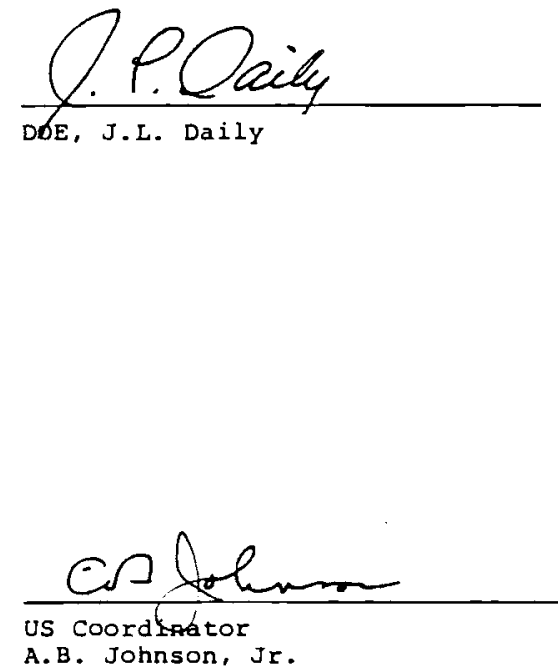

\section{Faind tor th. Geipe?} BMFT, H. Geipe

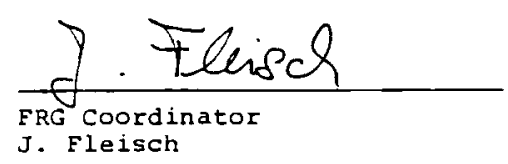

October 20,1984 



\section{JAPAN (JA)}

BLANKET AGREEMENT (Attachment JA-1)

Parties: $\quad$ US/DOE; J apan/Power Reactor and Nuclear Fuel Corporation (PNC)

Term:

March 4, 1969 to January 31, 1989 (LMFBR Agreement)

Technical Scope:

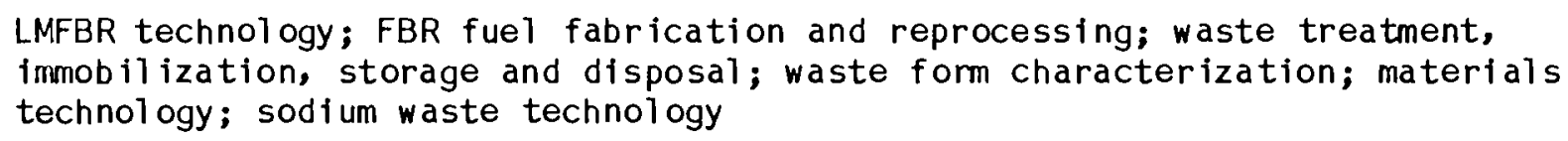

\section{SUBSIDIARY AGREEMENTS}

1. Collaborative Testing of a Radioactive Liquid-Fed Ceramic Melter (Attachment JA-2)

2. Joint Working Group on Waste Management (Attachment JA-3)

3. Joint Working Group on FBR Fuel Reprocessing

4. Contract research for PNC on Criticality Data Development (Attachment JA-4)

5. Research and Development at TMI: Apri1 16, 1984 to Apri1 16, 1988 (contact J. Metzler - DOE/HQ for more information)

\section{Under negotiation:}

- DOE/STA Agreement (Attachment JA-5) 


\section{STATUS/PLANNING REPORTS}

1. Record of Third DOE/PNC Joint Working Group--Japan, 07/84 (Attachment JA-6)

\section{ADMINISTRATION}

Principal Coordinators: US -- J. A. Coleman (DOE)

JA -- S. Araya (PNC)

Document Exchange: $\quad$ see Appendix $C$ 
AGREEMENT BETTEEN

THE UNITED STATES DEPARTMENT OF ENERGX

THE POLER RFACTOR AND NUCLEAR FUEL DEVELOPMENT CORPORATION OF JAPAN LN THE FIELD OF LIQUID METAL-COOLED FAST BREEDER REACTORS

WHEREAS

The United States Atomic Energy Commission (AEC) and the Power Reactor and Nuclear Fuel Development Corporation (PNC) of Japan exchanged research and development information in the field of fast breeder reactors under the terms of an-Arranzement between ther signed on March 4, 1969, as amerided by additions made in March 1976.

This agreement is subject. to the applicable terms and conditions of the Agreement for Cooperation In the Civil Uses of Atomic Energy between the Governments of Japan and the United States signed February 26, 1968, as amended, and other terms and conditions set forth herein.

PNC had been established by Law 73 of July 20, 1967 enacted by the Government of Japan in order to conduct the development of certain nuclear technology including that related to fast breeder reactors. Pursuant to such legislation, PNC was authorized to enter into a cooperative arrangewent related to fast breeder reactors.

The United States and Japan are both parties to the Treaty on the Non-Proliferation of Nuclear Heapons and, therefore, have as a mutual
Interest the development of nuclear energy in such a manner as to enhance prospects for restraining the proliferation of nuclear weapons.

Certatn responsibilities of the AEC were transferred to the Untred Stares Energy Research and Developrent Administration (ERDA) on January 18, 1975, and the exchanges of fast breeder reactor 1nformation continued between ERDA and PNC since that date. These responsibilities Included authorization for ERDA to enter into a cooperative arrangeveat related to fast breeder reactors.

On October 1, 1977, all the functions vested by Law in the ERDA were transferred to the Department of Energy (DOE). DOE and PNC have a mutual Interest in developing the Liquid Metal-Cooled Fast Breeder Reactor (LMFBR) and in maintaining important roles 1n such development.

DOE and PNC wtsh to cointigue close and long term cooperation in the field of LWBR technology which, for purposes of this Agreement, includes resezrch, development and demonstration.

IT IS AGREED AS FOLLOWS

\section{ARTICLE 1}

Cooperation between the Parties 1a the development of the LMFBR shall be directed towards finding solutions to mutually agreed problems associated with the design, development, construction and operation of nuclear power systems utillzing LFFBR, and to exchanging infomation developed during the resolution of these problems. This cooperation may include exchange of experience and results of theoretical, experimental, and conceptual design programs; and agreed research and development projects. Cooperation between the two Parties shall be on the basis of nutual benefit, equality and reciprocity. 
The areas of cooperation In IMFBR technology covered by this Agreement may Include -

1. Reactor neutroalcs analysis and experimentation, to include reactor and plane shielding and nuclear data.

2. Reactor and plant safety.

3. Fuels and materials compatible with high neutron flux and high temperature coolant, to fnclude structural, component, absorber and circuit materials, and fuels which could tend to reduce or eliminate the production of material directly usable in nuclear explosive devices.

4. Fuel cycle including fabrication, reprocessing, waste processing and storage, shipment and fuel cycles which may be resistant to diversion of material for the production of nuclear explosive devices.

5. Nuciesr steam supply systems and their associated components, to Include component and system design, Instrumentation and control, thermal hydraulics, structural analysis and architectural design.

6. Sodium technology, to Include detection of impurities, purification control, component cleaning and decontamination, sodfum leaks and sodium fires.

7. Qualicy assurance and non-destructive practices.

B. Design, construction, cest and operation of LMFBRs, with emphasis on plant experience.

9. Economic and environmental considerations.

10. Safeguards cechnology.

11. Research and developrent conducted in non-nuclear test facilities that support LMFBR programs.

Other areas of cooperation may be added by mutual agreement.
Cooperation in accordance with this Agreement may faclude but is not limited to the following forms -

1. Exchange of sclentists, engineers, and other specialists for partictpation in agreed research, development and deconstration, analysis, design, and experimental foint activities conducted in sclentific centers, laboratories, engineering offices and factlities of each of the Parties of 1 ts contractors for agreed periods.

2. Exchange or loan of samples, materials, 1nstruments, and conponents for testing.

3. Exchange of scientific and technical information Including results and methods of research and development.

4. Org $\equiv$ ization and conduct of working groups as defined in Article 4(3), seminars and other meetings on specific agreed topics covering basic probleas of research and development concerning WF́̈R technology in areas listed in Article 2, in a manner agreed by the Joint Coordinating Comnittee (Article 4).

5. Short visits by spectalist teans or Individuals to the LMFBR factlities and non-nuclear test facilities in support of the WFBR programs of the other Party.

6. The use by one Party of the facllities ouned or operated by the other Party. Such use of facilities shall be the subject of separate agreements between the Parties, and may be subject to cormercial terms and conditions.

7. Joint projects in which the Parties agree to share the work and/or costs. Each such joint project shall be the subject of - separate agreement between the Parties. 
other specific forms of cooperation ray be agreed by the Parties and approved by the Joint Coordinating Committee (Articles 4 and 5).

\section{ARTICLE 4}

1. To supervise the execution of this Agreement, DOE/PNC Joint Coordinating Conmittee on Cooperation In Liquid Metal-Cooled Fast Breeder Reactor Development shall be established. The Joint Coordinating Committee shall consist of up to ten members, half of whom shall be appointed by each Party. This Committee shall weet each year alternately in the United States and in Japan, or at other agreed times and places. The Head of the Delegation of the Receiving Party shall act as Chairman during meetings of the Committee. In addition, each Party shall have the right to invice asvisors to such geetings, as necessary.

2. At its meetings the Joint Coordinating Committee shall evaluate the status of cooperation under this Agrement. This evaluation shall include an assessment of the balance of exchange in the vartous areas of cooperation listed in Article 2 and, if necessary, a consideration of measures required to correct any 1mbalances.

3. For the detalled management of the cooperation, foint working groups shall be appointed by the Joint Coordinating Comittee to cover each of the areas listed in Article 2. Each joint worklag group shall agree on speciflc plans for cooperation in Its respective area, withla guidelines and polfcy set by the Joint Coordinating Committee. Each Joint working group shall be responsible for the working concacts between the Parties in their respective areas of cooperation.

4. At least once a year each joint working group shall report on their cooperative activities since the previous meeting of the Jolnt Coordinating Comaittee, and shall propose for acceptance a program of cooperation for the next twelve wonths.

\section{ARTICLE 5}

1. Major new proposals for cooperation proposed by efther of the Partles shall be reviewed, if deemed sufficiently important, by the Joint Coordinating Committee.

2. Where it is decided that a folnt profect under this Agreement shall be subject to a formalized speciftc Memorandum of Agreement executed by both Partles, the specific agreement shall cover all detailed provisions including pacents, exchange of equipment, and information disclesure.

\section{ARTICLE 6}

1. The Pazties shall exchange, as agreed on a murually beneficial basis, scientific and technical information documents and results of research and development of related work carried out under this Agreement. Such Information shall be limited to that which they have the right to disclose, elther in their possession or available to them, from the technical areas described in Article 2.

2. PNC shall provide DOE with abstracts in English of reports or other Information from Japan's IMFBr program to be exchanged in accordance with the provisions of this Agreement. PNC shall provide the full text in English of mutually agreed upon numbers of reports. Payceots for translation will be decided by the Partes on a caseby-case basis.

3. Seminar proceedings and reports of joint activities carried out under this Agreement shall be published as joint publications, as 
mutually agreed by both Parties.

4. Both Parties agree that information developed and exchanged under this Agreement should be given wide distribution. Such Information, except as noted fo paragraphs 5 and 6 of this Article, may be made available to the publlc by elcher Party through customary channels and in accordance with noral procedures of the Parties.

5. It Is recognized by both Partes that in the process of exchanging Information, or in the process of other cooperation, the Parties may provide to each other "industrial property of a proprtetary nature." Such property, including trade secrets, inventions, patent information and know-how, made available hereunder which is acquired by either Party prior to, or outside, the course of these activities, and which bears a restrictive designation, shall be respected by the receiving Party and shall not be used for conmercial purposes or made fublic without the written consent of the trans=itting Party. Such property is defined as --

a) of a type customarily held in confidence by cormercial firms;

b) not generally knom or publicly available from other sources;

c) not having beed made available previously by the transmitting Party to others without an agreement concerning its confidentiality; and

d) not already in the possession of the recelving Party or Its contractors.

6. Recognizing that "industrial property of a proprietary nature" as defined above, ray be necessary for the conduct of specific foint activities or may be included in an exchange of fnformation, such property shall be used only in the furtherance of LMFBR programs in the receiving country. Its dissemination shall, unless otherwise mutually agreed, be 11mited as follows -

a) to persons within or employed by the receiving Party, and to other concerned agencies of the Governaent of the receiving Party; and

b) to prime or subcontractors of the receiving Party for use only within the territory of the receiving Party and within the framework of its contract(s) with the respective Party engaged in work relating to the subject watter of the information so disseminated,

proviced that the Information disseminated to any person under subparagraphs a) or b) above shall bear a marking restricting dissemination outside the recipient's organization.

Each party shall use its best efforts to ensure that the dissedination of proprietzry data received under this Agreenent is controlled as prescrib $=0$ herein.

\section{ARTICLE ?}

Copyrights of either Party or of cooperating organizations and persons shall be accorded treatment consistent with internationally recognized standards of protection. As to copyrights of material within the scope of paragraphs 1, 3 and 4 of Article 6 owned or controlled by a Party, each Party shall make efforts to grant to the other a 1icense to reproduce copyrighted material.

\section{ARTICLE 8}

The application or use of any information exchanged or transferred between the Parties under this Agreement shall be the responsibility of the Party recelving 1t, and the transmitting Party does not warrant the 
suitabillty-of such Information for any particular use or application.

\section{ARTICLE 9}

1. With respect to any invention or discovery rade or concelved in the course of or under this Agreement --

a) If made or conceived by personnel of one Party (the Assigning Party) or its contractors while assigned to the other Party (Recelving Party) or fits contractors, in conectlon with exchanges of scientists, engineers and other specialists:

1) The Receiving Party shall acquize all right, title and 1aterest $1 n$ and to any such invention or discovery in Its own country and in third countries, subject to a non-exclusive, frrevocable, royalty-free license in countries to the Assigning Party, with the right to grant sublicenses, under any such invention or discovery and any patent application, patent or other protection relating thereto, for use in fast breeder reactor programs and facilities.

2) The Assigning Party shall acquire all right, title and Interest in and to any such Invention or discovery in its own country, subject to a non-exclusive, irrevocable, royalty-free 11cense to the Receiving Party, with the right to grant sublicenses, under any such invention or discovery and any patent or other protection relating thereto, for use in fast breeder reactor prograns and facilicles.

b) If made or concelved by a Party or its contractors as a direct result of employing information which has been communicated to it under this Agreement by the other Party or its contractors or comsunicated during seminars or other foint meetings, the Party making the invention shall acquire all right, title and Interest in and to such invention or discovery in all countries, subject to a grant to the other Party of a royaltyfree, non-exclustve, irrevocable Iicense with the right to grant sublicenses 1 and to any such lavention or discoverg and any patent application, patent or other protection relatIng thereto, in all countries for use in fast breeder reactor programs and facilities.

c) With regard to other specific forms of cooperation, including loans or exchanges of materials, instruments, and equipment for special jolat projects, the Parties shall provide for appropriate distribution of rights to Inventions or discoveries resulting from such cooperation. In general, however, each Party should normally own the rights to such inventions or discoveries in 1 ts oun country wich a non-exclusive, irrevocable, royalty-free license to the other Party with the right to grant sublicenses in and to such invention or discovery for use in fast breeder reactor programs and facillties, and their rights to such Inventions or discoveries in other countries should be agreed by the Parties on an equitable basis.

2. The preceding paragraph 1 of this Article shall apply mutatis mutandis to design protection.

3. Ne1ther Party shall discriwinate agalnst citizens of the country of the other Party with respect to granting any licenses or sublicenses under any Invention or discovery pursuant to paragraph 1 above. It is understood that the licensing pollcies and practices of each Party may be affected because of the rights of both Parties to grant licenses utchin a single country. Accordingly, either Party gray request, In regard to a single Invention or discovery or class of 
Inventions or discoveries, that the Parties consult in an effort to lessen or elfuinate any detrimental effect that the parallel Ifcensing authorities may have on the polficles and practices of the Parties.

4. Each Party shall assume the responsibility to pay awards or compensation required to be paid to its own nationals according to Its own laws. In view of the provistons of Article 35 of the Japanese Patents Act of Apr11 13, 1959, PNC shall, prior to the assignment of any Japanese personnel to a United States facility, secure from the Japanese employer of such personnel, a comitwent that the employer agrees to hold the Goverament of the United States of America and its contractors harmless with respect to any clain of the employee for compensation under Article 35 of the Japarese Patent Act vith respect to any inventions within the scope of paragraph 1 hereof, and PNC will pay any resuneration to tive laventor under sald Article 35.

\section{ARTICLE 10}

Both Partles agree that in the event equiprent is to be exchanged or supplied by one Party to the other for use in Joint projects, or projects as mutually agreed upon, the following provisions shall apply covering the shiprent and use of agreed equipment.

1. The sending Party shall supply as soon as possible a detalled list of the equiprent to be provided together ulth the relevant spectfications and technical and informational documentation.

2. The equipwent and necessary spare parts supplied by the sending Party for use in joint projects shall remain its property and shall be returned to the sending Party upon completion of the joint project unless otherwise agreed.
3. The above-mentioned equipment shall be brought into operation at the host establishment only by mutual agreement batween the Parties or between their senior representatives at the host establishment.

4. The host establishmeat shall provide the necessary premises for the equipment, and will provide for electric power, water, gas, etc., In accordance with techaical requirements which shall be es mutually agreed.

5. Responsibility and expenses for the transport of equipment and materials from the United States by plane or ship to an authorized port of entry 1a Japan convenient to the ultinate destination. and return, and also responsibility for thetr safekeeping and fnsurance en route, shall rest with DOE.

6. Responsibility and expenses for the transport of equipment and matertals from Japan by plane or ship to an authorlzed port of entry 1a the United States convenient to the ultimate destination, and raturn, and also responsibility for thetr safekeeping and insurance en route, shall rest with PNC.

7. The equipment provided by the sending Party for carrying out foint projects shall be considered to be scientific, not having a commercial character.

8. The recelving Party shall be responsible for safekeeping and Insurance en route from authorized port of entry to the ultirate destination and return.

\section{ARTICLE 11}

The following provisions shall apply concerning exchanges of staff.

1. Whenever an exchange of staff is contemplated under thls Agreement, each Party shall ensure the selection of adequate staff with skills 
and competence necessary to conduct the agreed upon cooperation. Each such attachment of staff shall be the subject of a separate attachment agrement between the Parties.

2. Each Party shall be responsible for the salaries, Insurance and allowances to be pald to Its staff.

3. Each Party shall pay for the travel and living expenses of its staff when staying at the estabilshment of the host Party unless otheruise agreed.

4. The host establishment shall arrange for comparable accomodations for the other Party's staff and their fagilles on a mutually agreeable reciprocal basis.

5. Each Party shall provide all necessary assistance to the staff of the other Party as regards administrative formalities.

6. The staff of each Party shall conform to the general rules of work and safoty regulations in force at the host establishoent, or as agreed in separate attachment-of-staff agreements.

\section{ARTICLE 12}

Both Parties agree that the following provisions shall apply concerning compensation for damages incurred under this Agreement. It is understood that such compensation shall be in accordance with the laws of the country on whose territory damages will have been incurred, except as otherulse provided.

1. Defialtions

a) "Staff" of a Party means the employees of the Party, its contractors and subcontractors performing services under this Agreement, and employees of these contractors and subcontractors performing services under this Agreement.

b) "Equipment" or "Property" of a Party means the equipment or property ouned by that Party, or by the contractor and subcontractors of that Party uho perfors services in connection with joint activities under this Agreement.

2. First and Second Party Damages

-) Each Party shall alone be responsible for payment of compensation for damages suffered by its staff regardless of where the damages have been incurred, and shall not bring suit or lodge any other claims against the other Party for damages to 1ts property, except as noted in paragraphs $2 . b$ and 2.c.

b) If the damage suffered by the staff of one of the Parties is due to the gross negligence or intentional misconduct of the staff of the other Party, the latter shall relmburse the former an agreed sum of nonies which the former would be obliged to pay to the person or persons suffering the damages.

c) If carages to the property of one Party are due to the gross nesllgence or Intentional misconduct of the staf $f$ of the other Party, the latcer shall compensace the former for the damages suffered.

3. Third Party Damages

a) By Defective Equipment

Damages caused to the staff or property of a Third Party by defective equipment of a Party shall be compensated for by the Party to which the equipment belongs, except as noted 10 paragraph 3.c.

b) By Staff

Damages caused to the staff or property of a Third Party by the staff of a Party shall be compensated for by the Party in whose territory the damages occurred, except as noted in paragraph 3.c. 
c) Gross Negligence or Intentional Misconduct

If damages referred to in paragraphs $3 . a$ and $3 . b$ were due to the gross regligeoce or 1nsentional wisconduct of the staff of a Party, that Party shall bear the fluanclal responsibility In regard to the Third Party.

d) Damage by Third Party

In the event of damage of any kind caused by a Third Party to the staff or property of one or boch of the Parties, each of these, upon the request of the other Party, shall render $1 t$ aid in the corroboration of claims on the Third Party.

e) Resolution of Questions

The Party on whose territory the damage was Incurred shall, In consultation with the other Party, take upon itself the resolution, with the Third Party, of all questions connected with the determization of the causes, extent and necessity for compensation for danages incurred. Any such resolution shall have the concurrence of the other Party. After determining the extent of the damages, both Parties shall decide, between themselves, the questions relating to compensation for damages incurred.

4. In the event of any dispute betueed the two Parties, a Comittee shall be appointed by the Parties, with equal representation. The conclusions of the Committee shall be presented to DOE and PNC who uill review the conclusions and arrive at a mutual agreement concerning final disposition.

5. The foregoing provisions of this Article shall have no applicability to damages caused by a nuclear incident, as defined by the laws of the countries to which the Parties belong. Compensation for damages caused by such nuclear Incident shall be in accordance with the laws of the countries of the Parties.

\section{ARTICLE 13}

The provisions of this Agreement shall not affect the rights or dutles of the Parties hereto under other agreements or arrangements. This Agrement also in no way precludes comercial firms or other legally constituted enterprises in each of the two countries from engaging in commerctal dealings in accordance with the applicable laws of each country; nor does it preclude the Parties from engaging in activities with other Covernments or persors, except that Industrial property of a proprietary nature shall have limited dissemination as set forth in Article 6, paragraphs 5 and 6, of the Agreement. Moreover, it is expected that the present Agreement should factlitate 1ndustzial and commercial exchanges in the field of the LMFBR between the firms of the countries of the Parties with a view to mutual benefits fros such exchanges for both countries.

\section{ARTICLE 14}

Cooperation under this Agreement shall be in accordance with laus and regulations of the respective countries. All questions related to the Agrement arising during its term shall be settled by the Parties by mutual agreement.

\section{ARTICLE 15}

Each Party shall bear the costs of 1 ts participation in the activities under this Agreement. It is understood that the abillty of the Parties to carry out their obligations is subject to the avallability of appropriated funds. 


\section{ARTICLE 16}

1. This Agreement shall enter into force upon signature, shall continue for - ten-year period, and may be extended by mutual agreement of the Parties. The implementation and progress under this Agreemeat may be subject to annual revieu by the Parties. This Agreement may be terninated at any time at the discretion of either Party, upon one year's advance notification in uriting by the Party seeking to cerminate the Agreement. Such cermination shall be uf thout prejudice to the rights which way have accrued under this Agreeneat to either Paxty up to the date of such termination.

2. In the event that, during the period of this Agreement, the nacure of elther Party's LMFBR prograw should change substantially, whether this be by substantial expansion, reduction, transformation or amalgagation of major elements with the LMFBR program of a Third Party, either Party shall have the right to request revisions in the scope and/or teras of this Agreerent.

3. All joint activities not completed at the termination of this Agreement shall be continued until their completion under the terms of this Agreement.

4. This Agreement shall, as of the date of signature, supersede the Arrangement between the United States Atowic Energy Commission and the Power Reactor and Nuclear Fuel Development Corporation of Japan on Fast Breeder Reactors executed on March 4, 1969, as amended.

Done at Tofgro In duplicate in the English and Japanese 1anguages, each equally authentic, this $3 /$ st dey of Gatecency,

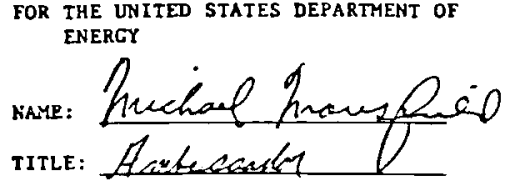

FOR THE POHER REACTOR AND NUCLEAR FUEL DEVELOPMENT CORPORATION

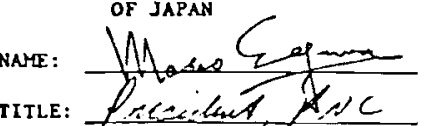



Memorandum of Agreement
Between

The Power Reactor and Nuclear Fuel Development

Corporation of Japan

$$
\text { and }
$$

the United States Department of Energy

for the Collaborative Testing of a Radioactive Liquid-Fed

Ceramic Melter

Whereas the United States Department Energy (hereinafter referred to as "DOE") and the Power Reactor and Nuclear Fuel Development Corporation of Japan (hereinafter referred to as "PNC") (hereinafter referred to as "the Parties"), have a long history of successful collaboration under the Agreement Between the United States Department of Energy and the Power Reactor and Nuclear Fuel Development Corporation of Japan in the Field of Liquid Metal-Cooled Fast Breeder Reactors of January 31 1979 (hereinafter referred to as "the LMFBR Agreement");

Whereas DOE and PNC have established familiarity with each other's programs in waste management through the Waste Management Working Group of the LMFBR Agreement;

Whereas DOE operates the Radioactive Liquid-Fed Ceramic Melter Facility (RLFCMF) as a user-funded facility at the Pacific Northwest Laboratory (PNL) under contract DE-AC-06-76RLO 1830,

DOE and PNC hereby agree to a joint demonstration project (hereinafter referred to as the "joint project") in the RLFCMF under the LMFBR Agreement as follows:

1. Objective

The objectives of this joint project are to demonstrate cooperatively the ability of the liquid-fed ceramic melter to vitrify civilian high level waste from the nuclear power fuel cycle through an experimental program to test a pilot-scale liquid-fed ceramic melter in the RLFCMF, and to provide DOE and PNC with the opportunity to observe and participate in future civilian applications of the technology developed in this experimental program.

\section{Project}

2.1 The liquid-fed ceramic melter is a joule-heated device designed to combine a high-level waste stream with glass formers or frits to produce a borosilicate glass waste form that can be transported. The pilot-scale RLFCMF includes feed, off-gas, melter and canister-turntable systems contained within a shielded "hot cell" and a microprocessor control system. DOE has invested over $\$ 10$ million to modify an existing facility to become the RLFCMF. In 1984, the RLFCMF began radioactive operations. In 1985, the RLFCMF is to commence tests with various feedstocks and operating conditions.

2.2 The joint project shall be one of several at the RLFCMF; the RLFCMF will not be dedicated exclusively to the joint project.

\subsection{The responsibilities of DOE are:}

2.3.1 Accept for assignment one PNC scientist to the start-up and operation of the RLFCMF; to the testing of various feedstocks (West valley and commercial wastes) under a range of operating conditions; to the maintenance of the RLCFMF; and to the decontamination, decommissioning and examination of the RLFCMF at the end of its useful life. The RLFCMF shall be under the sole control of DOE.

2.3.2. Transmit to PNC or permit PNC to have access to:

2.3.2.1 documentation describing the operational conditions and configuration of the RLFCMF;

2.3.2.2 information on the operation of the control system:

2.3.2.3 information on general operation;

2.3.2.4 information on the decommissioning of spent RLFCMF system components; and

2.3.2.5 other information from the joint work under this Memorandum of Agreement.

2.3.3 Test PNC components and PNC simulated waste compositions, and permit up to two PNC personnel in the pre-test planning, in the conduct of such tests, and in the post-test analysis.

2.3.4 Assign its personnel to PNC facilities and operating systems and receive information from PNC similar in kind as ing systems and receive inf

\subsection{The responsibilities of PNC are:}

2.4.1 Assign one PNC scientist to the start-up and operation of the RLFCMF; to the testing of various feedstocks. (West Valley and commercial wastes) under a range of operating conditions; to the maintenance of the RLFCMF; and to the decontamination, decommissioning and examination of the RLFCMF at the end of its useful life.

2.4.2. Receive through transmission or through access to:

2.4.2.1 documentation describing the operational 
conditions and configuration of the RLFCMF

2.4.2.2 information on the operation of the contro system:

2.4.2.3 information on general operation;

2.4.2.4 information on the decommissioning of spent RLFCMF system components: and

2.4.2.5 other information from the joint work under this Memorandum of Agreement.

2.4.3 Assign up to two PNC personnel during the tests of PNC components and PNC simulated waste compositions, as well as in the pre-test planning and post-test analysis.

2.4.4 Provide DOE with the opportunity to assign DOE personnel to PNC facilities and operating systems and to transmit information from PNC to DOE similar in kind as in 2.1 through 2.3 above.

2.5 The schedule for the joint project is given in Figure 1.

\section{Management}

3.1 DOE and PNC shall each appoint a Coordinator for the joint project who shall be responsible for the general management of the joint project.

3.2 The Coordinators shall be responsible for:

3.2.1 Developing the annual work plan for the joint project;

3.2.2 Reviewing the implementation of the joint project

3.2.3 Reviewing the experiments to be started, completed or

3.2.4 Reviewing plans for joint publications

3.2.5 Discussing personnel assignments 3.2.6 Estimating costs and agreeing on payments for

3.2.7 Discussing other matters as mutually agreed.

3.3 The Coordinators shall report the results of their work to the Joint Coordinating Committee established under the LMFBR Agreement.

\section{Finance}

4.1 Because the RLFCMF is user-funded, 258 of the expenses of the multi-year testing program, up to a maximum of $\$ 1.25$ million per year, shall be borne by PNC.

4.2 Activities conducted specifically for the benefit of PNC (design, fabrication, and testing of PNC equipment or simulated waste compositions) shall be funded by PNC.
Payments shall equal actual costs incurred by DOE for such activities. The payment amounts and schedules for these activities shall be determined by mutual agreement between the Coordinators.

4.3 Specific payment schedules and credits shall be made by the Coordinators

\section{General Provisions}

5.1 Articles $7,8,11,13$ and 14 of the LMFBR Agreement are hereby incorporated by reference.

5.2 The ability of the Parties to carry out their obligations is subject to the availability of appropriated funds.

5.3 Compensation for damages incurred during the implementation of this agreement shall be in accordance with the applicable laws of the countries of the Parties.

\section{Information and Patents}

6.1 DOE and PNC shall exchange information as set forth in Article 2. All information arising from this Memorandum of Agreement as set forth in Article 2 shall be promptly exchanged between DOE and PNC.

6.2 The information exchanged under and arising from this Memorandum of Agreement may be given wide distribution, subject to paragraphs 6.4 through 6.7 below. Such information may be made available to the public by either DOE or PNC through its customary channels and in accordance with its normal procedures.

6.3 Proprietary information shall not be accepted for or utilized under this Memorandum of Agreement without the express written approval of DOE and PNC setting forth the terms and conditions for such acceptance or utilization.

The term "proprietary information" means information which contains trade secrets or know-how or commercial or financial information which is privilege or confidential, and may only include such information which:

a) has been held in confidence by its owner;

b) is of a type which is customarily held in confidence by its owner;

c) has not been transmitted by the transmitting Party to other entities (including the receiving Party) except on the basis that it be held in confidence; and 
d) is not otherwise available to the receiving Party from another source without restriction on its further dissemination.

6.4 Inventions made or conceived in the course of or under this Memorandum of Agreement resulting from an assignment of personnel, as a direct result of employing information that has been communicated under this Memorandum of Agreement, or as a result of the testing of the PNC components and PNC simulated waste compositions (hereinafter referred to as "arising inventions") shall be identified and reported promptly by the inventing Party to the other Party. Information regarding inventions on which patent protection is to be obtained shall not be published or publicly disclosed by either Party or until a patent application has been filed in either country of the Parties, provided, however, that this restriction on publication or disclosure shall not extend beyond six months from the date of reporting of the invention. It shall be the responsibility of the inventing Party to appropriately mark priately protected by the filing of a patent application.

6.5 Arising inventions shall be owned (1) by PNC in Japan. subject to a royalty-free, nonexclusive, irrevocable license to DOE, its government and the nationals of its country designated by it and (2) by DOE $1 \mathrm{n}$ the United States and third countries, subject to a royalty-free, nonexclusive. irrevocable license to PNC, its government, and the nationals of its country designated by it.

\subsection{This Article shall apply mutatis mutandis to the} protection of utility model and of design.

6.7 DOE and PNC shall each assume the responsibility to pay awards or compensation required to be paid to its own nationals according to its own laws. DOE and PNC each shall, without prejudice to any rights of inventors under its national laws, take all necessary steps to ensure the cooperation of its inventors and authors as required to carry out the provisions of this Article.

6.8 Information transmitted by one Party to the other Party under this Agreement shall be accurate to the best knowledge and belief of the transmitting Party, but the transmitting Party does not warrant the suitability of the information transmitted for any particular use or application by the receiving party or by any third Party. Information developed jointly by the parties shall be accurate to the best knowledge and belief of both Parties. Neither Party warrants the accuraan of the jointly developed information or its suitability for any particular use or application by either Party or by any third Party.

\section{Additional Provisions}

7.1 Final disposition of all samples and equipment used in the joint project shall be carried out in accordance with recommendations of the project Coordinators and decisions of DOE and PNC. Equipment provided by PNC under this Memorandum of Agreement shall be returned to PNC, unless such equipment is unable to be decontaminated or transported. The equipment with fixed contamination shall be disposed of by DOE as radioactive waste. The costs of return or disposal of PNC-specific equipment shall be borne by PNC and included in the payment agreements of Article 4, paragraph 4.2 of this Memorandum of Agreement.

7.2 The joint project shall enter into force upon signature of this Memorandum of Agreement by DOE and PNC and shall remain in force for a period of five years. The joint project may be renewed or amended by written agreement between DOE and PNC. The joint project may be terminated at the discretion of either DOE or PNC upon six (6) months advance notice in writing by the side seeking to terminate the joint project. PNC shall reimburse DOE for any costs DOE has incurred prior to DOE receipt of such advance notice of termination if such costs were incurred specifically for the benefit of PNC.

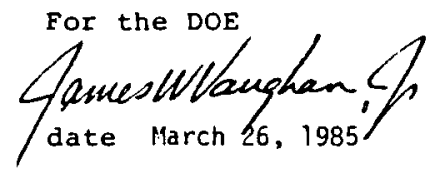

For PNC

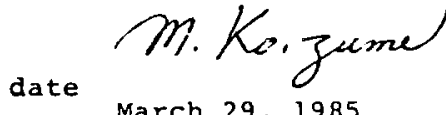




\section{Definition of the Financial Terms \\ for the DOE/PNC Memorandum of Agreement \\ on Collaborative Radioactive Testing of the \\ Liquid Fed Ceramic Melter}

As described in Section 5 of the DOE/PNC Memorandum of Agreement on Collaborative Radioactive Testing of the Iiquid Fed Ceramic Melter, the pilot-scale radioactive Liquid-Fed Cermic Melter (LFCM) is a user-funded facility and PNC will be required to make a financial contribution as a part of the agreement. The following are the proposed specific changes, credits and payment schedules as required by section 4.3 of the Memorandum of Agreement.

\section{Basis for PNC Financial Contribution}

The 324 Building hot cell capability has a current value of approximately $\$ 100$ million $(M)$. The total cost for facility preparation, design, fabrication, and installation of the pilot-scale radioactive LFCM is approximately $\$ 10 M$. The annual operating cost is approximately $\$ 4 M$ per year (not including waste form/canister preparation and characterization activities) increasing at roughly $10 \%$ per year. Given the substantial benefit to the PNC and the possible involvement of other countries in the LFCM testing activity, $25 \%$ of the annual operating cost seems like a fair minimum value for the technology transferred to PNC under the Memorandum of Agreement. Of the $25 \%$, a minimum of 158 seems reasonable as a PNC direct funding percentage, with a maximum of $10 \%$ being a PNC technology contribution to DOE.

PNC CONTRIBUTION SCHEDULE

\begin{tabular}{llllll} 
& $\begin{array}{l}\text { Annual } \\
\text { Operating } \\
\text { Cost }\end{array}$ & $\begin{array}{l}\text { Total PNC } \\
\text { Contribu- } \\
\text { tion }\end{array}$ & $\begin{array}{l}\text { PNC } \\
\text { Financial } \\
\text { Contribution }\end{array}$ & $\begin{array}{l}\text { PNC } \\
\text { Technology } \\
\text { Contribution }\end{array}$ & $\begin{array}{l}\text { Date } \\
\text { Paymen }\end{array}$ \\
\hline $\begin{array}{l}\text { Effective } \\
\text { date of }\end{array}$ & & & & \\
$\begin{array}{l}\text { agreement } \\
\text {-9/85 }\end{array}$ & $\$ 4.0 M$ & $\$ 1.0 M$ & $\$ 0.3 M$ & $\$ 0.2 M$ & $3 / 85$ \\
& & & $\$ 0.3 M$ & $\$ 0.2 M$ & $8 / 85$ \\
$9 / 85-9 / 86$ & $\$ 4.5 M$ & $\$ 1.125 M$ & $\$ 0.338 M$ & $\$ 0.23 M$ & $3 / 86$ \\
& & & $\$ 0.337 M$ & $\$ 0.22 M$ & $9 / 86$ \\
$9 / 86-9 / 87$ & $\$ 5.0 M$ & $\$ 1.25 M$ & $\$ 0.38 M$ & $\$ 0.25 M$ & $3 / 87$ \\
& & & $\$ 0.37$ & $\$ 0.25 M$ & $9 / 87$
\end{tabular}

The PNC technology contribution or equivalent will be recommended to DOE by PNC and the project coordinators will work together to obtain concurrence concerning DOE's interest in that technology. 
F1gute 1: ACTIVITY SCHFDULE TOR RLFCM DFHONSTRATION

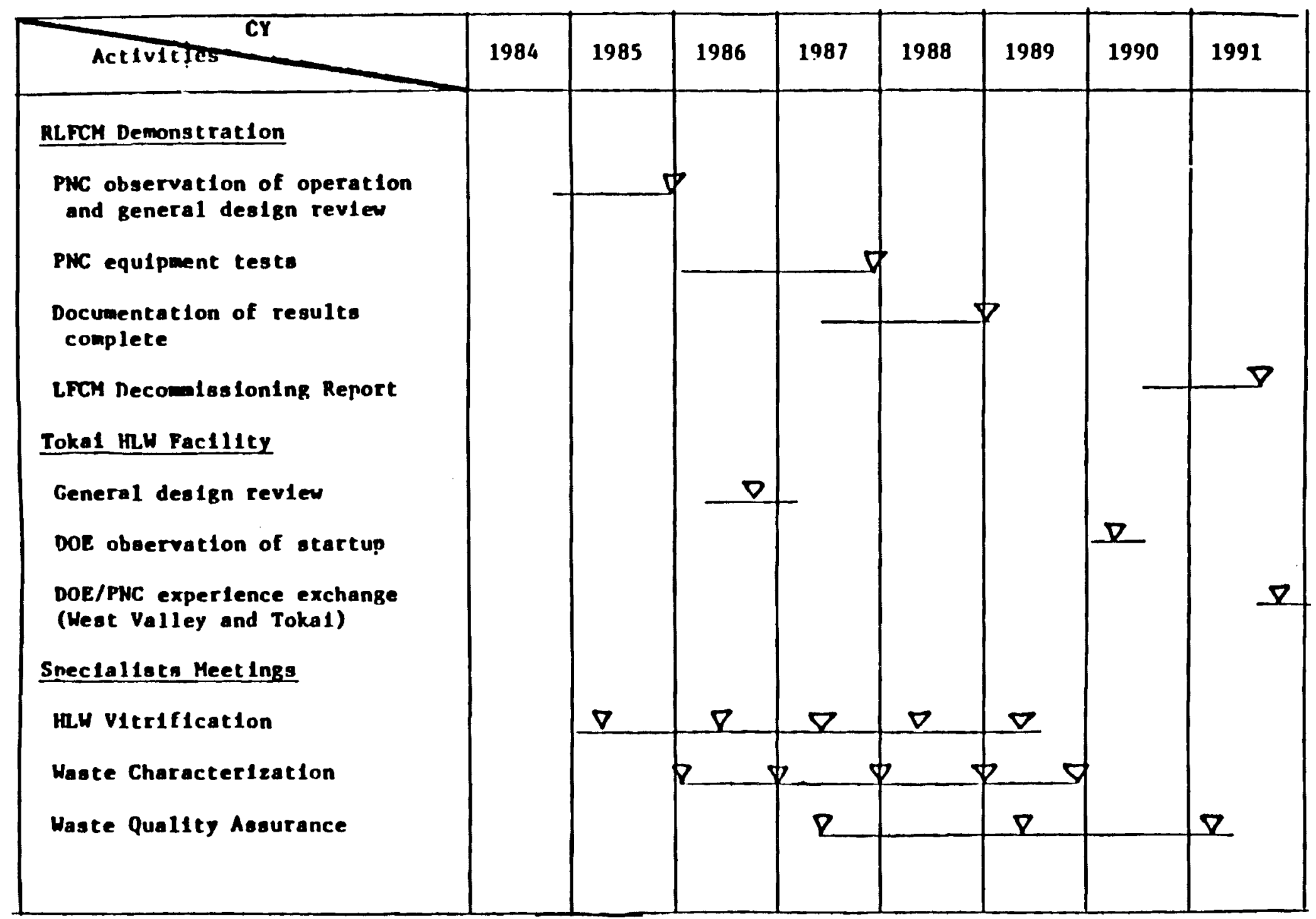


vets/01/20

PNC rrojosal on the Establish-ent OE PNC/EOE Joint Uorbinz Grour on Waste Mers ement

\section{Terms and Reierence}

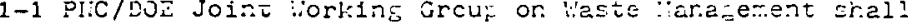

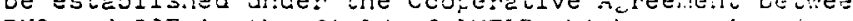
Piic and DUE in the field ot L
liarch 4, 1969 and was supersedec on January $31,1979$.

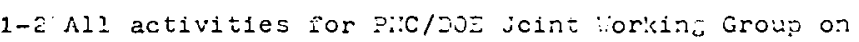
thas te ianainent shall de procesces in accorciarce the terms and reference ciescritec in the eoove Lir

\section{Purgose and Scope of Cooperation}

2-1 The purpose of the cooperation stall be the excharge ot Inforiation and cooperation in the areas of reseact and cevelopment of wastes betweer Fi: and DuE.

The cooperation shall oe imilet.ertec for futual benerit or the basis o $\vec{i}$ mutual conficence.

2-2 Fossible areás of tecrnical anci scientiäic cooperátion between Fid anc DUE ane sez innth in Arendix $A$ PI:C anc DUE shall use their best enforts to inplement this cooperation tilexilly grovitud that the scope of cooperation may be arended oy mutual agrement, as nay be necessary z̈ror: time to tiae.

2-3 For each sfecific activity of cooperation as specisied in hipendix A, the exclian̈e of fr:formation shall be deterinined by filc and Juz o.h e. case by case jasis tre in consicieration of the balance or value ci txchanae information.

2-4 There are activities that a Fert; $;$ ill not $a_{c}$ ree to incluce in the specific aetivitiss of coojeration urisss

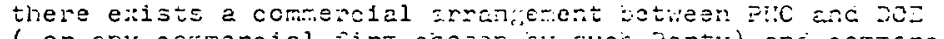

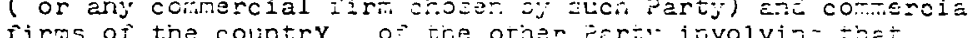

\section{Implericntation of eooteretion}

3-1 The activities of this working crout shal 2 be procerded within guicielines añ policy eet by the Fic/ COE joinc Coodirating Comnittes which supervise the extcution of the LMFBR Conperative Mgrcement as soz fortr. in Article

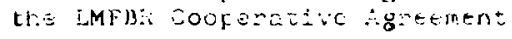

3-2 Tire imjlementation and progress unden tlis wonking croup shall be suiject to anmal review at tre joint working Eroup meeting witich shail be heid each yeer aiternateiy in the Unitec States anc in Jajan, or at other agreed times and places.

3-3 PiC/DUE Jcint Coorcinating Comintttoe shall evaluate the status of cooperation lancier this :oritine crowi.

3-4 Cooperation of this iorkint Group stall be inflerentec in accorcance :ith article 3 os the inje cooperative freerent.

\section{Information E::chance}

Scientifle and Technical informetion siall be exchangec in

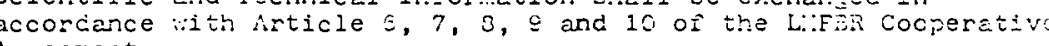
Agreement.

\section{Exchange of staif}

Exchange of staff shall je concluctec for participation in azree research, cevelopient arü ceuonstration, analysis, cesin, ar.c experimental joint activities to be periormed in scientific centers, ladoratories, enjineerins ofices anc facilities $0 \vec{z}$

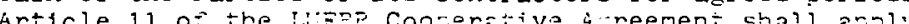
concernins exchanies of stäis.

\section{Compensatic: For Damaes}

Article 12 of the LuFER Coorerative Agroerent shall apply to the compensation for iamaios incurred uncer the activities of
this liorling Group.

7. Application of Laits and Reculations

Cooperation uncier this itorling crous shall se in accorcance in Artiole 14 of the L:Fsa Cooserative Afreement.

s. Cozts of Aotivities

Eech Party shall bear the costs of its participation in the activities uncer tisis lortino crou as stated in drticle 15 of the Ligz? Coojerative hareenent.

Q. Coordination of Activities

In orcier to settle the cetails of the implementation of the activities oz titis lorrin: Crouj, FNC anc EUE shall abpoint anci nowincse Cookiratozs 
I. Storage and Disposal of Radioactive Wastes
A. Engineered Storage
B. Disposal in Geologic Formations of mutual interest
c. Feasibility for Sea-bed Disposal
D. Waste Form Characterization relevant to Storage and/or Disposal

II. Treatment of Radioactive Wastes
A. Immobilization and Packaging of High-level Radioactive Waste and TRU-contaminated vaste
B. Incineration, Volume Reduction and Liquid isaste Treatient
c. Handling Systems of Solidified and/or Packaged Wastes
D. Accountability Systems for Radioactive wastes
E. Partitioning and/or Trasmutation

III. Decontamination and Decommissioning of Equipment, Facilities or Land

IV. Transportation of Radiouctive Wastes including Nuclear Fuels

v. Public Acceptance Issues

Wher freas of coppration ma' be aders by mutual interect. 
MEMORANDUM OF AGREEMENT

BETWEEN

THE UNITED STATES DEPARTMENT OF ENERGY

AND

THE POWER REACTOR AND NUCLEAR FUEL DEVELOPMENT CORPORATION, JAPAN

IN THE AREA OF

CRITICALITY DATA DEVELOPMENT

This Agreement is made as of the 12 th day of August

1983 between the United States Department of Energy (DOE) and the Power Reactor and Nuclear Fuel Development Corporation, Japan (PNC), hereinafter called the "Parties."

\section{WHEREAS}

DOE and PNC have agreed to cooperate in selected areas of $f$ ast breeder reactor technology including the fuel cycle under their Agreement in the Field of Liquid Metal-Cooled Fast Breeder Reactors of January 31, 1979, hereinafter called the -DOE/PNC LMFBR Agreement."

Both DOE and PNC have a mutual interest in the conduct of studies of the nuclear criticality aspects of fuel material facilities associated with the LMFBR.
DOE has the means for the experimental and analytical verification of nuclear criticality at its Pacific Northwest Laboratory (PNL), its Los Alamos National Laboratory (LANL), and el sewhere.

Both the United States and Japan are parties to the Treaty on Nonproliferation of Nuclear Weapons and, therefore, have as a mutual interest the development of nuclear energy in such a manner as to enhance prospects for restraining the proliferation of nuclear weapons.

IT IS AGREED AS FOLLOWS

ARTICLE 1 - OBJECTIVE

The objectives of cooperation under this Agreement are to verify computer code calculations of nuclear criticality, to measure the reactivity of subcritical configurations, and to measure the neutron energy spectra for various configurations of materials and geometries. 
ARTICLE 2 PROGRAM

1. The Parties have agreed on a Joint Program designed to achieve the objectives of this Agreement, hereinafter called the "Program," which is outlined in Appendix A to this Agreement. Any changes to the Program shall require the prior agreement in writing of the Parties.

2. The Program shall constitute a Joint Project of the type contemplated by Article 3, Paragraph 7, of the DOE/PNC LMFBR Agreement. Unless otherwise specified in this Agreement, cooperation under this Agreement shall be subject to applicable provisions of the DOE/PNC LMFBR Agreement. The provisions of Article 10 (Exchange of Equipment), Article 11 (Exchange of Personnel), and Article 12 (Damages) of the DOE/PNC LMFBR Agreement are hereby incorporated in this Agreement.

3. In summary, the Program envisages:

a. Performance at DOE critical experiment facilities of the 24 items of verification of computer code calculations in the areas listed in Table 1 to Appendix A.

b. Use of techniques developed by DOE to measure the reactivity of subcritical configurations of materials in the areas 1 isted in Table 1 to Appendix $A$. c. Performance of additional experiments in neutron spectrum measurement in the areas listed in Table 1 to Appendix A, if requested by PNC and subject to amendment to this Agreement.

d. Recording and exchange between the Parties of agreed data and results arising from the program.

e. Analysis of the experimental results by each Party and agreed exchange between the Parties of the results of such analysis.

f. The completion of all work by March 31, 1986.

ARTICLE 3 - RESPONSIBILITIES

1. DOE shall be responsible for:

a. Scheduling and conducting the 24 items of verification - listed in Table 1 to Appendix $A$.

b. Recording the experimental data arising from the Program and making them available to PNC.

c. Analyzing the experimental data arising from the Program, using its own codes, and making the results available to PNC. 
d. Preparing and issuing quarterly and final reports and, as mutually agreed, topical reports concerning the work performed under the Program.

e. Providing personnel support, office space, and unclassified access to computing facilities for any PNC staff attached to DOE or DOE contractors under this Agreement.

2. PNC shall be responsible for:

a. Sharing in the cost of the Program by froviding financial contributions as described in Article 5 of this Agreement.

b. Providing to DOE for use in the Program an annular tank, a boiler tube, and related equipment, designed to DOE specifications, subject to the provisions of Article 10 of the DOE/PNC LMFBR Agreement.

c. Analyzing the experimental data arising from the Program, using its own codes, and making the results available to DOE.
3. PNC shall have the right to participate in the planning of the experiments and measurements to be conducted at DOE facilities under the Program, and shall have the right to participate in the analysis of the results of such experiments and measurements. These rights may be exercised by short term visits or by attachment of staff, subject to the prior approval of DOE on each occasion. Attachment of staff shall be the subject of separate attachment agreements in respect of each person, in accordance with Article 11 of the DOE/PNC LMFBR Agreement. Not more than two PNC staff shall be attached to any one DOE facility at any one time.

4. DOE may arrange, at its own discretion, for PNC staff to observe selected experiments, on terms and conditions as agreed in writing by the Parties.

5. DOE and PNC each propose to undertake analysis of the results arising from the Program according to its own requirements, using its own codes and at its own expense. However, each Party shall inform the other Party of. its intentions in this respect, so as to provide for the possibility of cooperation between the Parties on appropriate aspects of analysis. Each Party shall make available to the other Party the results of analyses, and the Parties shall cooperate in attempts to establish the

reasons for any differences between results of analyses. 
1. The Joint DOE/PNC Coordinating Committee established pursuant to Article 4 of the DOE/PNC LMFBR Agreement shall be responsible for the review, evaluation, and assessment of the Program.

2. For periods between meetings of the Joint DOE/PNC Coordinating Committee, each Party shall designate one or more persons to act on its behalf in all matters concerning cooperation under this Agreement.

\section{ARTICLE 5 - FINANCIAL TERMS}

1. In consideration of the materials and services to be provided by DOE under the Program. PNC agrees to provide to DOE a financial contribution of $\$ 2,300,000$ in U.S. dollars for that portion of the Program to be conducted in Japanese Fiscal Year 1983 (Apri1 1, 1983 to March 31, 1984).

2. Preiminary estimates of PNC contributions in support of the Program for Japanese Fiscal Years 1984 and 1985 are $\$ 2,300,000$ and $\$ 1,700,000 \mathrm{U} . \mathrm{S}$. dollars, respectively. However, at least two months prior to the start of each Japanese Fiscal Year 1984 and 1985, the Parties shall negotiate the scope of the Program for that fiscal year, together with the amount of the annual PNC contribution in support of the Program for that fiscal year, and this Agreement shall be amended to reflect such negotiations. Contributions by PNC shall be provided to DOE in advance of any work to be performed.

3. In the event the actual cost of the agreed Program in any one fiscal year shall vary from the estimated cost for that fiscal year, PNC shall adjust its contribution to DOE to match the actual cost.

4. All contributions by PNC shall be made within 30 days of receipt of invoice, together with detailed instructions for transfer of funds, to be provided to PNC by the DOE Office of the Controller. DOE shall provide quarterly invoices to PNC, and the amounts to be billed by DOE in any one year shall be divided into approximately equal amounts among the four quarterly invoices.

5. Unless otherwise provided in this Agreement, each Party shall bear all costs of its participation in the Program under this Agreement.

6. The ability of each Party to carry out its obligations under this Agreement is subject to the availability of appropriated funds. 


\section{ARTICLE 6 - INFORMATION AND PATENTS}

1. DOE shall provide to PNC information necessary to carry out the Program. PNC shall provide to DOE results from its analysis of such information so provided to PNC. PNC shall also provide to DOE all information relating to equipment which PNC shall loan to DOE under this Agreement.

2. All information arising from this Agreement shall be promptly exchanged between the Parties.

3. The application or use of any information provided under or arising from this Agreement shall be the responsibility of the Party receiving it, and the other Party does not warrant the suitability of such information for any particular use or application.

4. The information provided under and arising from this Agreement may be made available to the public by either Party through customary channels and in accordance with the normal procedures of the parties.

5. Copyrights of either Party or of cooperating organizations shall be accorded treatment consistent with internationally recognized standards of protection.
6. Inventions made or conceived in the course of or under this Agreement (hereinafter referred to as "arising inventions") shall be identified and reported promptly by DOE to PNC. Information regarding inventions on which patent protection is to be obtained shall not be published or publicly disclosed by the Parties until a patent application has been filed in either country of the Parties; provided, however, that this restriction on publication or disclosure shall not extend beyond six months from the date of reporting of the invention. It shall be the responsibility of DOE to mark appropriately reports which disclose inventions that have not been appropriately protected by the filing of a patent appl ication.

7. Arising inventions shall be owned:

(1) by PNC in Japan subject to a royalty-free, nonexclusive, irrevocable license to DOE, its Government, and the nationals of its country designated by $i t$; and

(2) by DOE in the United states and in third countries, subject to a royalty-free, nonexclusive, irrevocable license to PNC, its Government, and the nationals of its country designated by it. 
8. Each Party shall assume the responsibility to pay awards or compensation required to be paid to its own nationals according to its own laws.

9. Each Party shall, without prejudice to any rights of inventors under its national laws, take all necessary steps to provide the cooperation from its inventors required to carry out the provisions of this Article.

ARTICLE 7 - LEGAL PROVISIONS

Cooperation under this Agreement shall be in accordance with the laws and regulations of the respective countries of the Parties. All questions related to this Agreement arising during its term shall be settled by mutual agreement of the Parties.

\section{ARTICLE 8 - DURATION AND TERMINATION}

1. This Agreement shall enter into force upon the later date of signature, and shall continue through March 31, 1986 unless sooner terminated in accordance with paragraph 3 of this Article.

2. This Agreement may be amended or extended, at any time, by mutual written agreement of the Parties.

3. This Agreement may be terminated, at any time, upon 90 days written notice by either Party. Such termination shall be without prejudice to the rights which may have accrued to either Party up to the date of such termination. In the event of such termination, the settlement of payments from PNC to DOE and the furnishing of information and data from DOE to PNC shall be negotiated on a pro-rata basis.

Done in duplicate.

FOR THE UNITED STATES DEPARTMENT OF ENERGY

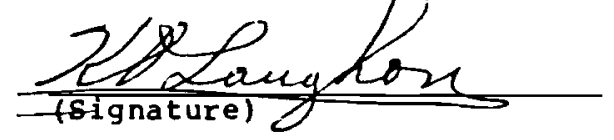

Kermit 0. Laughon Name

Director, Office of Spent Fuel Mgt. and Reprocessing Systems, Office Title of Nuclear Energy

June 27,1983 Date
FOR THE POWER REACTOR AND NUCLEAR FUEL DEVELOPMENT CORPORATION, JAPAN

\section{Koifumu}

Masumicht Kolzumi Name

Director, Technology Title

August 12,1983

Date 


\section{$\underline{05-11-83}$}

\section{APPENDIX A}

DOE/PNC Study of Nuclear Reactivity of Arrangements of Nuclear Fuel Materials in Facilities Associated with the LMFBR.

\section{Background and Purpose}

Based on an agreement attained at the Department of Energy/ Power Reactor and Nuclear Fuel Development Corporation (DOE/PNC) specialist meeting on Fast Breeder Reactor (FBR) Reprocessing Technical Exchange held on March 14 and 19, 1982, the U.S. DOE and the PNC agreed to a cooperative program to conduct critical experiments, subcritical measurements, and measurements of the neutron spectra for materials and geometries which would be present in a fuel facility. This geometries which would be present in document outlines the experiments to be conducted and a cost agreement for those experiments to be paid by PNC. Cost data for Japanese FY 1983 are given explicitly with estimates give for the Japanese FY 1984 and 1985 costs. Activities to be conducted during Japanese FY 1983 (April 1983 through March 1984 ) are outlined in this document.

2. Study outline

The PNC has outlined 24 items of verification which compose the experimental program. These items were identified in the Record of the First Department of Energy/Power Reactor and Nuclear Fuel Development Corporation Data Development and Exchange. A list of these items is provided in Table 1 . Some of these items have already been started. Table 1 notes those items which will be initiated or continued during Japanese FY 1983 .

It is the intent of the DOE to schedule the experiments supported by PNC at DOE critical experiment facilities in a manner which will provide the needed information on a timely basis and at the minimum cost to PNC. The critical experiment facilities involved will be the Pacific Northwest Laboratory (PNL) and the Los Alamos National Laboratory (LANL) facilities with perhaps 20 percent enriched $\mathrm{UO}_{2}$ experiments being performed at the Rocky flats Facillty.
Specifically, the following items have been selected to be perfolited at the listed facility.

IANL

Pu+U damp oxide-basic case

PNL

Putu aqueous solution with fixed poison

PutU aqueous solution interaction between 3 slabs Fuel pin in aqueous solution with soluble poison

Pu aqueous solution temperature effect

The cholces of the locations of the remaining experiments will be made on the basis of fissile material availability and the requirement that all experiments be completed by April, 1986 . The removal of either of these two restraints would influence the site chosen.

development effort will be initiated by ORNL to utilize the subcriticality monitoring system which he has developed to supply measurement of $k$-effective for subcritical configurations of materials involved in these experiments. Personnel and equipment will be maintained at each facility for the purpose of making the subcriticality measurements. The PNL will also utilize the pulsed neutron technique, as appropriate. to provide a basis for comparison and confirmation of this technique and the system developed by Mihalczo.

A program to provide neutron spectrum measurements will be instituted if requested by PNC. Techniques involving solid state track recorders appear to provide the best available technique for making this type of measurement. Due to uncertainty about the cost of this type of measurement and uncertainty about the number of measurements to be made, no. provision has been made in the Japanese FY 1983 costs for conducting neutron spectrum measurements. The PNL advises that the cost of making these measurements would be from $\$ 10,000$ to $\$ 20,000$ per experiment.

The Japanese FY 1983 costs to PNC are estimated as follows:

Cost of materials, personnel, and facility expense for conducting critical experiments Cost of development and conducting subcritical measurements by ORNL

Total Japanese FY 1983 costs
500,000

$\$ 2,300,000$ 
The cost of joint critical analysis using computer codes based on experimental data obtained in this program is included in the cost estimates herein.

Cost estimates (in FY 1983 dollars) for Japanese FY 1984 and 1985 are given below. These estimates are subject to revision based on information learned from critical data generated, the cost of available fissile material and preparation cost uncertainty.

\section{FY $1984 \quad$ FY 1985}

Cost of materials, personnel, and

facility expense for conducting

critical experiments

$\$ 1,900,000 \$ 1,300,000$

Cost of conducting subcritical

measurements by ORNL

$400,000 \quad 400,000$

The subcriticality tracking items of verification have not been included in the costs. Further definition of the exact systems to be studies and the associated costs can be made after the ORNL technique has been shown to be adequate for this type of measurement.

\section{Rey Personnel}

A. Power Reactor and Nuclear Fuel Development Corporation

a. Technical

Toshihide Otake, General Manager Nuclear Fuel Development Division

Power Reactor and Nuclear Fuel Development Corporation

b. Contract

Chikao Rinoshita, General Manager International Cooperation of $f$ ice Power Reactor and Nuclear Fuel Development Corporation
B. United States Department of Energy

a. Technical

Richard B. Chitwood

Office of Nuclear Fuel Cycle

U.S. Department of Energy

b. Contract

Margie C. Wallace

Oak Ridge Operations office

U.S. Department of Energy

P.O. Box E, Oak Ridge, Tennessee 37830

C. Union Carbide, Nuclear Division

G. E. Whitesides, Manager

Technical Applications

Computer Sciences

Union Carbide, Nuclear Division

\section{Programmatic Responsibilities}

A. The U.S. Department of Energy shall provide personnel assistance, unclassified access to computing facilities (but not $f$ inancial support for computer calculations) and office not financial support for computer calculations) and of 1 ice responsible for the conduct of experiments and the documentation responsible for the conduct of experiments and the documen be issued in July and October 1983 and in January and April 1984. A similar schedule is expected to be maintained during Japanese $F Y 1984$ and 1985 . Topical reports shall be issued as required.

B. Representatives from both the Power Reactor and Nuclear Fuel Development Corporation and the U.S. DOE shall jointly plan the experiments and measurenents to be conducted at the PNL and the LANL facilities.

5. Assignment Schedule of PNC Engineer(s)

Calendar Year

\begin{tabular}{cccc}
1983 & 1984 & 1984 & 1986 \\
\hline $1 / 2 / 3 / 4$ & $1 / 2 / 3 / 4$ & $1 / 2 / 3 / 4$ & $1 / 2 / 3 / 4$ \\
$X$ & $X$ & $X$ &
\end{tabular}


$05-11-63$

Table 1.

Areas to be examined in joint USDOE/PNC Experimental Program

Fuel type

$\mathrm{Pu}+\mathrm{U}$ aqueous solution

Pu+U organic solution

Fuel pin and assembly

Fuel pellet (FTR type)

$\mathrm{PuO}_{2}$ particle
(I Iludge)
Pu aqueous solution
and phase change

Pu+U damp oxide

Enriched uranium damp oxide
Item of verification

initiated/

continued during

Japan FY 1983

Limiting concentration Basic case

Soluble poison

Fixed poison

Np, Am, and $\mathrm{Cm}$ effect

Interac

Basic case

Limiting concentration

Interaction

Interaction with aqueous

solution

Subcriticality tracking

Basic and fixed poison

Aqueous solution and

soluble poison

Interaction

Heterogenity

Subcriticality tracking

Heterogenity

Subcriticality tracking

Temperature effect

Subcriticality tracking

Basic case

Fixed poison

Interaction

Basic case $x$

$\mathbf{x}$

$\mathrm{x}$

$x$

$\mathrm{x}$

$\mathbf{x}$

$\mathbf{x}$

$x$

JA-4.9 



\section{DRePR}

AGREEMENT BETWEEN THE UNITED STATES DEPARTMENT OF ENERGY AND THE SCIENCE AND TECHNOLOGY AGENCY OF JAPAN IN THE AREA OF RADIOACTIVE WASTE MANAGEMENT

Whereas the Department of Energy of the United States of America (DOE) and the Science and Technology Agency of Japan (STA), hereinafter referred to as the Parties, wish to enter waste management

Whereas cooperation has been established under the Waste Management Working Group under the Agreement Between the United States Department of Energy and the Power Reactor and Nuclear Fuel Development Corporation of Japan in the Field of Liquid Metal-Cooled Fast Breeder Reactors of January 31 . 1979 ; Whereas the waste management programs of DOE and STA share
common interests and objectives in the treatment and handing of High Level. Intermediate, Low Level. Transuranic, and Special Wastes from all nuclear power systems; and

Whereas the conduct of research, development and demonstration programs in radioactive waste management requires long periods of time for evaluation and validation

DOE and PNC agree as follows:

\section{ARTICLE I}

The objective of this cooperation is to study mutually agreed topics associated with, and to develop jointly technology and techniques necessary for, the management of radioactive wastes.

\section{ARTICLE II}

The areas of cooperation covered by this Agreement shall include:

1. categorization of, and methods of determination of, types of radioactive wastes:

3. waste form development and characterization;

4. by-product recovery:

5. preparation and packaging of radioactive wastes;

6. transportation requirements

7. surface and subsurface waste storage

8. Characterization of geologic formations:

9. disposal and isolation in geologic formations

10. decontamination and decomnissioning;
11. systems and facility operations:

2. environmental and safety considerations

13. public acceptance issues; and

14. Other areas as may be mutually agreed in writing.

Table 1 further defines the type of activity associated with the waste form.

\section{ARTICLE III}

1. The Cooperation may be implemented by any of the following means:

a. exchange of information and data on scientific and technical activities, developments, practices, methods and results in the areas Iisted in Article II in accordance with Article IV;

b. exchange of scientists, engineers and other specialists for agreed periods of time in order to participate in experiments, analysis, design and other research and development activities at existing and new research centers, laboratories. engineering of $f$ ices and other facilities and enterprises of each of Aricle $x_{i}$

c. organization of, and participation in, seminars and other meetings on specific agreed topics in the areas 1 isted in Article II:

d. exchange and provision of samples, materials, instruments and components for experiments, testing and evaluation;

e. execution of joint studies, projects or experiments including their joint design, construction and operation, and

f. other areas as may be mutually agreed in writing.

2. When necessary, any specific details to implement activities listed in subparagraphs (a) through (c) of 1 above may be determined through consultations or auxiliary arrangements between the Parties or as Annexes to this Agreement. Specific terms and conditions necessary to implement activities listed in subparagraphs (d), (e) and (f) above shal be determined through written agreement between the Parties and shall contain:

a. specific details, procedures and financing provisions for individual cooperative activities 
b. assignment of the responsibility for the operational management of the concerned activity to a single organization or operating agent; and

c. detailed provisions on dissemination of înformation and tretailed prof intellectual property.

ARTICLE IV

1. To supervise the execution of this Agreement, the Parties shall each name a Principal Coordinator. As deemed Parties shall each name a Principal Coordinator. As deemed the status of cooperation under this Agreement. This evaluation shall include a comprehensive review of each Party's radioactive waste management program status and plans, an assessment of the balance and mutual benefit of exchanges among the various areas of cooperation listed in Article II, and a consideration of measures required to correct any imbalance. These meetings shall be held alternately in Japan and the United States.

2. The Principal Coordinators shall review plans for future cooperation and act on any major new proposals for cooperation.

3. For day-to-day implementation of this Agreement, the Principal Coordinators shall each designate Technical Coordinators to oversee the cooperation under this Agreement. The Technical Coordinators shall agree on specific programs of cooperation in their respective areas as described in Article II within policy guidelines set by the Principal Coordinators. The Technical Coordinator or his designee shal be responsible for the working contacts between the Parties in his respective area of cooperation.

\section{ARTICLE V}

Except when otherwise specifically agreed at the time in writing, all costs resulting from cooperation under this Agreement shall be borne by the Party that incurs them.

\section{ARTICLE VI}

1. The Parties shall support the widest possible dissemination of information provided or exchanged under this Agreement, copyect to the need to protect proprietary information,

2. Use of proprietary information

Definitions as used in this Agreement:

(i) The term "information" means scientific or technical data, results or methods of research and development, and any other information intended to be provided or exchanged under this Agreement.

(ii) The term "proprietary information" means information which contains trade secrets or know-how or privileged or confidential, and may only include such privileged or confid

a) has been held in confidence by its owner;

b) is of a type which is customarily held in is onfidence by its owner:

c) has not been transmitted by the transmitting Party to other entities (including the receiving confidence; and

d) is not otherwise available to the receiving Party from another source without restriction on its further dissemination.

3. Procedures

(i) A Party receiving proprietary information pursuant to this Agreement shall respect the privileged nature thereof. Any document which contains proprietary information shall be clearly mark substantially similar) restrictive legend:

This document contains proprietary information furnished in confidence under the Agreement

between the United States Department of Energy and the Science and Technology Agency of Japan of (date) and shall not be disseminated outside these organizations, their contractors, and the concerned depart ments and agencies of the Government of the United States and Japan without prior approval of

This notice shall be marked on any reproduction hereof, in whole or in part. These limitations shall automatically terminate when this information is disclosed by the owner without

(ii) Proprietary information received in confidence under this Agreement may be disseminated by the receiving Party to:

a) pergons within or employed by the receiving 
Party and to concerned Government departments and Government agencies of the receiving Party and

b) prime contractors or subcontractors of the receiving Party located within the geographical limits of the Party's nations for use only within the framework of their contracts with the receiving Party in work relating to the subject matter of the proprietary information;

provided that any proprietary information so dissemlnated shall be pursuant to an agreement o confidentiality and shall be marked with restrictive legend substantially identical to that appearing in subparagraph $3(i)$ above.

(iii) With the prior written consent of the Party providing proprietary information under this Agreement, the receiving Party may disseminated such proprietary information more widely than otherwise permitted in with each other in developing procedures of wequesting and obtaining the prior written for grant such approval to the extent permitted by its national policies, regulations and laws.

4. If one of the Parties becomes aware that it will be, or may reasonably be expected to become, unable to meet the non-dissemination provisions of this Article, it shall immediately inform the other party. The Parties shall thereafter consult to define an appropriate course of action.

5. Information arising from seminars and other meetings arranged under this Agreement and information arising from the attachments of staff shall be treated by the Parties according to the principles specified in this Article; provided, however, no proprietary information orally communicated shall be subject to the 1 imited disclosure requirement of this Agreement unless the individual communicating such information places the recipient on notice as to the proprietary character of the information communicated.

\section{ARTICLE VII}

Information transmitted by one Party to the other Party under this Agreement shall be accurate to the best knowledge and belief of the transmitting Party, but the transmitting Party does not warrant the suitability of the information transmitted for any particular use or application by the
receiving party or by any third party. Information developed receiving Party or by any third Party. Information developed jointly by the parties shall be accurate to the best know accuracy of the jointly developed information or its suitability for any particular use or application by either Party or by any third Party.

\section{ART ICLE VIII}

1. With respect to any invention or discovery made or conceived in the course of or under this Agreement:

a. If made or conceived by personnel of one party (the Assigning Party.) or its contractors while assigned to the other Party (Receiving Party) or its contractors in connection with exchanges of scientists, engineers of other specialists:

(1) The Receiving Party shall acquire all rights, title and interest in and to any such

invention or discovery in its own country and in third countries, subject to a nonexclusive irrevocable, royalty-free license to the Assigning Party, with the right of the Assigning or discovery and any patent application, patent or aiscovery and any

(2) The Assigning Party shall acquire all right, title and interest in and to any such invention or discovery in its own country, subject to a nonexclusive, irrevocable, royalty-free license national designated by it

b. If made or conceived by a Party or its contractors as a direct result of employing information which has been communicated to it under this Agreement by another Party or its contractors or communicated during seminars or other joint meetings, the Party making the invention shall acquire all rights, title and interest in and to such inventions or discoveries in all countries. subject to a grant to the other Party its Government and its nationals designated by it of a royalty-free, nonexclusive, irrevocable license.

c. With regard to other specific forms of cooperation, the Parties shall provide for the appropriate distribution of rights to inventions or discoveries resulting from such cooperation, in accordance with paragraph 2 of Article III of this Agreement.

2. The provisions of the preceding paragraph 1 of this Article shall apply mutatis mutandis to the protection of 
3. Each Party shall, without prejudice to any rights of inventors or authors under its national laws, take all necessary steps to provide the cooperation from its inventors or authors required to carry out the provisions of this Article and Articles VI and IX. Each Party shall assume the responsibility to pay awards and compensation required to be paid to is own nationals according to its own laws.

\section{ARTICLE IX}

Copyrights of the Parties or of cooperating organizations and persons shall be accorded treatment consistent with internationally recognized standards of protection. As to copyrights on materials within the scope of paragraph 1 of Article VI owned or controlled by a Party, that Party shall make efforts to grant to the other Party a license to

reproduce copyrighted materials.

ARTICLE $X$

With respect to the exchange of staff under the Agreement:

1. Each Party may, at its own expense, observe test activities and analytical work of the other Party. Such observation may be exercised by short term visits written agreement of the receiving Parti on each occaision.

2. Whenever an exchange of staff is contemplated under this Agreement each Party shall ensure that qualified

3. Each such assignment of staff shall be the subject of a separate assignment aqreement between the parties.

4. Each Party shall be responsible for the salaries,

5. The sending party shall pay for the travel and living expenses of its staff while on assignment to the receiving Party unless otherwise agreed.

6. The receiving Party shall arrange for adequate accommodations for the assigned staff and their families on a mutually agreeable reciprocal basis.

7. The receiving Party shall provide all necessary assistance to the assigned staff and their families as regards administrative formalities (travel arrangements, etc.l.

B. The staff of each Party shall conform to the general and special rules of work and safety regulations in force at the host establishment, or as agreed in separate assignment agreements.

9. The Party proposing an attachment shall notify the receiving Party of the name of the persons proposed for the attachment and shall provide such information by the receiving Party.

\section{ARTICLE XI}

Both Parties agree that in the event equipment, instruments, materials or necessary spare parts (hereinafter referred to as "the equipment, etc.") are to be exchanged, loaned or supplied by one party to the other, the following provisions shall apply covering the shipment and use of the equipment, etc.

1. The sending party shall supply as soon as possible a detailed list of the equipment, etc. to be provided together with the relevant specifications and technical

2. The equipment, etc. supplied by the sending Party shall remain its property and shall be returned to the sending party upon conpletion of the mulually agreed writing.

3. The equipment, etc. shall be brought into operation at the host establishment only by mutual agreement between the parties.

4. The receiving party shall provide the necessary premises for the equipment, etc. and shall provide for technical requirements which shali' be mutually agreed.

\section{ARTICLE XII}

Performance of the Parties under this Agreement is subject to the availability of appropriated funds.

\section{ARTICLE XIII}

Cooperation under this Agreement shall be in accordance with the laws of the respective countries and the regulations of the respective Parties.

\section{ARTICLE XIV}

Compensation for damages incurred during the implementation of this Agreement shall be in accordance with the applicable laws of the countries of the parties.

ARTICLE X 
1. This Agreement shall enter into force upon signature and shall continue in force for ten years. The Agreement may be amended or extended by written agreement of each of the

Parties.

2. All activities not completed at the expiration of this Agreement may be continued

3. In the event that, during the period of this Agreement, the nature of either Party's radioactive waste management program should change substantially. whether this be by substantial expansion, reduction or transformation, or by amalgamation of major elements with the radioactive waste management program of a third party, either party shall have the right to request revisions in the scope and terms of this Agreement.

4. This Agreement may be terminated at any time at the

discretion of either Party upon six months advance notification

in writing by the Party seeking to terminate the Agreement.

Such termination shall be without prejudice to the rights

that may have accrued under this Agreement to either Party

up to the date of the termination. 
TABRE 1

Scope of Activities in Radioactive Waste Management

\begin{tabular}{|c|c|c|c|c|c|c|c|}
\hline $\begin{array}{l}\text { Activity } \\
\text { Waste } \\
\text { Type }\end{array}$ & $\begin{array}{l}\text { Catagorization } \\
\text { and } \\
\text { Determination }\end{array}$ & $\begin{array}{l}\text { Waste Form } \\
\text { Develop- } \\
\text { ment and } \\
\text { Character- } \\
\text { ization } \\
\text {. }\end{array}$ & $\begin{array}{l}\text { Treatment } \\
\text { Process } \\
\text { Develop- } \\
\text { ment and } \\
\text { Testing }\end{array}$ & $\begin{array}{l}\text { Byproduct } \\
\text { Reoovery }\end{array}$ & $\begin{array}{l}\text { Storage } \\
\text { and } \\
\text { Transpor- } \\
\text { tation }\end{array}$ & $\begin{array}{l}\text { Disposal } \\
\text { and } \\
\text { Isolation }\end{array}$ & DSD* \\
\hline Spent Fuel & & 2 & 6 & 6 & 11 & 12 & \\
\hline $\begin{array}{l}\text { High-Level } \\
\text { Waste }\end{array}$ & 1 & 3 & 7 & 7 & 11 & 12 & 13 \\
\hline $\begin{array}{l}\text { Transuranic } \\
\text { Waste }\end{array}$ & 1 & 4 & 8 & & 11 & 12 & 13 \\
\hline $\begin{array}{l}\text { Low-level } \\
\text { Waste }\end{array}$ & 1 & 5 & 9 & & 11 & 12 & 13 \\
\hline $\begin{array}{l}\text { Mill } \\
\text { Tailings }\end{array}$ & & & 10 & & 11 & 12 & 13 \\
\hline $\begin{array}{l}\text { Others } \\
\text { To Be } \\
\text { Determined }\end{array}$ & & & & & & & \\
\hline
\end{tabular}

1. waste sorting techniques; development and testing of radiological-assay instruments 2. spent-fuel perfomance testing under disposal conditions, both test development and application

3. Borosilicate glass optimization for various high-level waste canpositons; standardization of glass performance tests and applications to predict performance during

4. development of cement and metal waste forms for remote-handled wastes

5. development of grout waste forms

6. development of spent-fuel treatment processes including recovery of useful by-products

7. vitrification technology including useful by-product recovery, especially technology processing techniques and equipment for advanced waste forms

8. remote incineration, cementation and metal-melting technologies

9. grout processing and emplacement techniques

10. Stabilization techniques for tailing piles

11. storage-systens design and testing; container and cask design; handling and packaging techniques

12. develogment and application of in-place stabilization; assessment of deep geologic disposal systen performance; rock responses to thermal, mechanical, chemical and radiological stresses

13. vitrification, cementation, incineration and metal-melting equipment D\&D*; low-level and mill-tailing waste site clean-up techniques and applications

- Decontamination and Decomissioning 
RECORD OF

THE THIRD DOE/PNC JOINT WORKING GROUP MEETING ON WASTE MANAGEMEN'

JULY 9-13, 1984

TOKYO, TOKAI, O-ARAI ENGINEERING CENTER

JAPAN

The Third Meeting of the United States Department of Energy (DOE) and Power Reactor and Nuclear Fuel Development Corporation (PNC) Joint Working Group on Waste Management was held in Tokyo, Japan, on July 9 and 13, 1984, at PNC's Tokai Works on July 10 and 11, and at PNC's O-Arai Engineering Center on July 11. Visits to Nippon Atomic Industry Group Co., Ltd. (NAIG) and Ishikawajima-Harima Heavy Industries Co.. Ltd. (IHI) facilities were conducted on July 12.

The purpose of the Working Group Meeting was to review DOE and PNC waste management activities, to plan for future DOE and PNC actions in the waste management area, and to formulate recommendations for future activities.

Recommendations to the Joint Coordinating Committee (JCC) are included as Appendix $I$ to this record. Appendix II is a listing of agreements reached by the Joint Working Group. The agenda for the meeting is listed in Appendix III, and the list of participants is given in Appendix IV.

The two delegations note that the stated purpose of the meeting was satisfactorily attained, reflecting the commitment of both parties to maintain the positive and productive nature of this exchange.

FOR TUE LNTTED STATES DEPARTMENT OF ENERGY

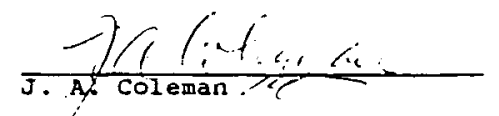

July 13, 1984
FOR THE POWER REACTOR AND NUCLEAR FUEL DEVELOPMENT CORPORATION

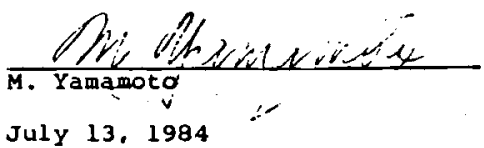

LISTING OF AGREEMENTS MADE AT

THIRD DOE/PNC JOINT WORKING GROUP

ON WASTE MANAGEMENT

JULY 9-13, 1984

JAPAN

1. Because the PNC working group chairman, Mr. S. Araya, was incapacitated, Mr. M. Yamamoto acted as PNC cheirman of this meeting.

2. Dr.J.A. Coleman from USDOE and Mr. S. Araya of PNC will be the Chairmen of the Waste Management Working Group.

3. A proposed General Agreement (see Attachment 1) between DOE and PNC in the area of radioactive waste management was presented by DOE to PNC. It was agreed that this proposal would form a basis for negotiations subsequent to this meeting with the goal of reaching agreement by the next Working Group meeting. The Working Group chairmen will act as correspondents on this matter.

Any disclosure of this proposal and its negotiation to a third party may be made only by mutual agreement.

4. A proposed Annex to the General Agreement (see Attachment 2) (nier after called the Project Agreement) for PNC-DOE collaborative testing of the radioactive liquid-fed ceramic melter was presented by DOE to PNC.

It was agreed that this Project Agreement will be treated henceforth as a separate agreement with the goal to complete the project Agreement in three months. 
5. Project Agreements are intended to provide a balanced technology exchange between DOE and PNC.

PNC will pay for the net benefits derived from DOE, and DOE will pay for net benefits derived from PNC. Payment formulas will be determined by Working Group Chairmen based upon an assessment of net benefits.

6. PNC wishes to participate in a program of collaborative testing of the radioactive liquid-fed ceramic melter. with Attachment 2 as the basis for the final project

Agreesent. DOE will submit a revised Project Agreement to PNC for approval in the next few weeks.

7. DOE and PNC agreed that Mr. Shinichiro Torata of PNC will begin an assignment at PNL as soon as possible (August 1, 1984. as target date).

Mr. Torata's continued stay at PNL will be contingent upon final approval by DOE and PNC of the Project Agreement in item 6 above. [NOTE: Although final details of the assignment will await the approved Project Agreement, it is planned that the assignment be for one year. subject to renewal ].

8. PNC agreed that if participation in the West Valley Demonstration Project is desired, a formal request will be submitted to DOE. DOE would welcome such a proposal from PNC.

9. DOE and PNC agreed that visit requests to PNC and DOE facilities shall be based on established formal visit request procedures. Visits pertaining to the activities of the Waste Management Working Group will henceforth have the endorsement of the Working Group chairman of the visitor's country.
10. Since many DOE sites in the waste management area have activities in both the civilian and defense waste programs, visitor access to all sites may be very difficult. It was agreed that DOE would do its best to honor site visit requests in accord with guidelines in item 9 above.

11. The Specialists Meeting on HLW Vitrification will be held in the Spring of 1985 in the United States. The technical coordinators for HLW will act as correspondents to further define this meeting's details.

12. Mr. JL McElroy of Battelle PNL will replace Mr. LT Lakey of PNL as DOE technical coordinator for HLW.

13. The Fourth Meeting of the DOE/PNC Joint Working Group on Waste Management will be held in the United States in the fourth quarter of $\mathrm{CY}-1985$. 


\section{KOREA (ROK)}

\section{STATUS/PLANNING REPORTS}

1. Summary Record of the US/ROK Eighth Joint Standing Committee Meeting on Nuclear and other Energy Technologies--US, 06/84 (Attachment KS-1)

2. Excerpt from Protocol of Joint US/ROK Technical Information Exchange Meeting--ROK, 04/85 (Attachment KS-2) 
SUMPARY PECORD OF

THE EIGHTH PREPARATORY MEETING OF THE U.S.-REPUBLIC OF KOREA JOINT STANDIIG COMMITTEE ON NUCLEAR AND OTHER ENERGY
TECHNOLCGIES

June $21-22,1984$

WASH INGTON, D.C.

The eighth preparatory meeting of the Joint Standing Committee on Nuclear and Other Energy Technologies was held during June 21 and 22 at the U.S. Department of State for the purpose of continuing our cooperation in the peaceful uses of nuclear and other energy technologies.

The Korean delegation was headed by the Director General of the Atomic Energy Bureau, Dr. Shiyolil Park and the U.S. delegation was headed by Dr. Allen Sessoms, Director, Office of Nuclear Technology and Safeguards, Bureau of Oceans and International Environmental and Scientific Affairs of the Department of State.

The two delegations agreed to the summary record of the eight preparatory meeting of the Joint Standing Committee.

Annex $A$ is the Agenda for this meeting and Annex $B$ is a list of participants. The report on the Agenda items follows:

1. MOST - NRC COOPERATION

\section{A. Training of Regulatory Personnel}

NRC reviewed ROK participation in on-the-job training with NRC: one long-term assignee is currently at NRC; two long-term assignees are approved and expected to start at INR later this year; and 4-5 applicants are proposed for placement.

NRC also noted that two staff members are presently in Korea as lecturers in the Argonne-IAEA advanced training course on safety analysis review, and that one lecturer will be provided to the Argonne-IAEA emergency planning course in korea in late August.

RoK noted its commitment to an earlier objective of providing regulatory and safety training to 109 personnel with particular emphasis on inspection and test fields although the original schedule may have to be adjusted to allow some additional time to accomplish this.

\section{B. Emergency Preparedness}

NRC received a letter from MOST which responds to recent correspondence from TRC and will form the basis for future NRC-MOST activities.

The IJRC Operations Center will not be in a position to participate in the September 1984 exercise at KORI.

The US will examine the feasibility and alternate methods for financing US experts to attend the KORI exercise. The experts, if they attend, will act as consultants to MOST.

In principle both NRC and MOST are interested in utilizing the IAEA to promote the ROK emergency preparedness program, especially in upgrading capabilities. However, for the September 1984 exercise, the ROK is not considering the participation of a multinational group of IAEA experts but participation of us experts.

\section{Other}

\section{(1) NSIC Data Tapes}

On May 30. MTRC sent three magnetic tapes to KAERI containing the complete NSIC data file, both License Event Reports (LER) and general safety information.

Updating of the LER data will be done on an annual basis at no cost to Korea. (Other data will not be updated by NRC.)

In return for the data file and in the spirit of reciprocal cooperation, NRC wishes to receive reports of significant incidents (Korean language is acceptable) routinely and any analyses or evaluations that use the U.S. LER data. ROK indicated they planned to provide such reports.

(2) U.S. Offer to Cooperate with INWS on Waste Storage and Disposal (Under the Ifuclear Waste Policy Act

NRC, on January 26,1984 , transmitted to MOST/AEB all currently available NRC documents on nuclear waste storage and disposal. These documents were provided to give the ROK a better understanding of the regulatory work under way in the U.S. and of the information available to the ROK in the U. these documents, the ROK was to suggest areas for possible waste management cooperation with NRC. 


\section{(3) Transportation Cask Information}

NRC recently sent detailed information to MOST/AEB regarding licensing reviews of transportation casks. Some and MOST/AEB was referred directly to the U.S. licensees.

2. KAERI-MRC COOPERATION

\section{A. Joint Study on Severe Accident Programs}

KAERI, by letter dated May 11, 1984 from Dr. Pil Soun Han, officially notified NRC's research office that it was prepare to join the severe accident research program for a period of three years beginning in llay 1984. Wording of the proposed NRC-KAERI agreement was discussed during this meeting and both parties expect to sign a formal agreement in the near future.

As a separate matter, the RoK indicated that it has under consideration NRC's offer of participation in another U.S. research activity, the Steam Generator Project.

\section{B. Tzaining Course for Nuclear Power Plant Inspectors.}

ROK requested U.S. support of a 5-week training course for nuclear power plant inspectors to be held at KAERI in November 1984. The course would be carried out by Argonne tational Lavoratory (Division of Educational Programs) as part of the IAEA technical cooperation program. KAFRI is seeking u.s. funding support of the training course as an IAEA "Footnote $A$ " funding support inspectors to serve as lecturers. $s$. will check the status of this proposal with IAEA and Argonne, including funding options and scheduling problems, if any. NRC will cooperate. within available manpower resources, to identify possible lecturers.

\section{STATUS OF POST IRPADIATION EXAMIIATICN OF REACTOR FUEL}

A Report was given on the status of the Republic of Korea request for a joint determination with respect to the post irradiation examination of spent fuel from the kori-1 reactor (12 assemblies for 1985-88 period) to determine the cause of fuel failures experienced over a period of time.
It was reported by the us delegation that the request by the ROK had formally been received on May 10 and that the required review by the Department of Energy had been completed. On May 22, the recommendations and findings of the Department of Energy were submitted to other U.S. Agencies for their required review and comment. Upon completion of the review process, expected in the near future, a federal register notice of the proposed joint determination will be published and, barring any problems, the joint determination will be approved by the U.S.

The Korean Delegation reported that a final notice had been received on June 1 from the IAEA with respect to the facility attachment for the post irradiation facility and was under review by the ROK.

This agenda item is essentially complete and no further action is required unless, and this is not expected, problems arise.

\section{COOPERATION BETWEEN U.S. AND ROK UTILITIES}

The rok expressed its desire in entering into a cooperative arrangement between Kepco and a U.S. Utility such as TVA. A major objective is to exchange information and experience in all fields of management of an electric power company. The U.S. explained that since utilities are in the private sector, the Government cannot direct a utility to enter into such an agreenent. Commonwealth Ldison and Dulie Power were suggested as possible alternates to TVA. Direct communication between kepco and U.S. utilities was recommended by the U.S. As to government assistance. the U.S is prepared to introduce kepco to a utility fointing out the value of cooperation from the U.S. government point of view.

\section{COOPERATION ON SPENT FUEL STORAGE}

The U.S. and ROF agreed on steps to be taken for further cooperation on spent nuclear fuel storage under section 223 of the iuclear Waste Policy Act. Discussions on areas of cooperation were initiated during the Seventh JSCNOET meeting in Seoul, October 27 through November 4, 1983, and the meeting in conjunction with the DOE sponsored U.S. Civilian Radioactive Waste llanagement Information Heeting in Washington, D.C.. in December 1983. The cooperative program is described below. 


\section{Cooperative Program on Gpent Fuel Storage}

\section{a. Objectives and Justification}

This proposal is a follow-up to "US/Rok Joint Study on Spent Fuel Management," the final report of which was (KAnRI) with the assistance of US DOE and reported to tus/ROK Joint standing c (J) SSNOET )"

At the 7 th meeting of JSCrOET, the following areas were recommend as potential areas of cooperation betwcen the Ror and the us DOL, under section 223 of the Nuclear waste Policy Act of 1982:

(1) U.S. provision of technical expert advice on the assess ment of the technical feasibility of increasing at reactor (AR) storage.

(2) ROK participation in the US DOE-Utility Cooperative Spent Fuel Storage Demonstrations Projects to the extent that the U.S. utilitiss can accommodate such participation.

(3) RoK participation in engineering design of monitored retrievable storage (Mns) facilities at appropriate -tages of the design effort.

(4) Cooperation in the area of geologic repository R\&D.

Accordingly, the following areas of cooperation and responsibility were established:

\section{b. Work Scope}

Invitation for U.S. experts to advise KEPCO/KAERI on the assessment of the technical feasibility of increasing storage at existing nuclear power plants $(A \Omega)$ and away-fromreactor storage in (AFR) Korea.

Participation of ROK staff by assigning KEPCO/KAERI researchers to U.S. DOE-Utility spent Fuel Storage Demonstrations Projects such as:

- DCE's cask storage test at GE's-Morzis, III. site.

- CP\&L's concrete silo storage at H.B. Robinson site.

- TVA's cask storage with consolidated fuel at Browns Ferry Site.
- VEPCO's metal cask storage at DOE site.

(Scheduling subject to site operator approval)

Assessment of the feasibility of joint development of rod consolidation technology. It may be appropriate to initiate a rod consolidation demonstration project facility of facility of KAERI with the assistance of U.S. experts.

Informing ROK of the status of U.S. MRS and repository design through briefings and reports.

\section{c. Implementation Plan}

\section{Invitation of US Experts}

\begin{tabular}{|c|c|c|c|}
\hline Institution & No. of Experts & Period & Field \\
\hline $\begin{array}{l}\text { DOE/PNL } \\
\text { US Utility }\end{array}$ & 1 & $\begin{array}{l}2 \text { week visit } \\
\text { to Korea } \\
\text { in February } \\
1985\end{array}$ & $\begin{array}{l}\text { Advice on the the assessment } \\
\text { of Rck spent fuel storage } \\
\text { capacity expansion }\end{array}$ \\
\hline & RCK Staff & articipation at & Us sites \\
\hline Institution & No. of Experts & Period & Field \\
\hline $\begin{array}{l}\text { KAERI } \\
\text { KEPCO }\end{array}$ & $\begin{array}{l}1 \\
1-2\end{array}$ & $\begin{array}{l}2 \text { months } \\
\text { (Sep-Oct } 84)\end{array}$ & $\begin{array}{l}\text { Visit PNL for briefings and } \\
\text { observe storage cask test at } \\
\text { at GE. Morris. Also observe } \\
\text { rod consolidation test at } \\
\text { Browns Ferry }\end{array}$ \\
\hline
\end{tabular}

(as an alternative or in addition, a visit in March and April, 1985 to observe VEPCO storage cask tests at DOE site) 
Joint Rod Consolidation and Transportation Project

\begin{tabular}{|c|c|c|c|}
\hline Institution & Field & Period & Remark \\
\hline KAERI-PML & $\begin{array}{l}\text { Rod consoli- } \\
\text { dation s ship- } \\
\text { ment of } \\
\text { consolidated } \\
\text { fuel in a } \\
\text { transport } \\
\text { cask }\end{array}$ & $1985-1987$ & $\begin{array}{l}\text { Perform feasibility and } \\
\text { develop proposal for } \\
\text { joint demonstration project } \\
\text { to be carried out at PIE } \\
\text { facility of KAERI. KAERI } \\
\text { will assess technical } \\
\text { feasibility of demonstration } \\
\text { projects and develop pro- } \\
\text { posal. PNL expert will } \\
\text { review proposal and dis- } \\
\text { cuss with KAERI during } \\
\text { visit to Korea in } 2 / 85 \text {. } \\
\text { Final action on proposal } \\
\text { will be discussed as part } \\
\text { of ninth JSCIOET meeting } \\
\text { in seoul in } 1985 \text {. }\end{array}$ \\
\hline
\end{tabular}

Informing ROK on MRS and Geologic Repository Designs

KOPEC/KAERI/PEL

Brief ROK on MRS design prior

URS

$1984-85$

DOE

$\begin{array}{ll}\text { Geologic } & 1984 \& \\ \text { Repository } & \text { beyond }\end{array}$

Design

beyond

to Sept. 85, perhaps as part

of Ninth JSCNOET meeting.

Provide KAERI appropriate

documents on geologic

repository designs as they become available. Also provide periodic briefings as part of the annual JSCNOET meetings.

\section{d. Budget Estimation and Funding Arrangements}

Invitation of U.S. Experts to ROK on AR Expansion:

Round trip air travel expenses and living expenses will be borne by KEPCO/KAERI.

Korean Staff Participation:

Travel and living expenses will be borne by KEPCO/KAERI.

Joint Demonstration Project on Rod

Consolidation/Transportation:

IKAERI provides hardware, while operating expenses for each side will be borne by each side.

Informing Rok on MRS and Geologic Repository Designs:

Expenses for each side will be borne by each side.

\section{COORERATION ON ENERGY CONSERVATION}

Numerous documents on various aspects of the Building Energy Research Program were provided to Dr. Won-Hoon Park, Vice President for Energy of KIER during the course of the detailed work session. This material will be reviewed and discussed by the personnel of the Ministry of Energy and Resources and Korea Energy Management Corporation and KIER. This process should serve to identify specific areas of mutual interest with a goal towards defining an appropriate agenda for a future conservation work shop. In the interim any questions and/or any additional materials required will be provided through correspondence with identified personnel within the $B E$ $R \& D$ organization.

RCK recommends at least six months preparation period for any future workshop to be successfully organized and executed. It is also advised that coordinating institutes and a coordinator from both countries should be designated as was done in the exemplary case of the first joint workshop on coal utilization technology coordiated by PETC and KIER organization.

\section{A. JOINT STUDY ON COAL UTILIZATION TECHHOLCGY DEVELOPMENT}

Based upon a 1981 Memorandum of Understanding between the U.S. Department of Energy (DOE) and the Korea Ministry of Science and Technology (MOST), a cooperative laboratory relationship was established anong the Pittsburg Energy 
Technology Center (PETC) of the DOE, the Korea Institute of Energy and Rsources (KIER), and the Korea Advanced Institute of Science and Technology (KAIST). This relationship specifically identifies cooperation in the areas of (1) exchange of coal-related technical information, (2) assignment of KIER/KAIST staff to PETC for periods of technical training up to one year, and (3) provision of technical consultations to KIER/KAIST on coal utilization technologies.

Since the establishment of this relationship, over twenty KIER personnel have visited PETC for purposes of technical and/or administrative consultation. Technical reports, journal articles, and proceedings of meetings have been made available to KIER when requested. Assistance has been provided to KIER in processing ten tons of low-grade Korean anthracite coal for cleanability testing at the Ames Laboratory of Iowa state University.

This relationship is continuing in all areas of activity as specified in the original Memorandum of Understanding. A Workshop on Coal Utilization Technology is being organized jointly by KIER and PETC, and will be held in Korea during October, 1984. The goals of this workshop are first, to acquaint korean industrialists, scientists, and engineers with U.S. coal utilization technologies, and second, to provide an information exchange forum for potential U.S. exporters of utilization technolcgy and potential korean importers of such technologies.

Additionally, under the provisions of the memorandum of understanding calling for the provision of technical consultation, the DOE will investigate the possibility of supporting the KIER feasibility study on Fluidized Bed Combusion. The support anticipated may be in the form of technical advice and guidance to KIER, either through training of KIER engineers at U.S. facilities, or by providing short-tern visits of U.S. experts to KIER facilities.

Wo further actions appear to be required at this time.

\section{B. NIW AND RENEWABLE ENERGY DEVELOPMENT}

The Korea delegation was broadly informed of US activities in the use of renewable resources (solar, geothermal, organic materials.) The Korean delegation expressed particular

interest in passive solar, wind and ocean energy technologies. Documents on the three programs were provided to Dr. Park of

the ROK delegation. The korean delegation expressed immediate interest in passive solar technology and its implementation as a specific area of future cooperation.

\section{RENSSESSHELT OF JSCNOE'}

This Item was brought up by Director General Park as follows: The Joint Standing Committee was formed in 1977 and this is now the eighth meeting. It is appropriate at this time to assess and evaluate the scope, objectives and products of our cooperation in relationship to the needs and capabilities of our two countries. Retrospectively, knrea characterized the past cooperation, while highly constructlve and beneficial, as relatively narrow, that is a limited exchange of staff and information in non-sensitive areas. They proposed that we mutually re-evaluate and assess JSCHOET and discuss the results of both countries assessment at the ninth preparatory meeting. They hope that we can work together to upgrade the scope and level of cooperation including amendment of the bilateral agreement for atomic energy cooperation.

The U.S. response was that we saw a positive benefit to a U.S. assessment of JSCNCET at this time and would so recommend. 
The final report of the eighth preparatory meeting of ISCNOET was submitted to the delegation heads for approval.

APPROVED FOR REPUBLIC OF KOREA:

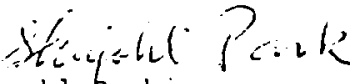

$$
\begin{aligned}
& \text { shiyohl. park: } \\
& \text { Director General. }
\end{aligned}
$$

APPROVED FOR THE UNITED STATES:

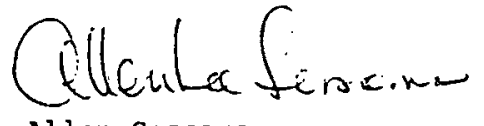

Allen Sessoms.

Director

Office of Nuclear Technology and

Safeguards,

Department of state. 


\section{RECOMMENDATIONS FOR FURTHER COOPERATION}

PROTOCOL

OVERALL CONCLUSIONS

\section{RECOMMENDATIONS}

FUTURE COOPERATION:

\section{Prepared and Reviewed}

by

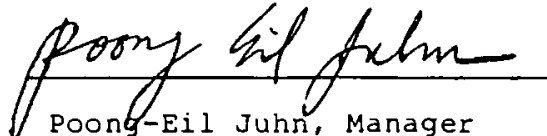

Nuclear Policy Department

Korea Advanc:ed Energy

Research Inititute

Republic of Korea

\section{Lauel Z. Hewnen}

Darrell F. Newman, ïanager Cominercial Spent Fuel

lianagement

Paciric Nortinest Laboratory USA
Based on technnical discussions held during the meetings in Korea between ROK and USA experts on spent fuel and waste management, the following recommendations are made for further cooperation.

1. OBSERVATION OF TESTS AND DEMONSTRATIONS IN THE USA BY KAERI AND KEPCO TECHNICAL STAFF

A. Observe and document reracking of North Anna spent fuel pool by Virginia Power in June 1985. Stainless steel racks of 14 -inch spacing will be replaced with poisoned racks of 10-inch spacing using divers in the pool while spent fuel is present. Video tape the operation and provide a copy to KAERI.

Observe Ti-8 transportation cask loading at surry for shipment to INEL.

B. Observe the large metal dry storage cask tests at Idaho National Engineering Laboratory in May 1986. Two transportable dry storage casks shipped from West Valley, NY, will be in monitored storage. Three large metal dry storage casks will be under test for Virginia Power with unconsolidated spent fuel. The dry rod consolidation equipment in the TA:-607 Eacilicy at INEL, which is being developed to consolidate 96 PWR assemblies from Virginia Power, could be observed.

C. Observe the hot demonstration of consolidation of rods from the first 10 PWR assemblies at Northeast Utilities Service Company's Millstone-2 reactor pool following NRC's licensing of this operation expected in 1987. The exact date of this observation visit will be established once the NRC license is issued. 
D. Observe dry rod consolidation demonstration in TAN-607 facility at INEL disassemble PWR spent fuel assemblies into a round canister for storage at liRS or disposal

in geologic repository. Estimated date is in 1988, but exact date will be discussed at future meetings of Joint Standing Committee.

2 OBSERVATION OF TESTS AND DEMONSTRATIOHS IN KOREA BY USA TECHNICAL STAFF

A. Observe the hot demonstration of PWR rod consolidation at the PIE facility in Daeduk using Ko-Ri spent fuel Videotape the operation and provide copy to the USA.

The date will be discussed later at the JSCNOET meeting. 
SPAIM (SP)

BLANKET AGREEMENT (Attachment SP-1)

SUBSIDIARY AGREEMENTS

None

STATUS/PLANNING REPORTS

None

ADMINISTRATION

Principal US Coordinator: M. Sol iman (DOE/IE)

Document Exchange: see Appendix C 


\section{COMPLEMENTARY AGREEMENT SEVEN}

Scientific, Technological, Cultural,

Educational and Economic Cooperation

\section{ARTICLE 1}

1.1 The Government of the United States of America and the Government of Spain, hereinafter referred to as the Parties, aware of the importance of scientific, technological, cultural, educational, and economic cooperation for the strengthening of the traditional friendship and understanding between their peoples, agree to expand cooperation in these fields.

1.2 Cooperation and activities in these fields will be subject to the legislative requirements of the two Parties, including the annual appropriation of funds.
2.1 Scientific and technological cooperation will be carried out primarily in those areas of applied research and technology that will be most relevant to the economic modernization and social well-being of the peoples of the United States and Spain.

2.2 Cultural and educational cooperation will be aimed at promoting mutual understanding of the achievements of the United States and Spain in those areas.

2.3 Economic cooperation will focus on economic issues of mutual interest to both countries.

2.4 For the purposes of the implementation of this Agreement, a United States-Spanish Joint Committee for each of the above three areas will be established.

Scientific and Technological Cooperation ARTICLE 3

In the context of scientific and technological cooperation, the following areas will merit special consideration and activity: nuclear and non-nuclear energy, industrialization, agriculture, environment, health, natural resources, and such other areas as may be mutually agreed. 


\section{ARTICLE 4}

The planning and carrying out of scientific and technological cooperation between thertwo Parties will be based on the following principles:

(a) The mutuality of interest and the overall benefits of their cooperation,

(b) The selection of specific scientific and technological fields relevant to achieving the goals of this Agreement, and

(c) The encouragement of cooperation between institutions, organizations, and agencies of the two countries.

\section{ARTICLE 5}

Scientific and technological cooperation under this Agreement may include:

(a) Joint or coordinated planning, support, or implementation of projects and the supply of equipment,

(b) Exchange of scientific, academic, and technological information, (c) Establishment, operation, and joint utilization of scientific and technical installations related to cooperative projects and activities conducted under this Agreement,

(d) Exchange of scientific and technical personnel related to cooperative projects and activities conducted under this Agreement, and

(e) Other forms of scientific and technological cooperation as may be mutually agreed.

\section{ARTICLE 6}

Subject to approval by the Joint Committee for. Scientific and Technological Cooperation, institutions, organizations, and agencies may enter into specific agreements for the appropriate implementation of cooperative programs in the areas listed in Article 5 of this Agreement as well as in other areas as may be mutually agreed. 
ARTICLE 7

7.1 Cooperation in science and technology shall be coordinated through the Joint Committee for Scientific and Technological Cooperation. Co-chairmanship of the Joint Committee will be shared by the Department of State and the Ministry of Foreign Affairs. This Committee will be composed of members appointed by the respective Parties.

7.2 The Joint Committee shall be responsible for:

(a) Formulating programs of scientific and technical cooperation between the two countries,

(b) Reviewing programs, activities, and operations, including the preparation of an annual report;

(c) Following up and evaluating projects, activities and operations,

(d) Recommending to the Parties modification, postponement, or termination of programs and projects, and

(e) Such further functions as may be agreed upon between the Parties.
7.3 The Joint Committee will have a Permanent Secretary who will also serve as Secretary of the Spanish section of the Joint Committee.

7.4 The Joint Committee will meet at least once a year, alternately in the United States and Spain.

\section{ARTICLE 8}

8.1 Scientific and technical information of a nonproprietary nature derived from cooperative activities under this Agreement shall be made available to the world scientific community through customary channels and in accordance with the normal procedures of the Parties.

\subsubsection{Matters relating to patent and other} intellectual property rights that result from cooperative programs under this Agreement shall be provided for in the implementing agreement defining the cooperative program. Such property rights shall normally be acquired by each Party in its own country subject to

a non-exclusive, irrevocable license of the other Party. 
8.2.2 The allocation of patents and other intellectual property rights in third countries shall be provided for on an equitable basis in the implementing agreements referred to in Article 8.2 .1 of this Agreement.

Cultural and Educational cooperation ARTICLE 9

In the context of cultural and educational cooperation, the following will be given special consideration:

(a) The improvement of the Spanish educational system.

(b) The provision of documents and bibliographic, didactic and research material-to Spanish universities and other centers of higher learning and research,

(c) The expansion of exchanges in the cultural and educational sectorsi and

(d) Other programs as may be mutually agreed.

\section{ARTICLE 10}

The Parties will cooperate in the expansion and development of research and in the formation and specialization of teaching and research personnel. To that end, as well as in order to carry out concrete research projects, scholarships, travel grants, and assistance will be given to nationals and institutions of both countries.

The same type of assistance will be given to nationals of both countries to perfect their training in the fine arts field.

\section{ARTICLE II}

The Parties will encourage relationships and cooperation between universities and institutions of higher learning of both countries. 


\section{ARTICLE 12}

The Parties consider it a.matter of special interest to increase the knowledge of their respective languages by encouraging the activities of institutions and organizations engaged in the teaching of spanish and of English in each of the two countries.

To that end, interchanges of teachers of spanish and English will be encouraged.

\section{ARTICLE 13}

The Parties, wishing to encourage the best reciprocal knowledge of their respective cultures, will facilitate exchanges in this area and will, particularly, support activities aimed at the spreading of Spanish culture in the United States while at the same time encouraging the work of institutions and organizations engaged in similar activities in spain with respect to the culture of the United States.
ARTICLE 14

The Parties recognize the importance of the Fulbright/hays program in promoting cultural and educational exchanges between the two countries. The Commission for Educational Exchange between the United States of America and Spain and the Joint Committee for Cultural and Educational Cooperation will coordinate their activities in these fields. The parties will contribute regularly to the financing of the Fulbright/ Hays program.

\section{ARTICLE 15}

15.1 Cooperation in culture and education shall be coordinated through the Joint Committee for Cultural and Educational Cooperation. Co-chairmanship of the Joint committee will be shared by the United states International Communication Agency and the Ministry of Foreign Affairs. The Committee will be composed of members designated by the Parties. 
15.2 The Joint Committee shall be responsible for:

(a) Establishing cultural and educational cooperation programs and exchanges-of-persons programs. Likewise, the Joint Committee will examine programs of social interest which both parties agree to be of mutual benefit.

(b) Drafting and making public the official announcements of said programs;

(c) Selecting the projects submitted in response to the above-mentioned announcements, granting the scholarships, assistance, and travel grants;

(d) Reviewing programs, activities, and operations, including the preparation of an annual reports

(e) Following up and evaluating programs, activities, and operations; and

(E) Recommending to the parties modification, postponement, or termination of programs.
15.3 The Joint Committee will have a Permanent Secretary who will also serve as Secretary of the Spanish section of the Joint committee.

15.4 The committee will meet at least once a year at a place and date agreed to by the parties.

General Articles on Scientific,

Technological, Cultural and Educational Cooperation

\section{ARTICLE 16}

16.1 Funding for scientific, technological, cultural, and educational cooperation shall be as follows: (a) Programs jointly financed as agreed by the Parties;

(b) Programs in which each agency, organization, or institution will, in general, bear the costs pertaining to its obligations, and

(c) Programs that may be financed by private institutions or foundations from one or both countries as appropriate.

16.2 Programs under (b) and (c) above may also receive funds from the appropriate Joint Comittee. 
ARTICLE 17

The Parties agree to the creation of an Executive Secretariat responsible for the administrative functions as required for the implementation of the Agreement. The Secretariat will have its seat in Madrid, its Executive Secretary will be appointed by the United States-Spanish Council, and it will be provided with the funds needed for its operation by the Joint committees.

\section{ARTICLE 18}

The Parties will facilitate, consistent with law, the entry and exit of equipment and material to be utilized in cooperative activities conducted under this Agreement, as well as the personal effects of personnel and their dependents connected with programs under this Agreement.

\section{ARTICLE 19}

Nothing in this Agreement shall preclude or prejudice scientific, technological, cultural, or educational cooperation outside the terms of this Agreement by institutions, organizations, or agencies of the United States or Spain or by nationals of either country with each other or with third parties.

\section{ARTICLE 20}

Institutions, organizations, or agencies of third countries may participate in cooperative programs or activities with the approval of the Parties.

ARTICLE 21

Programs and activities currently in force and established by the competent authorities shall not be affected by this Agreement. However, they may be included in this Agreement when both Parties so decide. 
Economic Cooperation

ARTICLE 22

In their economic relations, the Parties will be guided by the common desire to promote economic growth, expand opportunities for trade in a balanced way, and develop other aspects of their economic relations of mutual interest to both countries.

\section{ART ICLE 23}

The Parties will endeavor to adopt appropriate measures to facilitate, in accordance with their national legislation, direct capital investment in their territory that nationals of the other Party may undertake.

\section{ARTICLE 24}

24.1. The Parties agree to establish a regular system of consultations on economic matters of common interest. To this end, a Joint Economic Committee is established within the framework of the United States-Spanish Council.
24.2 The Joint Economic Committee will have as its basic functions the following:

(a) To analyze bilateral economic relations,

(b) To exchange information on the principal domestic or international subjects of interest to both countries,

(c) To seek to resolve economic problems that may arise:

(d) To formulate appropriate recommendations to expand economic cooperation between both Parties.

24.3 The Joint Economic Committee will meet at the request of one of the parties, and in any event at least once a year.

\section{ARTICLE 25 \\ Entry into Force}

This Agreement shall enter into force and remain in force in accordance with the provisions of Article Six of the Agreement on Friendship, Defense and Cooperation. 
Done in Madrid this 2nd day of July, 1982, in duplicate, in the English and Spanish languages, both texts being equally authentic.

FOR THE UNITED STATES

OF AMERICA:

Herence $A$. Dodmen
FOR THE RINGDOM OF SPAIN:

- P. R. Mosra 



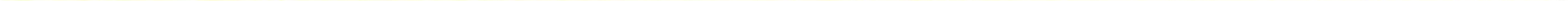




\section{SWEDEN (SW)}

BLANKET AGREEMENT (Attachment SW-1)

Parties: $\quad$ US/DOE; Sweden/Swedish Nuclear Fuel Supply Company (SKB)

Term:

July 1, 1977 to September 9, 1985

Technical Scope: Preparation and packaging of waste forms; surface and subsurface storage; geologic disposal; environmental and safety matters; institutional and public relationships

\section{SUBSIDIARY AGREEMENTS}

1. In situ tests at Stripa (NEA project; Attachment NEA-2)

2. International Nuclide IRAnsport CQde INtercomparison Study (INTRACOIN--Attachment SW-2)

3. HYDROlogic COde INtercomparison (HYDROCOIN--Attachment SW-3)

\section{STATUS/PLANNING REPORTS}

Excerpt from C. R. Cole (PNL) travel report for the First HYDROCOIN Coordinating Group Meeting--Stockholm, 10/84 (Attachment SW-4)

Excerpt from meeting minutes of US/SW Bilateral Meeting--US, 05/84 as reported by S. A. Mann (DOE-CRPO) (Attachment SW-5)

\section{ADMINISTRATION}

Principal Coordinators: US -- C. R. Cooley (DOE)

Document Exchange: see Appendix C 
AGREEMENT BETWEEN THE UNITED STATES DEPARTMENT OF ENERGY

AND THE SWEDISH NUCLEAR FUEL SUPPLY COMPANY

AB SVENSK KARNBRANSLFFORSORJUING) CONCERNING

A COOPERATIVE PROGRAM IN THE FIELD OF MANAGEMENT OF RADIOACTIVE WASTES

Whereas the Government of the United States of America and the Covernment of Sweden have signed an Agreesent for. Cooperation concerning peaceful uses of atom1c energy on July 28, 1966, as amended;

Whereas the Un1ted States Department of Energy (hereinafter referred to as DOE) and the Swed1sh Nuclear Fuel Supply Company (herelnafter referred to as SKBF) recognize the advantages of sharing information derived from the agreement to cooperate on radioactive waste storage in deep geological formatlons s1gned on July 1, 1977;

Whereas DOE and SKBF share common nonprollferation objectives and consequently have mutual interests in further comon development of rad10active waste management technology with a view to Improving the use of nuclear technology while minimizing the risks of prollferation;

Whereas DOE and SKBF noting the respective statutory authority of DOE and SKBF to disseminate information related to nuclear energy; and desiring to engage in specific cooperative arrangements to exchange a broad range of Information concerning radioactive waste management that includes the el ternatives of disposal of separated waste products and the disposal of Bpent fuel; have agreed to expand the cooperation as follows:
ARTICLE 1

The objective of cooperation under this Agreement is to maintain, for the mutual benefit of the Parties, a reasonable balanced exchange of information In the area of the management of radioactive wastes; to engage in cooperative programs for fleld-testing experiments and techniques related to weasuring the performance characteristics of a grantic rock system, utilizing the Str1pa miue in Sweden, 10 order to assess the sultab1l1ty of such rock types for terminal storage of radioactive material.

The areas and forms.of cooperation are listed in Article 2 and Article 3.

\section{ARTICLE 2}

The areas of cooperation covered by this Agreement may include:

1. Preparation and packaging of waste forms;

2. Surface and Subsurface storage;

3. Characterization of geologic formations;

4. Field and laboratory testing;

5. Disposal in geologic formations;

6. Operational considerations;

7. Enviromental and safety considerations;

8. Institutional and public relationships.

Other areas may be added by the Parties by mutual agreement in writing. 


\section{ARTICLE 3}

Specific cooperation in accordance with this Agreement, shall be decided by the Partles through the Coordinators or their designee. It 1 agreed that such cooperation may include, but is not limited to, the following:

1. Exchange of scientists, englneers and other speclalists in accordance wh Article 10 of this Agreement.

2. Exchange of samples, materials, instruments and components for testing.

3. Exchange, on a current basis, of scientific and technical information, and results and methods of reseasch and development.

4. The organization of seminars and other meetings on specific agreed toplcs concerning waste management technologies in the areas listed in Article 2, In a manner agreed by the coordinators (Article 4 ).

5. Short visits by speclalist teams or Individuals to the research and development facilitles of the other Party.

6. Perform experiments on the characteristics and behavior of granite rock and varlous bartier/backfill materials to evaluate thelr stability under conditions of characteristic temperature, pressure and hydrology for potential repositorles, In accordance wh Article 5 of this Agreement.
7. Jolnt projerts in the form of experiments, tests, design, analysis, or other technical collaborative activity. Such joint projects would be Implemented by the coordinators and executed by both Parties in accorddance with Article 5 .

Other specific forms of ccoperation may be added by the Parties by mutual agreement in writing between the Coordinators or their designee (Article 4).

\section{ARTICLE 4}

1. To supervise the execution of this Agreement, the Parties will name Coordinators. As deemed necessary the Coordinators shall meet to evaluate the status of cooperation under this Agreement. Th1s evaluation shall include a comprehensive review of each Parties radioactive waste management program status, plans, an assessment of the balance of exchanges in the varfous areas of cooperation listed In Article 2, and a consideration of measures required to correct any Imbalances. In addition, the Coordinators shall consider and act on any major new proposals for cooperation; any new proposals shall be entered Into pursuant to Article 5 of this Agreement. These meetings shall be held alternatively in Sweden and the United States.

2. For day to day Implementation of this Agreement, the Coordinators shall designate a Technical Director for each party to oversee the cooperation under this Agreement. The Technical Directors shall agree on specific programs of cooperation in their respective areas, within policy guldelines set by the Coordinators. The Technical Director or his designee SW-1.2 
shall be responsible for the working rontacts between the Parties in the ir respective areas of cooperation.

\section{ARTICLE 5}

If it is decided a cooperative project under this Agreement should be subject to a formalized specific memorandum, the specific memorandum should cover all detalled provisions for implementing that project, including such matters as funding, patents, exchange of equipont and information disclosure specific to the particular project.

\section{ARTICLE 6}

1. Ceneral

The Parties support the widest possible dissemination of information provided or exchanged under this Agreement, subject to the need to protect proprietary information exchanged hereuider, and to the provistons of Article $B$.

2. Use of Proprietary Information

A. Definitions as used in this Agreement:

(1) The term "Information" means scientific or technical data, results or methods of research and development, and any other information intended to be provided or exchanged under this Agreement.
(11) The term "proprietary information" means information thich contains trade secrets or commercial or financial information which is privileged or confidential, and may only include such Information which:

a) has been held in confidence by its owner;

b) Is of a type which is customarily held in confidence by 1ts owner;

c) has not been transmitted by the transmitting Party to other entities (including the recelving Party) except on the basis that it be held in confidence; and

d) Is not otherwlse avallable to the recelving Party from another source without restriction on its further dissemination.

B. Procedures

(1) A Party recelving proprietary information pursuant to this Agreement shall respect the privileged nature thereof. Any document which contains proprietary information shall be clearly marked with the following (or substantially similar) restrictive legend:

"Th1s document contains proprietary information furnished in confidence under an Agreement dated between the United States Department of Energy and the Swed 1 sh Nuclear Fue 1 Supply Company and shall not be disseminated outside the se organizations, their contractors, 11 censees and the 
concerned departments and agencles of the Governments of the United States and Eweden without the prior approval of

Th1s notice shall be warked on any reproduction hereof, in wole or in part. These 1 imltations shall automatically terminate when this information 1s disclosed by the omer without restriction."

(11) Proprletary information recelved in confidence under this Agreement may be disseminated by the recelving Party to:

a) persons within or employed by the recelving Party, and other concerned Government departments and Covernment agencles in the country of the recelving Party;

b) prime-or-subcontractors of the receiving Party located within the geographical 11mits of the recelving Party's nation, for use only within the framework of their contracts with the recelving Party in work relating to the subject watter of the proprletary inforwation; provided that any proprietary information so disseminated shall be pursuant to an agreement of confidentiality and shall be marked with a restrictive legend substantially identical to that appearing in sub-paragraph 2. B(1) above.
(111) With the prior written consent of the Party providing proprietary information under this Agreement, the recelving Party may disseminate such proprietary information more widely than otherwlse permitted in the foregoing sub-section (11). The Parties shall cooperate with each other in developing procedures for requesting and obtalning prior written consent for such wider dissemination, and each Party w1l grant such approval to the extent permitted by 1 ts national pol1c1es, regulations and laws.

C. Each Party sha11 exerc1se 1ts best efforts to ensure that proprletary Information recelved by 1 t under this Agreement is controlled as provided herein. If one of the Parties becomes aware that 1 will be, or may reasonably be expected to become, unable to meet the nondissemination provisions of this Article, it shall immediately inform the other Party. The Parties shall thereafter consult to define an appropriate course of action.

D. Information ar1sing from seminars and other meetings arranged under th1s Agreement and Information arising from the attachments of staff, use of facilities and foint projects shall be treated by the Parties according to the Principles specified in this Article; provided. however, no proprletary inforwation orally communicated shall be subject to the 1 imited disclosure requirements of th1s Agreement 
unless the Ind ividual comminicating such inforwation places the reclplent on notice as to the proprletary character of the information commun 1cated.

E. Nothing contained in this Agreement shall preclude the use or dissemination of Information recelved by a Party through arrangements other than those provided for under this Agreement.

\section{ARTICLE 7}

Information transmltted by one Party to the other Party under this Agreement shall be accurate to the best knowledge and bellef of the transmltting Party, but the transmitting Party does not warrant the sultability of the information transulted for any particular use or application by the Recelving Party or by any third Party. Inforwation developed jolntly by the Parties shall be accurate to the best lnowledge and bellef of both Partles. Nefther Party warrants the accuracy of the fointly developed information or lts sultabllity for any particular use or application by elther Party or by any third Party.

\section{ARTICLE 8}

1. With respect to any invention or discovery made or concelved in the course of or under th1s Agreement:

a. If made or concelved by personnel of one party (the Assigning Party) or 1 ts contractors whlle assigned to the other Party (Reciplent Party) or its contractors in connection with exchanges of scientists, engineers and other specialists:

(1) The Reciplent Party shall acquire all rights, t1tle and Interest in and to any such invention or discovery in own country and in third countrles, subject to a non-exclusive, 1rrevocable, royalty-free license in all such countries to the Assigning Party, its Government, and its nationals designated by 1 t under any such invention or discovery and any patent application, patent or other protection relating thereto.

(2) The Assigning Party shall acquire all rights, t1tle and Interest in and to any such invention or discovery in 1 ts own country, subject to a non-exclusive, irrevocable, royaltyfree license to the Rec1plent Party, 1ts Covernment, and 1ts nationals designated by $1 t$ under any such invention or discovery and any patent application, patent or other protection relating thereto.

b. If made or concelved by a Party or its contractors as a direct result of employing information which has been communicated to it under this Agreement by the other Party or 1ts contractors or communicated during seminars or other joint meetings, the Party making the invention shall acquire all rights, title and interest in and to such fnvention or discovery in all countrles, subject to a grant to the other Party, 1ts 
Government, and 1ts nationals designated by $1 t$, of a royalty-free, non-exclusive, 1rrevocable license in and to any such invention or discovery and any patent application, patent or other protection relating thereto, in all countries.

c. With regard to exchange of samples, materials, instruments, and components for testing, the Reclplent Party shall have the same rights as the Assigning Party as set forth in paragraph a. above and the Sending Party shall have the same rights as the Reciplent Party as set forth in paragraph a. above.

d. With regard to other specific forms of cooperation, the Parties shall provide for epproprlate distribution of rights to Inventions or discover1es resulting from such cooperation, in accordance with Article 5 of this Agreement.

In general, however, each Party should normally own the rights

to such 1nventions or discoverles in 1 ts own country with a nonexclusive, 1rrevocable, royalty-free license to the other Party, 1 ts Government, and 1 ts nationals designated by $1 t$, and the rights to such inventions or discoveries in other countrles should be agreed by the Parties on an equitable basis.
2. Each Party shall, whthout prejudice to any rights of Inventors or authors under 1ts national laws, take all necessary steps to provide the cooperation from its inventors and authors required to carry out the provisions of Articles 8 and 9.

3. Each Party shall assume the responsibility to pay awards or compensation required to be pald to 1 ts own nationals according to 1 ts own laws.

\section{ARTICLE 9}

Copyrights of the Pattles or of cooperating organizations and persons shall be accorded treatment consistent with internationally recognized standards of protection. As to copyrights or materials within the scope of paragraph 1 of Article 6 owned or controlled by a Party, that Party shall make efforts to $g$ rant to the other Party a license to reproduce copyrighted material.

\section{ARTICLE 10}

A. Staff

1. Whenever an exchange of staff 15 contemplated under th1s Agreement, each Party shall ensure that qualified staff are selected for attachment to the other Party.

2. Each such attachment of staff shall be the subject of a separate at tachment agreement. 
3. Each Party shall be responsible for the salaries, Insurance and allowances to be paid to 1 ts staff.

4. Each Party shall pay for the travel and living expenses of 1 ts staff while on attachment to the host Party unless otherwse agreed.

5. The host establishment shall arrange for acceptable accommodations for the other Party's staff and their familles on a mutually agreeable reciprocal basis.

6. Each Party-shall provide all necessary assistance to the attached at aff (and their familles) of the other Party as regards admin1strative formalities (travel arrangements, etc.).

7. The staff of each Party shall conform to the general and special rules of work and safety regulations in force at the host establishment, or as agreed in separate attachment of staff agreements.

\section{ARTICLE 11}

The provistons of this Agreement shall not affect the rights or dutles of the Parties hereto under other agreements or arrangements. Th1s Agreement also in no way precludes commercial firms or other legally constituted enterprises in each of the two countries from engaging in commercial dealings in accordance with the applicable laws of each country, nor does it preclude the Parties from engaging in activitles with other covernments or persons. Moreover, 1t 16 expected that the present Agreement shall facilitate Industrial and commerclal exchanges in the fleld of radloactive waste management between the firms of the countries of the Parties with mutual benefits from such exchanges for both countries. DOE and the SKBF shall act as the points of coordination for contracts and arrangements involving commercial firms in their respective countries when such firms or enterprises act on behalf of their respective Governments under the terms of this Agreement. It $1 \mathrm{~s}$ understood that all such contracts and arrangements shall conform wh th applicable laws and regulations under which eaci party operates.

\section{ARTICLE 12}

Compensation for damages incurred during the Implementation of this Agreement shall be in accordance with the applicable laws of the countries of the Parties.

\section{ARTICLE 13}

Cooperation under th1s Agreement shall be in accordance with laws of the respective countries and the regulations of the respective Partles. All questions related to the Agreement arising during 1 ts term shall be settled by the Parties by mutual agreement. 


\section{ARTICLE 14}

Except when otherwise specifically agreed at the time, all costs resulting from cooperation under this Agreement shall be borne by the Party that Incurs them. The Implementation of this Agreement w1ll be subject to the ava1lability of appropriate funds.

\section{ARTICLE 15}

1. Th1s Agreement shall enter into force upon signature and, subject to paragraph 2 of this Article, shall continue for a flve (5)-year per1od, and may be amended or extended by mutual written agreement of the Parties. Th1s Agreement may be extended subject to agreement by the Partles following a review of accomplishments under this Agreement.

2. Th1s Agreement way be terminated at any time at the discretion of eithe Party, upon six (6) months advance notffication fn writing by the Party seeking to terminate the Agreement. Such termination shall be without prejudice to the rights which may have accured under this Agreement to either Party up to the date of such termination.

3. In the event that, during the perlod of this Agreement the nature of elther Party's radloactive waste management program should change substantially whether this be by substantial expansion, reduction, transformation or amalgation of wajor elements wh the radioactive waste management program of a third Party, elther Party shall kave the right to request revisions in the scope and/or terms of this Agreenen:

4. All jolnt efforts and experinents not completed at the explration or terrination of this Agreement may be continued unt1l their completion under the teras of this Agreemed.

Done at

Srockinolm this $9 \tau$ th day of Seprember, 1980.

FOR TEE DEPARITENT OF ENERGY OF THE URITED STATES OF AMERICA

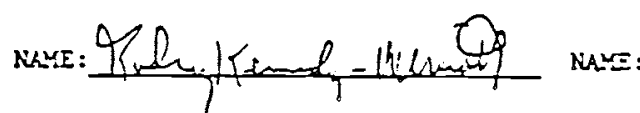

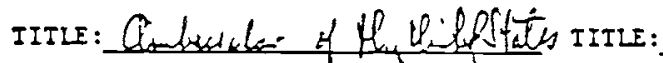
Ambassador Kennedy-Minott of the United States
FOR THE SWEDISE NUCLEAR FUEL SUPPLY COMPANY

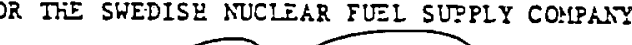


INTERNATIONAL NUCLIDE TRANSPORT CODE

INTERCOMPARISON STUDY (INTRACOIN)

\section{A GREEMENT}

Considering the importance of a safe final disposal of high-level radioactive waste;

taking account of the need for having an adequate physical knowledge of a proposed repository for nuclear waste disposal;

giving attention to the importance of getting appropriate tools for the evaluation of different sites and different designs of a repository;

regarding mathematical models describing the nuclide transport as a valuable instrument in making such evaluation:

assuming that the licensing authorities will pay great attention to the use of these models in their own judgement of a particular site,

a number of organisations, called the Parties, have agreed to perform a study making comparisons between different mathematical models describing the transport of radioactive nuclides in geological media.

\section{PARTIES}

The agreement is concluded between the following organisations:

\section{ADDITIONAL MEMBERS}

The coordinating group may decide to co-opt further members to the study, taking into account the fact that for the study to be successfully accomplished the number of active participants has to be limited.

\section{OBJECTIVES}

The purpose of the project is to obtain improved knowledge of the influence of various strategies for radionuclide transport modelling for the safety assessment of final repositories for nuclear waste. To this end a comparison is made between different mathematical models used by a number of organisations. The study comprises:

a) the impact on the transport calculations of incorporating various physico-chemical phenomena;

b) the impact of choosing different solution algorithms;

c) the closeness of fit of different models to in situ measurements.

The details of the technical content of the study is described in Annex 1. 


\section{ORGANISATION}

4.1 Coordinating group

The study is directed by a coordinating group. Each Party appoints one member to the group. The member from the managing participant acts as chairman. Each Party can decide to nominate a deputy for the appointed member to represent the Party at any of the group meetings.

The group appoints a vice chairman among its members. Secretary is provided by the project secretariate. The principal investigator participates in the meetings of the coordinating group. Additional representatives of the secretariate may take part in the group meetings.

The chairman, the vice chairman and the secretary will decide if non-members can attend the meetings of the group as observers.

The tasks of the coordinating group are:

- to decide on the technical content, planning and time schedule of the study;

- to give general directives for the work of the project teams;
- to select the codes for intercomparison;

- to decide on the initial formulation of the bench-mark problems;

- to decide on the organisation of workshops;

- to review and coordinate the results and the reports of the project teams;

- to take decisions on the final project report;

- to decide on any other matter that the group wants to take up or is referred to the group by any of the project teams.

\subsection{Managing Participant, Project Secretariate and} Principal Investigator

Managing participant will be the Swedish Nuclear Power Inspectorate. The managing participant will set up a project secretariate in cooperation with NAGRA, Switzerland. Kemakta Consultant Co will for the study and within the project secretariate act as principal investigator.

The tasks of the secretariate are:

- to give administrative assistance to the coordinating group for the fulfilment of the tasks of the group;

- to organise meetings of the coordinating group and arrange workshops; 
- to compile and analyse progress results with the assistance of the project teans;

- to produce and distribute quarterly progress reports to the coordinating group;

- to give administrative and technical advice to the project teams;

- to coordinate the preparation of the final report.

\subsection{Project Teams and Workshops}

Project teams are organised by the Parties. Each project team has a head who is responsible for the execution of the tasks assigned to the team.

The tasks of the project teams are:

- to perform the calculations defined by the coordinating group and formulated by the project secretariate on the basis of discussions in workshops;

- to appoint representatives to workshops;

- to report results to the managing participant for distribution to the coordinating group;

- to propose changes in the work assigned to them if necessary;

- to assist the project secretariate in analysis of results.

\section{BUDGET}

Each Party covers the costs for its participation in the study including representation in the coordinating group and workshops and any other meetings necessary for the study. Each Party is responsible for organizing the budget for its own project team or teams including computer costs and any travelling expenses.

The cost for the secretariate will be covered according to Annex 2.

6. FIRST MEETING OF THE COORDINATING GROUP

The first meeting of the coordinating group will take place as soon as the participating organisations have confirmed their intent to participate in the study to the Swedish Nuclear Power Inspectorate.

\section{FINALISATION OF THE STUDY}

The study is tentatively scheduled to last for two years. It is terminated when the final report is distributed to the Parties. The coordinating group has to reach an unanimous decision on the form and content of the final report.

\section{USE OF THE RESULTS}

The final report should be made publicly available. The managing participant takes no responsibility for the use of the results outside the framework of the study 
9.

\section{PREMATURE TERMINATION OF THE STUDY}

If the study has to be terminated prematurely due to unforeseen circumstances, the coordinating group has to reach decision on the use of the results already achieved.

\section{Stockholm,}

INTERNATIONAL NUCLIDE TRANSPORT CODE INTERCOMPARISON TECHNICAL CONTENT OF THE STUDY

The main purpose of the study is to increase the understanding of the impact of choosing different strategies for radionuclide transport modelling on the repository safety assessment. A modelling strategy involves a choice of governing equations and a solution algorithm for these equations. One would thus have to study these two factors to understand the impact of the strategy choice. The purpose of this Annex is to give some technical information about the strategies to be studied and about the actual carrying through of the study.

\section{Modelling Strategies to be Compared}

Among the growing number of transport models now becoming available throughout the world there is a clear tendency that the models become more complex inciuding new physicochemical phenomena. The first generation models inciude phenomena like chain decay, hydrodynamic dispersion and retardation as given by linear sorption equilibria between the liquid and the solid phase. Typical representatives of the first generation models are GETOUT, GARD2 and MIGRATO3.

The first generation models are typically one-dimensional and based on analytical solutions of the governing set of differential equations assuming spatially constant values of the paraneters dispersivity and retardation factors and assuming a radionuclide release rate from the waste that is constant in time. To overcome these constraints computer codes based on various numerical algorithms for solving the same equations as in first generation models have been developed. Choosing a numerical algorithm gives a greater flexibility in what concerns the choice of boundary conditions and parameter variability in both time- and space domain though possibly at the expense of higher computing costs.

Representatives of this type of models are FACSIMILE (employing a finite difference algorithm), MHT (discrete parcel random walk algorithm) and COLUMN (method of characterictics). These models can, except for the COLUMN code, be grouped together with the first generation models. 
The COLUMN code is designed to model other retardation effects than just linear sorption and can therefore be put in a group specially treating this topic. Another code in this group is DRAMA, which is a development from MMT.

Another way of overcoming the relative stiffness of the first generation models is analytical solution of the transport equations with piece-wise constant parameters and an arbitrary source term as implemented in the RANCH code.

The results from more recent research have shown a misfit between the first generation models and field experiments. Especially have field tracer experiments yielded larger spreads in the responses than can be foreseen by the classical concept of hydrodynamic dispersion. This is one of the reasons for developments like incorporating into the models diffusion from flow-active regims into stagnant regions (matrix diffusion).

Representatives of the models including matrix diffusion are TRUCHN, NAIITAR, TRANSAT and a French model developed at Ecole de Mines. These models all employ numerical schemes for solving the governing differential equations. TRUCHN uses an integrated finite difference approach, NAMTAR a discrete parcel algorithm and the other two models the finite element method.
Another line of development has been combining the transport calculations with calculations of the ground water flow and, eventually, the heat transport into the same computer code.

This has been done in SUIIFT ( 30 finite difference), DPCT (2D finite element for ground water flow and discrete parcel for transport) and TROUGH (3D integrated finite differences).

In conclusion there are five distinguishable groups of models available:

1. Classical advection - dispersion models

2. Advection - dispersion models with piece-wise constant parameters

3. Models incorporating diffusion into the rock matrix

4. Models for non-linear sorption, irreversible sorption and multispeciation

5. Models combining flow-, heat- and nuclide transport calculations

In these models the governing differential equations are solved using either analytical or numerical methods. The numerical methods used are finite differences, finite elements, integrated finite differences, discrete parcels and the method of characteristics. 
2.

\section{Performing the Comparison}

As described in the preceeding section the modelling strategies currently used in the world include a number of specific physico-chemical phenomena out of which some are known to have a strong impact on the calculation results. An increased completeness in the modelling is often achieved at the expence of rising computing costs. These costs can be affected by the choice of solution algorithm. The choice of algorithm can also affect the numerical properties of the solution.

In the light of these facts and in order to fulfil the objectives of the study, the transport code intercomparison should be performed at three levels to describe:

1. The numerical accuracy of the codes compared.

2. The capabilities of the codes to describe in-situ measurements.

3. The quantitative impact of choosing either modelling strategy on the nuclide transport calculations in a typical repository scenario assessment.

In the following subsections these levels are motivated and feasible strategies for performing them are presented.

\subsection{The Numerical_Accuracy_of the Codes_Compared}

This lowest level of comparison is set up to establish the numerical accuracy of the participating codes and to provide a basis for understanding deviating results in the higher levels. To make it meaningful the cases to be computed must be formulated such that essentially equal results are expected from all participating models. That is, as different models include different physico-chemical effects, several cases have to be formulated. It is proposed that one case.is set up for each group of models.

Level one includes comparison between analytical solutions and numerical ones. This is an important step for understanding the properties of the numerical algorithms employed as weil as for getting an indication of the cost at which numerical accuracy can be obtained with these algorithms. For this level it is important that analytical solutions are collected that are compatible to as many of the modeling strategies as possible. It is recognized that a comparison of the hydrological- and heat transfer parts of those codes which include these phenomena against analytical solutions is outside the scope of this study. Thus the transport part should, when possible, be decoupled during this level one comparison. 
Measurements

At level two a careful choice of in situ tracer tests should be made to serve as a basis for the comparison. There should be at least one sample case in a fractured medium and one case in a porous medium. This will take care of the fact that the interests of the participating countries are divided between the two types of media and that some of the codes are especially designed for porous media whereas other codes describe fractured media such as crystalline rock.

Most of the codes depend on the supply of independent hydraulic calculations. It seems suitable that the codes having a capacity for performing also the hydraulic calculations should do so. This means that the sample cases should be defined in terms of raw data entering the hydraulic calculations. It should be pointed out that the purpose of using the full capacities of the codes combining hydraulic and transport calculations is to investigate how the coupling of the equations for flow and transport affects the numerical properties such as stability of the solution and the computational costs including input preparation. The purpose is thus not to compare the hydraulic calculations.
The Quantitative Impact of Choosing either Modelling Strategy on the Nuclide Transport Calculations in a Iypical Repository_Scenario Assessment.

The final level of comparison is intended to demonstrate the influence of the various physico-cinemical effects included in the different participating models on the results from a repository simulation. The properties of the hypothetical site chosen should be close to those deemed realistic for a candidate site. Again it is plausible that two sites, one in a porous and one in a fractured medium, have to be set up.

At level three, comparison of the computational results and costs should be complemented by a sensitivity analysis. As the cost for a full repository scenario simulation can rise significantly when the complexity of the models increase a interesting aspect to be studied is whether relatively simple models could be used for parameter variations. 
INTERNATIONAL NUCLIDE TRANSPORT CODE INTERCOMPARISON

ESTIMATED BUDGET FOR THE PROJECT SECRETARIATE

The administrative effort for the secretariate will

be provided by the Swedish Nuclear Power Inspectorate.

The cost for the technical and scientific work within the secretariate will be covered by the Swedish Nuclear Power Inspectorate and NAGRA as follows:

$\begin{array}{lll} & \text { SKI } & \text { NAGRA } \\ \text { Work } & 9 \text { manmonths }^{2)} & 4 \text { manmonths } \\ & \text { 3) } \\ \text { Travelling expenses } & 60000 \text { SEK } & 40000 \text { SEK } \\ \text { Printing costs etc } & 10000 \text { SEK } & 10000 \text { SEK } \\ \text { Unforeseen } & 25000 \text { SEK } & 25000 \text { SEK }\end{array}$

1) Costs do not include administrative work performed by SKI personnel

2) Work performed by Kemakta Consultant Co, Sweden

3) Work performed by Eidgenössisches Institut für Reaktorforschung, Switzerland 
STATENS KARNKRAFTINSPEKTION

Swedish Nuclear Power Inspectorate

HYDROCOIN AGREEMENT

Considering the importance of a safe final disposal of high-level radioactive wastes:

taking account of the need for having an adequate physical knowledge of a prorepository for nuclear waste disposal:

giving attention to the importance of getting appropriate tools for the evaluations of different sites and different designs of a repository,

regarding mathematical models describing the ground water flow around a repository as valuable instruments in making such evaluations;

assuming that the licensing authorities will pay great attention to the use of these models in their own judgment of a particular site,

a number of organisations, called the parties, have agreed to perform a study to calculate ground water flow in geologic media using mathematical models (HYDROCOIN)

\section{PARTICIPATION}

Participation in HYDROCOIN is open to the organisations given in Annex 2.

In addition the Organisation for Economic Cooperation and Development/Nuclear Energy Agency (OECD/NEA) participates as an observer at HYDROCOIN meetings.

The Nordic Liason Comnittee for Atomic Energy Matters (NKA) gives certain economical support to the project secretariate and will receive information on the results from the study.

\section{OBJECTIVES}

The purpose of the project is to obtain improved knowledge of the influence of various strategies for ground water flow modelling for the safety assessment of final repositories for nuclear waste. To this end calculations are made with different mathematical models used by a number of organisations. The study comprises:

a) the impact on the ground water flow calculations of different solution al gori thms,

b) the capabilities of different models to describe field measurements, and

c) the impact on the ground water flow calculations of incorporating various physical phenomena.

The details of the technical content of the study is described in Annex 1 .
3. ORGANISATION

3.1 Coordinating Group The study is directed by a Coordinating Group. Each Party appoints one member
to the group. The member from the Managing Participant acts as chaiman. Each to the group. The member from the Managing Participant acts as cha represent the Party can decide to nominate a deputy
party at any of the group meetings.

The Group appoints a vice chairman among its members. Secretary is provided by the project secretariate. The Principal Investigator participates in the meetings of the coordinating Group. Additional representatives of the secretariate may take part in the group meetings.

The chaiman, the vice chaiman and the secretary will decide if nonmembers may ttend the meetings of the group as observers.

The tasks of the Coordinating Group are:

- to decide on the technical content, planning and time schedule of the

study;

- to give general directives for the work of the project teams;

- to approve the codes for calculations:

- to decide on the organisations of workshops

- to review and coordinate the results and the reports of the project

teams;

- to take decisions on the final project report;

to decide on any other matter that the group wants to take up or is referred to the group by any of the project teams.

3.2 Managing Participant, Project Secretariate and Principal Investigator

Managing participant will be the Swedish Nuclear Power Inspectorate. The Managing Participant will set up a Project Secretariate in cooperation with United Kingdom Atomic Energy Authority (Atomic Energy Research Establishment, Harwell). Kemakta Consultants Co. will for the study and within the project secretariate act as Principal Investigator.

The tasks of the secretariate are:

- to give administration assistance to the Coordinating Group for the fulfilment of the tasks of the group;

to organise meetings of the Coordinating Group and arrange workshops

- to compile and analyze progress results with the assistance of the Project Teams

- to produce and distribute progress reports to the Coordinating Group:

- to give administrative and technical advice to the Project Teams;

- to coordinate the preparation of the final report.

3.3 Project Teams and Workshops

Project Teams are organised by the Parties. Each Project Team has a head who is responsible for the execution of the tasks assigned to the team. 
Annex 1 4) Free surface problems relevant to shallow/and burial repositories.

\section{TECHNICAL DESCRIPTION OF HYDROCOIN}

1. GENERAL

The study is performed at three levels, the general aims of which can be expressed as:

Level 1 - Comparison of the participating codes' numerical accuracies.

Level 2 - Comparison of computed and measured data.

Level 3 - Sensitivity to the involvement of various physical phenomena.

It is foreseen that the second and third levels will be coordinated to treat the same experiment/site.

The problems calculated shall be relevant to nuclear waste disposal. They should al so represent the forefront of current research work. In order to be able to fulfill these intentions it is necessary that the participants take an active part in the problem formulation. All proposed test problems will thus be sent out in draft to the participants for reviewing before the issuing of the final definition.

The technical contents of the 3 levels are defined below to the detailization that is possible today.

2. TECHNICAL CONTENTS

2.1 Level 1

The verification of a numerical code's accuracy is normally performed by comparing results with analytical solutions. However, analytical solutions cannot be found but for physically relatively simple cases. In the cases for which one cannot find analytical solutions one is restricted to intercomparing results from several numerical solutions. In HYDROCOIN both types of verification procedures will be applied in order to be able to fulfill the two intentions mentioned in Section 1.

Many problem areas can give rise to test problems that are both close to the forefront of current research and relevant to the disposal of radioactive waste, e.g., the following list of eight areas:

1) Simple well scenario (20 and/or 30$)$ for which there are analytical solutions available.

2) Problems including an intersecting fracture zone (discontinuity in hydraulic conductivity).

3) Problems involving a sedimentary layer system, eventually including unsaturated aquiphers.

5) Problems involving thermal- or/and salinity gradients.

6) Problems involving pressure dependent permeabilities (rock mechanics).

7) Problems involving temperature dependent permeabilities (thermo mechanics).

8) Problems involving stochastic permeability distributions.

After discussions with potential participants the following four test problems for HYDROCOIN level 1 are proposed.

1. Comparison of numerical solutions with an analytical solution involving the intersection of a borehole of finite radius with a fracture in a porous rock.

2. Intercomparison of numerical solutions of a two-dimensional, vertical cut through a fractured rock with two major fracture zones. The zones are inclined so that they intersect. Both the intact rock and the fracture zones are modelled as porous media.

3. Intercomparison of numerical solutions to a two-dimensional problem involving saturated-/unsaturated flow in a layered system with al ternating permeable-semipervious layers.

4. Comparison of numerical solutions with an analytical solution for time dependent thermally induced flow in a porous medium. The predominant heat transport mechanism is conduction in the solid.

The output parameter to be compared is the hydrodynamic pressure (head) as a function of time and/or spacial coordinates. In case four also the temperature can be compared.

The list of proposed test problems is preliminary and may be subject to changes following comments from the participants of HYDROCDIN.

2.2 Levels 2 and 3

The last two levels of HYDROCOIN are yet less well defined than the first

level. It is anticipated that at least two sets of experiments will be selected for comparison purposes, one for a fractured rock and one for a porous selium. The experiments should be performed on a regional or subregional scale. This implies that the selected experiment sets should be comprehensive scale. This explies that the selected experiment sets should be comprehensive of the data.

The second and third levels address the question of validating physical models rather than verifying numerical solution schemes and computer codes. The definition of the test problems will therefore leave some freedom for the participants to apply different physical models. As a sensitivity analysis the 
The tasks of the Project Teams are:

to perform the calculations defined by the coordinating Group and formulated by the Project Secretariate on the basis of discussions in workshops;

int representatives to workshops

- to report results to the managing participant for distribution to the Coordinating Group

- to propose changes in the work assigned to them if necessary;

- to assist the Project Secretariate in analysis of results.

4. BUDGET

Each Party covers the costs of its participation in the study including representation in the Coordinating Group and workshops and any other meetings necessary for the study. Each Party is responsible for organising the budget for its own Project Team or Teams including computer costs and any traveling expenses.

The cost for the secretariate will be covered according to special agreements between the Swedish Nuclear Power Inspectorate and United Kingdom Atomic Energy Authority (Atomic Energy Research Establishment, Harwell) and between the Swedish Nuclear Power Inspectorate and the Nordic Liason Committee for Atomic Energy Matters.

\section{ADDitIONAL MEMBERS}

The Coordinating Group may decide to co-opt further members to the study, taking into account the fact that for the study to be successfully accomplished the number of active participants has to be limited.

6. COMMENCEMENT OF THE STUDY

The study will commence as soon as five participating organisations have confirmed their intent to participate in the study to the Swedish Nuclear Power Inspectorate. After the commencement of the study places will be left open for the organisations given in Annex 2 .

The Project Secretariate will propose definitions of cases to be calculated on level 1 of the study according to Annex 1 . The definitions will be reviewed by Coordinating Group members and Project Team leaders and then fixed by the

secretariate. The first Coordinating Group meeting and the first workshop will be held in November 1984 , at the latest.

7. FINALISATION OF THE STUDY

The study is tentatively scheduled to last for three years. It is terminated when the final report is distributed to the Parties. The Coordinating Group when to reach en unanimous decision on the form and content of the final report.
8. USE OF THE RESULTS

The final report should be made publicly available. The Parties take no responsibility for the use of the results outside the framework of the study.

9. PREMATURE TERMination OF THE STUDY

If the study has to be terminated prematurely due to unforeseen circumstances, the Coordinating Group has to reach decision on the use of the results already

Stockholm, January 30, 1984 
implementation of different physical phenomena will be made in a systematic way to investigate their impact on parameters that are essential in the repository performance assessment. These parameters are e.g., the flow
assumed repository and the flow paths from this repository.

The output parameters to be compared at level 2 will be dependent on the design of the selected sets of experiments. However, the piezometric head is likely to be an essential part in this comparison.
LIST OF POTENTIAL HYDROCOIN PARTICIPANTS

Atonic Energy of Canada $L t d$.

\section{CANADA}

Comissariat à l'Energie Atomique/Institut de Protection et de Soreté Nucléaire FRANCE

Institute of Geological Sciences UNITED KINGDOM

Institut für kerntechnik der Technische Universităt Berlin

FEDERAL REPUBLIC OF GERMANY

Japan Atomic Energy Research Institute JAPAN

Nationale Genossenschaft für die Lagerung Radioaktiver Ab fälle

SHITZERLAND

Swedish Nuclear Fuel Supply Co.

SHEDEN

Technical Research Centre of Finland

FINLAND

U.K. Atomic Energy Authority/Atomic Energy Research Establ i shment

UNITED KINGDOM

U.S. Department of Energy

U.S.A.

U.S. Nuclear Regulatory Commission

U.S.A. 


\section{FOREIGN TRAVEL REPORT}

(Excerpt from report by C. R. Cole, PNL, October 1984)

First HYDROCOIN Coordinating Group Meeting

October 25,1984

Stockholm, Sweden

This meeting, while officially only for the coordinating group members, was open to all interested HYDROCOIN participants and dealt with the planning for completion of Level 1 as well as the initial planning and organization for Levels 2 and 3 of HYDROCOIN.

The meeting was opened and chaired by A. Larsson of SKI. In his initial remarks he indicated that they were very pleased with the number of countries that were interested in participating. Each participant must cover their own costs and hoped that everyone would continue to participate to the end (approximately three years). N. Eisenberg (DOE) was appointed Vice-Chairman. The coordinating group then discussed the various modifications suggested for the Level 1 problems during the workshop and essentially adopted the suggestions which have been summarized above. The suggestion of a newsletter was also adopted. In terms of documentation, each project team will prepare their own reports with the format being rather free.

They will also supply tapes and/or other standard code outputs for use by the Secretariate in preparing the code inter-comparison report. Code documentation is likely to be more difficult for HYDROCOIN than for INTRACOIN and the Secretariate is to investigate and recommend a format.

Discussions on Levels 2 and 3 resulted in recommendations to try to 1 imit any adopted Level 2 problems to ones requiring no more than a six man month level of effort and that the selection include but not be limited to the following three categories:

- a problem with heat;

- a problem on fractures;

- a problem dealing with heterogeneities. 
A11 Level 2 proposals and references are to be documented for reference and future use. It was also felt that it would be useful for the project teams to have a Level 2 problem made available prior to the next workshop. The Cornish Granite Experiment suggested by David Hodgkinson was adopted and David was charged with preparing this problem definition. All Level 2 proposals must include:

- the aspect of validation that they address;

- an outline or approach for applying this problem to the Level 2 goals;

- well-documented background material;

- a proposed method for measuring success or fallure of the val idation exercise.

The next item discussed dealt with NEA participation. NEA, at the time, only had observer status and they must be a member of the Secretariate in order to provide any support. They were promptly renamed to member. NEA can collect the individual project team reports and publish them in a bound volume. They can collect and distribute project team codes as well as relevant validation data sets. They can also convene workshops specifically to discuss modeling problems.

The 1 ast items dealt with the schedule, which as best I understood it, (the Secretariate will undoubtedly send out the actual schedule) is:

- Final Level I problem descriptions sent out to project teams by the Secretariate by the end of December 1984;

- Project team Level 1 problem results to Secretariate by May 1, 1985;

- Level 2 proposals sent to the Secretariate by January 1, 1985;

- Cornish Granite Experiment problem description (Level 2) sent to project teams sometime in January 1985;

- Level 2 proposals assembled and mafled to project teams by May 1, 1985;

- Next HYDROCOIN workshop--the latter part of May 1985 or the early part of June. The meeting is to be held in the U.S. and to be jointly hosted by the U.S. DOE and U.S. NRC with N. Eisenberg (DOE) and C. R. Cole (PNL) making the arrangements. The site and time is to be set as the arrangements are made. 


\section{MINUTES OF UNITED STATES/SWEDEN BILATERAL MEETING}

\section{Chicago, Illinois}

May 21-22, 1984

(Excerpt from report by S. A. Mann, DOE-CRPO, July 1984)

A summation of the meeting was done by listing the areas of agreements and commitments made during this meeting and are listed below:

\section{Site Characterization}

Crystalline Repository Project (CRP) personnel visit to Sweden -- Agreement was reached that SKB would prepare a program and schedule for the visit to Sweden for the purpose of exchange of information on site characterization activities in Sweden, visits to sites under investigations, a trip to the Stripa mine and a summation to the workshop. This proposal would be sent to DOE/CPO for comments and agreement.

Lars Nilsson mentioned that the Materials Research Society would hold its annual meeting in Stockholm in September 1985. He indicated the meeting should focus on activities related to spent fuel and the characterization of crystalline rock bodies for potential high-level waste repository.

\section{Performance Assessment}

It was agreed that close information exchanges in this area would be mutually beneficial. Possible joint efforts in the future would be considered as cooperative activities in these areas progressed.

\section{Natural Analogue Studies}

General agreement was reached on the need for natural analogue studies because these studies may be very useful in validation of computer modelling efforts.

An International Workshop on Natural Analogues will be held in the US on October 1-3, 1984. It was agreed the invitations, call for abstracts, agenda and the preparation of the proceedings and other related matters would be handled by Sweden. The DOE would make all practical arrangements for this workshop. (Arrangements have been made at the Americana Resort at Lake Geneva, Wisconsin, approximately $1-1 / 2$ hours from 0'Hare airport). 
The DOE agreed to review the points of geochemical interest for cooperative funding for studies of the Murro de ferro site in Brazil.

Fred Carlsson of SKB was named as the Swedish contact on Natural Analogues and Michael Shea of OCRD was named as the US contact.

\section{Waste Package}

It was agreed that planning should commence on a workshop for waste package activities related to crystalline rock. The timing of this workshop should be early in 1986. Informal discussion would be held with the members of the Joint Technical Committee during their next meeting to find out what activities in waste packaging are going on now and to develop topics for this workshop.

\section{Stripa Project}

General agreement was reached on using the Stripa mine beyond Phase II of the project. The DOE will begin to develop a proposal for testing for Phase III of the Stripa Project.

\section{Exchange of Reports}

The DOE agreed to send three copies of the January 1984 Draft Overview of the Screening Methodology, the final draft of the Screening Methodology when available, and the OCRD publication bibliography. Sweden requested a copy of the NAS/NRC study entitled "Social and Economic Aspects of Radioactive Waste Disposal." One copy was given to Per-Eric Ahlstrom during the meeting. Finally, OCRD will put SKB on the distribution list for all OCRD and DOE documents. 
SWIIZERLAND (SZ)

BLANKET AGREEMENT (Attachment SZ-1)

\section{SUBSIDIARY AGREEMENTS}

None

\section{STATUS/PLANNING REPORTS}

None

\section{ADMINISTRATION}

Principal Coordinators: US -- C. R. Cooley (DOE)

SZ -- C. MCCombie (NAGRA/CEDRA)

Document Exchange: see Appendix C 


\section{AGREEMENT}

BETWEEN

THE UNITED STATES DEPARTMENT OF ENERGY

AND

THE NATIONAL COOPERATIVE FOR THE STORAGE OF RADIOACTIVE WASTE IN SWITZERLAND

IN THE FIELD OF RADIOACTIVE WASTE MANAGEMENT

WHEREAS

The Department of Energy of the United States of America (DOE) and the National Cooperative for the Storage of Radioactive Waste of Switzerland (NAGRA), hereinafter referred to as the Parties, have a mutual interest in the safe, effective, and economic treatment, handing, isolation, disposal, and retrieval of spent radioactive fuel and separated radioactive waste products;

DOE and NAGRA believe that a cooperative program of equitable sharing of their respective research and development data, technology, and experience in the management of radioactive waste would be of mutual benefit; and

DOE and NAGRA recognize the contribution that such research and development in radioactive waste management can make to protecting the environment, whi Te furthering the safe and economic application of nuclear energy.

DOE is responsible in the United States, and NAGRA is responsible in Switzerland, for the disposal of spent fuel and high-level waste from commercial nuclear reactors; consequently for the purposes of this Agreement NAGRA acts on behalf of the Swiss Federal Republic.

THEREFORE, in consideration of the mutual covenants contained herein, and in conformity with the Agreement for Cooperation between the Government of the United States of America and the Government of Switzerland concerning Civil Uses of Atomic Energy, which was signed at Washington on December 30, 1965 , entered into force on August 8, 1966, and was amended on November 2, 1973. with effect from January 29,1974 .

IT IS AGREED AS FOLLOWS

\section{ARTICLE 1 - OBJECTIVES}

Cooperation under this Agreement shall be directed towards a study of mutually agreed topics associated with the management of radioactive waste and related activities of the nuclear fuel cycle. Cooperation between the Parties shall be on the basis of mutual benefit, equality, and reciprocity.
ARTICLE 2 - AREAS OF COOPERATION

The areas of cooperation in the field of radioactive waste management covered by this Agreement may include:

1. Characterization of geologic formations

2. Field and laboratory testing

3. Preparation and packaging of radioactive wastes

4. Disposal in geologic formations

5. Surface and subsurface storage of radioactive wastes

6. Environment and safety issues

7. Design and operational issues

8. Performance assessment issues

9. Transportation requirements

10. Public acceptance issues

Other areas of cooperation may be added by mutual written agreement.

ARTICLE 3 - FORMS OF COOPERATION

Cooperation under this Agreement may include, but is not limited to, the following forms:

1. Exchange of scientists, engineers, and other specialists for agreed periods for participation in agreed research, development, analys is, design and experimental activities conducted in research centers, laboratories engineering offices, and other facilities and enterprises of each of the Parties or its contractors. Such exchanges of staff shall be in accordance with Article 5 of this Agreement.

2. Exchange of scientific and technical information, and results of research and development. Such exchanges of information shall be in accordance with Article 6 of this Agreement.

3. Exchange of samples, materials, and equipment for testing, subject in each case to a separate written agreement.

4. Organization of and participation in seminars and other meetings on specific agreed topics in the areas listed in Article 2.

5. Short visits by specialist teams or individuals to the radioactive waste management facilities of the other Party. 
6. Observation of and participation in studies dealing with the areas of cooperation listed in Article 2,. subject in each case to a separate written agreement.

7. Joint projects in which the Parties agree to share the work and/or costs, subject in each case to a separate written agreement.

Other forms of cooperation may be added by mutual written agreement.

\section{ARTICLE 4 - MANAGEMENT}

To supervise the execution of this Agreement, each Party shall name a Coordinator. The Coordinators shall normally meet annually to review the past year's activities, to evaluate the status of cooperation, including the balance of exchanges, and to approve plans for the following year's activities. The Coordinators shall also consider any new major proposals for cooperation. Day-to-day management of the cooperation shall be carried out by Correspondents designated by each Coordinator.

\section{ARTICLE 5 - ATTACHMENT OF STAFF}

1. Whenever an exchange of staff is contemplated under this Agreement, each Party shall ensure that qualified staff are selected for attachment to the other Party.

2. Each such attachment shall be the subject of a separate attachment agreement between the Parties.

3. Each Party shall be responsible for the salaries, travel, and living expenses of its personnel while on attachment to the host Party, unless otherwise agreed.

4. The host establishment shall arrange for accommodations for the attached staff and families of the other Party or its contractors on a mutually agreeable, reciprocal basis.

5. Each Party shall provide all necessary assistance to the attached staff and their families regarding administrative formalities such as travel arrangements and work permits.

6. The attached personnel shall conform to the general and special rules of work and safety regulations in force at the host establishment, or as agreed in separate attachment of staff agreements.

\section{ARTICLE 6 - EXCHANGE OF INFORMATION}

\section{General}

The Parties agree that information provided, exchange, or arising under this Agreement may be given wide distribution, subject to the need to protect pro- prietary information, to copyright restrictions, and to the provisions of Article 7. Such information may be made available to the public by either Party through customary channels and in accordance with normal procedures of the Parties.

2. Use of Proprietary Information

A. Definitions as used in this Agreement

(i) The term "information" means scientific or technical data, results or methods of research and development, and any other information intended to be provided, exchanged, or arising under this Agreement.

(ii) The term "proprietary information" means information provided or exchanged which contains trade secrets or commercial or financial information which is privileged or confidential, and may only include such information which:

(a) has been held in confidence by its owner;

(b) is of a type which is customarily held in confidence by its owner:

(c) has not been transmitted by the transmitting Party to other entities, including the receiving Party, except on the basis that it be held in confidence; and

(d) is not otherwise available to the receiving Party from another source without restriction on its further dissemination.

B. Procedures

(i) A Party receiving proprietary information pursuant to this Agreement shall respect the privileged nature thereof. Any document which contains proprietary information shall be clearly marked with the following, or substantially similar, restrictive legend:

"This document contains proprietary information furnished in confidence under an Agreement dated States Department of Energy and between the United Storage of Radioactive Waste of Switzerland and shall not be disseminated outside these organizations, their contractors, and the concerned departments and agencies of Governments of the United States and Switzerland without prior approval of

"This notice shall be marked on any reproduction hereof, in whole or in part. These limitations shall automatically terminate when this information is disclosed by the owner without restriction."

(ii) Proprietary information received in confidence under this Agreement may be disseminated by the receiving Party to: 
(a) persons within or employed by the receiving Party, and concerned Government departments and Government agencies in the country of the receiving Party; and

(b) prime or subcontractors of the receiving Party working on projects within the geographical limits of the receiving Party's country, for use only with in the framework of their contracts with the receiving Party in work relating to the subject matter of the proprietary information;

provided that any such proprietary information shall be disseminated pursuant to an agreement of confidentiality and shall be marked with a restrictive legend substantially identical to that appearing in sub-section 2.B.(1) above.

(iii) With the prior consent of the Party providing proprietary information under this Agreement, the receiving Party may disseminate such proprietary information more widely than otherwise permitted in the foregoing sub-section ( $i i)$. The Parties shall cooperate with each other in developing procedures for requesting and obtaining prior written consent for such wider dissemination, and each Party shall grant such approval to the extent permitted by its national policies, regulations, and laws.

C. Each Party shall exercise its best efforts to ensure that proprietary information received by it under this Agreement shall be controlled as provided herein. If one of the Parties becomes aware that it will be, or may reasonabiy be expected to become, unable to meet the nondissemination provisions of this Article, it shall immediately inform the other Party. The Parties shall thereafter consult to define an the other Party. The Parties
appropriate course of action.

D. No proprietary information orally communicated shall be subject to the limited disclosure requirements of this Agreement unless the individual communicating such information places the recipient on notice as to the proprietary character of the information communicated.

\section{ARTICLE 7 - PATENTS}

1. With respect to any invention or discovery made or conceived in the course of or under this Agreement by personnel of one Party (the Assigning Party) or its contractors while assigned to the other Party (Receiving Party) or its contractors, in connection with exchange of scientists, engineers, and other specialists:

(a) The Receiving Party shall acquire all right, title, and interest in and to any such invention or discovery in its own country and in third countries, subject to a non-exclusive, irrevocable, royalty-free license to the Assigning Party, its Government, and its nationals designated by $i t$, in all such countries.

(b) The Assigning Party shall acquire all right, title, and interest in and to any such invention or discovery in its own country, subject to non-exclusive, irrevocable, royalty-free license to the Receiving Party, its Government, and its nationals designated by it, in such country.

2. With respect to any invention or discovery made or conceived in the course of or under this Agreement by a Party or its contractors as a direct results of employing information which had been communicated to it under this Agreement by the other Party or its contractors or communicated during seminars or other joint meetings, the Party making the invention shall acquire all right, title and interest in and to such invention or discovery in all countries. subject to the grant to the other Party, its Government, and its nationals designated by $i t$, of a non-exclusive, irrevocable, royalty-free license in all such countries.

3. Information regarding inventions on which patent protection is to be obtained shall not be published or publicly disclosed by the Parties until a patent application has been filed in either country of the Parties;

provided, however, that this restriction on publication or dissemination shal not extend beyond six months from the date of reporting of the invention. It shall be the responsibility of the Party reporting the invention to mark appropriately reports which disclose inventions that have not been appropriately protected by the filing of a patent application.

4. Each Party shall, without prejudice to any rights of inventors or authors under its national laws, take all necessary steps to provide the cooperation from its inventors and authors required to carry out the provisions of this Article and Article 8.

\section{ARTICLE 8 - COPYRIGHTS}

Copyrights of the Parties shall be accorded treatment consistent with internationally recognized standards of protection. As to copyrights on materials within the scope of paragraph 1 of Article 6 above owned or controlled by a reproduce or translate the copyrighted materials.

\section{ARTICLE 9 - DISCLAIMER}

The application or use of any information exchanged under this Agreement shall be the responsibility of the Party receiving $i t$, and the other Party does not warrant the suitability of such information for any particular use or application.

\section{ARTICLE 10 - APPLICABLE LAWS AND REGULATIONS}

Cooperation under this Agreement shall be in accordance with the laws and regulations under which each Party operates. All questions relating to this Agreement arising during its term shall be settled by the Parties by mutual agreement. 
ARTICLE 11 - COSTS

Except when otherwise agreed, all costs resulting from cooperation under this Agreement shall be borne by the Party that incurs them. Cooperation under this Agreement shall be subject to the availability of appropriated funds.

ARTICLE 12 - ENTRY INTO FORCE AND TERMINATION

1. This Agreement shall enter into force upon the later date of signature and, subject to Paragraph 2 of this Article, shall continue for a five-year period.

2. This Agreement may be amended or extended at any time by mutual written agreement of the Parties.

3. This Agreement may be terminated at any time at the discretion of either Party, upon six months advance notification in writing. Such termination shall be without prejudice to the rights which may have accrued to either Party up to the date of such termination.

Done in duplicate.

FOR THE UNITED STATES DEPARTMENT OF ENERGY

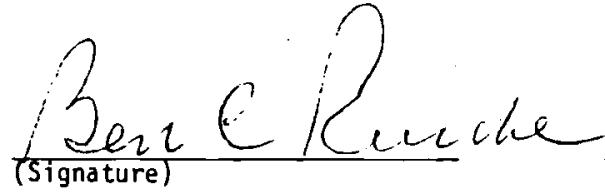

Ben C. Tusche (Name)

Director, Office of civilian RADIOACTIVE WASTE MANAGEMENT (Title)

ApRIL 19,1985 (Date)
FOR THE NATIONAL COOPERATIVE FOR THE STORAGE OF RADIOACTIVE WASTE OF SWITZERLAND

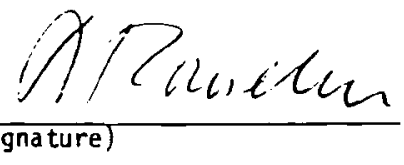

Rudolf Rometsch (Name)

President (Tithe)

$\frac{\text { April } 19,1985}{\text { (Date) }}$

$S Z-1.4$ 


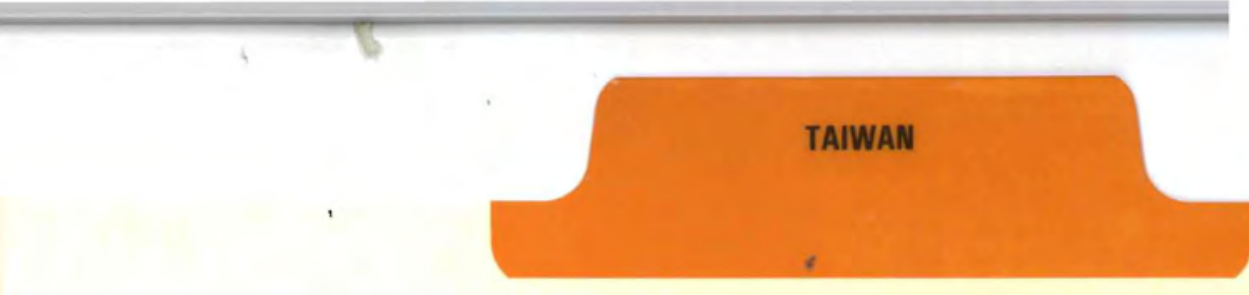

\author{
|
}




\title{
IAIMAN (TWI)
}

BLANKET AGREEMENT (Attachment TW-1)

\section{SUBSIDIARY AGREEMENTS}

None

\section{STATUS/PLANNING REPORTS}

Potential Areas of Cooperation (Attachment TW-2 -- excerpt from D. F. Newman (PNL) travel report to Taiwan May 26-31, 1985)

\section{ADMINISTRATION}

\author{
Principal Coordinators: US -- Harold D. Bengelsdorf (IEAL) \\ TW -- Y. H. Lee (CCNAA) \\ Document Exchange: see Appendix C
}




\section{AGREEMENT BETWEEN \\ THE AMERICAN INSTITUTE IN TAIWAN

$$
\text { AND }
$$ \\ THE COORDINATION COUNCIL FOR NORTH AMERICAN AFFAIRS RELATING TO THE ESTABLISHMENT OF A JOINT STANDING \\ COMMITTEE ON CIVIL NUCLEAR COOPERATION}

WHEREAS the American Institute in Taiwan (hereinafter referred to as "AIT") and the Coordination Council for North American Affairs (hereinafter referred to as "CCNAA") have deen cooperating tor some time in several areas designed to foster the peaceful ano nonexplosive uses of atomic energy;

WHEREAS this program of peaceful cooperation has been intensitying with the expansion of civil nuclear power activities in the territory represented by CCNAA

WHEREAS AIT and CCNAA perceive that they will benefit from an expansion of their technical cooperation and collaboration in a number of fields related to the civil uses of atomic energy;

WHEREAS AIT and CONAA also share the view that their existing and prospective new cooperation in the nuclear field will be mutually beneficial if it is subjected to. regular monitoring, ana guidance by a joint group of senior experts that will meet periodically to review and plan cooperarive activities; and

WHEREAS senior consultants to AIT and CCNAA nave recently discusseo the merits of inaugurating new or expanded programs of cooperation in several promising civil nuclear areas.
NOW THEREFORE, both Parties have agreed as follows:

ARTICLE I. Establishment of Joint Nuclear Cooperation Committee

A. AIT and CCNAA shall establish a Jolnt Standing Committee on Civil Nuclear Cooperation thereinafter referred to as "the Joint Comittee") that shall deet periodically, at least once a year, to review the civil nuclear cooperation between the two parties.

B. The Joint Committee shall monitor the civil nuclear cooperation between the two parties, shall discuss and stimulate desirable new directions, and where feasible, shall formulate specific new cooperative programs or exchanges that should be undertaken.

C. AIT and CCNAA shall each designate their representatives on the Comnittee, and each party may alter or expand its representation as it deems appropriate in lignt of the subject matter under discussion.

ARTICLE II. Basic Principles

The cooperation under this Agreement shall be carried out in accordance with the following principles:

A. The areas of cooperation that are proposed normally shall be of a character tnat promises to be of programmatic interest to both parties.

B. Unless otherwise agreed in writing, all costs shall be borne by the party that incurs them and this shall include the travel and salary expenses associated 
with the conduct of a cooperative program or technical exchange. If the parties agree in writing beforehand, this will not preclude one party from reimbursing the other for expenses should a given prograra or assignment be judged to be principally of benefit to one of the parties.

c. Implementation of this Agreement shall be subject to the availability of appropriated funds.

D. Cooperation under this Agreement shall be in accordance with applicable laws and regulations of the two parties.

E. Nothing in this Agreement shall alter or affect the existing agreements between AIT and CCNAA in fields related to the civil uses of atomic energy. Such agrements shall remain in effect until and unless they are modified or altered by the parties concerned.

ARTICLE III. Technical Areas of Collaboration

The expanded program of civil nuclear cooperation that has been agreed to by AIT and CCNAA may include work in the following fields plus such other fields as may be mutually agreed to by the parties in writing:

A. Severe Nuclear Accidents and Related Prenomena

B. Thermal Hydraulics and Kanetics

C. Instrumentation and control Programs

D. Spent Fuel Handing and Waste Management

E. Health Physics

F. Techinical Safety Support
The detailed implementation of exchanges and cooperative programs that are recommended or endorsed by the Joint Committee, incluaing the assignment of staff, shall be subject to separace written agreements between the parties as circumstances require.

\section{ARTICLE IV. Points of Contact}

Whenever a new program of cooperation or exchange is agreed to, each party shall designate its technical and scientific representatives that shall be responsible for carrying out the direct day to day implementation of the exchange within the AIT/CCNAA framework.

\section{ARTICLE V. Forms of cooperation}

Cooperation in accordance with this Agreement may include, but is not limited to, the following forms:

A. Exchange of scientists, engineers and other specialists for participation in agreed research, development, analysis, design and experimental activities conducted in research centers, laboratories, engineering offices and other facilities and enterprises of eacn of the Parties or its contractors for agreed periods. Exchanges of staff shall be in accordance with Article VI of this Agreement.

B. Exchange of samples, materials, instruments and components, for testing under such terms as are mutually agreed.

c. Fxchangr, on a elucrent basis, of scientific and technical information, and results and metroas of researin shu development in accordance with Article VII of this Agreement. 
D. Organization of and participation in, seminars and other meetings on specific mutually agreed topics in the fielas listea in Article II of tnis Agreement.

E. Joint projects in which the parties agree to share the work and/or costs. Each such joint project shall be the subject of a separate written agreement.

F. Other specific forms of cooperation mutually agreed to by the parties in writing.

ARTICLE VI. Exchange of Personnel

Whenever an exchange of staff is contemplated under this Agreement:

A. Each Party shall ensure that qualitied staff are selected for attachment or assignments to the other party.

B. The parties will prepare attachments or other such agreements as may be necessary in conjunction with work assignments under this Agreement.

C. Each Party shall be responsible for the salaries, insurance and allowances to be paid to its staff.

D. Each Party shall pay for the travel and living expenses of its staff while on atcachment to the host party unless otherwise agreed.

E. The host party shall arrange for comparable accommodations for the attached staff (and their families) of the other party on a mutually agreeable reciprocal basis.
F. The host party shall provide all necessary assistance to the attached staff (and their families) of the asaigning party as regards administrative formalities, such as travel arrangements, etc.

G. The staff of each party shall conform to the general and special rules of work and safety regulations in force at the host establisnment, or as agreed in a separate staff attachment agreement.

8. The party proposing an attachment shall notify the host party of the name of the person(s) proposed for attachment and shall provide such information respecting any of the said person(s) as may be required by the receiving Party.

\section{ARTICLE VII. Information and Patents}

A. The Parties shall exchange information necessary to carry out this agreement. All information arising under this Agreement shall be promptly exchanged between the Parties.

B. The application or use of any information exchanged under or arising from this agreement shall be the responsibility of the Party receiving it, and the other party does not warrant the suitability of such information for any particular use or application.

C. The information exchanges under and arising from this Agreement may be given wide distribution. Such informasion may be made available to the public by either Party through customary channels and in accordance with the normal procedures of the parties. 
D. Copyrights of either Party or of cooperating organizations or persons shali be accoroed treatment consistent with internationally recognized standaros of protection.

E. Proprietary information shall not be accepted for or utilized in this Agreement without an express written agreement entered into oy the parties setting forth the terms and conditions for such acceptance or utilization. For the purposes of this Agreement, proprietary information shall mean information of a confidential nature sucn as trade secrets and knowhow (for example, computer programs, design procedures and techniques, chemical composition of materials, or manufacturing methoas, processes, or treatments) which is appropriately marked, provided sucn information:

1. Has been held in contidence by its owner:

2. Is of a type which is customarily held in contidence by its owner;

3. Has not been trar.smizted by the transmitting party to other entitles (inclucing the receiving party) except on the basis that it be held in confidence, and

4. Is not otherwise available to the receiving party from another source witnout restriction on its further dissemination.

It snall be the responsidility of the party supplying proprietary information to identify the information as such a.d $=$ ensure tnat it is appropriately marked.
F. With respect to any invention or discovery made or conceived in the course of or under this Agreement:

1. If made or conceived by personnel or one party (the assigning party) or its contractors wnile assignea to the other party (the recipient party) or its contractors in connection with exchanges of scientists, engineers and other specialists:

(a) (i) AIT as the recipient party shall acquire all right, title and interest in and to any invention or discovery in the United States of America and in thifd countries, subject to a grant of a nonexclusive, irrevocable, royalty-free license in all such countries to the CCNAA as assigning party and to the chinese chat are in the territory represented by CCNAA and designated by CCNAA.

(ii) CCNAA as the assigning Party shall acquire all right, title and interest in and to any such invention or discovery in the territory represented by CCNAA subject to a grant of a nonexclusive, irrevocable, royalty-free license to AIT as the recipient party and to the nationals of the Unitec States of America designated by AIT.

(b) (i) CCNAA as the recipient party shall acquire all right, title, and inrecest in and to any invention or discovery in the terrtory representea by cinaA and in third countries, subject to a grant of a nonexclusive, irrevocable, soyalty-free license in all such countries to the AIT as assigning party and to the nationals of the united States of Anerica designated by AIT. 
(ii) AIT as the assigning party shall acquire all rignt, title, and interest in and to any sucn invention or discovery in tne United States of America, subject to a grant of a nonexclusive, irrevocable, royaltyfree license to CCNha as the recipient party ano to the Cninese tnat are in the territory represented oy CCNAA and designated Dy CCNAA.

2. (a) If made or conceived Dy CCNAA or its contractors as a direct result of employing information which has been communicatad to it under this Agreement by AIf or its contractors or communicated auring seminars or otner joint meetings, CCNAA making the invention shall acquire all rlght, title, and interest in and to such invention or discovery in all countries, subject to a grant of a nonexclusive, irrevocaole, royalty-free license to AIT and to the nationals of the United States of America designateo by AIr.

(b) If maje or conceived by AIT or its contractors as a direct result of employing information which has been communicated to it under tnis Agreement by CCNAA or its contractors or communicated during seminars or other joint meetings, AIT making tne invention snall acguire all rignt, title, ano interest in and to such invention or discovery in all countries, supject to a grant of a nonexclusive. irrevocable, royalty-fiee license to CCNAA and the Cninese that are in tne territory represented dy CCNAA and designated DY CCNAA.

G. With regard to other specitic forms of cooperation including the exchange ot samples, materials, instruments, and components for testing as contemplaced in Article v. paragrapn $B$ of tnis Agreement, and tne joint projects as contemplated in Article V., paragraph $E$ of tnis Agreement, the parties stall agree in writing as to the appropriate distribution of rignes to inventions or discoveries resulcing from such cooperation. In general, however. AIT should normally aetermine the rights to such inventions in the United states of America, and cCNAA should normally determine the rights to such inventions in the territory represented by CCNAA. Rights to such inventions in otner countries shall be agreed upon by the parties on an equitable basis.

H. CCNAA shall assume tae responsibility to pay awaras or compensation required to be paid to tne chinese that are in the territory represented by CCNAA according to the laws of the territory represented by CCNAA. AIT shall assume the responsiblity to pay awards or compensation required to be paid to the nationals of the United States of America according to the laws of the United States of America.

I. Each party shall take all necessary steps to provice the cooperation from its inventors required to carry out the provisions of this Article.

J. AIt may designate a substitute party in place of AI' for the purposes of this Artigle and may assign or transfer its rignts and authority under tnis Article to said substitute party. 
ARTICLE VIII. Duration and Termination

A. This Agreement shall enter into force upon signature, shall continue in force for a perioo of tive years, and may be amenoed or extended by written agreement of the parties.

B. This Agreement and any annex hereunder may be terminated at any time at the discretion of either party upon six months prior notice in writing to the other. Such termination shall be without prejudice to the rights that may have accrued under this Agreement or Annex to either party up to the date of the termination.

C. All joint efforts and experiments not completed at the termination of tnis Agreement may be continued until their completion under the terms and conditions of this Agreement.

IN WITNESS WHEREOF, the undersigned, being duly authorized thereto for this purpose, have signed this Agreement.

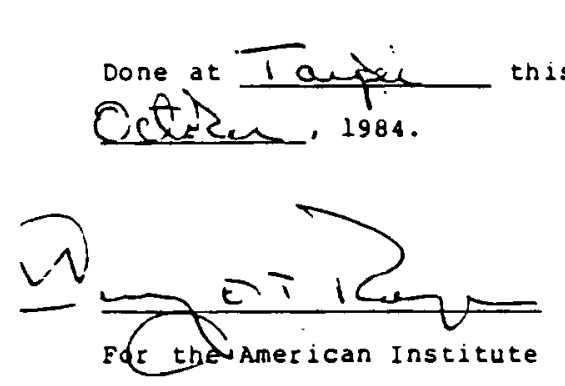

in Taiwan

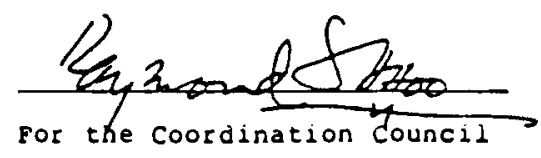

for North American Atfairs 
PUIENTIAL AREAS JT CUOPERWIION DETWEEN

IHE AMERICAN INSTITUTE LIN TAIMGIV A:D CCNAH

IN THE FIELO OF SPENT FLEL HAIDLING AND WASTE MA:WGEMENT

1. AIT will provide technical expert advice to CCNAA on the assessment of the technical feasibility of increasing "at-reactor" storage (tnrough rod consolidation, use of poisoned racks).

2. AIT and CCNiAA will excnange information as agreeo, in the form of oocu ments and reports, review meeting and site visits on researzh and gevelopment projects in the areas of spent fuel handing, transportation storage ano disposal. These incluae pool storage, spent fuel packacing for storage or disposal, dry storage in metal casks, arywells, vaults and concrete silos, the technology of away-from-reactor (AFR) storage monitored retrieval storage (MRS) and repositories. As appropriate site selection cirteria will be incluoed.

3. Representatives of CCNAA will be oriented on the "Cooperative Spent ruel Storage Demonstration Projects" being conducted in the united States. This will be offintingent upon establishment of the necessary overall cooperative arrangement by DOE with utility companies concerneo.

a) AIT may afford CCNAA technical teams the opportunity to observe or provide video tape documention of roo consoljdation demonstration projects being conducted by the Tennessee valley Authority (IVA) and Northeast Utillties. These will include gemonstrations relating to the consolioation of:

-- BWR fuel at the Brovins ferry site of TVA

-- Prir fuel at the Millstone 2 site of vortheast utilities

D) CONAA designated technical teams will oe accordec the opportunity through AIT to observe and obtain technical information from ory storage test and demonstration programs. These could incluoe obtaining vioeo tape oocumentation or direct observation of:

-- A BWR fuel test in a metal cask at the General Electric Company storage site at Morris, Illinois, completed in April 1985.

-- SwR fuel storage demonstrations at the TVA drowns ferry site using: a German manufactureo cask (GNS) with intact fuel

-- Pwri fuel tests in metal casks at tne DoE-Inel

-- A PwR fuel storage oemonstration using metal casks at a utility site (The Surry Plant of the virginia Electr ic and Power Company)

-- A PWR fuel storage demonstration using concrete silos at a utility site (Carolina Power and Light Company)

-- The demonstration of two aual purpose (transport/storage) casks involving Doth PwR and BWR spent fuel.

4. CCNAA representatives will receive orientations relating to proposed monitoreo retrievable storage (MRS) facilities within the united States.

-- CCNAA technical teams could be afforded the opportunity to visit and become knowleogeable about the MRS program witnin the U.S.

-- CCNAA designated engineers would be informed of MRS facility designs Deing developed by an American arcnitect/engineer team. 
5. In the area of yeologic repository development. CCrwat tecrinical teams could be affordeo the opportunity to visit the U.S. and become knowledgeable about repository development activities within the U.S.

- AIt would periodically provide technical experts, on terms to de mutually agreed, to provioe technical assistance to CONAA in the establishment of a program in Taiwan.

-- CCNAA technical personnel woulo have the opportunity to periodically visit and review progress of the waste nanagement program activities in the U.S.

6. As mutually agreed, AIT will arrange for CONiA designees to visit commercial low-level waste management sites in the U.S., and provide technical experts to assist CCNAA in the establishment of low-level waste management related Programs in Taiwan.

7. As matually agreed, AIT oesignated tecnnical experts from the WRC will give lectures on the licensing requirements and procedures for storage, transportation and aisposal of spent fuels and wastes to ICNAA experts. Additionally, AIT will provide on-tne-job training opportunities at $N R C$ on the licensing of spent fuels storage and waste oisposal to CCNAA designated experts.

\section{ATTACHMENT H}

vew I tems $25 / 96$

c. Nuclear Instrumentation and Control (New Program)

\begin{tabular}{|c|c|c|}
\hline Subject & : & $\begin{array}{l}\text { Participating in i and } C \text { jivision of JRivL to scuay } \\
\text { the Jesign and implementation of digital control } \\
\text { systems ano monitoring systems for reactcr doplica. } \\
\text { tion, especially in safety-related appiications. }\end{array}$ \\
\hline Personnel & $:$ & $\begin{array}{l}2 \text { engineers of INER (one for digital control and th } \\
\text { otner for monitoring system oevelopinent). }\end{array}$ \\
\hline \multicolumn{2}{|c|}{ Time requireo: } & 6 months, $1985-1986$. \\
\hline Site & : & OPNL. \\
\hline \multirow[t]{2}{*}{ Oojective } & : & $\begin{array}{l}\text { to obtain technology and overview of current oigita } \\
\text { computers applieo in reactor applications for pur- } \\
\text { poses of: (1) sequence control and (2) generai sur- } \\
\text { veillance with data processing, display and logging }\end{array}$ \\
\hline & & $\begin{array}{l}\text { To practice application of raoiation detection and } \\
\text { analysis on instrumental nethods for variety of mon } \\
\text { toring tasks in the operation of nuclear reactor. }\end{array}$ \\
\hline Resources & : & Travel and living costs shall oe borne by INER. \\
\hline Remark & : & For the details, further negotiation is required. \\
\hline \multicolumn{3}{|c|}{ Me thod of Per sonal Dosimetry } \\
\hline
\end{tabular}

Di Subject : Method of Personal Dosimetry

Personnel $\&$ I AEC officer 
Site $\quad$ : ORNL

Resources : Travel and living costs shall De Dorne by MEC

Remark : To be negociated

02 swject

\section{Per sonnel}

Resources

Remárk

: un-tne-joo training on "Non-gestructive examination of the stored radioactive waste"

: 1 engineer of Zadwaste Haministration

travel and iving costs shall oe oorne by refít

: waiting for DOE response. Coodinators: Dr. Tsai ana Mr. Mcüoff

D3 Enviromental Impact of Radioactive Material Transport (Neu Program "i th Sil)

Sw ject : Research on transportation of radioactive material with emphasis on severe accidents scenarios ano consequence.

Personnel : 1 senior engineer/scientist of Iner.

Tine required: $6-12$ months, $1985-1986$.

Site : Sandia National Laboratory.

objective : To study the advanced technology for the estimation of large-consequence transportation accidents of raoioactive material including spent fuel, raoioactive waste. To analyze the radiological impact of the transportation of raoioactive involves a wide range of events that can have enviromental consequences, e.g. radionuclides release from transportation accidents, enviromental contamination, the prooability ano categories of accident, racionuclide characteristics, and release rate analysis. The radiological impact of the sea transportation accident of raoioative material is a special case in Taiwan, and thus would be an appropriate part of tnis coorperative program. Estadisnment of a long-term relationship on this subject would be nutually beneficial.

Resources : Travel ano living costs shall be jorne oy Inēin.

Remark

\section{G. Spent Fuel Management Programs}

Long-Term Geological di sposal (New Prograin)

Swject : Participating in the $R$ ano $D$ programs of the final disposal of spent fuel.

Personnel : l engineer/scientist of INEH.

Time requireo: 3 months, $1985-1986$.

Site

: To De identifieo.

Gojective : To study and to acquire in-depth understanding of project management, system engineering of spent fuel disposal, thermal and physical scoping of waste package, and cost analysis, etc.

Resources : Travel and livin costs shall be borne by INER.

Remark : This appears to be an appropriate subject and coulo (AIT) be arranged. However, we will need some time to eva- 
luate the specific request ano make arranyements witn the host site. Please try to be somewhat more specific as to what type(s) of yeology may be of interest to you. Further negotiation is requireo.

\section{Mecnanicàl Enüineering}

1. Fracture mechanics and Pipe Rupture Study (New Program with Bike)

Swject : Participate in any on-going program in relate to following research areas:

(1) Design of Fracture-Resistance Nuclear Piping Structure.

(2) Large-scale Fracture Experiment.

(3) Improved Evaluation of vuclear Piping ratigue Damage.

(4) Piping Structure Failure Analysis.

(5) Plastic Fracture methodology.

(6) Thermal Fracture mechancis.

Personnel , I senior engineer/scient ist of INER.

Tine requireo: 12 months, 1986 - 1987.

Site $\quad$ : ENL.

objective : To practice the technology and gain experiences coneming fracture mechanics and pipe rupture analysis for power reactor toenable application to reactor facilities.
Remark

: Very large and complex finite element computer codes require long time for fmiliarization and learning. At least a period of 1 year residence is neeoed to learn the inetnods. Engineers participating must de conpetent inechanical Engineering specialists. Further negotiation is requireo.

2. International Piping Integrity Research Group (IPIRS) (New Program with NRC)

NRC is sponsoring an international piping integrity researcn group. This group's activities will focus on follow-up to NRC's Piping Review Group findings. L. Shao, Deputy birector of the Engineering Division, Gffice of Research will visit $A E C$ Defore the end of the year to aiscuss the freview Group's finoings and explain IPIRG.

AEC/INER/Taipower will review the IPIRG prospectus and discuss with Shao during his visit to Taiwan. Following Shao's visit, a decision will oe inave regaraing Taiwan participation in tne program.

$$
\begin{aligned}
\text { Coordinators: } & \text { NRC - H. Faulkner } \\
& \text { INER - S.I. Chang }
\end{aligned}
$$

Remark: Further negotiation is required.

\section{J. Decommissionino of Nuclear Facilities Proarams}

Decontamination and Decomissioning (New Program)

Subject : Participating in the $R$ and D programs of appropriate agency to inake studies ano collect information con- 
cerning the aecomissioning of Nuclear reactors ano related facilities, which include the decomissioning al ternatives, decontamination requirements, cost/benefit anlaysis for various decommissioning strategies, project planning and inanagement,

radiation protection program, waste management ano quality assurance.

\section{Personnel : l engineer/scientist of INER.}

Time required, To be negatiated.

Site

- To de identified.

objective : To obtain the technical experiences and knowlegge of decomissionng of nuclear facilities which Taiwan is planning to resolve in the next two cecades.

Remark : This appears to be an appropriate subject and could (AIT) be arrngned. However, the specifics of the program location and time requirea will need to be negotiated. The AIt side will make specific suggestion witnin 1 month. Further negotiation is requireo. 



\title{
UNITED KINGDOM (UK)
}

BLANKET AGREEMENT (Attachment UK-1)

Parties: $\quad$ US/DOE; UK/Atomic Energy Authority (UKAEA)

Term:

September 20, 1976 to September 20, 1986

Technical Scope: LMFBR technology. Areas specific to the fuel cycle and waste management include FBR fuel fabrication and reprocessing, waste processing and storage, and management of sodi um waste.

\section{SUBSIDIARY AGREEMENTS}

Decommissionfing Nuclear Facilities (Attachment UK-2)

\section{STATUS/PLANNING REPORTS}

None

\section{ADMINISTRATION}

\author{
Principal Coordinators: US -- C. R. Cooley (DOE) \\ UK -- R. H. Flowers (UKAEA-Harwe11) \\ Document Exchange: see Appendix C
}




\section{AGREF.MENT}

between

THE UNITED STATES ENERGY RESEARCH AND DEVELOPMENT ADMINISTRATION

and the

IJNITED KINGDOM ATOMIC ENERGY AUTHORITY

in the field of

LIOUID METAL-COOLEN FAST BREEOER REACTORS

This Agreement is made as of the 20th day of September, 1976 between the United States Energy Research and Development Administration (hereinafter referred to as "ERDA") having their principal office at 20 Massachusetts Avenue, NW, washington, DC 20545, and the linited Kingdom Atomic Fnergy Authority (hereinafter referred to as "UKAEA") having their principal office at 11 Charles II Street, London SWIY 4QP, hereinafter called the Parties.

WHEREAS

The United States Atomic Energy Commission (USAEC) and UKAEA have exchanged research and developinent information in the field of fast reactors under the terms of an "Arrangement" between them that became effective on 11 February 1965.

Certain responsibilities of the USAEC were transferred to ERDA on 13 January 1975, and the exchange of fast reactor information between the USAEC and UKAEA has continued as between EROA and UKAEA since that date.
The "Arrangement" of 11 February 1965 has been terminated on 20 July 1976, with the expiration of the Agreement between the Governments of the United States and the United Kingdom for Cooperation on the Civil Uses of Atomic Energy signed on 15 June 1955, as amended.

ERDA and IKAEA have a mutual interest in developing the Liquid Metal-Cooled Fast Breeder Reactor (LMFBR) and in maintaining important roles in such development.

ERDA and UKAEA wish to continue close and long-term cooperation in the field of LMFBR technology which, for purposes of this Agreement, includes research, development and demonstration.

ERDA and IJKAEA recognize the need to establish procedures governing the protection of privileged or confidential information in connection with activities under this Agreement.

IT IS AGREED AS FOLLOWS

\section{ARTICLE 1}

The objective of cooperation under this Agreement is to establish, for the mutual benefit of the Parties, a reasonably balanced exchange of LMFBR technology. The areas and forms of cooperation are listed under Articles 2 and 3 , respectively.

\section{ARTICLE 2}

The areas of cooperation in LMFBR technology covered by this Agreement may include: 
1. Reactor neutronics analysis and experimentation, to include reactor shielding and nuclear data.

2. Reactor safety.

3. Fuels and materials, to include structural, component, absorber and circuit materials.

4. Fuel cycle including fabrication, reprocessing, waste processing and storage.

5. Reactor and sodium systems and their associated components, to include component and system design, instrumentation and control, thermal hydraulics and structural analysis.

6. Sodium technology, to include detection of impurities, purification, control, component decontamination, sodium leaks and sodium fires.

7. Non-nuclear test facilities which support LMFBR programs.

R. Quality assurance and nondestructive practices.

9. Overall LMFBR programs of the US and UK.

10. Operation of LMFBRs.

11. Economic and environmental considerations.

12. Topics of interest to industry (design, construction experience, quality assurance).

Other areas of cooperation may be added by mutual agreement.

\section{ARTICLE 3}

Cooperation in accordance with this Agreement may include but is not limited to the following forms:

1. Exchange of scientists, engineers and other specialists for participation in agreed research, development, analysis, design and experimental activities conducted in scientific centers, laboratories, engineering offices and reactor facilities of each of the Parties or its contractors for agreed periods. Such exchanges of staff shall be in accordance with Article 9 of this Agreement .

2. Exchange of samples, materials, instruments and components for testing.

3. Exchange of scientific and technical information and results and methods of research and development.

4. The organization of seminars and other meetings on specific agreed topics concerning LMFBR technology in the areas listed in Article 2, in a manner agreed by the Joint Coordinating Committee (Article 4). Such seminars shall normally be held alternately in the US and UK for each topic.

5. Short visits by specialist teams or individuals to the LMFBR facilities of the other Party.

6. The use by one Party of the facilities owned or operated by the other Party. Such use of facilities shall be the subject of 
separate agreements between the Parties, and may be subject to commercial terms and conditions.

7. Joint projects in which the Parties agree to share the work and/or costs. Each such joint project shall be the subject of a separate agreement between the Parties.

Other specific forms of cooperation may be agreed by the Parties and approved by the Joint Coordinating Committee.

\section{ARTICLE 4}

1. To supervise the execution of this Agreenent, a Joint ERDA/UKAEA Coordinating Committee in the field of Liquid Metal-Cooled Fast Breeder Reactors shall be established. This Committee shall meet each year alternately in the US and IIK, or at other agreed times and places. The Head of the Delegation of the Receiving Party shall act as Chairman during meetings of the Committee.

2. At its meetings, the Joint Coordinating Committee shall evaluate the status of cooperation under this Agreement. This evaluation shall include a comprehensive review of each Party's LMFBR program status and plans, an assessment of the balance of exchanges in the various areas of cooperation listed in Article 2, and a consideration of measures required to correct any imbalances. In addition, the Joint Coordinating Committee shall consider and act on any major new proposals for cooperation.
3. For periods between meetings of the Joint Coordinating Committee, each Party shall nominate one person to act on its behalf in all matters concerning cooperation under this Agreement.

4. Day to day management of the cooperation under this Agreement shall be carried out by correspondents or others designated by the persons nominated under paragraph 3 of this Article.

\section{ARTICLE 5}

1. Where it is decided a cooperative program or project under this Agreement should be subject to a formalized specific memorandum of agreement executed by both Parties, the specific agreement should cover all detailed provisions for implementing that agreement including such matters as patents, exchange of equipment and information disclosure specific to the particular program or project.

\section{ARTICLE 6}

1. General

The Parties support the widest possible dissemination of information provided or exchanged under this Agreement, subject to the need to protect proprietary information exchanged hereunder, and to the provisions of Article 8. 
2. Use of Proprietary Information

A. Definitions as used in this Agreement:

(i) The term "information" means scientific or technical data, results or methods of research and development, and any other information intended to be provided or exchanged under this Agreement;

(ii) The term "proprietary information" means information which contains trade secrets or commercial or financial information which is privileged or confidential, and may only include such information which:

a) has been held in confidence by its owner;

b) is of a type which is customarily held in confidence by its owner;

c) has not been transmitted by the transmitting Party to other entities (including the receiving Party) except on the basis that it be held in confidence; and

d) is not otherwise available to the receiving Party from another source without restriction on its further dissemination.

B. Procedures

(i) A Party receiving proprietary information pursuant to this Agreement shall respect the privileged nature thereof. Any document which contains proprietary information shall be clearly marked with the

following (or substantially similar) restrictive legend:

"This document contains proprietary information furnished in confidence under an Agreement dated between the United States Energy Research and Development Administration and the United Kingdom Atomic Energy Authority and shall not be disseminated outside these organizations, their contractors, licensees and the concerned departments and agencies of the governments of the US and UK without the prior approval of

This notice shall be marked on any reproduction hereof, in whole or in part. These limitations shall automatically terminate when this information is disclosed by the owner without restriction."

(ii) Proprietary information received in confidence under this Agreement may be disseminated by the receiving Party to:

a) persons within or employed by the receiving Party, and concerned Government departments and Government agencies in the country of the receiving Party;

b) prime or subcontractors of the receiving Party located within the geographical limits of the receiving Party's nation, for use only within the framework of their contracts with the receiving Party in work relating to the subject matter of the proprietary information;

c) organizations licensed by the receiving Party in the field of development, design and construction 
of LMFBRs and their fuel for use only within the

terms of such licenses.

provided that any proprietary information so

disseminated shall be pursuant to an agreement of

confidentiality and shall be marked with a

restrictive legend substantially identical to that appearing in subparagraph $2 . B(i)$ above.

(iii) With the prior written consent of the Party providing proprietary information under this Agreement, the receiving Party may disseminate such proprietary information more widely than otherwise permitted in the foregoing subsection (ii). The Parties shall cooperate with each other in developing procedures for requesting and obtaining approval for such wider dissemination, and each Party will grant such approval to the extent permitted by its national policies, regulations and laws.

C. Each Party shall exercise its best efforts to ensure that proprietary information received by it under this Agreement is controlled as provided herein. If one of the Parties becomes aware that it will be, or may reasonably be expected to become, unable to meet the nondissemination provisions of this Article, it shall immediately inform the other Party. The Parties shall thereafter consult to define an appropriate course of action.
D. Information arising from seminars and other meetings arranged under this Agreement and information arising from the attachments of staff, use of facilities and joint projects shall be treated by the Parties according to the principles specified in this Article; provided, however, no proprietary information orally communicated shall be subject to the limited disclosure requirements of this Agreement unless the individual communicating such information places the recipient on notice as to the proprietary character of the information communicated.

E. Nothing contained in this Agreement shall preclude the use or dissemination of information received by a Party other than pursuant to this Agreement.

\section{ARTICLE 7}

Information transmitted by one Party to the other Party under this Agreement shall be accurate to the best knowledge and belief of the Transmitting Party, but the Transmitting Party does not warrant the suitability of the information transmitted for any particular use or application by the Receiving Party or by any third Party. Information developed jointly by the Parties shall be accurate to the best knowledge and belief of both Parties. Neither Party warrants the accuracy of the jointly developed information or its suitability for any particular use or application by either Party or by any third Party. 
1. With respect to any invention or discovery made or conceived in the course of or under this Agreement:

a. If made or conceived by personnel of one Party (the Assigning Party) or its contractors while assigned to the other Party (Recipient Party) or its contractors, in connection with exchanges of scientists, engineers and other specialists;

(1) The Recipient Party shall acquire all right, title and interest in and to any such invention or discovery in its own country and in third countries, subject to a nonexclusive, irrevocable, royalty-free license in all such countries to the Assigning Party, with the right to grant sublicenses, under any such invention or discovery and any patent application, patent or other protection relating thereto, for use in the production or utilization of special nuclear material or atomic energy.

(2) The Assigning Party shall acquire all right, title and interest in and to any such invention or discovery in its own country, subject to a nonexclusive, irrevocable, royalty-free license to the Recipient Party, with the right to grant sublicenses, under any such invention or discovery and any patent application, patent or other protection relating thereto, for use in the production or utilization of special nuclear material or atomic energy.

b. If made or conceived by a Party or its contractors as a direct result of employing information which has been communicated to it under this Agreement by the other Party or its contractors or communicated during seminars or other joint meetings, the Party making the invention shall acquire all right, title and interest in and to such invention or discovery in all countries, subject to a grant to the other Party of a royalty-free, nonexclusive, irrevocable license with the right to grant sublicenses in and to any such invention or discovery and any patent application, patent or other protection relating thereto, in all countries for use in the production or utilization of special nuclear materials or atomic energy.

c. With regard to other specific forms of cooperation, including loans or exchanges of materials, instruments and equipment for special joint research projects, the Parties shall provide for appropriate distribution of rights to inventions or discoveries resulting from such cooperation. In general, however, each Party should normally own the rights to such inventions or discoveries in its own country with a nonexclusive, irrevocable, royalty-free license to 
the other Party, and the rights to such inventions or discoveries in other countries should be agreed by the Parties on an equitable basis.

d. It is understood that after the European Patent Conventions have come into force, either Party may request a modification of this paragraph 1 for the purpose of according equivalent rights as provided in subparagraphs 1 .. $-c$. above under the European Patent Conventions.

2. Neither Party shall discriminate against citizens of the country of the other Party with respect to granting any license or sublicense under any invention or discovery pursuant to paragraph 1 above. It is understood that the licensing policies and practices of each Party may be affected because of the rights of both Parties to grant licenses within a single jurisdiction. Accordingly, either Party may request, in regard to a single invention or discovery or class of inventions or discoveries, that the Parties consult in an effort to lessen or eliminate any detrimental effect that the parallel licensing authorities may have on the policies and practices of the Parties.

3. Each Party shall assume the responsibility to pay awards or compensation required to be paid to its own nationals according to its own laws.

\section{ARTICLE 9}

1. Whenever an exchange of staff is contemplated under this Agreement, each Party shall ensure that qualified staff are selected for attachment to the other Party.

2. Each such attachment of staff shall be the subject of a separate attachment agreement between the Parties.

3. Each Party shall be responsible for the salaries, insurance and allowances to be paid to its personnel.

4. Each Party shall pay for the travel and living expenses of its personnel while on attachment to the host Party unless otherwise agreed.

5. The host establishment shall arrange for comparable accommodations for the other Party's personnel and their families on a mutually agreeable reciprocal basis.

6. Each Party shall provide all necessary assistance to the attached staff (and their families) of the other Party as regards administrative formalities (travel arrangements, etc.).

7. The personnel of each Party shall conform to the general and special rules of work and safety regulations in force at the host establishment, or as agreed in separate attachment of staff agreements.

8. Liabilities incurred during attachment of staff shall be covered in separate attachment of staff agreements. 


\section{ARTICLE 10}

The provisions of this Agreement shall not affect the rights or duties of the Parties hereto under other agreements or arrangements. This Agreement also in no way precludes commercial firms or other legally constituted enterprises in each of the two countries from engaging in commercial dealings in accordance with the applicable laws of each country; nor does it preclude the Parties from engaging in activities with other Governments or persons. Moreover, it is expected that the present Agreement should facilitate industrial and commercial exchanges in the field of LMFBR between the firms of the countries of the Parties with a view to mutual benefits from such exchanges for both countries. IJKAEA has funded and expects to continue to fund substantial development work on fast reactor technology. Use of the results of such technology by industrial organizations in the IJK is governed by appropriate regulations and agreements involving UKAEA. Accordingly, UKAEA will seek to coordinate arrangements with UK industrial organizations involving such technology. ERDA shall act as the point of coordination for contracts and arrangements involving US commercial firms when such firms or enterprises act on behalf of the US Government under the terms of this Agreement. It is understood that all such contracts and arrangements shall conform with applicahle laws and regulations under which each Party operates.

\section{ARTICLE 11}

Cooperation under this Agreement shall be in accordance with laws of the respective countries and the regulations of the respective Parties. All questions related to the Agreement arising during its term shall he settled by the Parties by mutual agreement.

\section{ARTICLE 12}

Except when otherwise specifically agreed at the time, all costs resulting from cooperation under this Agreement shall be borne by the Party that incurs them. It is understood that the ability of the Parties to carry out their obligations is subject to the availability of appropriated funds.

\section{ARTICLE 13}

1. This Agreement shall enter into force upon signature and, subject to paragraph 2 of this Article, shall continue for a five (5)-year period. This Agreement may be extended subject to agreement by the Parties following a review of accomplishments under the Agreement.

2. This Agreement may be terminated at any time at the discretion of either Party, upon six (6) months advance notification in writing by the Party seeking to terminate the Agreement. Such termination shall be without prejudice to the rights which may have accrued under this Agreement to either Party up to the date of such termination.

3. The Parties agree that all discussions, meetings, exchanges of documents or other acts of cooperation hetween them since the termination of the "Arrangement" of 11 February 1965, and prior to signature of this Agreement which, if they had occurred 
subsequent to the signature of this Agreement, would have been subject to this Agreement, shall be subject to the terms hereof.

4. In the event that, during the period of this Agreement, the nature of either Party's LMFBR program should change substantially whether this be by substantial expansion, reduction, transformation or amalgamation of major elements with the LMFBR program of a third party, either Party shall have the right to request revisions in the scope and/or terms of this

Agreement .

5. All joint efforts and experiments not completed at the termination of this Agreement shall be continued until their completion under the terms of this Agreement. this

FOR THE UNITED STATES
ENERGY RESEARCH AND

DEVELOPMENT ADMINISTRATION

NAME: Siv S 9Sink. 121

Director, Division of Reactor

TITLE: Development and Demonstration
FOR THE UNITED KINGNOM

ATOMIC ENERGY AUTHORITY

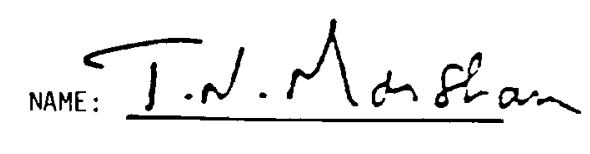

Deputy Managing Director,

TITLE: The Reactor Group 


\section{Er. C. A. Welch}

Heac, Technical Secretariat

United Kingrom Stomic Enaroy Authority

Risley, Werrington, Cheshire WAz $6 A T$

Unites Kingocm

Des: Dr. Welch:

I am pleased to inform you that the unitej States nepartment of Eneroy considers that your letter of April 30, 1981, tozether tith this reply, constitute an egreegent to extent in force until septerber 20,1986 the existing hareement between the Unites States Department of Energy and the United Kingiom Atomic Energy Authority in the fiels of Liguid Metol-Coslej

fast erecier feactors signea on Septenter 20,1576, es amenjce

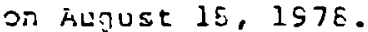

We lool: forvari to continus $J$ and expanding cosperation in tris imporzant fielt.

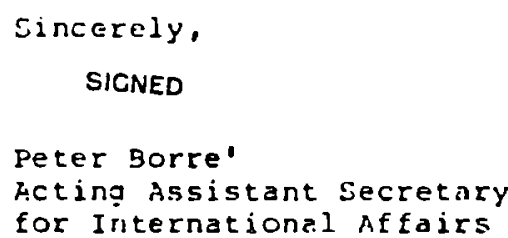

M/R: This action takes into aocount the Memo from the AS/NE dated Nov 13, 1731 sukj: Extension of the US DOE/UK Atanic Energy Authority Cooperative Agreenent in Lizuid Metal Fast Breeder Reactors.
bec w/incoming:
M. Gates, NE-1
T. Dillon, NE-50
N. Goldenberg, NE-520
R. Staker, NE-560
S. Rosen, NE-523
A. Perae, NE-30
A. Perae, NE-30
H. Bengelsdorf, IA-2I
L. Singer, $G-32$

K. Izell, GC-42
S. Griffith, IA-22
J. Boright, DOS/OES/NTS HGhandild

OFFICIAL FILE COPY 
Risley Nuclear Power Development Establishment United Kingdom Atomic Energy Authority

Risley, Warrington. Cheshire WA3 6AT.

\section{Risley}

UKAEA Northern Division

Telex: 629301

Telephone:Wornington (0925) 31244

Extension: 3394

Date: 30 April 1981

Dr J Vanderryn

Director

Office of Technical Co-operation

LUS DOE

liashington DC 20585

USA

\section{Dear Dr Vanderryn}

The Agreement signed on 20 September 1976 between the United Kingoiom. Alonic Energy Authority and the United States Energy Research $\&$ Developmient Adisinistration, and continued with the United States Department of Energy in the field of Liquid lietal-Cooled Fast Breeder Reactors is due to terminate in September 1981.

At the annual meeting in December 1980 of the Joint Co-ordinating Comnittee established under Article 4 of this Agreement both sides agreed that the co-operation between our two organisations had been of considerable value to both parties and that early in IgSi steps should be taken to renew the agreement for another 5 years without modification.

I therefore have pleasure in proposing on behalf of the UKAEA that tnis letter and your reply agreeing to the extension on behalf of USDOE should constitute an agreement to extend the Lhit BP. Aoreement untıl 20 Septenber 1986.

Yours sincerely

$$
\lim \sqrt{c 2}
$$

GA $1: E L C H$

Head, Technical Secretariat 


\section{AGREEMENT}

be tween

THE UNITED STATES DEPARTMENT OF ENERGY

and

THE UNITED KINGDOM ATOMIC ENERGY AUTHORITY

in the field of

OECOMMISSIONING NUCLEAR FACILITIES
THIS AGREEMENT made as of the 1st day of March 1985

BETWEEN

THE UNITED STATES DEPARTMENT OF ENERGY

(hereinafter referred to as "USDOE")

having their principal office at

1000 Independence Avenue, S.W.

Washington, DC 20585

- and -

THE UNITED KINGOOM ATOMIC ENERGY

(hereinafter referred to as "UKAEA")

having their principal office at

11 Charles II St, London, SW14Q

\section{WHEREAS}

USDOE and UKAEA have a mutual interest in cooperation by means of technical exchanges in the field of decommissioning nuclear facilities. USDOE and UKAEA recognize the need to establish procedures governing the exchange of information in connection with future cooperation and to provide for the possibility of short term assignments of personnel to key decommissioning projects.

It is agreed as follows

\section{ARTICLE I}

The objective of cooperation under this Agreement is to establish, for the mutual benefit of the Parties, a reciprocal (balanced) exchange of decommission-

\section{ARTICLE 2}

The subjects of cooperation are listed in Appendix I to this Agreement and may be modified by written amendment to this Agreement. This cooperation shall not include any information or matters with a national security classification. 


\section{ARTICLE 3}

Cooperation in accordance with this Agreement may include, but is not 1 imited to, the following forms:

1. Exchange of scientific and technical information and results relevant to the topics of the exchange as listed in Appendix I.

2. Short visits by specialist teams or individuals to the appropriate facilities of the other Party.

3. Short term assignments of staff from one Party to the other may be arranged, and each such assignment shall be the subject of a separate agreement pursuant to Article 12 of this Agreement.

4. Exchanges of samples, materials, instruments, components, and equipment for testing. Each such exchange shall be the subject of a separate written agreement.

Other specific forms of cooperation may be agreed by the Parties from time to time in writing.

\section{ARTICLE 4}

1. General

The Partfes support the widest possible dissemination of information provided or exchanged under this Agreement, subject to the need to protect proprietary information exchanged hereunder and to the provisions of Article 6.

\section{Use of Proprietary Information}

A. Definitions as used in this Agreement

(i) The term "information" means scientific or technical data, result or methods of research and development, and any other information intended to be provided or exchanged under this Agreement.

(ii) The term "proprietary information" means information which contains trade secrets or commercial or financial information which is priviled or confidential, and may only include such information

(a) has been held in confidence by its owner;

(b) is of a type which is customarily held in confidence by its owner:

(c) has not been transmitted by the transmitting Party to other entities, including the receiving Party, except on the basis that it be held in confidence; and

(d) is not otherwise available to the receiving Party from another source without restriction on its further dissemination.
B. Procedures

(1) A Party receiving proprietary information pursuant to this Agreement shall respect the privileged nature thereof. Any document which contains proprietary information shall be clearly marked by the Party transmitting the document with the following restrictive egend:

"This document contains proprietary information furnished in conf idence under an Agreement dated United States Department of Energy and United Kingdom Atomic Energy Authority and shall not be disseminated outside these organizations, their contractors, licensees, and the concerned departments and agencies of Governments of the United States and
United Kingdom without prior approval of

"This notice shall be marked on any reproduction hereof, in whole or in part. These limitations shall automatically terminate when

(ii) Proprietary information received in confidence under this Agreement may be disseminated by the receiving Party to:

(a) persons within or employed by the receiving Party, and concerned Government departments and Government agencies in the country of the receiving Party;

(b) prime or subcontractors of the receiving Party located within the geographical limits of the receiving Party's nation, for use only within the framework of their contracts with the receiving Party in work relating to the subject matter of the proprietary information; and

(c) organizations licensed by the receiving Party in the field of decommissioning techniques and technology for use only within the terms of such licenses:

provided that any proprietary information so disseminated shall be pursuant to an agreement of confidentiality and shall be marked with a restrictive legend substantially identical to that

(i1i) With the prior written consent of the Party providing proprietary information under this Agreement, the receiving Party may disseminate such proprietary information more widely than otherwise cooperate with each other in developing procedures for requesting and obtaining prior written consent for such wider dissemination. its each Party shall grant such approval to the extent permitted by its national policies, regulations, and laws.

C. Each Party shall exercise its best efforts to ensure that proprietary information received by it under this Agreement shall be controlled as provided herein. If one of the Parties becomes aware that it will be, 
or may reasonably be expected to become, unable to meet the nondissemination provisions of this Article, it shall inmediately inform the other Party. The Parties
appropriate course of action.

D. Information arising from seminars and other meetings arranged under this Agreement shall be treated by the Parties according to the principles specified in this Article; provided, however, no proprietary information orally communicated shall be subject to the limited disclosure requirenents of this Agrement unless the individua cormunicating such information places the recipient on notice as to the proprietary character of the information communicated.

\section{ARTICLE 5}

Information transmitted by one Party to the other Party under this Agreement shall be accurate to the best knowledge and belief of the Transmitting Party, but the Transmitting party does not warrant the suitabile tre transmitted for any particular use or application by the Receiving party or by to the accuracy of the jointly developed infonmation or its suitability for any particular use or application by either Party or by any third Party.

\section{ARTICLE 6}

1. With respect to any invention or discovery made or conceived in the course of or under this Agreement:

a. If made or conceived by personnel of one Party (the Assigning Party) or its contractors while assigned to the other Party (Recipient Party) or its contractors in connection with exchanges of scientists, engineers, and other specialists:

(1) The Receiving Party shall acquire all right, title, and interest in and to any such invention or discovery in its own country and in third countries, subject to a non-exclusive, irrevocable, royalty-free license to the Assigning Party, its Government, and its nationals designated by it, under any such invention or discovery and
application, patent, or other protection relating thereto.

(2) The Assigning Party shall acquire all right, title, and interest In and to any such invention or discovery in its own country, subject party its Government, and its nationals designated by it, under any such invention or discovery and any patent application, patent, or other protection relating thereto.

b. If made or conceived by a Party or its contractors as a direct results of employing information which has been communicated to it under this
Agreement by the other Party or its contractors or communicated during seminars or other joint meetings, the Party making the invention shall acquire all right, title and interest in and to such invention or discovery in all countries, subject to the grant to the other Party, its Government, and its nationals designated by it, of a non-exclusive, irrevocable, royalty-free license in and to any such invention or patent application, patent, or other protection thereto, in all countries.

c. With regard to other specific forms of cooperation, including exchanges of samples, materials, instruments, components, and equipment as provided in Article 3 of this Agreement, the Parties shall provide for appropriate distribution of rights to inventions or discoveries resulting from such cooperation. In general, however, each Party should normally own the rights to such inventions or discoveries in its own country with a non-exclusive, irrevocable, royalty-free license to the

other Party, and the rights to such inventions or discoveries in other countries should be agreed by the Parties on an equitable basis.

2. Each Party shall assume the responsibility to pay awards or compensation required to be paid to its own nationals according to its own laws.

\section{ARTICLE 7}

Each Party shall be prepared to advise the other upon specific request and to the best of its ability on particular questions involving the topics of this Agreement.

\section{ARTICLE 8}

A coordinator shall be designated by each Party, who shall develop and control the arrangements and procedures for implementing the cooperation, in particular the effective exchange of information under this Agreement. Approximately annually, the coordinators shall organize joint working sessions at which achievements, problems, effectiveness, and future programs will be discussed with the objective of improving the cooperation. These working sessions will nomally be held in the United States and the United Kingdom on alternate years. other visits may be requested by either Party in addition to the annual working sessions.

\section{ARTICLE 9}

It is understood that the ability of the Parties to carry out their obligations under this Agreement is subject to the availability of appropriated funds. Cooperation under this Agreement shall be in accordance with the laws of the of this Agreement shali be settled by mutual agreement between the Parties.

\section{ARTICLE 10}

No provision is made for reciprocal cost reimbursement between the Parties such as travel expenses and subsistence allowances for their staff members and cost of transport for apparatus and other equipment transported under this Agreement into the territory of the other Party. Except when otherwise specifically agreed at the time, all costs resulting from cooperation under this Agreement shall be borne by the Party that incurs them. 


\section{ARTICLE 11}

1. This Agreement shall enter into force upon signature and shall continue in force for a period of four years unless sooner terminated in accordance with paragraph 4 below.

2. This Agreement may be amended or extended at any time by written agreement of the Parties.

3. Cooperation under this Agreement shall be reviewed by the Parties at the end of the third year this Agreement has been in force to consider the possibility of a mutually-agreeable extension of the Agreement.

4. This Agreement may be terminated at any time upon six months advance notice rights which may have accrued to either Party up to the date of termination.

\section{ARTICLE 12}

1. Short term assignments of qualified personnel from one Party to the other may be arranged and each assignment shall be subject to a separate agreement.

2. Each personnel assignment agreement shall be subject to the terms of this Agreement.

3. Each agreement for personnel assignment shall include statements regarding the name of the assignee, the location of the assignment, the attachment in the Recipient Party organization, the nature of the duties in the Recipient Party organization, the term of the assignment, provisions to be made by the Recipient Recipient Party, provisions for liability in the event of accident or other casualties, availability of reports and other information prepared by the assignee, protection of proprietary information, rights to inventions and discoveries made by the assignee arising from the assignment, and other matters that are deemed appropriate by the Parties.

4. Each Party shall be responsible for the salary, allowances, insurance, travel, living expenses, and any other costs that may be identified in the personnel assignment agreement.

5. Each Party shall provide office space, secretarial assistance, telephone access, and other office support to the assigned personnel.

6. Assigned personnel shall conform to the general and special rules of work and safety regulations in force at the Recipient Party's establishment.
Agreement Between the United States Department of Energy Ginacon Atomic Energy tuthority in the

Field of Deconmissioning Nuclear Facilities

Done in duplicate at Washingtan, D.C. this lst day of March . 1985.

For the United Kingdom Atomic Energy Authority:

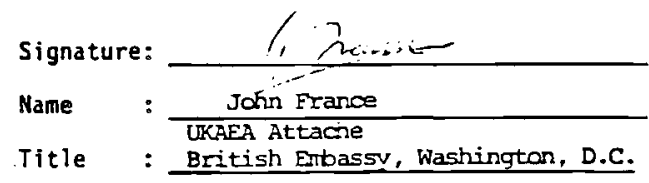

For the United States Department of Energy

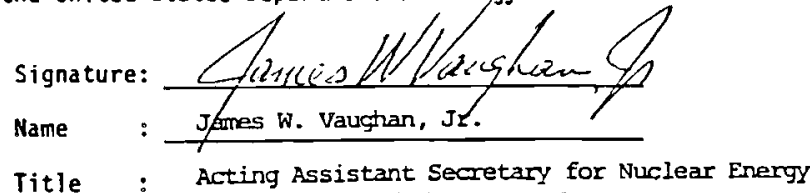


APPENDIX I

Technical Areas of Cooperation and Exchange

1. Information on the planning and accomplishment of the Shippingport Station Decommissioning Project and the Windscale AGR decommissioning project. The information exchanged will include the techniques used, schedule, costs,

manpower, radiation exposures, and waste arisings, as well as other matters relevant to these projects. The treatment, packaging, storage, transportation and disposal methods, and costs for wastes arising from the decomissioning operations for these projects will be included.

The Organisation for Economic Co-operation and Development, Nuclear Energy Agency (NEA), may propose an NEA-sponsored cooperative project for information NEA cooperative project is established and the UKAEA and USDOE agree, the exchange of information on the Shippingport and Windscale AGR decommissioning projects could be implemented under the NEA-sponsored project.

2. Information on other reactor and fuel cycle decommissioning projects that are being conducted in the Department of Energy Surplus Facilities Management Program or in the United Kingdom Atomic Energy Authority program. The information exchange $w i l l$ be the same in scope as that exchanged for the Shippingport and Windscale AGR decomstissioning.

3. Information on technology research and development for decormissioning including techniques, performance characteristics, costs, and other features relevant to use of the technology for decommisstoning. 



\section{COMMISSION OF THE EUROPEAN COMMUNITIES (CEC)}

BLANKET AGREEMENT (Attachment CEC-1)

Parties: US/DOE; European Atomic Energy Community

Term: $\quad$ October 6, 1972 to October 6, 1987

Technical Scope: Characterization of waste forms; disposal in geologic formations

STATUS/PLANNING REPORTS

None

\section{ADMINISTRATION}

Principal Coordinators: US -- C. R. Cooley (DOE)

CEC -- S. Orlowsk 1

Document Exchange: see Appendix C 
AGRFEMENT FOR EXCHANGE OF INFORMATION CONCERNING A CCOPERATIVE PROGRAM IN THE FIELD OF MANAGEMENT OF RADIOACTIVE HASTES BETHEEN THE UNITED STATES DEPARTMENT OF ENERGY AND THR EUROPEAN ATOMIC ENERGY COMYUNITY

The Department of Energy of the United States of America, (DOE), and the European Atomic Energy Community (EURATOM), acting tbrough and represented by the Commission of the European Communities, hereinafter referred to as the Parties,

having a mutual interest in the development of radioactive vaste management techniques;

recognizing the advantages of sharing inforation derived from their respective experience and capabilities;

noting the statutory authority of DOE to disseminate information related to nuclear energy and

desiring to engage in specific cooperative arrangements to exchange a broad range of information concerning radioactive waste management

have agreed as follows:
ARTICLE 1

The objective of cooperation under this Agreement is to establish, for the mutual benefit of the Parties, a reasonably balanced exchange of information in the area of the management of radioactive wastes. The areas and forms of cooperation are listed under Articles 2 and 3 respectively.

\section{ARTICLE 2}

The areas of cooperation covered by this Agreement include (see attachment 1), but are not limited to:

1. Characterization of waste forms;

2. Disposal in geologic formations.

Other areas may be added by the Parties by mutual agreement in writing, pursuant to Article 14, paragraph 1, below.

\section{ARTICLE 3}

Cooperation in accordance with this Agreement may include, but is not limited to, the following forms:

. Exchange of scientists, engineers and other specialigts. Such exchanges of staff shall be in accordance with Article 9 of this Agreement.

2. Exchange of samples, materials, instruments and components for testing, as agreed in writing by the Parties.

3.' Exchange, on a current basis, of scientific and technical information, and results and methods of research and development.

4. The organization of seminars and other meetings on specific agreed topics concerning waste management technologies in the areas listed 
in Article 2, in a maner agreed by the Coordinators (Article 4).

5. Short visits by specialist reams or individuals to the research and development facilities of the other Party including in the case of EURATOM such facilities of the Member States which agree thereto. All vigits and assignments to the laboratories or facilities of a researcb institute of a Member State shall require the prior written consent of such institute.

Other specific forms of cooperation may be added by the Parties by mutual agreement pursuant to Article 14, paragraph 1, below, in writing that includes such matters as patents, exchange of equipwent and information disclosure specific to the particular program or project.

\section{ABIICLE 4}

1. To supervise the execution of this Arreement, the Parties will name Coordinators. As deemed necessary the Coordinators shall meet to evaluate tha status of cooperation mider this Agreemenc. This evaluation shall include a comprehensive review of each Party's radioactive vaste management program status plans, an assessment of the balance of exchanges in the various areas of cooperation listed in Article 2, and a consideration of measures required to correct any imbalances. In addition, the Coordiators shall consider and act on any major new proposals for cooperation. These meetings shall be beld altematively in the Comounity and in the Onited States.

2. Day to day management of the cooperation under this Agreement shall be carried out by correspondents desigated by the Coordinators. The correspondenta shall be responsible for the working contacts between the Parties in their respective areas of cooperation.
1. General.

Each Party shall make available to the other Party information which they have the right to disclose and which is either in their possession or available to them. The Parties support the widest possible dissemination of information provided or exchanged under this Agreement, subject to the need to protect proprietary information exchanged hereunder, and to the provisions of Article 7 .

2. Definitions, procedures and use of proprietary information.

A. Definitions as used in this Agreement:

(i) The term "information" means scientific or technical data, resules or methods of research and development, and any other inforwation intended to be provided or exchanged under this Agreemenc.

(ii) The term "proprietary information" means information which contains trade secrets or comercial or financial information which is privileged or confidential, and may only include such information which:

a) has been held in confidence by its ouser;

b) is of a type which is customarily held in confidence by its owner;

c) bas not been transmitted by the transmitting Party to otber eatities (including the receiving Party) except on the basis that it be held in confidence; and

d) is not otherwise available to the receiving Party from another source without restriction on its furtber dissemination.

B. Procedures and use of proprietary information

(i) A Party receiving proprietary information pursuant to this Agreement shall respect the privileged nature thereof. Any document which contains proprietary informacion shall be clearly marked with the following (or substancially similar) rescrictive legend: 
"This doctment concains proprietary information furnished in confidence under an Agreement dated O.P.t.8t ar 6, 1982

betueen the United States Department of Energy and the European Acomic Energy Community and shall not be disseminated outside these organizations, their contractors, licensees and the concerned departments and agencies of the government of the U.S., of the European Atomic Energy Community (EURATOM) and of the Goverments of the Member States of Euratom wichour the prior approval of the Coordinator of the transmitring Party. This notice shall be marked on any reproduction bereof, in whole or in part. These limitations shall automatically terminate when this information is disclosed by the ouner without restriction."

(ii) Proprietary information received in confidence under this Agreement may be disseminated by the receiving Party to: a) persor.s within che receiving Party, and other concerned Government departments and Government agencies of the receiving Party;

b) prime or subcontractors of the receiving Party located within the geographical limits of the receiving Party's country, for use only withia che framework of their contracts with the receiving Party in work relating to the subject matter of the proprietary information;

provided that any proprietary information so disseminated shall be pursuant to an agreement of confidentiality and shall be arked with a restrictive legend substantially identical to that appearing in sub-paragraph $2 . B(i)$ above.

(iii) With the prior written consent of the Party providing proprietary information under this Agreement, the receiving Party may disseminate such proprietary information more videly than otherwise permitted in the foregoing subsection (ii). The Parties shall cooperate vith each other in developing procedures for requesting and obtaining prior written consent for such wider dissemination, and each Party will grant such approval to the extent permitted by its oun policies, regulations and laus.

C. Each Party shall exercise its best efforts to ensure that pro- prietary infomation received by it under this Agreement is controlled as provided herein. If one of the Parties becomes aware that it will be, or may reasonably be expected to become, unable to meer the non-dissemination provisions of this Article, it shall imediately inform the other Party. The Parties shall chereafter consult to define an appropriate course of action.

D. Information arising from seminars and other meetings arranged under chis Agreement and information arising from the attachments of staff and use of facilities shall be treated by the Parties according to the principles specified in this article; provided, however, no proprietary information orally communicaced shall be subject to the limited disclosure requirements of this Agreement unless the individual communicating such information places the recipient on notice as to the proprietary character of che information communicated.

E. Nothing contained in this Agreement shall preclude the use or dissemination of information received by a Party through arrangements other than those provided for under this Agreement.

\section{ARTICLE 6}

Information transmitted by one Party to the other Party under this Agreement shall be accurate to the best knouledge and belief of the Iransmitting Party, but the Transmitting Party does not varrant the suitability of the information transmitced for any particular use or application by the Receiving Party or by any third party. Information developed jointly by the Parties shall be accurate to the best kaowledge and belief of both Parties. Neither Party warrants the accuracy of the jointly developed inforwation or its suitability for any particular use or application by either Party or by any third party. 
1. With respect to any invention or discovery unceived or first actually reduced to practice in the course of or under this Agreement:

2) If conceived or firgt actually reduced to practice by personnel of one Party (the Assigning Party) or its contractors while asaigned to the other Party (Recipient Parcy) or its contractors in connection with exchanges of scientists, engineers and other specialists, the Receipient Party shall acquire all right, title and incerest in and to any such invention or discovery in all countries subject tc a non-exclusive, irrevocable, royalty-free license in all such countries to the Assigning Party, vith the right of the Assigning Party to grant sublicenses, under any such invention or discovery and any patent application, patent or other protection relating thereto.

b) If conceived or first acsually reduced to practice by a Party or its contractors as a direct result of employing inforiation which has been communicated to it under this Agreement by the otber Party or its contractors or communicated during seminars or other joint meetings, the Party making the invention shall acquire all right, title and interest in and to such invention or discovery in all countries, subject to a grant to the other Party of a royaltyfree, non-exclusive, irrevocable license, with the right of the other Party to grant sublicenses, in and to any such invention or discovery and any patent application, patent or other protection relating thereto, in all countries.

c) With regard to exchange of samples, materials, instruments, and components for testing. the Recipient Party shall have the same rights as the Recipieat Party as set forth in paragraph a) above and the Assigning Party shall have the same rights as the Assigning Party as set forth in paragraph a) above.
2. Each Party shall, vithout prejudice to any rights of inventors or authors under the laus of its country, take all necessary steps to provide the cooperation from its inventors and authors required to carry out the rovisions of Articles 7 and 8. None of the Parties shall assume the responsibility to pay avards or compensation required to be paid to the nationsls of the other Party according to the lava of the comtry of that other Party.

\section{ARTICIE 8}

Copyrights of the Parties or of cooperating organizations and persons shall be accorded treatment consistent with internationally recogrized standards of protection. As to copyrights on materials within the scope of paragraph 1 of axticle 5 owned or coatrolled by a Party, that Party shall make efforts to grant to the other Party a license to reproduce copyrighted meterial.

\section{ARTICLE 9}

1. Thenever an exhange of staff is concemplated under this Agreement, each party shall ensure that qualified staff are selected for attachment to the other Party.

2. Each such attachmeat of staff shall be the subject of a detailed seperate attactment agreement between the Parties.

\section{ARTICLE 10}

The provisions of this Agreement shall not affect the rights or duties of the Parties hereto under other agreements or arrangements. This Agreement also is no way precludes comercial firms or other legally 
constituted encerprises in each of the two countries from engaging in comercial dealings in accordance with the applicable laws of eacb country, nor does it preclude the Parties frow engaging in activitiea with other governments or persons.

\section{ARTICLE 11}

Compensation for damages incurred during the implementation of this Agreement shall be in accordance with the applicable laus of che countries of the Parties.

\section{ARTICLE 12}

Cooperation under this Agreement shall be in accordance with laws of the respective countries and the regulations of the respective Parties. All questions related to the Agrsement arising during its term shall be settled by the Parties by mutual agreement.

\section{ARTICLE 13}

The implementation of this Agreement will be subject to the availability of appropriated funds. Except when otberwise specifically agreed at the time, all costs resulting from cooperation under this Agreement shall be borne by the Party that incurs them.

\section{ARTICLE 14}

1. This Agreement shall enter into force upon signature and, subject to paragraph 2 of this Article, shall continue for a five (5)-year period, and may be amended or extended by wutual written agreement of the Parties. This Agreement may be extended subject to agreement by the Parties following a review of accouplishments under the Agreement.

2. This Agreement way be ceminated at any time at the discretion of either Party, upon six (6) months advance notification in witing by che Party seeking to terminate the Agreement. Such termination shall be without prejudice to the rights which may have accrued under this Agreement to either Party up to the date of such termination.

3. In the event that, during the period of this Agreement the nature of either Party's radioactive vaste management program should change substantially whether this be by substantial expansion, reduction, transformation or amalgamation of major elements with the radioactive waste management program of a third party, either Party shall have the right to request revisions in the scope and/or terms of this Agreement. Revisions shall become the subject of an amendment to the Agreement according to the provisions of Article 14, paragraph 1, above.

4. All efforts and experiments not completed at the expiration or cemination of this Agreement may be continued until their completion under the terms of this Agreement.

\section{ARTICLE 15}

This Agreement shall apply in so far as the European Atomic Energy Community is concerned, to the territories in which the Treaty establishing the European Acomic Energy Community is applied and under the conditions laid dow in that Treaty. 


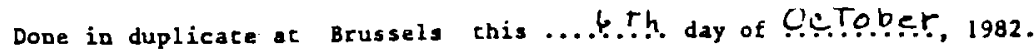

DEPARTMENT OF ENERGY OF THE UNITED STATES OP AMERICA

\section{AMDÁ SSA DER G.VEST}

$G_{1}=$ George
EUROPEAN ATOMIC ENERGY COMMUNITY, Represented by the Commission of

the European Communities

V.P.W.HAFRKAMP

$\mu=$ wilhelm
ATTACEMENT 1

\section{Radioactive waste magement co-operation} between US-DOR and EURATOM

\section{Scientific areas of co-operation}

1. Characterisation of waste forms:

2. Disposal in geologic formations (including disposal in crystalline rocks, salt and argillaceous formations as well as disposal in the sea bed);

2.1. Characterisation of site including research in deep drillings:

2.2. Underground experimental rooms/shafts and associated researcb;

2.3. Additional barriers, backfilling and sealing materials;

2.4. Characterisation, before and after disposal, of the interal equilibria of rock formations; modelling;

2.5. Radionuclides migration and modelling;

2.6. Risk analyais

2.7. Repository design

2.8. Basic studies of general interest and development of neu methods for assessmene and characterisation of sices. 



\section{OECD Nuclear Energy Agency (NEA)}

The US is a member of the NEA and participates actively in NEA waste management programs.

\section{RELATED AGREEMENTS}

1. Terms and Conditions for the Development of an International Sorption Information Retrieval System (ISIRS) (Attachment NEA-1)

2. Agreement on the International Stripa Project (Attachment NEA-2)

3. Technical Information Exchange on Nuclear Installations Decommissioning Projects (Final will be supplied when available)

\section{STATUS/PLANNING REPORT}

1. Summary record of Fourth Technical Committee Meeting of ISIRS--France, 06/84 (Attachment NEA-4)

\section{ADMINISTRATION}

Principal Coordinators: US -- C. R. Cooley (DOE)

NEA -- J.-P. 01 ivier

Document Exchange: see Appendix C 
TERMS AND CONDITIONS FOR THE DEVELOPMENT OF AN INTERNATIONAL SORPTION INEORMATION RETRIEVAL SYSTEM

Atomic Energy of Canada Limited, the Technical Research Centre of Finland, the Commissariat a l'Energie Atomique of France, the Hahn Meltner Institute, Berlin, of the Federal Republic of Germany, the Comitato Nazionale per I Energia Nucleare of Italy, the Japan Atomic Energy Research Institute, the National Institute for wazer Supply of the Netherlands, the AB Svensk KarmbransleNationale pour Reacteurs jointly with the société Cooperative Nationale pour l'Entreposage des Léchets Radioactifs of Switzerland. the Department of the Environment of the United Kingdom, and the Department of Energy of the United States of America, being Governments or bodies designated by their respective Governments (the "Participants");

CONSIDERING that a Sorption Information Retrieval System and assoclated data bank have been developed and are operated by the Department of Energy of the United States of America "DOE") Battelle Institute ("PNL")

CONSIDERING that the Steering Committee for Nuclear Energy has recogalzed the lnterest of lnternational co-operation in the waste isolation in geologic formations;

CONSIDERING that the data on the sorption of radionuclides by geologic materials are essential for the safety assessment of geologic disposal

CONSIDERING that the DOE has invited the other Participants to undertake under the aegis of the OECD Nuclear Energy Agency (the "OECD/NEA") a Project to study the feasibility of developing an International Sorption Information Retrieval System ("ISIRS"), herelnafter referred to as the "Project", and to this efsect to

CONSIDERING that, if the conclusions of this feasibilit study are positive, it is envisaged to set up the ISIRS within the NEA Data Bank in Saclay (Erance);

AGREE to participate in this Project under the Terms and Conditions set out below:

\section{Objectives}

1. The objectives of the co-operation between the Participants under these Terms and conditions shall be to

(1) derelop the data bank operated for DOE by FNL in order to make it suitable for processing, storing, and retrieving date from international sources on sorption oy geologic materials;

(11) develop additional coding procedures to expand data management options and to install current available data from perticipants with the lintention of making the dat baak sortware compatible with the NEA Data Bank compute? equipment;

(111) carry out tests of the software for international users in order to demonstraie and to foprove the usefulness of the ISIRS 105 Participants;

2. A Programme of Work desl gned to meet the objectives of the Project ls detailed in Annex i hereto. Any signiflcant changes this

\section{Technical Committee}

3. A Technical Comnlttee shall be set up for the purpose of:

(1) determining the general orientation of the Project;

(11) reviewlog the progress of the Programme of Work adopted oy the Participants, as well as the practical arrange-
ments proposed by DoE;

(111) assessing the results of the Programme of Worly with view to examining the possibility of setting up th ISIRS w1 thin the NEA Data Bank.

4. The Technical Committee shall consists of a member designat by each Participant. The Technical Committee shall elect Chalrman and a V1ce-Chairman from among its members.

5. The Technical Comittee shall report regularly to the The general progress of work.

6. The Technical Committee shall meet at least once a year and shall be convered by 1 ts Chairman.

7. The Rules of Procedure of the Organdsation for Economic Co-operation and Development shall apply to the Techaical Commit subject to any additional internal rules which may be adopied by 


\section{Operating Agent} 8. The Operatigg Agent for the Project sinall be DOE, whlch 9. Under these Terms and Conditions, the Operating Agent
shell:

(1) develop and operate the data bank and implement the 1mprovements planned according to the Programie of Work;

(11) generate computer sortware compatible with the computer equipment of the NEA Data Bank

(111) allow the other Participants access, on an experimental basis, to the information stored win the data bank for - maxidin of five requests per year from each participar in accortance with guldeilnes prepared by the Tech Comittee; additicnal reouests would be satisiled accordIng to procedures and payment of fees, each to be agreed upon by the requesting Paricipant and the Opereting Agent; (1v) return processed data to Farticipants for purposes of
verification and quality assurance;

(v) undertake to lac1l1tate the ultimate transfer of the ISIRS to the NEA Data Bank, If so dec1ded at the ead of the perlod planned for the project.

10. To this elfect, the Operating Agent shall:

(1) make avaliable to the Project the personnel and equipmeri required for 1ts operation; the personnel shall remet

(11) supply the Technlcal Committee with all information relevent to the Project, fbcluding Inancial accounts reflec: lag expenditures relating to the carrying out of the
Project.

\section{Participants}

11. During the first year, each Participant shall supply to the Operating Agent data sheets (up to 400 ) resulting from experimeats in their own country, in accordance with condlitsons to be determi

12. The Participants may, at the end of the f1rst year and in the light of the results achieved, re-examine the Programe of Wort and the level of contributions for the following year.

\section{OECD Muclear Energy Agency (OECD/NEA)}

13. In accordance with 1ts statute, the OECD/NEA will encourage the broadest possible particlpation in this Project by 1ts Membe OECD/NEA's other activities in this fleid.

14. The OECD/NEA shall be 1avited to provide the Secretarlat of the Technical Committee.

15. Once each calendar year the OECD/NEA shall be invited, at the request of the Operating Agent, to make the necessary arrangement to bave a call for contributions from the other Participants issu and bave such funds transferred to the Operating Agent.

\section{Funding}

16. Each Participant in the Project other than DOE shall contribute each year funds for the expenditures and services requidred for the development of the ISIRS in the amount of US $\$ 10,000$. DOE shall bear the costs inclired by the Project which are no us 100,000 ther Participants Us $\$ 100,000$ per year lor a two-year peziod.

\section{Information and Intellectual Proverty}

17. Information resulting from the carrying out of the Programme of Work, 1ncludiog results of testinterrogations shall be commun cated by the Operating Agent on a quarterly basis to the Technic Committee. An annual repost sheil also be prepared by the Operating Agent.

18. The Techofical Comittee shall report on the progress of the Programme of Work to the Steering Committee ror Waclear Dergy into Goologic Formations. 19. The Participants shall bave the Fight to publish all 1arorm and Conditions.

20. These Terms and Conditions do not cover the exchange of proprietary information.

Legal Resoons1bilities.

21. In carrying out these Terms and Conditions, the Particlpant. shall be subject to the appropriation of funds by their respecti Covernments, where necessam, and to the constitution, laws and Governments, where necessaty, and to the constitution, 


\section{Admisston and Withdrawal of Partictpants}

22. The covernment (or any body designated by such Goverment) Of any Member country of OECD/NEA may subsequently join the Project under terms to be agreed by ihe Participants.

23. Any Participant may withdraw from the Project at the end of the flrst year or at any time following the consent of the other Participants or by giving twel

\section{Final Provisions} 24. These Terms and Conditions shall enter into force on extended by unanimous decision of the participants.

25. These Terms and Conditions may be amended at any time iby unanimous decision of the Participants. Any such amendment shar be appended to these Terms and Conditions.

\section{Proeramme of Work}

1. Prroose

The main purpose of the Intermational Sorption Information Retrieval System (ISIRS) is to provide a mechanism for the collection and anelysis of large amounts of experimental sorptior comminity.

The term "sorption" as used berein is a general term incluretaln radionuclides from migratiog.

The Operat1ng Agent for this Project is the Depertont of Energy of the United States of America (DOE), which intends to act through the Facific Norihwest Laboratory or the Battelle Institute (FNL). The Operating Agent will cembine the existing WRTT Sorption Information Recrieval Systel (SIRS) described in PNI 3528 with the more versatile Analysis of Large Data Sets (ALDS) sortware system as a basis for the ISIRS.

\section{Computer System}

A D1gital Equipment Corporation VAX-11/700 Computer at FNL WIIl be used to combine the existing SIRS with the developiag system, as weil as on the PNL system.

The simple statistical analysis routines present in SIRS w11] be augmented by routines common to ALCS. Best-fit curves, histograms, graphs, covariance matrices, experimental data, etc., can be directed to either a Calcomp plotter or lineprinter for hard copy output.

The ISIRS data base will be organized as a Ilat-Iile as opposed to the current SIRS multi-level hierarchical tree. AlI information on the auclide retardation and solubility coding forms will be placed in approprlate flles within memory. Each category will be given a unique mnewonic name with up to risteen characters such as "EXP. METHOD" OT "ROCK TYPE," etc.

3. Standard Coding Eorns

Standard forms delfnearing all the currently needed informetion on rock, groundwater, nuclide characteristics, and experi- 


\section{Statistical Analusis Features}

The ISIRS system will foclude as a minimum the following statistical capabilities:

(a) determination of means and standard deviation for any population of a given variable;

(b) abillty to determine the covariance of any independent variable with one dependent variable (typically $\mathrm{Kd}$ );

(c) multiplelinear regression, 1.e., $y=f\left(x_{1}, x_{2}, \ldots . x_{2}\right)$.

Multiple non-linear regression and other sophisticated statistical techoiques may also be made available 1 rom the develof ing AIDS programme. Simple two dimensional plots of one variable versus another, bargraphs, and frequency distributions will also be avallable in ISIRS.

5. Revorts Ouarterly and annual progress reports will be prepared by
the Operatiog Agent.

6. Schedule

The following scheduls is provided for planaing purposes onl

a. First Yoar

(1) The Operating Agent will prepare standard coding form and instuctions for properly liling out the forms.

(2) The Techolcal Committee will review the trial forms and make inal recommendations.

(3) The Operating Agent will dist-1bute standard forms.

(4) All participants will fill in forms (up to 400 per

(5) AIl submitted coding forms will be reviewed by a geochemist/sorption expert of the operating Agent. Acceptable data will be installed into the data base. hasd copy of 1nstalled data will be sent to the originating Participanis for informatioy and validation. (Compute: installation of data lito ISIRS can start no sooner Terms and Conditions, provided data are available.)
(6) A workable sorption coerficient data selection capability will be operational within elght months of mequests for dem capabilities will be accepted at this time. Sorption tributed as specilied by the Techalcal Comittee.

(7) A workable ISIRS statistics package will be operational wh thin the first year after entry into force of the Terms and Conditions.

(8) A preliminery ISIRS system will be operational on the VAx computer withln twelve months of entry into force or the Terms and Conditions. At this time, a formal system demonstiation will be perrormed in Richland, Washington, for the benefit of Participants' representatives and NEA observers.

\section{b. Second Year}

(1) The Operating Agent will respond to Participants' requests as advised by the Technical Committee.

(2) The Operating Agert will document ISIRS in the sorm of a user's manual if the Technical Committee so instructs.

(3) It 15 estimated that 1.5 years will be necessary to:

(a) comblee SIRS with ALDS;

(b) Install selected backlogged and current sorption coefficient and nuclide solubility data available lrom Partic1pants;

(c) operate the ISIPS for Interim sorption coeffictent and muclide solubility selections requested by Perticipants.

(4) Should the Techalcal Comittee request after the syste demonstration desc-ibed in subparagraph 6. (a) (a) The Operating Agent will grovide up to one man-month of consulting service to assist in the installation of ISIRS on the NEA Data Bank (Saclay) compute= wi thin twenty-four months of entry into force. If requested the Ope:ating Agent w1ll assist in transferring 
ANEX II

Preliminary cost estimated for the proposed two-year programme

(10 US dollars)

Year 1

Management

\$ 20,000

Geocbemical Support

$\$ 11,000$

Data Installation

(Including computer costs)

ISIRS Soltware Development

(including computer costs)

Foreion Travel

(assumes no more than two trips)

$\$ 60,000$

$\$ 55,000$

$\$ \quad 4,000$

$\$ 150,000$ est1mat

Year 2

Management

$\$ 15,000$

10,000

Goochemical Support

Data Installation

(including computer costs)

ISIRS Soltware Derelopment

including computer costs)

$\$ 45,000$

30,000

$\$ 25,000$

Transfer to NEA Data Bank
(including forelge travel)

ISIRS Documentation and NEA Stafe Training

$\$ 25,000$

$\$ 150,000$ estimat 


\section{AGREEMENT ON THE INTERNATIONAL STRIPA PROJECT}

AB Svensk Kärnbränsleförsörjning of Sweden ("SKBF"), the Depanment of Energy of the United States of America ("DOE"), Teollisuuden Vioma Oy of Finland ("TVO"), the Nationale Genossenschaft für die Lagerung radioaktiver Abfälle of Switzerland ("NAGRA"), the Power Reactor \& Nuclear Fuel Development Corporation of Japan ("PNC") ("the Participants");

Considering that the Steering Committee for Nuclear Energy of the OECD Nuclear Energy Agency has undertaken to promote international co-operation in the field of geologic disposal of radioactive waste:

Considering that SKBF has invited Member countries of the OECD Nuclear Energy Agency to participate uncer the aegis of this Agency. in a joint experimental program of an approximate duration of four years, using the Stripa Mine and its related

Considering that the OECD Nuclear Energy Agency shall foster the broadest possible participation in the Project by its Member countries and shall ensure co-ordination of the activities 0

AGree to participate in the International Stripa Project (hereinafter referred to as the "Project"), on the terms and conditions herein stated:

\section{Aricle 1}

OBJECTIVES

1. The Project shall consist of an experimental program comprising tests concerning radioactive waste disposal as derailed in Annex I hereto. The Project shall be carried out at the Stripa Mine in Sweden.

2. Additional work incidental to the Project as defined in Annex I hereto mas be undertaken as the Participants acting by unanimity agree through the Joint Technical Committee in writing in amendment of such Annex 1 .
Arricle 2

JOINT TECHNICAL COMMITTEE

1. Control of the Project shall be vested in the Joint Technical Committee constituted under this Article and decisions reached by the Joint Technical Committee pursuans to this Article shall be binding on cach Participant.

2. The Joint Technical Committee shall consist of one member designated by each Participant with two additional members. one designated by SKBF and one by DOE. For each member, one deputy shall be appointed as an alternate.

3. The Joint Technical Committee shall

(i) Unanimously adopt for each year the program of work and budget of the Project in accordance with the scope outlined in Annex I here. to following a proposal from the Managing Participant under Article 3:

(ii) Determine whether or not to undertake additional work as contemplated by Article 1.2:

(iii) Make such rules and regulations as may be required for the sound management of the Project, including financial rules as provided in Article 5:

(iv) Establish technical subgroups of experts in accordance with Annex II to review and advise the Joint Technical Committee on major areas as set forth in the annual program of work:

(v) Consider any matters submitted to it by any Participant: and

(vi) Carry out the other functions conferred upon it by this Agreement.

4. The Joint Technical Committee shall meet in regular session at least once a year or more frequently in special meetings which shall be convened by the Chairman upon the request of a Participant which can demonstrate the need therefor. A representative of the OECD Nuclear Energy Agency may take part in meetings of the loint Technical Committee and meetings of technical sub-groups of experts in an advisory capacity

5. The Chairman of the Joint Technical Committee shall be appointed by SKBF from amongst its members. At least forty days before each meeting of the Joint Technical Committee, notice of the time, place, and agenda of the meeting shall be given by the Chairman to each Participant and to other persons otherwise entitled to atend the meeling. Three lourths of the members of the Join Technical Comminee 
6. It is agreed that the Joint Technical Committee shall operate and reach its decisions to the greatest extent possible on a mutually agreed basis. To the extent tha be adoped by a least three fourths of the conber shall have one vore and decisions shall which the decision is taken, unless unanimity is expressly provided for herein meeting a which the agreement of each member present and voting at the meeting at which the decision is taken.

7. A decision of the Joint Technical Committee may be reached by telex commu nication. subject to paragraph 6 of this Article 2. The Chairman shall have the onsuring that all Participants are informed of recommendations to be acted upon and any decisions taken pursuant to this paragraph.

8. The Joint Technical Committee shall keep the Steering Committee for Nuclear Energy regularly informed of the general progress of work. through the OECD Agency Committee on Radioactive Waste Management and its Coordinating Group on Radioactive W'aste Disposal into Geologic Formations.

Article 3

\section{THE MANAGING PARTICIPANT}

1. The Project shall be operated by SKMF which shall perform the function of Managing Participant of the Project (hereinafter "Managing Participant").

2. All legal acts required to operate the Project shall be performed on behalf of the Participants and in the interest of any associate participants by the Managin Participant in accordance with the laws of its country. The Managing Participant shall be responsible for taking all steps required to implement the Project in accordance uith the provisions of this Agreement and the decisions of the Joint Technical Committee.

\section{Article 4}

\section{ADMINISTRATION AND STAFF}

1. The Managing Participant shall maintain an adequate organization for the administration of the Project.

2. Subject to the provisions of Article 7. the Managing Participant shall furnish the Joint Technical Committee with such information concerning the operation of the Project as the Joint Technical Committee shall request. Reports on the carrvins out of the Project shall be submitted by the Managing Participant to the Joint Technical Committee at biannual intervals or at such other intervals as the Joint Technical Com. mittee shall determine.
3. Each Participant shall be entitled to nominate observers to monitor the Projec in accordance with rules determined by the Joint Technical Cornmittee.

4. Staff to work on the Project other than staff for its routine administration shall be selected by the Managing Participant in accordance with rules determined by the Joint Technical Committee and shall be responsible to the Managing Participan The Participants may propose experts to work on the Project as on-site test managers and investigators; such experts. if selected, shall be made anailable to the Project. Such by the Managing Participant in agreement with the Part-

5. Each Participant may send trainees to the Project, and such trainees shall be remunerated by the Participant concerned. The Joint Technical Committee shall adop

Aricle 5

FINANCE

1. Each Participant hereby agrees to commit to the Project the amounts sel forth in Annex III hereto. To the extent that nex Participants and associate participants shall agree ho commit funds to the Project in excess of what is required for otheruise is unanimously agreed by the Joint Technical Comple such

2. The Joint Technical Committee may adjust funding allocations within the overall budget for the Project to take account of changing price levels so as to ensure that the adjusted figures represent a realistic assessment of the funds needed for the purpose of the Project If inere are significant chanees in price levels the for Technical Commiuee un unimous decision (ave additional funds to be contributed by the Participants.

3. The Managing Participant shall prepare annually for the approval of the Joint Technical Committee, and in accordance with a format agre od to by the Joint Technical Commiuree. ing accounis) covering the previous year. The draft program of work and bud includbe submilted nor later than two months before the beginnine of the year in question. The report question. The financial year shall be from January 1 to December 31

4. The Joint Technical Committee may make such rules and regulations as may be required for the sound financial management of the Project.

5. The system of accounts employed by the Managing Participant shall be in 
applied. The Joint Technical Committee shall be provided with financial statements in a format agreed by it on a quarterly basis. The financial records maintained by the custody or possession in connection with the Project funds and propeny coming into its

6. The schedule for payment of contributions shall be determined by the Joint Technical Committee upon proposal by the Managing Participant.

7. A Participant supplying equipment to the Project or making available experts employed by it in agreement with the Managing Participant and in accordance determined by the Joint Technical Committee, against its contribution.

8. The cost of provision of the Stripa mine and related facilities, ancillary serprovided by the Managing Participant inanagement and admisement with the Joint Technical Committee shall be allowed as a credit against the contribution due by the Managing Participant.

9. Contributions due hereunder from the Participants shall (unless otherwise specified by the Managing Participant. in agreement with the Joint Technical Committee. for the purpose of meeting a commitment in another currencyl be paid in the currency of the Managing Participant.

10. The Managing Participant shall pay all taxes and similar impositions imposed by national or local governments and incurred by it in connection with the Project. as expenditure incurred in the operation of the Project, under the budget. The Manasing Participant shall endeavour to obtain all possible exemptions from or facilitations of such taxes.

11. Each Participant shall bear all costs of its participation in the Project other than the common costs funded by the budget of the Project.

12. Each Participant shall have the right. at its sole cost. to request the Managing Participant to furnish copies of all original records relative to the accoun of the Project. The requested copies shall be provided to the Participant.

\section{Article 6}

\section{PROCUREMENT PROCEDURES}

The Managing Participant shall have the power to enter into contracts for the p.ocurement of equipment and materials in the interest of the Project provided that such agreements are allowed for in an approved budget. by the provisions of this Agreement or by authorization of the Joint Technical Committee.

2. The Managing Participant shall undertake to secure the best contractual terms and conditions available.
Arricle 7

INFORMATION AND INTELLECTUAL PROPERTY

1. This Article sets forth the provisions applicable to the publication distribution, handling. protection and ownership of information and intellectual property relevant to and arising out of the Project. Additional rules and procedures related thereto. where necessary, shall be adopted by the Joint Technical Committee acting b) unanimity in conformity with this Agreement.

2. Subject only to restrictions applying to patents and copyrights the Participants shall have the right to publish all information arising from the Project and all information provided to the Project, except proprietary information.

3. For the purpose of this Article. proprictary information shall mean information acquired prior to or outside the Project of a confidential nature such as rade secrets and know how (lor example. computer programmes, design procedures and techniques. chemical composition of materials. or manufacturing methods. processes. or tratments) which is appropriately marked. provided such information

(i) Is not generally known or publicly available from other sources:

(ii) Has not previously been made available by the ounet to others without obligation concerring its confidentiality; and

(iii) Is not already in the possession of the recipient Participant without obligation concerning its confidentiality.

The Managing Participant and the other Participants shall take all necessary measures in accordance with this Article, the laws of their respective countries and international las to protect proprictary information provided to the Project. It shall be the responsibilis of the Participant supplying proprietary information to identif: the information as such and to ensure that it is appropriately marked.

4. The Participants shall notify the Managing Participant of and contribute to the Project. all pre-existing information and information developed independently of the Project which is or may potentially be relevant to the Project and the transfer of which is not subject to any contractual or legal limitation. To the extent that the provision of such information entails costs of any significance, the Joint Technical Committee acting by unanimity shall determine whether and on what terms to acquire the information.

5. Reports of all work performed under this Agreement and the results thereof including studies. assessments. produced and compiled in the manner and format decided by the Joint Iechnical Committee. Such reports shall be provided by the Managing Participant to the other Participants. 
6. The Participants agree with respect to inventions made or conceived in the course of or under the Project that each Participant shall. in its own country. own such inventions, subject to a non-exclusive, assignable royalty-free licence for the other Participants with the right to grant sub-licences in such inventions. In determining owner ship of such inventions in third countries. the Joint Technical Committee shall. actin by unanimive equilably apporion the ights to the Paripans. Paking into

7. All material generated under the Project may be copyrighted in the name of the Managing Participant for the benefit of the Participants in proportion to their to reproduce and distribute such material.

8. Each Participant shall. without prejudice to any rights of authors and inventors under its national laws. take the necessary steps 10 secure such co-operation or assignment of rights as are required to implament the provisions of this Article. Each Participant shall assume the responsibility 10 pay auards or compensation required to be paid to its employees according to the laws of its country.

Arsicle 8

\section{ASSOCIATE PARTICIP.ANTS} 1. The Managing Porticipant. with the approval of the Joint Technical Com-
mittee, mav conclude an agreement to admit any Government (or any body designated mittee. may conclude an agreement to admit any Government for any body designated by such government) of any Member count

2. The terms of admission and the rights of associate participants shall be established by the Participants acting through the Joint Technical Committee. Such terms and rights shall provide and be i.e.. that the contribution by any associate participant shall be at least Su:Crs. 2.6 million for the full term of the Project. and tha the associate participant shall be entited io receive technical reports from the Project revieu meetings but no other meecings unless agreed.

\section{Article 9}

\section{LEGAL RESPONSIBILITY AND INSURANCE} The Managing Participant shall use all reasonable skill and care in carrying
out its duties under this Agreement and shall be responsible for ensuring that the Project is conducted in accordance with all applirable laws and regulations. Excep as otherwise provided in this Article. the cost of all damage to property and all legal liabilities, claims, actions, costs and expenses connected therewith. shall be borne by the Participants in proportion to their contributions to the Project.
2. The Managing Participant shall propose to the Joint Technical Committee all necessary liability. fire and other insurance for the Project. and subject to availability shall procure such insurance as the Joint Technical Committee may direct. The cost of obtaining and maintaining insurance shall be charged to the budget of the Project.

$3 . \quad$ Notwithstanding the provisions of paragraph 8 of Article 5, the Managing Participant in accordance with Swedish law shall be liable in its capacity as such in indemnify the Participants and associate participants against the cost of any damage to property and against all legal liabilities. actions. claims. costs and expenses connect ed therewith to the extent that they:

(i) Result from the failure of the Managing Participant to maintain an such insurance as it is required to maintain under paragraph 2 ahose

(ii) Result from the gross negligence or uilful misconduct of any of its employees or officers carrying out its duties under this Agreement.

Arricic 10

\section{LEGISLATINE PROVISIONS}

1. Each Participant and associate participant shall. within the framework of applicable legislation. use its best endeavours to facilitate the accomplishment of forma. lities involved in the movement of persons. the importation of materials and equipment and the transfer of currency which shall be be required to operate the Project.

2. Participation shall be subject to the appropriation of funds by the appropriate governmental authority. where necessary. and to the constitution, lau's and regulations applicable to the Participant and associate participant.

3. Any dispute among the Participants concerning the intrepretation or the application of this Agreement which is not settied by negotiation or other agreed mode of settlement shall be referred to a tribunal of three arbitrators. The respectice Participant or group of Participants concerned shall each appoint one arbitrator. and the arbitrators thus nominated shall choose the Chairman of the tribunal. Should the Parparty-nominated fortitsators fo agree upon the composition of the tribunal or the party-nominated urbitrators fail to agree on the appointment of the Chairman. the Pre. sident of the Intenatinnal Court or Justice shall. al the request of any of the Participants by reference 10 the lerms of this Agreement and any applicate laus and such by

4 Insofar as a dispute involves the rights and obligations of the Managing Par ticipant other than these set forth in Article 7 , this Agreement shall be governed $h$ Sulish substantive law, and. unless otherwise is agreed by the disputing parties. art settle such a dispute shall take place in Siockholm. Sueden. and shall be conducted in the English language. 
Article 11

\section{ADDITION AND WITHDRAWAL OF PARTICIPANTS}

1. Participation in the Project as a Participant shall be open to the Government of any Member country of the OECD Nuclear Energy Agency or a national agency. public organization, private corporation, company or other entity proposed by such Government which signs this Agreement and assumes the rights and obligations of a Participant. Such participation shall be effective upon the adoption by the Joint Technical Committee of consequential amendments to this Agreemen.

2. It shall be a condition of participation of any neu Participant under paragraph I that the Participant shall contribute, in accordance with rules laid doun by the Joint Technical Committee by unanimits, an appropriate proportion of the expenditure of the Project prior to the date of such participation.

3. With the agreement of the Participants acting through the Joint Technical Committee. and upon the request of a Government. a Participant proposed by tha Government may be replaced by another party. The replacement party shall sign this Agreement and assume the rights and obligations of a Participant.

4. Any Participant may withdraw from this Agreement (a) at any time with the agreement of the Joint Tectinical Committee. or. $(b)$ in the event that vithdrawal the agreement of the Joint Technical Commitee. or. Abs in the event that withdrawal that effecr to the paragraph shall nor affect the rights and obligations of the continuing Paricipants. paragraph shall except that the proporfin

5.

5. Any Participant which fails to fulfill its obligations under this Agreemen within sixty days after its receipt of notice invoking this paragraph and specifying the nature of those obligations. may be deemed by the Joint Technical Committee. actins upon the unanimous decision of the other Participants. to have withdraun from this Agreement.

Article 12

FINAL PRONISIONS

1. This Agreement shall be effective as from I May, 1980 and shall remuin in force for a period of four years from such date and may continue in force there-
after on the unanimous agreement of the Participants acting through the Joint Technical Commitree.
2. Any notice or information required to be served or given to a Participan under this Agreement shall be addressed to the representative of the Participant designated to the Joint Technical Committee and deemed to be duly given twenty-four hours after being dispatched.

Upon expiry of this Agreement, the Joint Technical Committee shall decide 3. which might be made to the present and former Participants Commitee shall so far as practicable distribute the assets of the Project or the proceeds therefrom, in proportion to the contributions which the Participants have made from the beginning of the operation of the Project and for that purpose shall take into account the contributions and any outstanding obligations of former Participants (provided that no former Participant shall be entitled to have any access to or rights in any assets of the Project acquired after it ceased to be a Participant). Disputes with a former Participant about the proportion allocated to it under this provision shall be settled under Article 10.3 and for that purpose a former Participant shall be regarded as a Participant.

4. Upon expiry of this Agreement. the Joint Technical Committee shal also agree upon appropriate arrangements 10 ensure that the Managing Participant is Project in accordance with this Agreement.

5. This Agreement may be amended at any time by the Participants acting by unanimits through the Joint Technical Committee. Such amendments shall come into force in a manner determined by the Joint Technical Committee. 


\section{ANNEX}

\section{GENERAL SCOPE FOR EXPERIMENTAL PROGRAM WITHIN} THE STRIPA PROJECT

The following is a summary of the investigations defined so far within the Stripa Project, which are

- Hydrogeological Investigations in Boreholes:

- Migration Tests in a Single Fracture:

- Buffer Mass Test

\section{HYDROGEOLOGICAL INVESTIGATIONS IN BOREHOLES} Objecrive

The purpose of the investigations is to design and test methods and instru. ments for geologic, hydraulic and geophysical studies in horizontal or subhorizontal boreholes to a length of $300 \mathrm{~m}$, where the purpose is to determine hydraulic characteristics and interactions between fractures in the bedrock. The investigation also aims at gaining further knowledge on the chemical and physical conditions in the groundwater at great depth in crystalline bedrock by drilling a vertical borehole to a depth of $1,000 \mathrm{~m}$.

Proposed tests

The investigation will be carried out in two phases, each selfcontained but based on the results and instrumentational development of the preceding phase. Other phases may later be added. The preliminary contents of the phases are as follow: ed problems.

Phase 1 . Work in individual horizontal and vertical boreholes with associat

(a) Methods, techniques and instrumentation to measure hydraulic properties and conditions at depth in nearly horizontal boreholes in fractured granitic and similar rocks will be developed. tested and compared.

(b) Basic quantitive information on the hydrogeologic conditions at depth in granitic rock will be obtained.

(c) Supplementary data on the geochemistry of grounduater in the deeper sections of fractured granitic rock will be oblained.

(d) The analysis and interpretation of the forthcoming results will form the basis for the continued development of methods to characterize the near basis for the continued development of methods to characterize the near/
far-field conditions in fractured rock of low hydraulic conductivity at repository depths.
Phase 2. Work concerning the hydraulic interconnection between different horizontal boreholes with associaled problems.

(a) Methods and instrumentation for establishing the hydraulic properties of existing fracture zones and the hydraulic interconnection berween bore. holes along existing fractures or fracture zones.

The investigations are scheduled to start in the summer of 1980 and be completed in early 1983

\section{MIGRATION IN A SINGLE FRACTLRE}

Objecrive

The proposed study has the following main objectives:

- To observe the movement of non-sorbing and sorbing tracers under controlled and well defined conditions in a real environment:

- To interpret the movement of the tracers in such a way that the results become useful for the prediction of radionuclide migration.

- To obtain a basis for comparing laboratory data on sorption with obser ations in a real environment.

- To develop good techniques for small volume sampling of water and techniques for investigating fissure surfaces with sorbed tracers:

- To gather experience with stable tracers before using radioactive tracers.

Proposed resis

An experiment is proposed where various stable tracers representing al important types of radionuclides are introduced in the naturally flowing water in single fissure in granite.

The migration distance is about $5 \mathrm{~m}$. As the hydraulic gradient and flow rate i; many orders of magnitude larger than in a natural system a time scaling of to 3 orders of magnitude is automatically achieved. The fissure is excavated after completion of the runs with the sorbing tracers. The concentration of tracers on the surface is analysed. The experiment will shou how well sorption datacers on laboratory can be used to predici radionuclide migration in the field with real sur the and waters. It will also pive dat on longivelinal and inansverse dispersion in a singlo fissure.

The investigations are scheduled to start during summer 1980 and to be completed in 1983. 


\section{BUFFER MASS TEST}

Objective

Highly compacted bentonite and mixtures of bentonite and quartzsand are proposed as buffer materials in final repositories for HLW according to the KBS concept. The objective of the tests described in this program is to verify the suitability of the suggested buffer materials at real conditions on site.

Proposed tests

General outline. An approximatively $40 \mathrm{~m}$. long tunnel section will be used Six deposition holes. three meters deep and with a diameter of $0.75 \mathrm{~m}$.. will be drilled in the floor. The diameter of the six deposition holes is chosen as $0.75 \mathrm{~m}$. since thi $1: 2$ compared to the KBS 2 concept in which coring is applied. The scale factor is thus 1.2 compared

In order to obtain a scaled tunnel section a concrete structure is cast on the tunnel floor around four of the deposition holes.

In the innermost pan of the tunnel with two deposition holes. the entire tunnel section is filled with bentonite/quartzsand. This provides an opportunity to test. on a full scale. the technique for application of the tunnel backfill and its behaviour during water uptake.

The deposition holes are equipped with heaters to simulate the canisters. The buffer mass in the holes consists of highl! compacted bentonite.

Instrumentation and recording. The field test comprises the determination of

- Rate and distribution of water uptake in the tunnel fill and the buffer mass in the deposition holes:

- Swelling pressures in the backfill and in the buffer mass in the deposition holes:

- Temperature changes in the backfill and in the buffer mass in deposition holes:

- Water pressure at the rock/tunnel fill interface and at the base of the deposition holes.

The detailed water uprake pattern is tetermined by excavating and investigat ing the buffer mass in the deposition holes and in the tunnel section.

The recording of signals from moisture. temperature and pressure gauges vill be made already during the application of the buffer material and connected to a computer system.

Time schedule. The activities in Stripa will start during fall 1980 and the test is scheduled to be completed in 1984
ANNEX

\section{TECHNICAL SUBGROUPS}

The organization of the Stripa Project shall include two Technical Subgroups (TSGs). The members of the TSGs shall review and comment on technical programs that are proposed to the JTC to be included in the Stripa Project. During the imple.
mentation of defined programs they shall give advice and comments to the investigators. who continuously will report the progress of the specific investigations in written reports and by oral presentation at the TSG̈s meetings.

Technical Subgroup No. 1 (TSG No. 1) shall cover the fields of hydrogeolog: (including geochemistry) and chemical uransport.

Technical Subgroup No. 2 (TSG No. 2) shall cover the fields of rock mecha nics and engineered barriers.

Each Technical Subgroup shall consist of a maximum of two members designated by each partucipant having a full membership in the Stripa Project and the shall be the representatives for the scientific interest of each participant.

The TSGs shall meet at intervals as considered needed by the chaiman in a participant who can demonstrate the need therefor. The chaiman of each TSC shall be appointed by the members within the group. Notice of time, place and agenda for meetings shall be given by the chairman in co-operation with the project manager. 


\section{ANNEX III}

FUNDS REQUIREMENTS FOR THE STRIPA PROJECT

This Annex sets forth certain provisions with regard to the contributions to the Project due by the Participants.

As shown in the following Table the total cost for the defined programs will

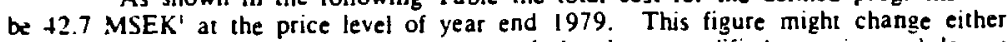
due to an alteration in the scope of work and thereby a modified experimental layou ane in the general price level. If for instance the inflation amounts to 10 per year then the required funding increases to 51.2 MSEK over a four year period.

CASH FLOW STRIPA PROJECT

All amounts in million Swedish Kroner

\begin{tabular}{|c|c|c|c|c|c|c|}
\hline Item & Budget & 1980 & 1981 & 1982 & 1983 & 1984 \\
\hline Project Management & 3.1 & 0.43 & 0.77 & 0.76 & 0.76 & 0.38 \\
\hline Stripa Generally (Mine rent. etc.) .... & 14.0 & 0.98 & 4.27 & 3.5 & 3.5 & 1.75 \\
\hline Hydrogeological Investigations & 6.5 & 0.61 & 3.19 & 1.82 & 0.88 & \\
\hline Buffer Mass Test & 15.0 & 0.76 & 9.24 & 2.0 & 2.0 & 1.0 \\
\hline Migration in Rock Fissures & 4.1 & 0.15 & 1.99 & 1.16 & 0.8 & \\
\hline
\end{tabular}
follows:

The Participants agree to assign funds for a four year period apportioned as

$$
\begin{aligned}
& \text { Japan } \quad 7.2 \text { MSEK } 0.167 \text { share } \\
& \text { Finland 3.6 MSEK } 0.082 \text { share } \\
& \text { Sweden 12.6 MSEK } 0.292 \text { share } \\
& \text { Switzerland } 12.2 \text { MSEK } 0.167 \text { share } \\
& \text { USA 12.6 MSEK } 0.292 \text { share } \\
& 43.2 \mathrm{MSEK} \quad 1.000 \text { share }
\end{aligned}
$$

1 WSEK - Million Swedish Kroner.
For the AB SVENSK KärnarinsLefórsónNino (Sweden)

For the DePartment OF ENERGy OF IHE United States of America

For the TeOllisuUden Volma oy (Finland)

For the Nationale Genossenschaft For Die Lagerung Radioaktiver abfalle

(Swikerland)

For the Power Reactor \& Nuclear Flel Development CORPORATION

(Japan) 
ORGANISATION FOR ECONOMIC CO-OPERATION AND DEVELOPMENT

NICLEAR ENERGY AGENCY

RESTRICTED

Paris, drafted: 22nd June 1984

dist: 9 th July 1984

SEN/ISIRS( 84$) 3$

\section{STEERING COMMITTEE FOR NUCLEAR ENERGY}

\section{RADIOACTIVE WASTE MANAGEMENT COMMITTEE}

$\frac{\text { Summary Record of the Fourth Technical Committee }}{\text { Meeting of the Intermational Sorotion }}$ Information Retrieval System (ISIRS)

Paris, 14-15 June 1984

The ISIRS Technical Committee has as its mandate to review the progress and guide the development of the ISIRS computer-based storage and retrieval system for radionuclide sorption information and for related activities. The project was inaugurated in June 1981 with the suppore of 11 Member countries. The information management sof tware has been developed during the initial cwo-year period at Battelle Pacific Northwest Laboratory (PNL), USA. The priject entered an evaluation phase during the next two-year period, the firs year of which has just been compleced. As foreseen in the Terms and Conditions for the participation in the project, the data base management sof tware and the accumulated sorption data base have been installed on the VAY 730 computer at the NEA Data Bank at Saclay.

As it was last year, the Technical Committee Meeting was preceded by a demonstration of the capabilities of ISIRS. This demonstration, open to participants in the Workshop on the Coupling of Hydrologic and Geochemical lodels as well as to ISIRS Technical Committee members, was held at Saclay on 14 June 1984.
The Technical Comnittee meeting was chaired by Dr. T. Vandergraaf (Canada) with Dr. J. Hadermann (Switzerland) as Vice-Chai rman. Mr. E. ( represented by Dr. J. Kin. The Chai an welconed Dr. P. Krejsa (Austria) and Dr. J. Patyn (Belgium) as observers. Their participation was arranged in in ISIRS to an initation by the Secretariat for countries not participating in ISIRS to join the project during the final year of the current cwo-year evaluation perin. The Agenda as proposed in docr of Technical Committee was approved wi thout comment [SEN/ISIRS(83)2].

Progress Report on the Operation of ISIRS Project - July 1983 - June 1984

A report was presented by Mr. J. Serne of the PNL staff on the 列 meeting. It was reported that:

- Final version of the LIST program has been developed,

- Final documentation on the ENTRY program as well as the final draft of the ISIRS Users Manual have been prepared,

- The PDP $11 / 70$ Version of ISIRS was sent ot NEA in October and the revised VAX version was delivered in April 1984,

- A version of the NEWCASE module was also developed in April 1984 bu this model requires sone additional work before it is operational. and

- 86 new cases from Canada, Japan, Finland and FRG have been received and installed during the last year and 469 cases from the Netherlands and four Basalt cases from the US have been received and will be installed shorty. (PNL renewed its comaitunent to input a1 new data received until the NEA is able to perform updates of the data base.)

A report was presented by Dr. A. Muller of the Secretariat on NEA experience with ISIRS over the last year. The close and efficient cooperation between NEA and PNL staff which has led to the resolution of che difficulties noted at the last Technical Committee leeting was emphasized. Dr. P. Nagel of the NEA Data Bank reported on his experiences in installing the vax version of ISIRS. Some problems in sof tware transportability and potential difficulties with maintenance were identified. Mr. T. Matsunaga, Consultant to the Agency gined over the last six months as a user of ISIRS. In his report he noted

- A number of ISIRS features make the systen difficult to use interactively. Structuring the data base into a number of logical subsets should make routine operation easier. Further development to facilitate use was recommended. 
- During the next phase of the ISIRS project both software and data base maintenance are of major importance. Although the capability for this maintenance should be developed within the NEA, at least initially close collaboration with PNL will be mandatory.

- The requests for ISIRS data so far received have been designed primarily with a test of ISIRS capabilities in mind. Actual user experience will be required in order to perform an effective evaluation of the system. It was recommended that examples of data analyses be published in the NEA Newsletter on Radionuclide Uigration.

The Secretariat then presented an organogram of the structure of the ISIRS system envisaged for routine operation [ISIRS/DOC( 84$) 2$ ]. This structure was approved by the Conmittee.

It was reported that external dial-ups access to the ISIRS was now technically possible. Practical arrangements for such access would have to be developed by the NEA Data Bank staff if extemal access is to be provided. The Comnittee did not request this access option to be explored further and has agreed to limit access to written requests and on site usage at the Data Bank at this time.

The Committee members discussed their experience gained over the last year in providing data to ISIRS, in formulating requests for sorption information, and in evaluating and interpreting responses to these requests. General satisfaction was expressed with the request and response procedure. The new printing coding form was found suitable. It was felt that this form (and the procedure requiring only one sheet for data which would remain constant among a number of new experiments submitted to the data base) will facilitate input data preparation. It was noted that expanding and completin the data hase has now become a primary priority of the project. A number of participants indicated their intention to provide data over the next year.

On behalf of the Committee, the Chairman agreed to absolve PNL of any further contractual obligations in the project pending the completion of the remaining tasks mentioned above. PNL was warmly thanked for their enthusiastic and expert performance. Mr. M. Kreiter expressed the intention of PNL to provide systerns maintenance over the next year.

\section{Activities Proposed to June 1985}

\section{- Evaluation Report to RHMC}

The Committee approved the conditions of the programe of work for the next year as outlined in the Sumnary Record of the Third Technical Committee Meeting [SEN/ISIRS( 83)2].

The results of the evaluation of ISIRS performed by the Technical Committee during the current two-year period are to be reported to the NEA Radioactive Waste Management Committee. The evaluation is to include a summary of development and operational experience with ISIRS, a recommendation on the usefulness and viability of such a sorption data base and a plan for the operation of ISIRS at the end of the evaluation period. The Committee agreed that the report would emphasize the diverse needs for sorption data among the countries participating in the project. Estimates of operating costs at various levels of activity and a recomnendation for meeting these costs will be included. It was agreed that the system can make valuable
contributions in:

generic studies for countries which are not yet faced wi th a waste disposal problem or who have not yet identified specific disposal sites.

- the calibration of empirical as well as theorectical sorption models,

- providing a cross-check for new sorption experiments with data obtained under similar conditions on similar media,

- developing pheomenological understanding of the sorption process by having available results from sorption experiments over a wide variety of conditions, and in

- generating regression relationships and correlation matrices which can be used in coupling geochemical and transport models in performance analysis.

The Committee requested the Secretariat to prepare by 15 September a draft of the evaluation to be submitted to the Radioactive Waste Managemen Committee. The draft will be circulated to the Committee for comnent. Responses to the draft are to be used in revising the document, which will then be approved by the ISIRS Technical Committee Chairman and presented to the Radioactive Waste Management Comuittee at the beginning of 1985.

\section{- Citations of ISIRS}

The Comittee requested that the Secretariat recomend a format for citing data obtained from ISIRS. After consultations with an information science specialist, the Secretariat recomends that ISIRS data be cited in a format similar to that used for computer codes:

ISIRS: The International Sorption Information Retrieval System, OECD Nuclear Energy Agency, at NEA Data Bank, Paris, June 1984.

In French:

SIRIS: Système international de recherche de l'information sur la sorption des radionucléides, Agence pour l'Energie Nucleaire de 1'OCDE, à la Banque de Données de l'AEN, Paris, juin 1984

For users of the PNL facility.

ISIRS: The International Sorption Information Retrieval System, OECD

Nuclear Energy Agency, at Battelle Pacific Northwest Laboratories,

Hanford, WA, June 1984.

For formats which require the date to immediately follow the "author" entry, the recommended formats are: 
ISIRS, June 1984, The International Sorption Information Retrieval System, OECD Nuclear Energy Agency, at NEA Data Bank, Paris.

SIRIS, juin 1984, Système international de recherche de I'information sur la sorption des radionucléides, Agence pour l'Energie Nucléaire de l'OCDE, à la Banque de Données de l'AEN, Paris.

ISIRS, June 1984, The International Sorption Information Retrieval System, OECD Nuclear Energy Agency, at Battelle Pacific Northwest Laboratories, Hanford, WA.

Each of these formats lend themselves to reference numbers as well as citations of the form (ISIRS, 1984) or (SIRIS, 1984).

It is suggested that unless there is an unmanageably large number of them, the name and institution of the originator of data used should be mentioned in the text or in a footnote. Nevercheless, even if data was derived from a published in a foo, the arcicle itself since transcription errors and data manipulation may render the data in the the data base somewhat different than that actualy published. The name the person interpreting and processing the request (e.g. J.R. Serne or A.B. Wuller) should not appear in the citation. Neither should the request number, since no such number will be assigned to requests processed by visicors to the Data Bank. Indicating the month as well as the year in which the request
completed is important for recovering the status of the data base if any questions about the results may arise. Such recovery should be possible via the update accountability of the syster.

\section{- Jurisdiction}

It was informally agreed between the PNL representatives and the Secretariat that the ISIRS installation at PNL would input all data and service all requests from the US. The NEA Data Bank will provide the equivalent service to all other NEA countries. It was agreed that all new installations and that user experience and developments would be shared.

\section{Development of the Thermochemical Data Base: Progress from July 1983 -
June 1984 and Proposed Activities to June 1985}

The Secretariat reported that the recommendation at the last Technical Comnittee meeting for the addition of themochemical data to the scientific and technical data exchange activities of the NEA was endorsed at the last CGW and RWMC meetings [SEN/GD(83) 3 and SEN/RHM(83) IS]. Development of information management system for this purpose using the DBMS sof tware available on the VAX computer at the NEA Data Bank began in January 1984. The system and a number of utility programs were completed by June. Approximately 4,500 entries fron 110 sources (primarily compilations) have been input. The output from some of the utility programs and a listing of the current iodine data base was distributed to the Committee as examples. A complete current reference list and formula index for the nine elements of interest ( $U$, Np, Pu, An, Tc, I, Ra, Cs, Sr) was also distributed. The Committee agreed to include lead in the data base compilation because of interest by a number of Member countries. A short demonstration of the structure and of the number of data bank utilities was made to the Committee.
The Committee endorsed the proposed plan for thermochemical review as outlined in Part $V$, ISIRS/DOC (84)1. The critical review of uranium, technetium and iodine is to begin as soon as possible. Neptunium, plutonium and americium reviews for radiug, cesium and strontium are to begin shortly Data for lead is only to be compiled during the next programme year.

A number of suggested "specialist teams" were brought to the attention of the Committee. The formation of these teams was endorsed in principle. The critical review process is to have the following steps:

1) The specialist teams are first established. Each team, made up of no more than four members, is responsible for the critical evaluation of the chemical themodynamic data for one element. One member of each team is named by CODATA.

2) A listing of all data currently compiled in the data base and a copy of all references used is then sent to each member of the team. The team is requested to provide any additional data which they feel should be considered in the review.

3) Additional data provided by the team members is added to the data base.

4) The updated data base and new references are distributed to all the team members. The members are requested to perform a first cut rith ISIRS/DOC ( 84 )5.

5) The independent evaluations are assembled by the Secretariat. On compounds where there is general agreement, the Secretariat will

consensus is apparent, a meeting of the team may have to be arranged.

6) When consensus has been achieved, the resultant data set for recommended and preferred values will be tested and adjusted for internal consistency by the computer programs provided by the US NBS via CODATA.

7) The resulting critically reviewed data set will be published by NEA under the authorship of the specialist team. It will also be made under the authorship of the special is
available in machine readable form.

While this review is underway, the compiled (unreviewed) data will be available to users upon request. Since only referenced material is included in the data base, the original article should be cited with the addition "as note need not be included if the user cross-checks the note need not be included if the user cross-checks the data with the original citation, although an acknowledgment of the data base would be appropriate in such cases. 


\section{Workshops on the Coupling of Geochemical and Hydrologic Models}

A report was presented on the major conclusions of the workshop on the geochemical and hydrologic models which was held 12 and 13 June 1984. The major elements of these conclusions were endorsed by the Committee

1) There is a definite need for some coupling between geochemical and hydrologic models in nuclear waste performance assessment. This need arises from the inherently coupled nature of radionuclide migration which is dependent on advection, on dispersion and on chemical processes. There is no, and there need not be, a unique method to perform this coupling. Specific problems and analyses of specific systems require individual approaches.

2) Coupling in this context is not $1 \mathrm{imited}$ to mean exclusively the co-execution of geochemical and hydrologic computer codes but is intended to encompass all methods of passing data and of merging geochemical and hydrologic understanding in performance assessment modeling.

3) The development of "megacodes" (i.e. large directly coupled hydrochemical-geologic computer codes) is practically unrealistic and undesirable. Indirect coupling methods and the coupling of linited submadels should provide useful tools for helping to answer a number of specific questions. Since comprehensive megacodes are impractical, an understanding of where simplifications can be made is desirable.

4) Coupled models are only one tool among a wide variety which may be used to predict potential radionuclide migration. These simplified coupled models must be used in conjunction with larger

thermodynanically-based codes with laboratory work and wi th observation of nature (natural analogs). Reaction kinetics and collold formation cannot be neglected.

5) Basic to the use of any of these predictive techniques is the understanding of the physical and chemical processes involved. This understanding must be developed in order to maximize confidence in the predictions.

\section{Workshop Proposal for 1985}

Dr. P. Hooker of the UK presented a proposal for a workshop on microbial effects on the geological containment of high and intermediate level radioactive waste [ISIRS/DOC(84)3]. The Secretariat reported on the soraewhat limited response to its request for contributions to the NEA Newsletter on Radionuclide Migration on this topic. After some discussion, the subject of of Natural Organic Compounds and Microorganisms on Radionuclide Transport. Dr. Hooker will work with the Secretariat on developing a proposal for this their next meeting in October 1984 .

\section{Arrangements for the Next Committee Meeting}

It was agreed that the next meeting of the Technical Committee will be held at the OECD in Paris on 13 June 1985 . 


\section{ISIRS TECHNICAL COMITTEE}

\section{COMITE TECHNIQUE D'ISIRS}

Saclay, 14th-15 th June, 1984

Canada

\section{Dr. T.T. VANDERGRAAF (Chai man)}

AECl Research Company

(Chai man)

Pinawa

Mani toba ROE $1 L 0$

$$
\begin{aligned}
& \text { Te1: }(204) 7532311 \\
& \text { T1x: } 757553
\end{aligned}
$$

Finland

\section{Mr. E.K. PELTONEN}

Technical Research Centre of Finland

Nuclear Engineering Laboratory

SF-00181 Helsinki 18

Tel.: 90.648 .931

Tlx.: 122972 vttin sf

Represented by:

\section{Mr. K. RASILAINEN}

Technical Research Centre of Finland

Nuclear Engineering Laboratory

P.0. Box 169

SF-00181 Helsinki 18

Te1: (90) 648931

Tlx: 122972 VTTIN SF

France

Mr. G. BAUDIN

Departement de Recherche et

Développement Déchets

Centre d'Etudes Nucléaires

B.P No. 6

92260 Fontenay-aux-Roses

Tel: 6548222

Represented on 15 June by:

Dr. A. Billon

Commissariat à l'Energie Atomique

Département de Recherche et

Développement Déchets

B.P. No. 6

92260 Fontenay-aux-Rose

Tel: $6548222 / 3$

T1X: 204841
F.R. of Germany

Dr. E. BUTOW

Technische Universität Berlin

Institut für Kernteknik

M-1000 Berl in 10

Te1: (030) 3145485

Tlx: 184262 TUBLN

Represented by:

Dr. J.I. KIM

Institut für Radiochemie der

Technischen Universität Munchen D-8046 Garching

Tel.: (089) 32092202 Tlx.: 17898174 TUMGAR

$\underline{\text { Italy }}$

Dr. R. GRAGNAN

Dipartimento Radiazioni e Ricerche

di Sicurezza e Protezione

ENEA - CSN Casaccia

C.P. 2400

I-00100 Roma

Tel: (69) 481

TlX: 43-613296 ENEACA

Japan

Mr. S. MARAOKA

JAER I

Tokai Research Establishment

Tokai-mura

Naka-gun

Ibaraki-ken

Te1: 5036111
T1x: $J 24596$

Netherlands

Mr. P. GLASBERGE

National Institute for Water Supply

P.0. Box 150

2260 AD Leidschenda

Tel: 69425

Tlx: 33604 RIDVZ NL

Sweden

Dr. B. ALIAR

Insti tutionen för Kärnkemi

Chalmers Tekniska Hळgskola

S-412 96 Götebor

Tel: (031) $810100(x .2050)$

Switzerland

Mr. J. HADERMANN (Vice-Chai mman

Institut fédéral de recherches en

matière de réacteurs

CH-5303 Würenlingen

Tel: (056) 981741

Tlx: 52086 A NOK or 
United Kingdom

Dr. P.J. HDOKER

Fluid Processes Research Group

British Geological Survey

Keyworth

Nottingham NG12 $5 \mathrm{GG}$

Tel.: ( 06 077)6111

TlX.: 378173 IGSKEY G

United States Mr. M.R. KREITER

Manager, Waste Isolation

Battelle Pacific Northwest Laboratory

P.0. Box 999

Richland, Wa. 99352

Tel.: 152874

Mr. J. SERNE

Earth Sciences Section

Water and Land Resources Department

Battelle Pacific Northwest Laboratory

P.0. Box 999

Richland

Washington 99352

$$
\text { Tel: (509) } 3768429
$$

Observers

Austria

Dr. P. KREJSA

Österreichisches Forschungszentrum

Seibersdorf Ges.m.b.H.

Lenaugasse 10

Tel.: (0222) $4275 \quad 11$

Belgium Dr. A. BONE

Chef du Stockage en formations géologiques

Chef du Stockage en formations géologiqu

Boeretang 200

B-2400 Mol

Tel.: $014 / 311.801(X .3904)$

NEA Secretariat Dr. A. MULER

Rr. A. MULLER

Management Division

OECD Nuclear Energy Agency

38 bd Suche

F-75016 Paris

Tel: 5249678

T1X: 630668 AEN/NEA
Mr. J.-P. OLIVIER

Head, Radiation Protection and Waste Management Division

OECD Nuclear Energy Agency

38 bd Suchet

F-75016 Paris

Tel: 5249695

TlX: 630668 AEN/NEA

Mr. P. NAGEl

Nuclear Sciences Division

NEA Data Bank

91191 Gif-sur-Yvette Cedex

Tel: 908.60 .92

Tlx: 690920

Mr. T. MATSUNAGA

Radiation Protection and Waste

Management Division

OECD Nuclear Energy Agency

38 bd Suchet

F-75016 Paris

Tel: 5249669

TlX: 630668 AEN/NEA 

SECTION 223 OF THE NUCLEAR WASIE POLICY ACT (MUPA)

Section 223 (Attachment NWPA-1)

Federal Register Notice (Attachment NWPA-2) 


\section{TECHNICAL ASSISTANCE TO NON-NUCLEAR WEATON STATE IN THE}

TIELD OF SPENT TUIL STORAGE AND DISPOSAL

Sec. 203. (a) It shall be the policy of the United States to cooperate with and provide lechnical assistance to non-nuclear weapon states in the field of spent fuel storage and disposal.

Joint notice. (BXI) Within 90 days of enactment of this Act. the Secretary and publication in the Commission shall publish a joint notice in the Federal Register Rernster. stating that the United States is prepared to cooperate with and provide technical assistance to non-nuclear weapon states in the fields of at-reactor spent fuel storage; away-from-reactor spent fuel storage; monitored, retrievable spent fuel storage; geologic disposal of spent fuel; and the health. safety, and environmental regulation

Joint notice of such activities. The notice shall summarize the resources that can of avch activities. The notice shall summarize the resources that can be made available for inclernacional cooperation and assistance in these frelds through existing programs of the Department and the Commission, including the availability of. (i) data from past or ongoing research and development projects; (ii) consultations with expert Deparment or Commission personsel or contractors; and (iii) liaison with private business entites and organizations working in these field

Exprosione of (2) The joint notice described in the preceding subparagraph shall be updated and reissued annually for 5 succeeding years.

(c) Following publication of the annual joint notice referred to in paragraph (2), the Secretary of State shall inform the governments of non-nuclear weapon states and, as feasible the organizations operating Duclear powerplants in such states, that the United State is prepared to cooperate with and provide technical assistance to non-nuclear weapon states in the fields of spent fuel storage and disposal as set forth in the joint notice. The Secretary of State shal also solicit expressions of interest from non-nuclear weapon state governments and non-nuclear weapon state nuclear power reactor goverators concerning their participation in expanded United State programs in these fields The 作 Secretary of State shall transmit any such expressions of interest to the Deparment and the Commission.

-Nomnuclear.

d) With his budget presentation materials for the Department and the Commission for fiscal years 1984 through 1989, the President shall include funding requests for an expanded program of cooperation and technical assistance with non-nuclear weapon states in the fields of spent fuel storage and disposal as appropriate in light of expressions of interest in such cooperation and assistance on the part of non-nuclear weapon state governments and nonouclear weapon state nuclear power reactor operalors.

(e) For the purposes of this subsection, the term "non-nuclear weapon state" shall tave the same meaning as that set forth in article LX of the Treaty on the Non-Proliferation of Nuclear Weapons (21 U.S.C. 438)

(f) Nothing in this subsection shall authorize the Departmeat or the Commisaion to take any action not authorized under existing law. 



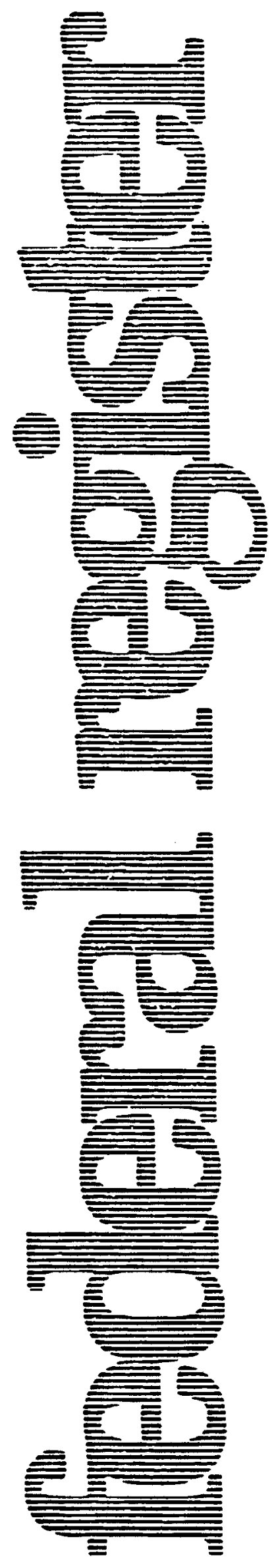

Friday

April 5, 1985

\section{Part VII}

Department of Energy Nuclear Regulatory Commission

Compliance With Section 223 of the Nuclear Waste Policy Act of 1982; Notice 


\section{DEPARTMENT OF ENERGY}

\section{NUCLEAR REGULATORY COMMISSION}

Compliance With Sec ion 223 of the Nuclear Waste Policy Act of 1982

AGENCIES: Department of Encrg! and Nuclear Refula:ory Commission. ACtion: Updals of the previously published notice of offer to cooperate uith and provide technical assistance to nonnuclear wcapon staies in the field of spent nuclear iue! storage and disposal.

summary: The Department of Enctgy and the Nuclcar Regulatory'

Commission. in accordance with section 223 of the Nuclear Woste Policy Acl of 1982 Pub.L. 9:-425). January 7.1983 (the Act). pubiished in the Fedcral Register on March 30. 2983 148 FR 13253.

corrected on April 20. 1983 by notice 48 FR 16960) and updated and reissued in the Federal Register on April 6. 1984 ( 49 FR 13858) an offer to cooperate with and provide technical assistance 10

nonnuclear veapon states for alleviating problems that may develop from accumulation of spent nuclear fuel. This notice is the second update and zgain lenders this offer as provides by the

Act. Available resources. scope. criteria. and modes of coope:ation are described in this offc:, which will be further updated and reissued annually for the nexi 3 years.

\section{Background}

Section 223 of the Act pro::ides that "it shall be the policy of the Lnited States to cooperate with and provide techrical assistance to non-nuclear weapon states in the field of spent fuel storage and disposal."

Section 203 (b) (1) of the Act required that within 90 days of enactment of the Act the Departient of Energy and the Nuclear Regulatory Commission would:

- Publish a juint notice in the Federal Register stuline that the United States is prepyred to rooperate with and provide technical assislonce to non-ruciear weapon states in the ficids of at-reactor spent fuel storage: away-from-reactor spent fuel storape: monitored. retrievable spent fuel storge: geologyc disposal of spent fuel: and the healin. safety and envionmental reguidion of suct, artivities. The notice shall summanze the resourccs that can be made avaiie jie for intemational cooperation and assisiance in these fie! ṡs through existing programs of the Depertment and the Commissior.. iseluding the dvailability of: (i) Data from past o: oneuing :esparrh and de:-ejoptent projects: (ii) consuttutions with expert Department or Commission personacl or contraciors: and (iii) lizison nith private business entittes and orgun::adtlors norking in these fictos.
11 is the irtention of the Departmest of Energy and the Nurlcat Regulatory Commission 10 offe: 10 provide cooperation ano lechrical assistance to ciher natiuns to improve spent fuel slorage conditions as deemed necessary. Il is not the iniention of this offer to include transfer to the United States of spent fuei from loieign nuclear power reactors.

Section 223(c) of the Acl specifies:

Following publication of the annual joint notice referted to in paragraph (2). the Secretary of Siate shall inform the governments of non-nuclear wenpon states and. as feasible. the crganizations operating nuclear powe.plants in such states. that the United States is prepared to cooperate with and provide technical assistance 10 non. nuclear weapon stales in the fields of spent fuel storage and disposal. as set forth in the joint notice. The Secretary of Siate shall also solicit expressions of interest from nonnuclear weapon state govemments and nonnuclear weapon slate nuclear power reactor operators concerning their participation in expanded United States cooperation and technical essistance programs in these fields. The Secretary of Stute shall transmu any such expressions of inlereat to the Deparmen: and the Commission.

\section{Response to the Olfers}

This notice was first published in the Federal Register on March 30. 1983 and was updated and reissued in the Foderal Register on April 6. 1984. To date. seven countries have accepted this offer and substantive exchanges have occurred with three countries.

Discussion and Description or Proposed Cooperative Activities and Programs

For several years the United States has been cooperating with other nations as well as intemational organizations in areas reiated to spend fuel handling. storage. and disposition. The Department of Energy and the Nuclear Regulatory Commission have adhered to policies of sharing the results of their studies and programs in these areas with other nations and they have sought to establish a framework to permit U.S. private organizations working in these fields to cooperate with their counterpars in the other nations. To the extent feasible. it is the intention of the Department of Energy and the Nuclear Regulatory Commission to augment their intema:ional cooperative ties in these areas. Any arrangements relative to funding of joint research and development projects will be developed on a case by case basis subject to program demands and the authorization and approprianon of funds by Congress.

In the course of developing the proposed new ertangements with other governments of foreign institutions. both the Department of Energy and the Nuclear Regulatory Commission will be: guided by number ol faciors and criterid includina the fullowina:

- Whethe: the proposed piusum o! cooperation will be useful in assisting a nonnuclear weapon state in overcoming siznificant and timely spent fucl storage or handling problems:

-Whether the arrangements will serve to advance knowledge in the field:

-Whether the arrangements will he!? solve common spent fuel handling problems: and

-Whether the arrangements will con:ribute to more predictability in fue! cycle operations.

While it is anticipated that in the near future most nations will be able to soive their spent fucl storage problems on a national basis. this is an area that could benefit from enhanced intemational cooperation. As noted by the Final Report of the Intemational Atomic Energy Agency's Expert Group on Intemational Spent Fuel Management [IAEA-ISFM/EG/26. Rev. 1. page 4. July' 1982). prior to 1990 there is reasonably good assurance that adequate provision for dealing with spent fuel will exist. During the 1990s. however, the Report states that greater reliance must be placed on spent fuel management options which are now mainly in the planning stage. and further states that "By the year 2000 additional capacity remains to be identified and eventually. provided. As greater reliance is placed upon planned facilities. some international cooperation could provide greater assurances that adequate means to deal with the spent fuel arisings would be provided."

Some new storage lechnologies now under development hold promise for achieving further economies in slorage arrangements. Also, there are incentives for developing common standarás and gujdelines beiween nations reiating to the conditions for shipping spent fuel. nations can benefit from comparing information on the applicable regulatory practices and. in some cases. it may be productive for nations sharing common spent fucl storage probiems to explore new institutional mechan:sms desizned to facilitate joint action.

The following paragraphs in this notice brie!ly summarize the nature of the activities of the Department of Energy and the Nuclear Regulator: Commission in these areas as nell as the major cooperative activities that these agencies would propose to explo-s or engage in. as circumstances wa.ta..?. 
The U.S. Department of Eoers;

The Department of Energy is now working with indusiry and utilities to assure that suftirient spent fuel storage. capicaly noill be availuble for meeting U.S. domesic needs. U.S. utihities operating power reactors are presenty storing spent fuel in water.filied pools at their reactor sites. Is the nexl few years. additional capacily will be nerded at some sites and the gravity of this proilem could increase rapidly unles additional storage capacities are made y vailable on a timely basis. Accordingly. the Department of Energy. industry. and utilities are now actively developing alternative methods for consolidating. transporting. and storing spent light nater resctor fuel in order to increase. at-reactor storage capaeity.

The emphasis of this domestic program is to work jointly with industry lor developing and licensing alternative storage technologies. Within this context. the Department of Energy is now in the process of working with industry and utilities in developing and demonstrating spesit fuel rod consolidation and dry storage equipment and technology in support of utility Jicense appiications and is participating in efforts to assure the licensability of the entire system for hand!ing. packaging. transportation. and storage. in addition. monitored retrievable storage facilities are being evaluated as integral components of the nuclcar waste management system.

With these considerations in mind. and considering the criterit cited above. the Department of Energy is prepared to engage in the following kinds of cooperative activities with nonnuclear weapon states and international organizations:

-To provide information. in the form of exchanges of documents and reports. on Deparment of Energy funded research and deveiopment projects in the specific areas of spent fuel handling and storage: pool storage: spent fuel packaging for storage or disposal: dry storage in metal casks. drywells. vaults and concrete silos: and on the technology of a way-from-reactor and monitored retrievable storage:

- To arrange. on an appropriate basis. visits and briefings between foreign representatives and Department of Energy and coniractor personnel in those areas and to facilitate. within the terms of applicable U.S. law's. regulations and policies. contacts with private U.S. business entities and organizations with specialized capabilities in these fields:

- To arrange consultations between foreign representatives and expert
Department of Energy und c('ntractor personnel to revieus and comment on. as uppropriate. other nations proposed develupment program pians and facility d. siens:

-To furnish. under mutually agreed lerms. informution on certain L.S. standards and verificd computer codes that may be used for equipmens. component and facility design: and

- To cooperate. as appropriate. with international organizations to disseminate information to nonnuclear weapon states.

As U.S. program demands and the authorization and appropriation ol funds by Congress permit. the Department of Energy also is prepared to participule in jointly funded development and demonstration activities such as:

-The demonstration of concepls for disassembling spent fuel assemblies and for consolidating fuel rods in operating reactor pools:

-The deveiopment and

demonstration of technology for packaging spent fuel for storage and disposal:

-Activities related to assessing the feasibility of away-from-reactor storage. including foreign participation in. or observation of. U.S. tests and demonstrations of equipment and technology for dry storage of spent fuels: and

- The conduct of joint studies to evaluate monitored retrieveble spent fuel storege.

in addition to the manegement of spent fuel in retrievoble modes, the

Department of Energy also is conducting extensive research and development on the geologic disposal of nuclear waste. including the spent fuel option. Where there is mutual interest. information in these areas can be exchanged through:

- The transmittal of published information:

- Arrangement of visits and consultations with the Department of Energy and contractor experts on spent fuel disposal methodology:

-Program planning: and

-Systems analyses.

The research and development activities conducted under the Department of Energy geologic isolation program include:

- The detailed characterization of spent fuel:

-Research and sy'stems studies on spent fuel disposal packages and containers. and their materials:

-Salety analyses: and

-Disposal repositon' designs. including their performance evaluations in various host rock media.
As part of these activities. the U.S Ceningical Suncey is also evailable through the Depirtment of Energy for discussions on the eapth science characteristics of disfiusal siltes

Lnde: the coopcrature activities thit histe been described above. thr information to be prnvided could possibly include exchinges of documents and reports. visits between specialists. short or long-term assignments. the undertaking of joint scminars and meetings, and jointly supported research and development projects.

\section{The Nuclear Regulatory Commission}

In regard to the issue at hund. the Nuclear Regulatory Commigsion is responsible for safety and environmental review's. licensing. inspection and enforcement. and the conduct of research on the safely and environmental regulation of reactor waste in the United States. including the handling. storage. treatment. and disposal of spent reactor fuel. These responsibilities include licensing ary and wet at-reactor and anay-from. reactor storage. monitored retrievable storage. and spent fuel and kiaste disposal (including geological disposal) at permanent repositories.

The Nuclear Regulator. Commission is prepared to cooperate with. and provide technical assistance to. nonnuclear weapon staies in the areas of the health. safery. and entironmental regulation of spent fuel management and disposal activities. Cooperation could include the following:

-Making available data from past and ongoing research and regulator: efforts: These data consisi of evaluated and documented experimental resuits. validated and fully documented computer codes. and research results for which documentation and evaluation are complete. These data are primarily documented as written reports. which the Nuclear Regulatory Commission can provide in specific technical subject areas. as agreed. State-of-the-art information on ongoing safery research programs can be acquired through attendance by representatives from paricipating countries at the annual Water Reactor Safety. Research information Meeting and othet occasional topical meetings. Additiona] data more directly reiated to regulatory activities. such as regulations. slandaros. and guides. can also be provided as appropriate in specific subject areas as requested:

- Consulting with expert Nuc!eur Regulatory Commission personnei nnd Nuclear Regulatory Commission 
contraclar statr. As arranged by specific afrcement with the Nuclear Regulutory Commission. expert lectrical consultation can be provided by Ruclear Reguidiury Cimm.nssion personncl and as necded. by contacint emplos res in the regulatory areas within the Commission's puricu:

- Helping llo the extent permilted by U.S. law.s. regulations. and policies foreign govemments to eslablish inilial contacts with private U.S. entities that conduct business in the applicable waste management activitues:

- Cooperating. as appropriate. with

international organizations 10 disseminate information to nonnuclear weapon stales: and

-Participating in joint research programs. The Nuclear Regulatory Commission is ready to negotiate and engage in jointly funded research programs. consistent with the Agency's mission. with appropriate foreign entities. subject to the authorization and appropriation of flinds by the Congress.

Relationships With Multinational Organizations and Intemational Scientific Bodies

In addition to the foregoing activities. and within the framework of such foreign policy guidance as may be provided by the U.S. Department of State. it is expected that the Nuclear Regulatoy Commission and Department of Energy will continue to participate in activities related to spent fuel handling that are undertaken by international organizations. if afpropriate. These organizations have sponsored a range of activities relevant to this subject. and it is recognized that some ncnauclear weapua siales may wish to avuil themseives of ine services of these bodies as well as the coiperative progions thul are uvaliable bialcealls The X', citar Enurgy Agency vi the Organization lor Ecunomic Cooperation and Development. for example. has been actively invoired in studies relaled 10 the disposal of nuclear wastes. Also. as mentioned above. through the effiorts of an Expert Group on International Spent Fuel Management. the Interrational Alomic Energy Agency in 1982 completed a study on the potential for intemational cooperation in the management of spert fuel. giving emphasis to technical, cconomic. institutional. and legal considerations. Several of the recommendations of the International Alomic Energy Agency Expert Group could sere as a stimulus for further cooperative initialives. Areas that may merit further study include the establishment of nuclear safety standards recommended by the Intemationa! Atomic Energy Agency for spent fuel storage and transport. and possible further studies, as the interests of the intemational community dictaie. such as multinational or regional approaches to spent fuel management and disposal.

\section{Slorage and Disposition of Research Reacior Spent Fuels}

The cooperative programs described in this asnouncement are addressed to the problems associated with the storage and handling of power reactor spent fuel that originates primarily in light water reactors. As such. they do nol add:ess any issues associdted with the uccumulation of forc:zn residatid reaclor fus!s

Solicitation of Expressions of Intercst From Vionnuclear Heapon Slates

As the next sicp in deselopine this offer of couperetion and iechnical assistance. nonnuclear weapon slates will again be contacled through diplnmatic channe!s to acquaini them with this proposal and 10 solicil expressions of interest. The Department of State will transmit any such expressions of interest to the Department of Energy and the Nuclear Regulatory Commission.

\section{Requests for Information}

Inquiries about this notice may be sent to the following:

Ben C. Rusche. Director. Office of Civilian Radioactive Waste Management. U.S. Department of Energy. Washinglon. D.C. 20585 (Tel. No. 202/252-6850)

Jamcs R. Shea. Director. Office of Intemational Programs. U.S. Nuclear Regulatory Commission. Washington. D.C. 20555 (Tel. No. 302/492-7886)

Dated: April 1. 1985.

Approval:

Beo C Rusche.

Director. Office of $\mathrm{Cj}$ ilion Radiooctive Woste Monogement Depertment of E:sry:

Dated: March 29, 1985.

William J. Dircks.

Executive Director for Operotions. Aiuclnor Regulotory Commisssian.

[FR Doc. 85-8245 Filed :-85: 8:45 am]

OILINC COOE MASO-OS- 


\section{APPENDIX A: DOE INFX POLICIES}

This appendix discusses the rationale for DOE participation in international exchange of fuel cycle technology, summarizes current US-DOE pol icy concerning such exchanges, and suggests the actions to be taken in initiating new INFX activities. A discussion of this subject may also be found in "Pol icy Options for International Cooperation in Radioactive Waste Management." (a)

\section{RATIONALE}

Since the years of the Eisenhower administration, the United States has, in general, maintained a national commitment to help other nations in their development of peaceful uses for nuclear energy. In the nuclear fuel cycle and waste management areas, this commitment has led to the extensive transfer of US technology to the rest of the world, partly through participation in IAEA and OECD/NEA activities and partly through bilateral information exchanges. As a result of this policy, the influence of the US can be seen in the fuel cycle/waste management programs of many other countries.

Current US policy to continue to participate in cooperative international R\&D programs is driven partly by foreign policy objectives (e.g., we minimize our involvement with countries whose fuel cycle plans and programs are not consistent with our nonproliferation objectives; we assist nations we wish to see become stronger industrially), partly by our interest in conserving resources by coordinating our R\&D activities with other countries or through joint use of test or demonstration facilities, and partly by the feeling that it is in the best interests of the United States to arrive at internationally accepted solutions to waste disposal problems. Thus specific Department of Energy policy regarding the transfer or exchange of fuel cycle and waste management technology with another country depends on the country and is shaped by the answers to questions such as these:

- Will the exchange be free and open, or will it be constrained by political or proprietary limits imposed by the other country?

- Does DOE have a cooperative exchange agreement with the other country covering fuel cycle and waste management technology?

- How advanced is the other country's technology? (US policy favors cooperative activities if the US can benefit in either of two ways--through exchange of fuel cycle/waste management technology, or by trading US expertise in this area for foreign expertise in another.)

(a) A white paper by F. A. Morris and A. H. Schilling of Battelle Human Affairs Research Centers, Seattle, WA. 
- Do the fuel cycle/waste management plans parallel those of the US? (If the other country does not plan to reprocess, or plans to use geologic formations which are not of interest to the US, there is little incentive for active cooperation.)

- Will a cooperative R\&D effort or transfer of technology help DOE meet the Department's objective of promoting US commercial dealings with other countries?

\section{CONSTRAINTS}

In planning INFX activities, the following criteria should be used:

- US-DOE pol icy guidelines regarding classifications of information (defined in DOE Order 5650.2), sensitive subjects (defined in DOE Order 1240.2) and unclassified activities in foreign atomic energy programs (10 CFR 810) must be followed.

- The bilateral agreements provide guidance, but should not be considered as setting absolute 1 imits, on subject areas.

- There should be a perceived benefit to the US. This might range from satisfying the objective of being friendly or helpful to a given nation to the expectation that access to specific foreign test data or equipment design will advance a US R\&D program.

There is a natural tendency to strive for exact quid pro quo in transferring US technology abroad. This is difficult to achieve and difficult to measure. If the perceived benefit to the US is achieved, it should not be necessary to worry about relative benefits for the two partners in the exchange.

In the United States, the transfer of waste management technology has not yet become subject to proprietary constraints, except perhaps in the area of reactor waste treatment. In a few other countries, notably France and the UK, waste treatment techology is a matter of commercial interest, and proposals for exchanges have to deal with questions of proprietary interest.

\section{INFX Program Development}

Various types of international cooperative activity may be considered:

1. Official foreign travel under DOE-NE sponsorship. Travel may be in the form of:

- a visit by an individual or team to one or more foreign sites for INFX planning, a broad program overview, or an in-depth review of a specific area of technology

- an assignment as part of a personnel exchange for consultation (expenses paid by the host) or for participation in a US-sponsored test in a foreign facility 
- participation in a bilateral, multilateral, or international agency workshop, committee meeting, or working group meeting

- attendance (usually with presentation of a paper) at an international technical seminar or symposium.

2. Hosting of foreigners visiting the US for the purposes described above.

3. The exchange of technical reports and other documents. This type of exchange is generally 1 imited to published reports, and loses some of its effectiveness because of the time it usually takes to prepare and issue formal topical reports. Furthermore, many foreign investigators tend to report their studies formally only at major symposia and conferences and do not issue formal topical reports as is done in the US. In some cases, DOE allows the exchange of progress reports or cleared but unpublished drafts with another country if a formal agreement is in place.

4. Partial or total sponsorship (and funding) of test activities conducted in another country.

5. Foreign participation in US test activities.

The cost of travel to US sites by foreign nationals to a US site to help complete contract-related work may be defrayed in part or in full by the Department of Energy depending on the case. Costs of exchange activities under formal bilateral or multilateral agreements are paid for by the party benefiting from the exchange; mutual benefit requires cost sharing by both sides. For extensive exchanges, cooperative projects, or long-term personnel exchanges, a specific program plan may be required or a memorandum of understanding signed by both parties may be needed (see Appendix B, Establishing Agreements). Guidance and approval for exceptional cases should be sought from the appropriate Program Office and the Assistant Secretary for International Affairs.

A1 though it appears impossible to make long-term projections of all cost-incurring international activities, probable funding needs should be reflected in each contractor's annual budget submission documents. Wherever possible, plans for INFX activities should be included in the contractor's annual work plans.

Suggestions or proposals for specific INFX activities or comprehensive, continuing technology exchanges may come from any of the participants in the planning function, including foreign agencies. Each proposed INFX activity should be discussed with the potential foreign partner and with appropriate DOE contractor and DOE program personnel. Once concurrence in the concept has been obtained and the source of funds for US activities identified, preparations for implementation can proceed. 




\section{APPENDIX B: ESTABLISHING AGREEMENTS}

This appendix shows the need for and preparation of international agreements for cooperation in energy R\&D.

\section{CATEGORIES OF COOPERATIVE ACTIVITIES}

Information will be provided in this appendix on four categories of cooperative activities. These will, by their nature, require increasing amounts of Headquarter's involvement in supporting agreement preparation. The categories are:

1. Activities which may be conducted without a formal agreement.

2. Activities which require a formal agreement, but for which the contractual type of agreement may be drafted in the field. These agreements will require Headquarters review for pol icy acceptability only.

3. Activities which require a formal international agreement of the type prepared at Headquarters. Typically, these activities pose no new policy issues as a result of their scope or of the national identity of the parties. Nevertheless, their undertaking must be authorized at the highest DOE level.

4. Activities which, by their scope of parties, are sensitive. The decision to enter into these international agreements will require substantial evaluation and weighing of nontechnical factors. These agreements are prepared at Headquarters with significant participation by other federal agencies.

\section{AGREEMENT FORMALITY}

It is the objective of DOE to utilize, for reasons of administrative efficiency, the most informal instrument of agreement which is feasible under the circumstances.

\section{HEADQUARTERS CONTACT}

It is imperative--whatever the category of the activities--that Headquarters Program Management be informed at the earliest stage of contacts with potential parties to an agreement. Where waste management activities are concerned, these persons (or their designees), should be informed: the Director, Office of Terminal Waste Disposal and Remedial Action; the Director, Office of Civilian Radioactive Waste Management, and the Director, Office of Defense Waste and Byproducts Management. 


\section{Activities Not Requiring a Formal Agreement}

Any international cooperative activity may be formal ized by an agreement between the parties, and all activities of substance must be so formalized. However, the utilization of an agreement is optional when certain criteria are all met. These criteria are:

1. No commitment to transfer funds, or for the US program to support work which is not of direct program benefit.

2. No exchange of proprietary, classified, 10 CFR 810, or 1 imited distribution information. In the latter case, however, information may be received with the understanding that limited distribution means only that positive actions to distribute such information are not intended.

3. No exchange of information requiring patent or copyright protection--an example of suitable information for exchange would be that which has received patent and program review and will be made available to the OTSI at Oak Ridge.

4. A relatively low level of information exchange. This applies both to volume exchanged and to implied commitment to arrange periodic exchanges.

5. No assignments or exchanges of staff, and 1 imited (as to staff numbers, meeting duration, and meeting frequency) schedule of meetings.

6. Very limited provision or exchange of physical materials, and those only of the expendable type and of normal value pursuant to applicable DOE regulations.

7. Acceptance by Program Management that the need for the information to be received does not warrant using an instrument suitable for compelling performance.

8. Understanding by recipients that the information received is in no way warranted and is used at their own risk.

9. No nontechnical (e.g., political) sensitivities because of the nationa] ity of the participants.

10. Understanding by those involved in the exchange process that activities not meeting the above criteria will require a formal agreement.

Al though these criteria appear imposing at first, a considerable number of potentially beneficial contacts may be accommodated within them.

\section{Activities for Which Agreements May Be Drafted in the Field}

Agreements may be drafted in the field for international activities which are primarily of a procurement or strongly facility-oriented nature. 


\section{Procurement Nature Agreements}

These agreements are, in essence, procurement contracts prepared in accordance with the Federal Procurement Regulations and executed by a Field Office Contracting officer. As such, they may be drafted in the field and receive detailed review by field counsel. For arrangements of this type, Headquarters involvement in the agreement-generating process is usually 1 imited to reviewing the product from a policy viewpoint only. The agreement should not be executed prior to policy review; in most cases, however, review will be prompt if Headquarters Program Management has been kept properly informed.

The need for these agreements usually arises as the result of the exchange of program information under an Umbrella Agreement, although it may be prompted by other information exchange mechanisms. The information may motivate a foreign party to seek the services of an affected DOE GOCO facility to help solve a current problem. Where there are no problems of political sensitivity and where such services can be provided on an acceptable cost recovery basis, an agreement may result. An example of such an agreement may be found in the Japan section (JA-2.1).

Since there may be many agreements of this type, covering activities at different facilities and prepared with guidance from different Operations Offices, they will differ considerably from each other. There is no general model. It would probably have been preferable, in the case of the example, to have drafted it more independently of the LMFBR Umbrella Agreement. The incorporation by reference of Umbrella Articles is undesirable.

\section{Facil ity-Oriented Agreements}

When an activity, usually one being conducted as part of a larger scale cooperative program, must be covered by a formal subsidiary agreement, but when the manner in which the activity is to be conducted is strongly conditioned by both local conditions and methods of operation, the most practical approach is the exchange, on a medium term (1-3 years), of technical staff between government-supported R\&D installations. Such assignments might be a part of any cooperative program. The staff members assigned may be specialists who will be integrated into ongoing host nation programs; they may serve as convenient points of contact for program coordination or they may act only as program observers.

Many blanket agreements contain an assignment article, specifically providing that such assignments will take place and will be covered by the preparation of a subsidiary assignment agreement. The assigment agreement will set forth the conditions of the assignment, including the qualifications and responsibilities of the assignee.

An example of a typical assignment agreement developed in response to the assignment article is provided in the Germany section (GE-6.1). Since the agreement is locally oriented, it should not be considered to be a model. In view of the widespread utilization of the staff assignment form of cooperation, Headquarters recentiy considered developing a model assignment agreement. 
Unfortunately, the effort was not a success because of the diversity of requirements and conditions at the various facilities which would have been affected.

\section{Activities Requiring Headquarters Prepared Agreements}

Activities of this category are typically conducted under either Umbrella (broad enabling) Agreements or Project Agreements. Umbrella Agreements will set forth specific fields within ongoing national programs, as areas for cooperation in which detailed information will be exchanged on a pericdic basis. Project Agreements are usually utilized when it is feasible and desirable for the parties to commit specific resources to attaining definite results through a cooperative program.

The forms of cooperation contemplated under Umbrella Agreements include, as a minimum, the exchange of technical documents and visitors, and usually extend to sponsorship of seminars and other periodic meetings and to assignment of technical specialists to facilities of the other party. It is also customary to provide in principle for the undertaking of joint projects, al though the details of such undertakings have usually not been defined at the time of entering into the Umbrella Agreement. In view of their inherent general ity, Umbrella Agreements will provide that separate subsidiary agreements be prepared when the parties are prepared to assign individual staff to other party facilities or when the parties are prepared to undertake a joint project.

\section{Headquarters' Roles in Agreement Preparation}

Al though there is considerable flexibility in the assignment of responsibility for drafting Umbrella and Project Agreements at Headquarters, the principal participants in the drafting process will be from the affected program organization, the International Affairs staff, and their supporting counsel.

The program organizations will usually establish, through exploratory discussions with their foreign counterparts and through drawing upon their technical support resources, the need for the cooperative program and its extent. These deliberations should culminate in the drafting of a scope of work, the evaluation of a management approach, and the allocation of resources to support the implementation of the cooperative agreement.

International Affairs staff usually drafts the overall agreement based upon program organization input and in consultation with counsel and other offices, both within and outside of DOE as appropriate. They then draft an authorization for an individual to sign the agreement on behalf of DOE and obtain the necessary concurrences to this authorization.

\section{Agreement Execution}

Because agreements of the type discussed here are highly visible commitments of the United States, their execution must be authorized at the highest level of DOE (Secretary or his designee). There is considerable latitude, however, in the naming of the individual to actually sign the agreement. It is frequently convenient to authorize the US Ambassador to the other country to 
sign the agreement, al though it is not uncommon to authorize officials in the most affected program organization to do so.

\section{Model Agreements}

In order to simplify and expedite agreement preparation, basic elements which would make up a model international agreement for cooperation in energy R\&D have been developed at Headquarters. This approach addresses preparation of Umbrella Agreements and two types of Project Agreements-- those evolving from cooperation conducted under a pre-existing Umbrella Agreement and those developed to stand independently because no suitable pre-existing Umbrella is in place.

The principal elements making up these types of agreements are identified in Table B-1 (page B-6). Examples of recently executed Umbrella and Project Agreements can be found in the Switzerland section (SZ-1.1) and the Germany section (GE-4.1), respectively.

\section{Correlation of the Project Agreement Example (Germany Section, Attachment GE-4) to a Model Agreement}

Scope Articles. The scope articles of Attachment GE-4 (Articles 1, 2, and 3) are titled QBJECTIVES; SCOPE; and SCHEDULE, MILESTONES, and REPORIING REQUIREMENTS. These titles are the suggested ones and are organizationally useful in Project Agreements. The content of the articles appearing in the example is considered typical. In the case of Umbrella Agreements, more useful titles for the three scoping articles are QBJECTIVES; EIELDS OF COOPERATION; and EORMS OF COOPERAIION. An example of the content of these articles is provided as example B-1 (page B-12).

Finance Article. ARTICLE 5 - FINANCE appearing in Attachment GE-4 is very similar to that of an Umbrella Agreement; this is because no transfer of funds was anticipated as part of the cooperative effort. If fund transfers were to take place, the article would be substantially expanded in a manner determined by the specifics of the cooperation. It would be necessary to coordinate the drafting of the article with the Office of the Controller; controller concurrence would also be required in the authorization process alluded to in the section on Headquarters' roles.

Redundant Articles. There is a pre-existing Umbrella Agreement in the case of Attachment GE-4; it is properly referenced in the prefatory section of the example. However, since the pre-existing Umbrella did not contain a Subsidiary Agreements article (Article 5, Table 1) which automaticaliy incorporated Articles 8, 12, 13, 14, 15, 17, and 18 (Table 1) into the Project Agreement, the model 1 anguage for these articles was adapted and made a part of Attachment GE-4 and Articles $7,10,11,12,13,15$, and 6 , respectively. Because many Umbrellas were drafted and placed into effect before the Model Agreement became available, it is not unusual to find that these articles must still be included in new $1 y$-drafted subsidiary agreements such as Attachment GE-4. 
TABLE B-1. Agreement El ements

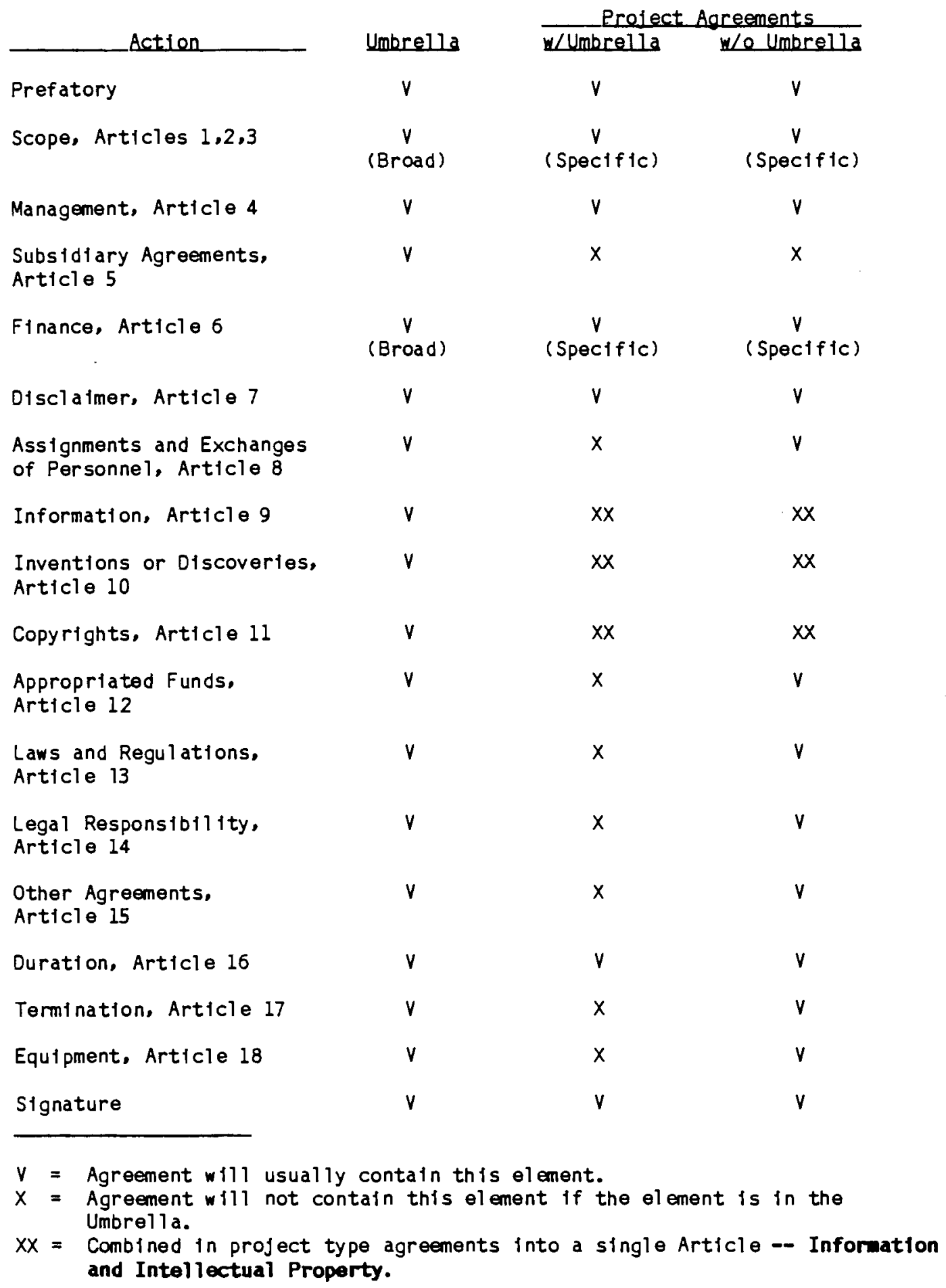


Intellectual Property Articles. The three Model Agreement articles which treat intellectual property- $-9,10$, and 11--have been combined in Attachment GE-4 into a single article, ARTICLE 9 - INFORMATION AND INTELLECTUAL PROPERTY.

This combination is not unusual in the case of Project Agreements. The three Model Agreement articles are recommended for use in Umbrella Agreements, and are provided as Example B-2 (page B-14).

Intellectual property is probably the most difficult area of agreement preparation and negotiation. This is due to: 1) the fact that the requirements of the US Freedom of Information Act introduce concepts which are difficult for many foreign organizations to accept, and 2) disagreement on the rights which should accrue to the various parties as a result of information arising from the conduct of agreement work--particularly if it is perceived to have commercial value. The negotiating stance assumed by the parties, especially in the case of Project Agreements, will be strongly influenced by the quantity and technological quality of the information material developed under current national programs, the anticipated results of the cooperation, and the resource level committed to the cooperative program.

Articles 9 and 11 of Example B-2 are quite straightforward and are usually suitable for incorporation in all types of agreements. Article 10 is usually acceptable for Umbrella Agreements, but may not be generalized further.

Unique Articles. It is not unusual for agreements to contain articles unique to the political realities or business methods of one of the parties. It was not feasible to include articles of this type in the Model Agreement. ARTICLE 16 - LAND BERLIN of Attachment GE-4 is 111 ustrative of this type of article.

\section{Multiparty Agreements}

Some cooperative arrangements $w i 11$ be entered into by more than two parties. An example is the multinational support of the research program conducted at the Stripa mine in Sweden. Multiparty agreements can be particularly challenging to negotiate because of: 1 ) the mechanical difficulty in attaining resolution of misunderstandings or points of issue among many parties, 2) the necessity to develop mutually acceptable provisions which will enable cooperative program work to proceed in the absence of unanimity (provisions for weighted voting in executive sessions are sometimes helpful--weighting can be based upon the level of country resource commitment), and 3) the need to maintain equity of financial support from participating countries when exchange rates fluctuate. Although the provisions of previous multinational agreements may provide helpful negotiating precedents, it is prudent to allocate significant time for negotiations in these areas.

A necessary condition for successful negotiation of multination agreements is to ensure that country representatives with technical and drafting responsibilities are afforded the opportunity to meet face-to-face at least once during the drafting process. 


\section{Agreement Amendment of Extension}

Umbrel 1a and Project Agreements usually contain provisions for amending their scope and for extending their term. Typical Project Agreement 1 anguage appears at the end of ARIICLE 2 - SCOPE and at the beginning of ARIICLE 14 - DURATION of Attachment GE-4. Umbrella Agreement language appears at the end of Article 2 and 3 of Attachment SZ-1 (Switzerland section).

It is important to recognize that these changes are required to be in writing. Therefore, the change must be authorized and executed in the manner described in the section on Agreement Execution.

\section{Activities of a Sensitive Nature}

Since the agreements used in furthering the conduct of this category of activities are drafted and authorized in essentially the same manner as those previously described, this section will address the factors which make some cooperative activities sensitive, and what type of deliberations may precede the decision to procede with such activities. The sensitizing factors are of three generic types: those which are political in nature, those which are legal in nature, and those which are commercial in nature.

\section{Political Factors}

Political factors strongly affect the parties to the agreement and the acceptability of specific fields and forms of cooperation. It is obvious, for example, that significant cooperation--or even the appearance of significant cooperation--with countries which are communist-controlled could sensitize an otherwise routine program of cooperation. Communist-controlled countries include:

Afghanistan
Albania
Bulgaria
Cuba
Czechoslovakia
Democratic Kampuchea (Cambodia)
German Democratic Republic
Hungary
Laos

\author{
Mongol ia \\ North Korea \\ People's Republic of China \\ Pol and \\ Romania \\ Union of Soviet Social ist \\ Republics (including Es- \\ tonia, Latvia, and Lithunia) \\ Vietnam \\ Yugoslavia.
}

Nonprol iferation considerations are another political factor which strongly affect the sensitivity of the parties to an agreement and its scope.

The impact of political factors varies with the passage of time. Change results from modifications of national policy (both that of the US and of the other party) as well as from current events--a program of cooperative activity which would be otherwise acceptable might be delayed or abandoned if the region in which the other party was situated was transformed from a peaceful one to one of substantial international tension. 
The evaluation of political factors during the decision-making process is much simplified if the details of national policy have been specifically estab1 ished in the affected areas; unfortunately this is not always the case. In order to further the policy definition process in the waste management area, DOE developed cooperation guidelines (Appendix D). Substantial participation by Department of State staff will usually be a necessary part of defining a position on sensitive cooperative programs. The position is crystallized by presentating positions of any doubtful issues to the appropriate DOE policymakers, in the format specified in department procedures, for their approval.

\section{Legal Factors}

The legal factors to be considered here stem from the requirements of 10 CFR 810 and the Nuclear Non-Prol iferation Act of 1978.

10 CFR 810. This regulation deals with: 1) authorization by government officials under the Atomic Energy Act of 1954, as amended, for persons other than the USERDA to engage in activities relating to the direct or indirect production of special nuclear material outside of the United States, 2) reporting requirements applicable to persons who engage in certain unclassified activities in foreign atomic energy programs, and 3 ) authorization procedures.

The determination that activities are not inimical to US interests will be granted if they are not, directly or indirectly, engaged in within countries or areas 1 isted in the regulation (generally, but not exactly, consistent with the Communist-controlled countries 1 isted above) and if the activities are not of certain types which are identified in the regulation. As to type, there is particular concern when related to facllities for 1) the chemical processing of irradiated special nuclear material 2) the separation of isotopes of any source or special nuclear material, or 3 ) the fabrication of nuclear fuel containing plutonium. Activities are prohibited which involve:

Furnishing information not available to the public in published form for use in the design, construction, fabrication or operation of such facilities or equipment or components especially designed, modified, or adapted for use in such facilities;. .

There are also other restrictions set forth in the regulation.

The extent to which the undertaking of desired cooperative activities involving information exchange may be 1 imited by 10 CFR 810 is, however, mitigated by the provision that "information available to the public in published form" includes (but is not 1 imited to) information available under the Freedom of Information Act. This is because the definition of records to be made available under the Freedom in Information Act is quite broad. It is certainly much broader than an otherwise justifiable, but narrow, construction of the term "in published form" would be. Considerable information may, therefore, by exchanged. 
The Nuclear Non-Prol iferation Act of 1978 (NNPA). The NNPA is quite a comprehensive and complicated piece of legislation; it is clearly beyond the scope of this appendix to discuss it either generally or in detail. Because it does, however, address the export of nuclear technology to foreign countries at considerable length, a very abbreviated mention is provided of some principal features.

The NNPA declares that it is the policy of the United States to pursue the establishment of:

- . more effective international controls over the transfer and use of nuclear materials and equipment and nuclear technology for peaceful pur poses in order to prevent prol iferation,...

The stated purpose of the NNPA is to ensure:

- . effective controls by the United States over its exports of nuclear materials and equipment and of nuclear technology.

Titles III and IV of the NNPA contain further amendments to the Atomic Energy Act of 1954 which establish 1) criteria governing the export of "sensitive nuclear technology" and 2) provisions for handling proposed agreements for forelgn cooperation involving sensitive nuclear technology-as well as for the renegotiation of certain existing agreements.

As used in the NNPA, "sensitive nuclear technology" means:

- . any information (including information incorporated in a production or utilization facility or important component thereof) which is not available to the public and which is important to the design, construction, fabrication, operation or maintenance of a uranium enrichment or nuclear fuel reprocessing facility or a facility for the production of heavy water, . .

It is probable that "available to the public" may be construed as information "available to the public in published form." Again, considerable information may be exchanged.

Contacts. When activities which might be affected by the provisions of 10 CFR 810 or the NNPA are contemplated in a cooperative program, the Headquarters Division of International Security Affairs and/or the Office of General Counsel should be consulted.

\section{Commercial Factors}

In some circumstances, the US will wish to obtain information which is perceived to be of substantial commercial value and has been developed under a foreign program. The negotiations associated with the exchange of information of this type are time-consuming, difficult, and not always successful. This is because many foreign countries seek either to recoup as much of their program cost as possible through the sale, or licensing the use, of such information, or to 
assure by other means that benefits will flow principally to their own industrial community.

The unwillingness of the French to support the exchange of operating information generated under their Super Phenix LMFBR Demonstration Program, despite the existence of an Umbrella Agreement, is an example of how commercial sensitivity can inhibit a cooperative information exchange program. This type of problem is not usually encountered when the information to be exchanged is general in nature or related to important but non-competitive areas, such as safety. 


\section{ABIICLE 1}

Cooperation under this Memorandum of Understanding shall be directed toward finding solutions to mutually agreed problems like design, development, construction and operation of alternative energy systems, and toward the exchange of information developed during the resolution of these problems.

\section{ARIICLE 2}

The fields of cooperation covered by this Memorandum of Understanding may include:

1. Peat technology.

2. Biomass technology, including the use of wood.

3. District heating technology.

4. Combined production of power and heat.

5. Rational use and conservation of energy in buildings, communities, and industries.

6. Low head hydro power technology.

7. Petroleum storage in underground rock caverns.

The above list does not indicate any priority order for the fields of cooperation.

Other fields of cooperation may be added by mutual written agreement.

\section{ARTICLE 3}

Cooperation in accordance with this Memorandum of Understanding may include, but is not limited to, the following forms:

1. Exchange of scientists, engineers and other special ists for participation in agreed research, development, analysis, design and experimental activities conducted in research centers, laboratories, engineering offices and other facilities and enterprises of each of the Parties or its contractors for agreed periods. Such exchanges of staff shall be in accordance with Article 10 of this Memorandum of Understanding.

2. Exchange of samples, materials, instruments and components for testing. 
3. Exchange, on a current basis, of scientific and technical information, and results and methods of research and development.

4. Organization of, and participation in, seminars and other meetings on specific mutual agreed topics in the fields listed in Article 2. Such seminars shall normally be held alternately in the United States and in Finland for each topic.

5. Joint projects in which the Parties agree to share the work and/or costs. Each such joint project shall be the subject of a separate agreement pursuant to Article 4 of this Memorandum of Understanding.

Other specific forms of cooperation may be added by mutual written agreement. 


\section{ABTICLE 9}

\section{INFORMATION}

1. The Parties support the widest possible dissemination of information provided or exchanged under this Agreement, subject to the need to protect proprietary information and to the provisions of Article 10, Invention or Discoveries and Article 1l, copyrights.

2. Use of Proprietary Information

Definitions as used in this Agreement:

(i) The term "information" means scientific or technical data, results or methods or research and development, and any other information intended to be provided or exchanged under this Agreement.

(ii) The term "proprietary information" means information which contains trade secrets, commercial or financial information which is privileged or confidential, and may only include such information which:

a) has been held in confidence by its owner;

b) is of a type which is customarily held in confidence by its owner;

c) has not been transmitted by the transmitting Party to other entities (including the receiving Party) except on the basis that it be held in confidence; and

d) is not otherwise available to the receiving Party from another source without restriction on its further dissemination.

3. Procedures

(i) A Party receiving proprietary information pursuant to this Agreement shall respect the privileged nature thereof. Any document which contains proprietary information shall be clearly marked by the providing Party with the following (or substantially similar) restrictive legend: 
"This document contains proprietary information furnished in confidence under a dated the United States Department of Energy and the between and shall not be disseminated outside these organizations, their contractors, and the concerned departments and agencies of the Governments of the U.S. and without prior approval of

This notice shall be marked on any reproduction hereof, in whole or in part. These limitations shall automatically terminate when this information is disclosed by the owner without restriction."

(ii) Proprietary information received in confidence under this Agreement may be disseminated by the receiving Party to:

a) persons with in or employed by the receiving party, and other concerned Government departments and Government agencies in the country of the receiving Party; and

b) prime or subcontractors of the receiving Party located with in the geographical limits of the receiving Party's nation, for use only within the framework of their contracts with the receiving Party in work relating to the subject matter of the proprietary information;

provided, that any proprietary information so disseminated shal 1 be pursuant to an agreement of confidentiality and shall be marked with the restrictive legend substantially identical to that appearing in subparagraph $3(i)$ above.

( $i i i)$ With the prior written consent of the Party providing proprietary information under this Agreement, the receiving Party may disseminate such proprietary information more widely than otherwise permitted in the foregoing subsection ( $i i)$. The Parties shall cooperate with each other in developing procedures for requesting and obtaining prior written consent for such wider dissemination, and each Party will grant such approval to the extent permitted by its national policies, regulations and 1 aws.

4. Each Party shall exercise its best efforts to ensure that proprietary information received by it under this Agreement shall be controlled as provided herein. If one of the Parties becomes aware that it will be, or may reasonably be expected to become, unable to meet the non-dissemination provisions of this Article, it shall immediately inform the other Party. The Parties shall thereafter consult to define an appropriate course of action.

5. Information arising from seminars and other meetings arranged under this Agreement and information arising from the attachments of staff, use of facilities and joint projects shall be treated by the Parties according to the principles specified in this Article; provided, however, no proprietary information orally communicated shall be subject to the 1 imited disclosure requirements of this Agreement unless the individual 
communicating such information places the recipient on notice as to the proprietary character of the information communicated.

6. Nothing contained in this Agreement shall preclude the use or dissemination of information received by a Party through arrangements other than those provided for under this Agreement.

\section{ARTICLE 10}

\section{INVENTIONS OR DISCOVERIES}

1. With respect to any invention or discovery made or conceived in the course of or under this Agreement:

a. If made or conceived by personnel of one Party (the Assigning Party) or its contractors while assigned to the other Party (Recipient Party) or its contractors in connection with exchanges of scientists, engineers and other specialists:

(1) The Recipient Party shall acquire all right, title and interest in and to any such invention or discovery in its own country and in third countries, subject to a non-exclusive, irrevocable, royalty-free license in all such countries to the Assigning Party, its government, and its nationals designated by it, in and to any such invention or discovery and any patent application, patent, or other protection relating thereto.

(2) The Assigning Party shall acquire all right, title and interest in and to any such invention or discovery in its own country, subject to a non-exclusive, irrevocable, royalty-free 1 icense to the Recipient Party, its Government, and its nationals designated by it, in and to any such invention or discovery and any patent application, patent, or other protection relating thereto.

b. If made or conceived by a Party or its contractors as a direct result of employing information which has been communicated to it under this Agreement by the other Party or its contractors or communicated during seminars or other joint meetings, the Party making the invention shall acquire all right, title and interest in and to such invention or discovery in all countries, subject to a grant to the other Party, its Government, and its nationals designated by it, of a non-exclusive, irrevocable, royalty-free 1 icense in all countries, in and to any such invention or discovery and any patent application, patent, or other protection relating thereto.

c. With regard to exchange of samples, materials, instruments, and components for testing, the Recipient Party shall have the same rights as the Recipient Party as set forth in paragraph la (1) above and the Sending Party shall have the same rights as the Assigning Party as set forth in paragraph la (2) above to any inventions or 
discoveries which are improvements to such samples, material, instruments or components.

d. With regard to other specific forms of cooperation, the Parties shall provide for appropriate distribution of rights to inventions or discoveries resulting from such cooperation. In general, however, each Party should normally own the rights to such inventions or discoveries in its own country with a non-exclusive, irrevocable, royalty-free 1 icense to the other Party, its Government, and its nationals designated by $i t$, and the rights to such inventions or discoveries in other countries should be agreed by the Parties on an equitable basis.

2. Each Party sha11, without prejudice to any rights of inventors or authors under its national 1 aws, take all necessary steps to provide the cooperation from its inventors and authors required to carry out the provisions of this Article and Article 11 (Copyrights).

3. Each Party shall assume the responsibility to pay awards or compensation required to be paid to its own nationals according to its own laws.

ARTICLE 11

COPYRIGHTS

Copyrights of the Parties or of cooperating organizations and persons shall be accorded treatment consistent with internationally recogized standards of protection. As to copyrights on materials within the scope of paragraph 1 of the Information Article owned or controlled by a Party, that party shall make efforts to grant to the other Party a license to reproduce copyrighted material. 

APPENDIX C: EXCHANGE OF TECHNICAL INFORMATION WITH FOREIGN COUNTRIES

\section{ORGANIZATIONAL RESPONSIBILITIES}

1. Office of Technical and Scientific Information (OTSI)

P. 0 . Box 62

Oak Ridge, Tennessee 37830

(Te1: FTS 626-1194)

Function. Collect, manage, announce and disseminate scientific and technical information, including reports of travel and meetings, resulting from DOE-funded and world-wide R\&D efforts. (DOE contractors are obligated to report their R\&D work to OTSI for inclusion in DOE's information data base. OTSI will control dissemination of proprietary and technical information as required.)

2. National Technical Information Service (NTIS)

United States Department of Commerce

5285 Port Royal Road

Springfield, Virginia 22151

Function. Serve as the exclusive marketing agent for the sale of DOE-genrated technical information to the public. (Unclassified documents sent to OTSI under the standard distribution system are sent by OTSI to NTIS unless the originator of the document specifies otherwise.)

3. National Energy Software Center (NESC)

Argonne National Laboratory

9700 South Cass Avenue

Argonne, ITlinois 60439

(Te1: FTS 972-7250)

Function. Collect, announce and distribute DOE-sponsored computer software. NESC does not provide user training, but may be able to answer specific questions concerning software use.

4. DOE and Contractors

Function. DOE and contractor personnel are obligated to collect and document technical and scientific information and to make it available for dissemination through the above agencies. 


\title{
TRANSMITTAL OF WASTE MANAGEMENT SCIENTIFIC AND TECHNICAL INFORMATION TO OTHER COUNTRIES
}

\author{
DOE Systems for Information Exchange(a)
}

1. Broad exchange program, establ ished by OTSI with an individual country. OTSI handles bulk dissemination of US reports and receipt and US distribution of foreign reports as specified in standard distribution 1 ists.

2. Specific exchange program, with tight controls on type and quantity of information exchanged to ensure adequate quid pro quo. OTSI handles distribution and receipt of information and maintans records of the exchange.

3. Direct exchange of information between DOE or DOE contractors and their foreign counterparts with a minimum of approval and documentation. The following guidelines should be observed:

a. Foreign distribution of $\mathrm{cleared}$ waste management documents may be made through DOE's standard distribution system (DOE/TIC-4500), provided the distribution is part of a document exchange covered by an approved DOE cooperative agreement. Guidance for standard distribution of such documents is provided in Tables $\mathrm{C}-1$ and $\mathrm{C}-2$. (b)

b. An author may send copies of cleared technical reports directly to his foreign counterparts, provided the transmittal is covered by an approved waste management agreement and provided an effort is made to gain equivalent information in return.

c. A limited number of cleared waste management reports may be given to a foreign visitor in the course of a visit to a DOE site, provided doing so will be of value to DOE and provided the visit is approved by DOE.

d. When an author receives a request for a report from a country or foreign agency not covered by a waste management cooperative agreement, the request should be referred to OTSI or NTIS for handling.

(a) DOE Order 1430.2, "Implementation of the Scientific and Technical Information Management Program" 12-13-83.

(b) Documents sent to the attention of a technical library should be covered by a note indicating that no one else in the agency is receiving a copy, and that the librarian is requested to circulate as appropriate. 
e. DOE has a cooperative arrangement with the NEA to exchange computer program packages, and requests from NEA member states for DOE computer codes may be referred either to the NEA or to NESC. (a) Al ternatively, developed software may be provided directly to foreign organizations under formal agreements to cooperate in the field of radioactive waste management, provided "the software is al ready available from NESC, any software obtained from foreign organizations is made available to NESC, and we (NESC) are informed about which software is being made available to which foreign organization under which Agreement. Software being developed can be provided to foreign organizations for further development under the terms of Agreements without the software al so being provided to NESC if we (NESC) are informed that the software is being provided and if a "Summary" describing the software is submitted to NESC. NESC can provide the "Summary form on which the software description is to be made."(b) When such transfer occurs, an effect should be made to gain information of equivalent value in return.

Requests for codes from countries which do not have cooperative agreements with DOE and are not members of the NEA are to be referred to NESC, unless special circumstances dictate that the material should be transferred directly. If such an execption occurs, NESC is to be notified.

f. OTSI is to be notified of informal transmittals of US documents to other countries and of receipt of foreign technical reports.

\section{SPECIAL DISTRIBUTION CONTROLS--APPLIED TECHNOLOGY}

"Reports and other forms of scientific and technical information (such as computer codes and engineering drawings) containing information related to engineering, development, design, construction, operations, or other activities pertaining to technology advances in particular projects or facility on which major funding emphasis has been placed may be designated as applied technology by the cognizant Headquarters organization. Reports 1 abeled "appl ied technology" are given controlled distribution initially in order to keep the information contained in the reports in domestic hands and thereby retain its foreign trade value. Such information is exchanged on a basis favorable to the US with nations with whom the Department of Energy has a formal exchange agreement." (c)

(a) DOE Order 1360.4, "Computer Software Sharing," 2-2-83.

(b) Letter, J. D. Cape (OTSI) to K. M. Harmon (PNL) 12-22-83.

(c) DOE Order 1430.2 , p. VII-2. 
TABLE C-1. Guidance for Standard Foreign Distribution of DOE Spent Fuel and Waste Management Technical Reports

Topis

1. Spent Fuel Storage and Transport

2. Waste Treatment and Immob 11 ization
- HLW

- TRU waste: contact

P.G. Hagen

TEL : 505-766-3406

ext. 22 for information

- LLW/ILW

- Materials

Characterization

\section{Remedial Actions}

- D\&D (Surplus Fac111ties)

- Mine \& M11l taflings

\section{CRNL \\ OHR}

WNRE

BMFT

DWK

KfK

IAEA Japan

NEA Sweden

Switzerland

IAEA

$\begin{array}{ll}\text { NEA } & \text { SKB } \\ & \text { SKI }\end{array}$

FOE

NAGRA

KAEA

CEGB

UKAEA

DOE

CEA

KB

$\begin{array}{lllll}\text { BMFT } & \text { IAEA } & \text { PNC } & \text { NEA } & \text { SKB } \\ \text { HMI } & & & & \text { SKI } \\ \text { KFA } & & & & \\ \text { KfK } & & & & \end{array}$

$\mathrm{KfK}$

WAK

$\begin{array}{ll}\text { CEN } & \text { CRNL } \\ & \text { OHR } \\ & \text { WNRE }\end{array}$

CEA $\quad$ BMFT

BMF

IAEA PNC

NEA

Stu
SKB
SKI

NAGRA

UKAEA

$\mathrm{KfK}$

CEN WNRE

CEC

CEA

HMI

GSF/I fT

IAEA PNC

KfK

NEA

Studsvik

SKB

SKI

NAGRA

UKAEA

KFA

$\begin{array}{ll}\text { CEN } & \text { CRNL } \\ \text { WNRE }\end{array}$

BMF

IAEA PNC

NEA

SKB

BNFL

UKAEA

BMFT IAEA

NEA 
TABLE C-1. Guidance for Standard Foreign Distribution of DOE Spent Fuel and Waste Management Technical Reports

Topic

4. Maste Disposal

- $\mathrm{LLW} / \mathrm{ILW}$

- Geologic disposal-salt medla

I

- Geologic disposal-crystalline rock media

- Geologic disposal-other media

- Waste form characterization

- Safety

\section{Belgium Canada}

CE

CEN

\author{
AECB
}

OHR

WNRE

CEN

AECB
WNRE

CEC

PSM

FRG

IAEA Japan

NEA

sin

Sweden

Sw1tzerland

UK

CEN

AECB

GSC

WNRE

CEC

C

CEA
BRGM
PSM

BMFT
GSF/IfT
KfK

IAEA PNC

NEA

SKB

PTB

NEA

UKAEA
BGR
GSF/I fT
HMI

PTB

$\begin{array}{lllll}\text { BGR } & \text { IAEA } & \text { PNC } & \text { NEA } & \text { Studsvik } \\ \text { BMFT } & & & & \text { SKB } \\ \text { GSF/IfT } & & & & \text { SKI }\end{array}$

FOE

NAGRA

HMI

PTB

CEN

AECB

CEC

CEA

BMFT

I T

IAEA PNC

NEA

PSM

GSF/I f

IAEA

CEN

CRN

CEC CEA

BMFT
DWK
GSF / IfT
HMI
KfK
PTB
WAK

IAEA PNC

NEA Studsvik

SKB

SKI
FOE
NAGRA

DOE

UKAEA

DOE

$$
\text { WNRE }
$$

$\begin{array}{ll}\text { CEN } & \text { AECB } \\ & \text { CRNL } \\ & \text { EC } \\ & \text { WNRE }\end{array}$

CEA
BRGM
PSM

BGR
BMFT
GSF /I

GSF /

PTB
FOE DOE

NAGRA UKAEA

$\begin{array}{ll}\text { EIR } & \text { DOE } \\ \text { FOE } & \text { UKAEA }\end{array}$

NAGRA

FOE

NAGRA

DOE 
TABLE C-2. Addresses for Distribution Lists

\begin{tabular}{|c|c|c|}
\hline Country & Agency & 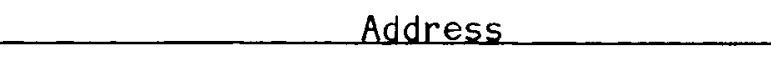 \\
\hline Belgium & CEN & $\begin{array}{l}\text { Laboratory of the S.C.K./C.E.N. } \\
\text { Boeretang } 200 \\
\text { B-2400 Mol } \\
\text { Belgium } \\
\text { ATTN: Prof.-Dr. P. Dejonghe }\end{array}$ \\
\hline Canada & AECB & $\begin{array}{l}\text { Atomic Energy Control Board } \\
\text { P.0. Box } 1046 \\
270 \text { Albert Street } \\
\text { Ottawa, Ontario KIP } 559 \\
\text { Canada } \\
\text { ATTN: Technical Library }\end{array}$ \\
\hline Canada & CRNL & $\begin{array}{l}\text { AECL Chalk River Nuclear Laboratories } \\
\text { Chalk River, Ontario KOJ lJO } \\
\text { Canada } \\
\text { ATTN: Technical Library }\end{array}$ \\
\hline Canada & GSC & $\begin{array}{l}\text { Geological Survey of Canada } \\
601 \text { Booth Street } \\
\text { Ottawa, Ontario KIA OE8 } \\
\text { Canada } \\
\text { ATTN: Earth Physics Branch }\end{array}$ \\
\hline Canada & $\mathrm{OHR}$ & $\begin{array}{l}\text { Ontario Hydro } \\
700 \text { University Avenue } \\
\text { Toronto, Ontario M5G 1X6 } \\
\text { Canada }\end{array}$ \\
\hline & & ATTN: Research Division Library \\
\hline
\end{tabular}


TABLE C-2. Addresses for Distribution Lists

\begin{tabular}{|c|c|c|}
\hline Country & Agency & Address \\
\hline Canada & WNRE & $\begin{array}{l}\text { Atomic Energy of Canada Limited (AECL) } \\
\text { Whiteshell Nuclear Research Establishment } \\
\text { Pinawa, Manitoba ROE ILO } \\
\text { Canada } \\
\text { ATTN: Technical Library }\end{array}$ \\
\hline European Communities & CEC & $\begin{array}{l}\text { Commission of the European Communities } \\
200 \text { Rue de 1a Loi } \\
\text { B-1049 Brussels } \\
\text { Belgium } \\
\text { ATTN: A. Cricchio }\end{array}$ \\
\hline France & $\begin{array}{c}\text { CEA } \\
\text { (French Atomic Energy Commission) }\end{array}$ & $\begin{array}{l}\text { Fontenay-aux-Roses Centre d'Etudes Nucleaires } \\
\quad \text { (CEN-FaR) } \\
\text { B.P. } 6 \\
\text { F-92260 Fontenay-aux-Roses } \\
\text { France } \\
\text { ATTN: Pierre Jourde }\end{array}$ \\
\hline France & $\begin{array}{c}\text { BRGM } \\
\text { (Bureau of Geological and Mineral } \\
\text { Research) }\end{array}$ & $\begin{array}{l}\text { Bureau de Recherches Geologique et Minieres } \\
\text { B.P. } 6009 \\
\text { F- } 45060 \text { Orleans, Cedex } \\
\text { France } \\
\text { ATTN: Technical Library }\end{array}$ \\
\hline France & $\begin{array}{c}\text { PSM } \\
\text { (Paris School of Mines) }\end{array}$ & $\begin{array}{l}\text { Ecole Nationale Superieure des Mines de Paris } \\
\text { Centre d'Informatique Geologique } \\
35 \text { Rue Saint-Honore } \\
\text { F-77305 Fontainebleau } \\
\text { France } \\
\text { ATTN: Dr: Ghislain de Marsily }\end{array}$ \\
\hline
\end{tabular}


TABLE C-2. Addresses for Distribution Lists

\begin{tabular}{|c|c|c|}
\hline Country & Agency & Address \\
\hline Germany (FRG) & $\begin{array}{c}\text { BGR } \\
\text { (Federal Institute for Geosciences } \\
\text { and National Resources) }\end{array}$ & $\begin{array}{l}\text { Bundesanstalt fuer Geowissenschaften und Rohstoffe } \\
\text { Stilleweg 2, Postfach } 510153 \\
\text { D-3000 Hannover } 51 \\
\text { Federal Republ ic of Germany } \\
\text { ATTN: Technical Library }\end{array}$ \\
\hline Germany (FRG) & $\begin{array}{c}\text { BMFT } \\
\text { (Federal Mintstry for Science and } \\
\text { Technology) }\end{array}$ & $\begin{array}{l}\text { Bundesministerlum fuer Forschung und Technologie } \\
\text { Heinemannstrasse } 2 \\
\text { Postfach } 200706 \\
\text { D-5300 Bonn } 2 \\
\text { Federal Republ ic of Germany } \\
\text { ATTN: Dr. Rol f-Peter Randl }\end{array}$ \\
\hline Germany (FRG) & $\begin{array}{c}\text { DWK } \\
\text { (German Fuel Reprocessing Company) }\end{array}$ & $\begin{array}{l}\text { Deutsche Gesellschaft fuer Wiederaufarbeitung } \\
\text { von Kernbrennstoffen mbH } \\
\text { Postfach } 1407 \\
\text { Hamburger Allee } 4 \\
\text { D-3000 Hannover } 1 \\
\text { Federal Republ ic of Germany } \\
\text { ATTN: Technical Library }\end{array}$ \\
\hline Germany (FRG) & $\begin{array}{l}\text { GSF/IfT } \\
\text { (Institute for Underground Storage, } \\
\text { Company for Radiation and } \\
\text { Environmental Research) }\end{array}$ & $\begin{array}{l}\text { Gesellschaft fuer Strahlen und Umweltforschung } \\
\text { mbH Institut fuer Tieflagerung } \\
\text { Theodor-Heuss-Strasse } 4 \\
\text { D-3300 Braunschweig } \\
\text { Federal Republ ic of Germany } \\
\text { ATTN: Technical Library }\end{array}$ \\
\hline
\end{tabular}


TABLE C-2. Addresses for Distribution Lists

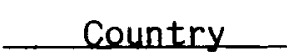

Germany (FRG)

Germany (FRG)

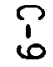

Germany (FRG)

International
PTB

(Federal Science and Engineering Laboratory)

WAK

(Fuel Reprocessing Company)
Agency

HMI

(Institute for Nuclear Research)

KFA

(Juelich Nuclear Research Center)

KfK

(Karlsruhe Nuclear Research Center)

Kert

Postfach 3640

D-7500 Karlsruhe

Federal Republic of Germany

ATTN: Technical Library

Physikal isch-Technische Bundesanstalt

Bundesallee 100

D-3300 Braunschweig

Federal Republic of Germany

Wiederaufarbeitungsanlage Karl sruhe Betriebsgesellschaft mbH

Postfach 220

D-7514 Eggenstein-Leopoldshafen 2

Federal Republic of Germany

International Atomic Energy Agency

P.0. Box 100

A- 1400 Vienna

Austria

ATTN: Waste Management Section 
TABLE C-2. Addresses for Distribution Lists

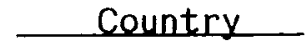

International

Japan

Sweden

$\frac{P}{0}$

Sweden

Sweden
Agency

NEA

PNC

CU

(Chalmers University of Technology)

RIT

SKI

(Swedish Nuclear Power Inspectorate)
Address

Organization for Economic Cooperation and Development--Nuclear Energy Agency

38 Boulevard Suchet

F-75016 Paris

ATTN: J.P. 01 ivier

Power Reactor and Nuclear Fuel Development Corporation

Sankaido Building

1-19-13 Akasaka

Minato-ku, Tokyo 107

Japan

ATTN: Director, Nuclear Fuels

Chalmers Tekniska Hoegskola

S-40220 Goeteborg 5

Sweden

ATTN: Department of Nuclear Chemistry

Royal Institute of Technology KTH

S-10044 Stockholm

Sweden

ATTN: Prof. Ivars Neretnicks

Statens Kaernkraftinspektion

Box 27106

S-102 52 Stockholm

Sweden

ATTN : Alf Larsson 
TABLE C-2. Addresses for Distribution Lists

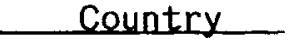

Sweden

Sweden

Switzerland

$\stackrel{P}{=} \quad$ Switzerland

Switzerl and
EIR

(Swiss Federal Institute for Reactor Research)

FOE

NAGRA

(National Cooperative for the Storage of Radioactive Waste)

United Kingdom

BNFL

Studsvik

SKB

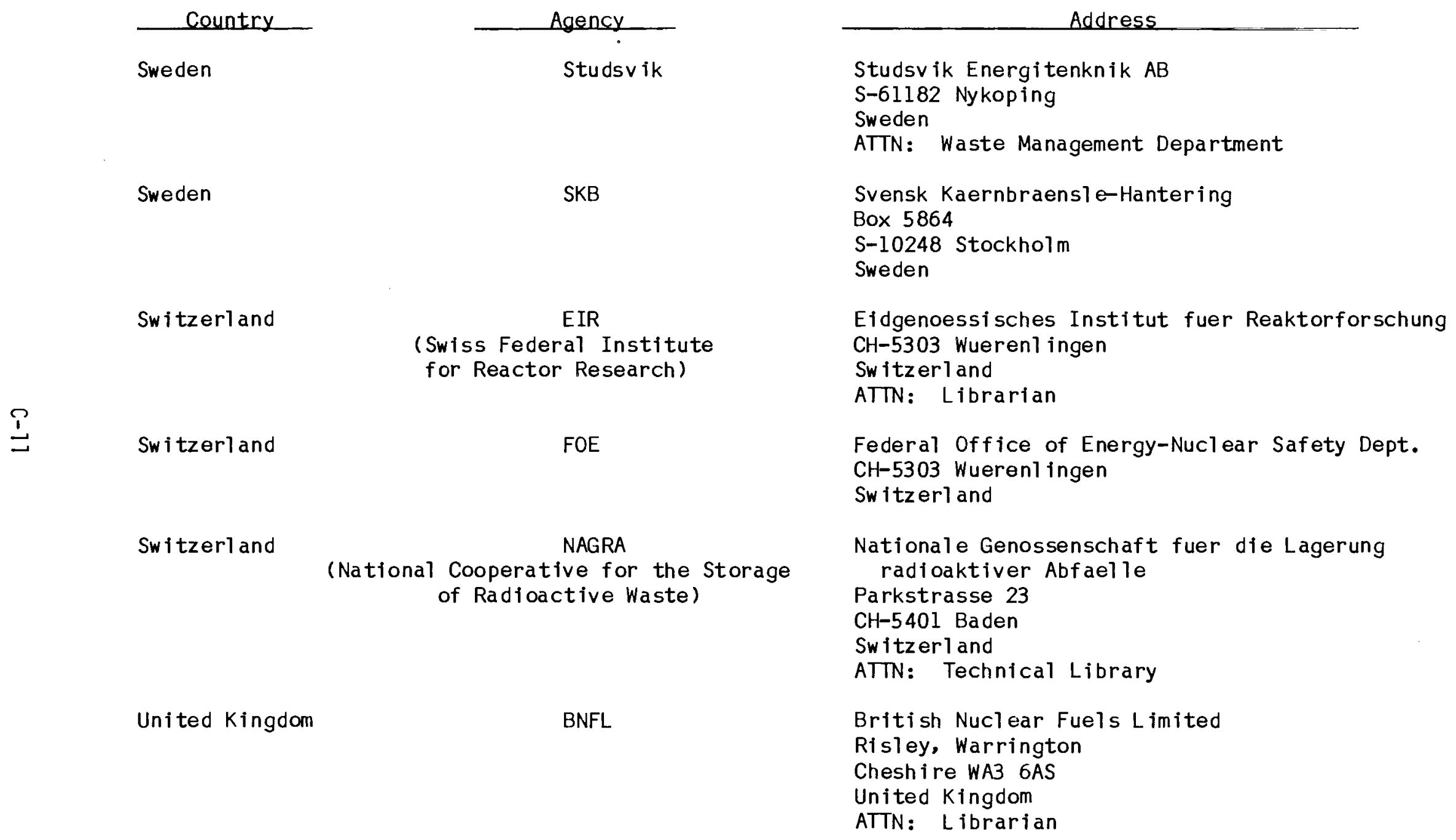


TABLE C-2. Addresses for Distribution Lists

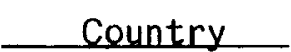

United Kingdom

United Kingdom

United Kingdom

$\frac{P}{N}$
Agency

DOE

NRPB

UKAEA AERE

United Kingdom
Department of Environment

2 Marsham Street

London SWIP 3EB

United Kingdom

ATTN: Radioactive Waste Division

National Radiological Protection Board

Chilton Didcot

Oxfordshire, Oxon OXI1 ORQ

United Kingdom

ATTN: Technical Library

UKAEA Atomic Energy Research Establ ishment Harwel1, Didcot

Oxfordshire OX11 ORQ

United Kingdom

ATTN: Technical Library

Central Electricity Generating Board

Sudbury House

15 Newgate Street

London ECIA 7AU

United Kingdom 


\section{APPENDIX D: INFX PROCEDURES FOR FOREIGN TRAVEL AND VISITS}

This section provides guidance and procedural instructions related to waste management technology international exchange programs. Included are:

- a summary of current US DOE policy concerning the topics on which information may be exchanged with foreigners;

- guidance for initiation, negotiation, and approval of specific international exchange activities;

- reporting requirements.

\section{CRITERIA}

In planning for international exchanges, the following criteria should be observed:

- US DOE policy guidelines regarding classifications of information (defined in DOE Order 5650.2), sensitive subjects (defined in DOE Order 1240.2), and foreign travel (DOE Order 1500.2) must be followed.

- Bilateral agreement summaries (PNL-3774) provide guidance, but should not be seen as setting absolute 1 imits on subject areas.

- The potential for adequate mutual benefit should be identified, through contributions to the same type of technology or through offsetting trade of technology in nonrelated areas.

\section{DOE POLICY}

Policy guidelines for coordinating visits and assignments by foreign nationals involved in international waste management technology exchanges are included in DOE Order 1240.2 and any supplements which DOE field offices may issue. Policy guidelines regarding foreign travel by US citizens on DOE business are included in DOE Order 1500.2.

Three categories of waste management technology information have been defined as followed. However, information exchanged during any visit, regardless of the category in which it falls, is to be unclassified, normally limited to open published literature or in accordance with a specific technology exchange agreement. Exceptions to this rule must be approved by the appropriate DOE program office with concurrence of the Assistant Secretary for International Affairs.

\section{Category I}

Those areas of waste management technology that are an integral part of a LWR spent fuel reprocessing plant design or that directly support the separation and purification of uranium and/or plutonium. Such technologies may include activities associated with dissolver gas separation, and uranium and plutonium scrap recovery and purification operations. 
Waste management technology under Category I will not normally be subject to international cooperation. Exceptions may be made at the DOE policy 1evel, if the overall benefits are judged to outweigh the adverse effect of direct US support of foreign reprocessing programs. Requests to host foreign visits and assignments which involve Category I information are to be forwarded to the Division of International Research and Development Cooperation, Office of International Affairs using DOE Form IA-473 (see Figure D-1). This replaces DOE Form 447 formerly used for this purpose.

\section{Category II}

Those areas of waste management technology that are required for treating waste from a spent fuel reprocessing operation but are not integral to the reprocessing operation or the separation and purification of uranium or plutonium scrap. Examples include high-level waste conditioning, actinidecontaminated waste volume reduction, spent fuel hardware processing for disposal and partitioning liquid waste for disposal.

Cooperation and exchange of waste management technology under Category II will be permitted only under existing agreements or under new agreements following review and approval at the policy level. The guidel ine is that such cooperation should offer significant programmatic and/or policy benefits to the US.

In assessing the desirability of cooperation with a given country in Category II technologies, the following considerations are particularly important:

1. What are the nonproliferation credentials of the country involved (e.g., Nonprol iferation Treaty signatory, degree of receptivity, and cooperation in international nonprol iferation matters)?

2. What is the status of the country's waste management technology and the benefit that the cooperation would provide the DOE program?

3. What is the status of reprocessing in the country? Is there a well-established reprocessing program or might the cooperation play an important role in facilitating or encouraging a new reprocessing venture? Is the waste management effort associated with advanced reactor programs or LWR recycle? Will the country consider placing generated plutonium under multinational auspices?

Visits involving Category II technology will be permitted in those areas where an approved, active cooperative agreement between the US and the country represented by the visitors exists, provided that programmatic guidance is secured from the appropriate DOE-HO program office. Requests to host foreign visits and assignments which involve Category II information are to be forwarded to the Division of International Research and Development Cooperation, Office of International Affairs, on DOE Form IA-473. 


\section{REQUEST FOR FOREIGN NATIONAL UNCLASSIFIED VISIT OR ASSIGNMENT}

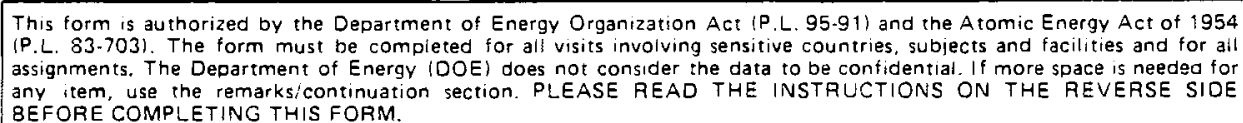

PART I: IDENTIFICATION (To be completed by requester or agent acting on his/ her behalf)

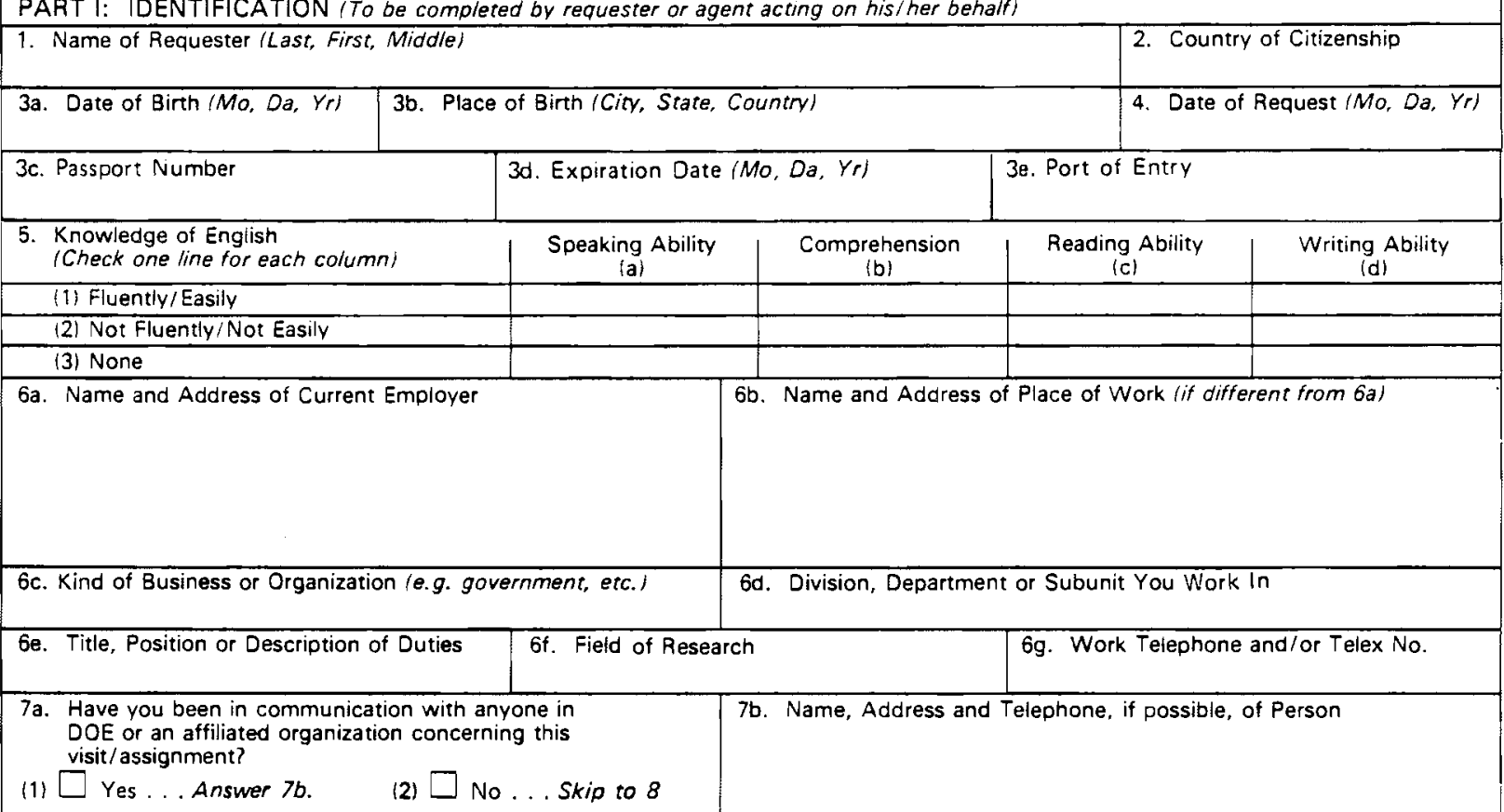

8a. This request is fo (Check appropriate box) (1) $\square$ A Visit

(2) $\square$ An Assignment

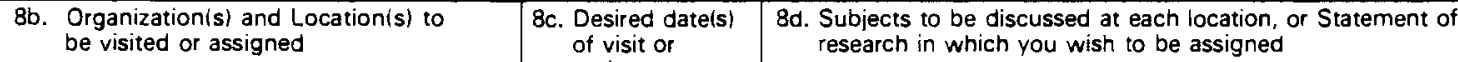
be visited or assigned $\quad \begin{aligned} & \text { of visit or } \\ & \text { assignmen }\end{aligned}$

9. A brief description of your technical qualifications and experience in relation to your visit/assignment. Iff an assignment, include university/college training with degrees and dates conferred.)

10. Your visit/assignment will be on whose behalf?

(1) $\square$ Educational Institution

(5) $\square$ Government
(2) $\square$ Industry

(6) $\square$ Other - Specify $=$
(3) $\square$ Scientific or technical organization

(4) $\square$ Yourself

FIGURE D-1. DOE Form IA-473, Request for Foreign National Unclassified Visit or Assignment (first of two pages) 


\section{Category III}

Those areas of waste management technology applicable both to spent fuel and separated waste, and all others that do not fall in the first or second category. Examples include waste transportation, geological disposal, seabed disposal, risk assessments, removal of airborne particulates, gas disposal, handling and packaging of spent fuel, decontamination and decommissioning, and disposal of low- and medium-level waste.

Cooperation and exchange of waste management technolegy in Category III are encouraged. Visits involving Category III technologies will be at the discretion of the DOE field office. Requests to host foreign visits and assignments involving Category III information are forwarded to the local DOE field office on DOE Form IA-473.

Table D-l provides further category definition for specific areas of waste management technology.

\section{Sensitive Countries}

Certain countries that are communist controlled, have not cooperated in international nonproliferation efforts, or are subject to increased world or regional tension are identified as sensitive. Exchange of waste management technology information with representatives of these countries always requires the review and approval of the Assistant Secretary for International Affairs with concurrence from the Assistant Secretary for Defense Programs and the appropriate DOE program office $v i a$ DOE Form IA-473 (for hosts of foreign visits or assignments) or travel approval via DOE Form F-1512.1 (see Figure D-2) and DP-290 for US travelers to sensitive countries (see Figure $D-3$ ).

Communist-controlled countries include:

\author{
Afghanistan \\ Albania \\ Bulgaria \\ Cuba \\ Czechoslovakia \\ Democratic Kampuchea (Cambodia) \\ German Democratic Republic \\ Hungary \\ Laos
}

\author{
Mongol ia \\ North Korea \\ People's Republic of China \\ Pol and \\ Romania \\ Union of Soviet Socialist \\ Republics (including Estonia, \\ vietnam \\ Latvia, and Lithuania) \\ Yugoslavia.
}

The 1 ist of other countries associated with nuclear nonprol iferation concerns or located in areas of increased world or regional tension is, by nature, changeable. (a) Check with the security offices, the International Coordinator at local DOE field offices, security office at major DOE contractors, or the DOE Office of International Affairs, Division of International Research and Development Cooperation (202-252-1881) for current information.

(a) Any commitments made with Japan require pre-approval by the Assistant Secretary for Nuclear Energy. All comunications with Japan require a copy sent to the Assistant Secretary. 
TABLE D-1. Categories of Waste Management Technology

\begin{tabular}{ll}
\hline \multicolumn{1}{c}{ Description } & Categery \\
$\begin{array}{ll}\text { Design or operation of reprocessing line components or } \\
\text { systems, e.g. dissolver off-gas collection equipment }\end{array}$ & I \\
$\begin{array}{l}\text { Design or operation of components or systems supporting } \\
\text { uranium or plutonium separation }\end{array}$ & I \\
Handling of hulls and fuel el ement hardware & II \\
Packaging of solidified high-level waste & II \\
Solidification of high-level waste & II \\
Volume reduction of transuranic waste & II \\
Partitioning & II \\
Handling and packaging of spent fuel & III \\
Disposal of gaseous fission products & III \\
Removal of airborne particulates & III \\
Disposal of low-level waste & III \\
Seabed disposal of high-level waste and spent fuel & III \\
Decontamination and decommissioning of facilities & III \\
Transportation of waste & III \\
Geological disposal of waste & III \\
Risk assessment & III \\
\hline &
\end{tabular}


(Previous Editions are Obsolete)

REQUEST FOR APPROVAL OF OFFICIAL FOREIGN TRAVEL

PART A-TO be completed by traveler's administrative of ficer

Budget and Reporting Classification to be charged

(See Appendix 1101, Part II)

The categony of a trip, either I, II, or III, is determined by the definitions set forth in Appendix 1501 . Part VIII)

TRIP CATEGORY

PART B-To be completed by traveler

\begin{tabular}{|c|c|}
\hline $\begin{array}{l}\text { 1. NAME OF TRAVELER } \\
\text { b. CITIZENSHIP }\end{array}$ & $\begin{array}{l}\text { c. DATE ANO PLACE OF BIRTH } \\
\text { o. PASSPORT NUMEER (if availabie) }\end{array}$ \\
\hline 2a. HOME ADDRESS & b. BUSINESS ADDRESS \\
\hline 3d. EMPLOYER & c. CONTRACT NUMBER \\
\hline D. ORGANIZATIONAL UNIT & d. POSITION TITLE (including profession) \\
\hline
\end{tabular}

4. PURPOSE OF TRAVEL-Include all pertinent background information leading to traves and attach copies of invitations and correspondence regarding travel to present papers, give speeches, or to attend conferences or symposia. Also identify by name and organization other DoE and contractor personnel who. to the traveler's knowledge, are going to the same destination at the same time as the traveler. In addition, specify nature and classification of information to be disclosed including titles of papers to be presented; nature of information to be obtained at each of the places to be visited and conferences to be attended and its reiation to travejer's work. Travelers are responsible for obtaining clearances for papers or speeches when necessary. If more sDace is required, attach a separate shest. NOTE: IF THIS INFORMATION IS CLASSIFIED BE SURE TO CLASSIFY THIS FORM APPROPRIATELY.

Privacy Act information Statement. Collection of the information is authorized by the Dedartment of Energy Organization Act of 1977 , P. L $95-91$. Disciosure of the personal information requested is mandatory to supdort authorization for official travel to foreign countries, and to obtain a passport

The information furnishea will be usea by DOE to authorize travel and payment of travel expenses; by the Department of State to issue a passport:

ind by the General Accounting Office to audit and verify the accuracy and legality of disbursements.

FIGURE D-2. DOE Form F 1512.1, Request for Approval of Official Foreign Trave1 (first of three pages) 
NOTIFICATION OF PROPOSED TRAVEL TO COMMUNIST CONTROLLED COUNTRIES

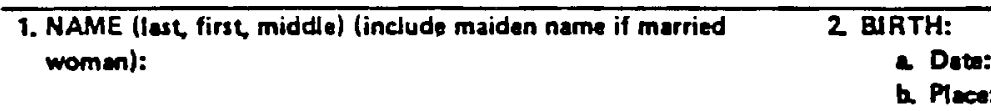

3. HOME ADDRESS: 4 HOME TELEPHONE:

5. PURPOSE OF TRIP (Include details concerning any papers, lectures, ete, if the information pertains to the U.S. Department of Enery program)

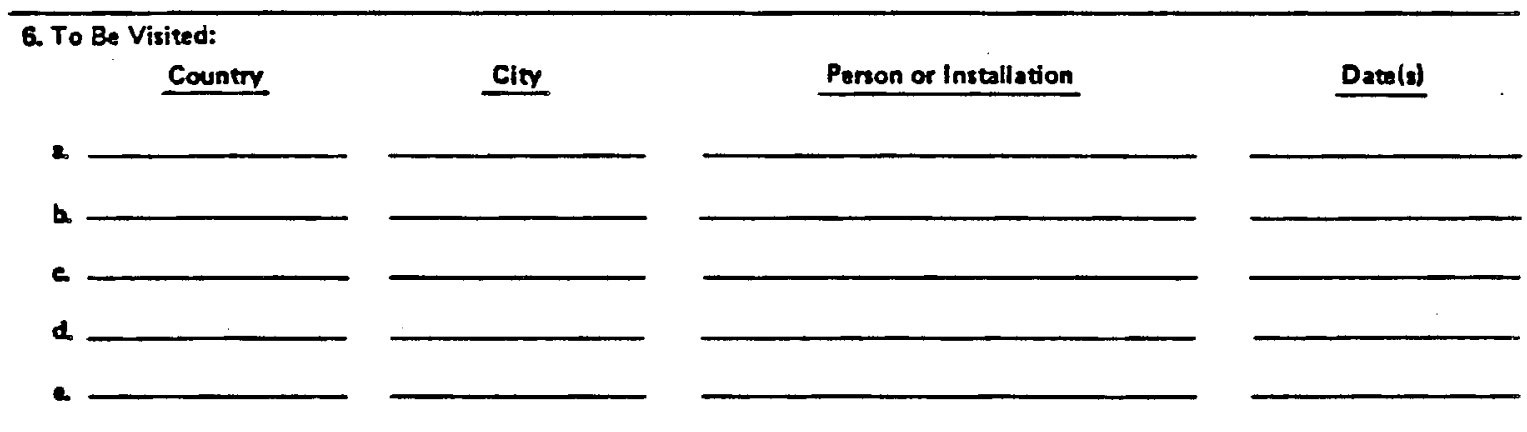

7. Names, addrestes, and citizenship of relatives, including in-laws, residing in Communist-controlled countries: (Define relation hip and inciude relatives within 3 generations)

\section{Present Employmant:}
- Name of employer
b. Present cepucity:
c. Business addresse
d Business telephom:

c. Highest classification of information recaired:

9. Previous AEC, ERDA or DOE Project Employmene
- Name of employor:
b. Capecity:
C. Approximate dates of employment
d. Nama of principal suparvisor:
- Highest dassification of information recaired:

10. Is proposed travel to be at DOE, DOE con tractor of eubcontractor of other government agency expense?

Date and place of deparaure on travel:

Dote of return:

$$
\text { 10etol }
$$

(Signature of Tramior)

NOTE: It in the responsibility of the traveler to inform the head of his or her division or office in writing of any change in the itimerery or pupose of the trip as set forth in this document

FIGURE D-3. DOE Form DP-290, Notification of Proposed Travel to Communist Controlled Countries 


\section{Sensitive Facilities}

Certain facilities and/or secure areas within facilities are identified as sensitive. Admission of visitors to these areas requires additional approvals and usually more advanced notice. These include:

1. Weapon Complexes (require DOE Defense Programs review and concurrence):

Lawrence Livermore National Laboratory--secure areas only

Los Alamos National Scientific Laboratory excluding the Fenton Hill geothermal site--secure areas only

New Brunswick Laboratory--secure areas only

Nuclear Weapon Test Installations

Nuclear Weapon Production Facilities (Plantex, Kansas City, Rocky Flats, Mound, Pinellas, and weapon production areas at $Y-12$ and Savannah River)

Sandia National Laboratories at Albuquerque and Livermore--secure areas only

Savannah River Laboratory--secure areas only

A1 buquerque Operations Office

Nevada Operations Office

Savannah River Operations Office

Those elements of the San Francisco Operations Office and the Oak Ridge Operations Office related to management of the weapon program and the weapon complex (Oak Ridge Operations for $Y-12$ and San Francisco Operations for Lawrence Livermore National Laboratory).

2. Production Facilities:

Hanford Production Operations (requires Defense Programs review and concurrence)

Idaho Chemical Processing Plant (requires Defense Programs review and concurrence)

Reactive Metals, Inc. (RMI Company) (requires Defense Programs review and concurrence)

Fernald Feed Materials Plant (requires Defense Programs review and concurrence)

Savannah River Production Operations (requires Defense Programs review and concurrence)

Oak Ridge, Paducah, and Portsmouth Gaseous Diffusion Plants and gas centrifuge support and production facilities (requires Resource Applications review and concurrence.

3. Other Sensitive Facilities (require Nuclear Energy review and concurrence):

Naval Reactors Facilities (Pittsburgh Naval Reactors Office, Bettis Atomic Power Laboratory, Shippingport Atomic Power Station, Schenectady Naval Reactors Office, Knolls Atomic Power Laboratory, Idaho Naval Reactors Facility, Kenneth A. Kesselring Site, Windsor Site)

Idaho National Engineering Laboratory--secure areas only

Hanford Engineering Development Laboratory--secure areas only

Battelle Pacific Northwest Laboratory--secure areas only

Energy Technology Engineering Center--secure areas only. 


\section{Types of Cooperative Activities}

Various types of international cooperative activity may be considered:

1. Official foreign travel under DOE-Nuclear Energy (NE) sponsorship requires submittal of DOE Form F 1512.1 and a NE questionnaire. If the travel itinerary includes a communist country, DOE Form DP-290 must be added to the submittal. Travel may be any of the following:

- visit by an individual or team to one or more foreign sites for international exchange planning, a broad program overview, or an in-depth review of a specific area of technology;

- assignment as part of a personnel exchange for consultation (expenses paid by the host) or for participation in a US-sponsored test in a foreign facility;

- participation in a bilateral, multilateral, or international agency workshop, committee meeting, or working group meeting;

- attendance (usually with presentation of a paper) at an international technical seminar or symposium.

2. Hosting of foreigners visiting the US for the purposes described above (Use DOE Form IA-473).

3. Partial or total sponsorship (and funding) of test activities conducted in another country.

4. Foreign participation in US test activities.

\section{PROGRAMMATIC APPROVAL OF INFX ACTIVITIES}

\section{Visits or Assignments of Foreigners to US Facilities}

The approval of the Assistant Secretary for International Affairs as well as review and concurrence by appropriate DOE-HQ program offices, is required for:

1. all visits by nationals of sensitive countries to sensitive facilities;

2. all visits by nationals of sensitive countries to discuss sensitive subjects;

3. al1 visits that concern sensitive subjects (Category I or II) not in accord with an international agreement;

4. all visits by diplomatic, political, technical, or administrative personnel from foreign countries or international organizations who, because of their positions, should be afforded special consideration or treatment. 
These approvals are secured by submitting DOE Form IA-473 to the Division of International Research and Development Cooperation, US Department of Energy, IE-121, Forresta1, Washington DC 20585 not 1ess than 8 weeks before proposed visits and not less than 10 weeks before proposed assignments. This form may be submitted by contractor organizations whose scientists may have been in direct contact with their counterparts in other countries; from DOE Headquarters program offices; or, through outside organizations in contact with the Office of International Affairs (such as American embassies overseas, foreign embassies in Washington, DC, the National Academy of Sciences, or international agencies).

A11 other visits may be approved by the heads of DOE field offices through DOE Form IA-473 or the local equivalent. Managers of operations offices may delegate all or part of this remaining approval authority to directors of national laboratories in writing, providing a copy to the Assistant Secretary for International Affairs.

Figure D-4 indicates approval authority for visits or assignments.

\section{Travel or Assignment of DOE Personnel or Contractors to Foreign Facilities}

Foreign trave1 requires submittal and approval of DOE Form 1512.1 (formerly (R-445), "Request for Approval of Official Foreign Travel." This form is to be completed by the prospective traveler and transmitted to the local field office, for approval, at least 50 days before the departure date.

Careful preparation should be made for any foreign travel. For example, if a team is to visit several sites to discuss a specific area of waste management technology, specific assignments should be made before the trip starts (e.g., lead the discussion, take notes, or assemble a joint trip report). The specific questions to be asked at each site should be 1 isted and transmitted by the team leader or individual visitor to the host, and background information concerning that site should be reviewed by each visitor.

(a) Travel to Canada and US territories and possessions is not considered foreign travel al though trip reports on Canadian travel relating to the Nuclear Waste Terminal Storage (NWTS) Program are still required.

(b) A limited amount of background information, inclucing an overview of R\&D activities, may be found in PNL-2478, "International Source Book: Nuclear Fuel Cycle Research and Development." Additional information may be available from PNL-International Program Support Office. 


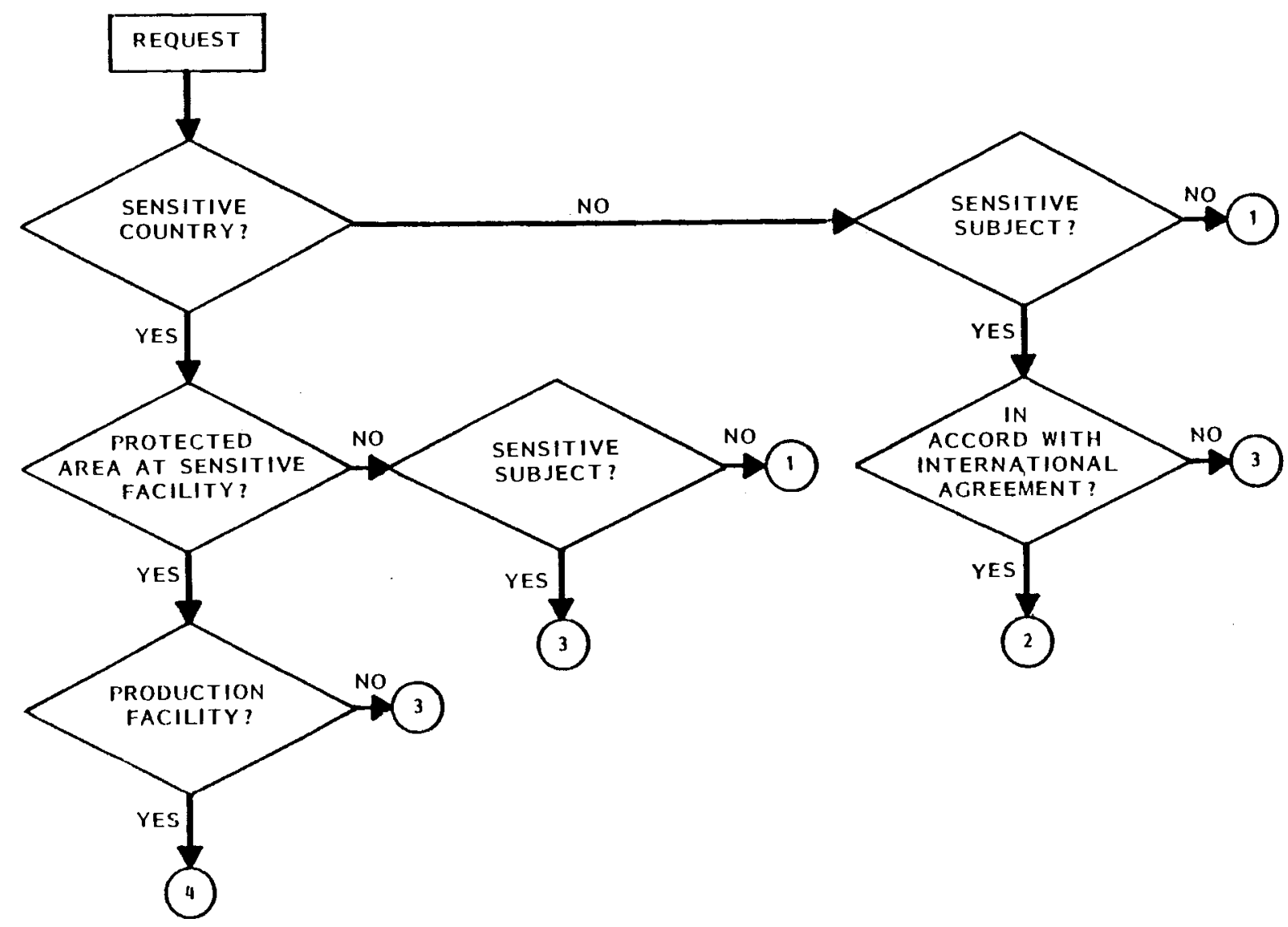

FIGURE D-4. Approval Authority for Foreign Visits and Assignments (Ref. DOE Order 1240.2)

(1) DOE Field Office Approves

(2) DOE Cognizant Program Office Revlews/Concurs, Field Office Approves

(3) DOE Cognizant Program Office Reviews/Concurs, DOE International Affairs Division (IE) Approves

(4) Defense Programs Reviews/Concurs, IE approves 


\section{REPORTING REQUIREMENTS}

\section{Foreign Trave1 Reports}

US travelers abroad will file a trip report within 30 days of return to their duty station. A single report suffices for team visits. Trip reports shall consist of three sections.

1. A summary, preferably one page, highlighting all pertinent information in the trip report, including:

- the name of the traveler, position, DOE or DOE contractor organization represented, and date of trip report;

- the exact destination(s), by installation, city, and country, and dates of the trip;

- a succinct statement of the purpose of the trip;

- an abstract of information contained in the full report

- a statement of the actual cost of the travel, with funding sources.

2. A comprehensive and detailed trip report, which includes the following information, as applicable:

- a detailed statement of the purpose or nature of foreign energy activities with which the travel is concerned, and the relationship to the US and DOE programs, commitments, and interests;

- a summary of the activities of the traveler, emphasizing conclusions, decisions, significant findings, problem areas, recommendations, and including appraisals of the work or activities in relation to the US and DOE interests;

- a brief description of the traveler's role, including participation in significant discussion and events;

- recommendations concerning future or followup activities;

- as appropriate, the identification, description, and evaluation of any information obtained that is pertinent to the general energy posture of any country visited.

3. An appendix, which includes:

- a full itinerary

- a list of persons contacted, with titles and organizations represented, grouped by context of contact;

- a bibliographical listing of 1 iterature acquired. 
In addition to the traveler's specific distribution, this report should be supplied to the following :

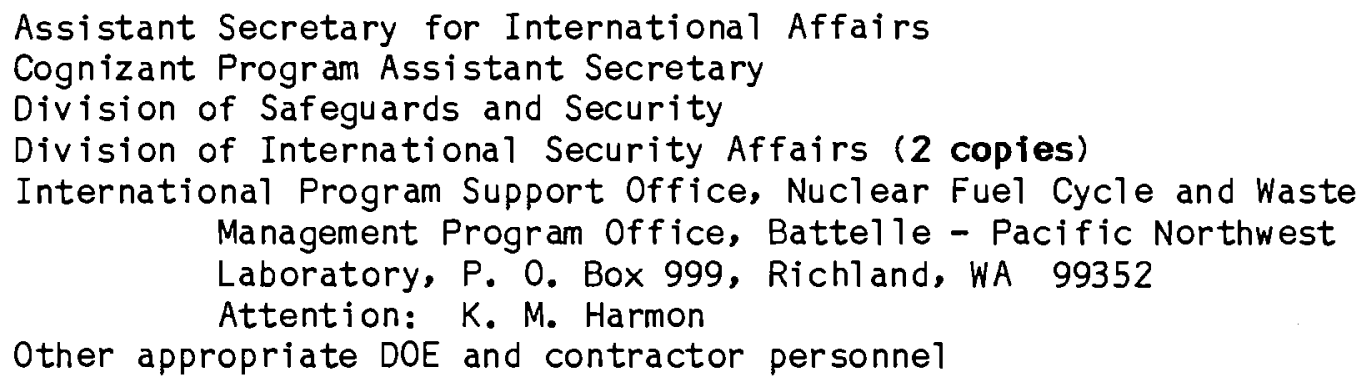

\section{Reports of Alien Visits to US Sites}

Hosts of visits or assignments that require approval from the Assistant Secretary of International Affairs must report (see Figure D-5), within 30 days after the conclusion of the exchange, the following particulars:

- full name and position of visitor or assignee;

- dates of arrival and departure;

- names of persons with whom discussions were held or the official sponsor of the assignee;

- subjects of major interest to the visitor including significant conclusions, observations, or opinions expressed by himher;

- significant information obtained from the visitor about his/her own country;

- major items of equipment used (or facilities toured);

- specific contributions of the assignee to the DOE program involved;

- lists of documents or other materials furnished to or by the visitor.

- specific organization who benefited; i.e., DOE or other

This report should be supplied to appropriate DOE and contactor personnel.

Hosts of visits and assignments which did not require approval of the Assistant Secretary of International Affairs are requested to report the particulars of the visit listed above within 30 days of the completion of the visit. Copies of the report should be suppl ied to appropriate DOE and contractor personnel. 


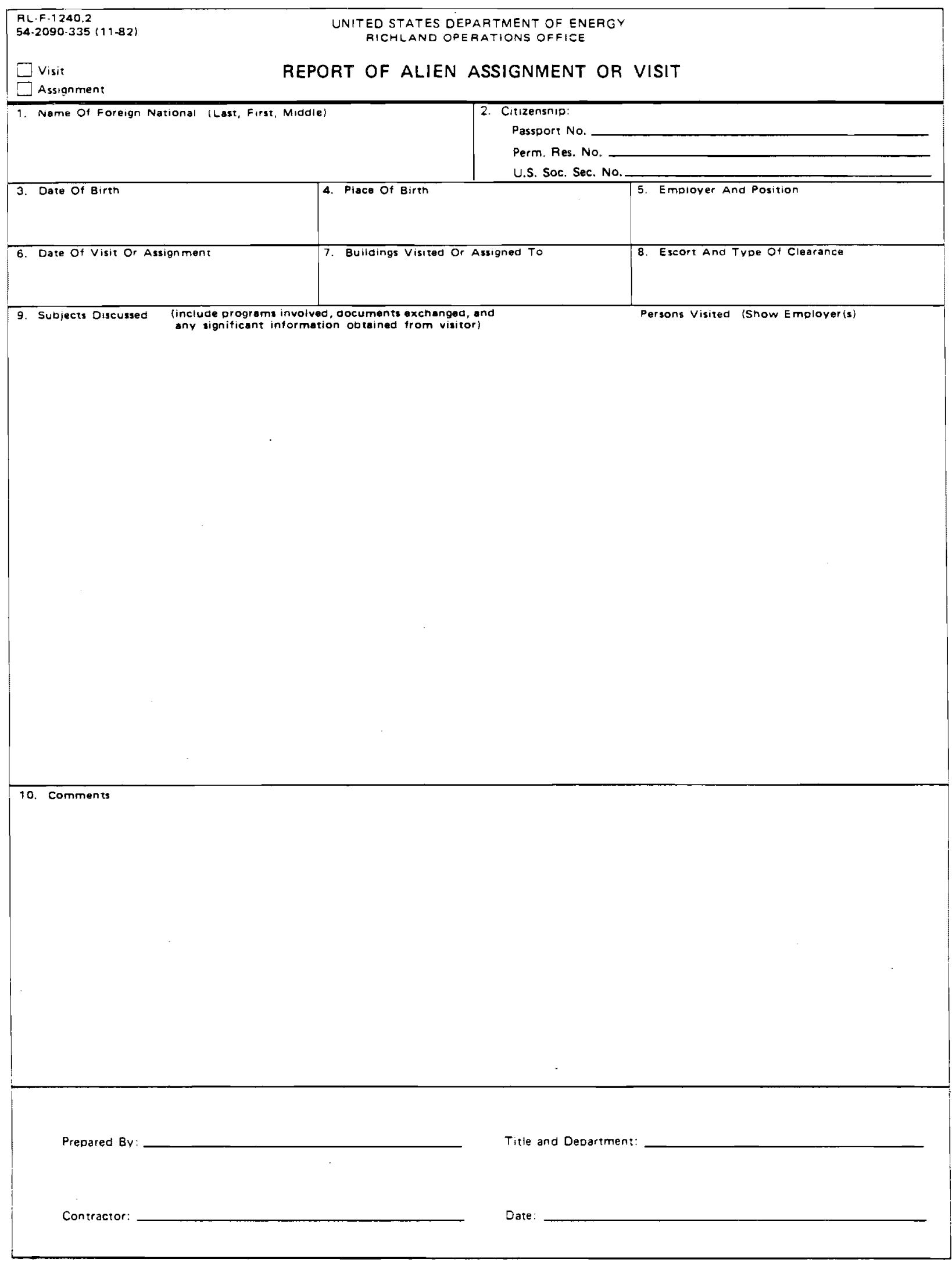

FIGURE D-5. DOE Form RL-F-1240.2, Report of Alien Assignment or Visit 


\section{Program Planning}

Copies of pertinent INFX program planning documents (e.g., IA-473's submitted by contractor personnel for approval, correspondence with foreigners discussing future exchanges, etc.) should be transmitted to PNL-International Program Support Office as early as available to maintain the INFX Guide and to appropriate DOE and contractor personnel who may be coordinating overall efforts in that particular technology area. 


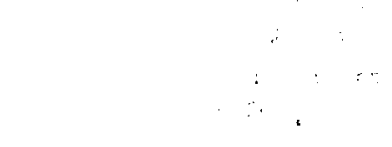

$\begin{array}{cc}\therefore & \cdots \\ \because & \therefore\end{array}$

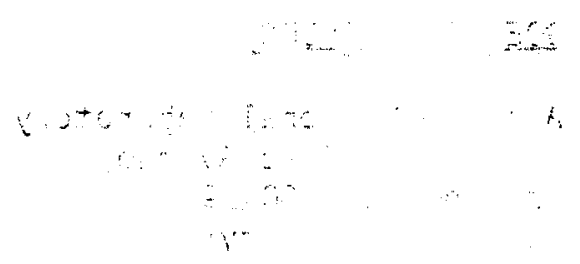

$\therefore 6$ 
PNL -3774

Rev. 5

\section{DISTRIBUTION}

No. of

Copies

\section{OFFSITE}

\section{DOE HEADQUARTERS}

Office of the General Counsel

U. S. Department of Energy

Forrestal

Washington, DC 20585

Attn: S. K. Kuznick, GC-31

8 U. S. Department of Energy

Forrestal

Washington, DC 20585

Attn: D. H. Alexander, RW-24

R. L. Bingham, DP-432

C. R. Cooley, RW-43

J. J. Fiore, RW-22

W. W. Henoch, DP-332.2

K. A. K1 ein, RW-32

F. A. Minton, $D P-432$

J. A. Dugger, IE-121

7 U. S. Department of Energy GTN

Washington, DC 20545

Attn: T. D. Anderson, DP-121

J. E. Baubl itz, NE-24

J. A. Col eman, NE-25

F. P. Falci, Jr., DP-123

T. B. Hindman, J r., DP-12

D. J. McGoff, NE-23

W. H. McVey, NE-42

DOE OPERATIONS

Chicago Operations Office

U. S. Department of Energy

9800 South Cass Avenue

Argonne, IL 60439

Attn: S. A. Mann
No. of

Copies

Salt Repository Project Office U. S. Department of Energy 505 King Avenue

Col umbus, $\mathrm{OH} 43201$

Attn: J. O. Neff

Idaho Operations Office

U. S. Department of Energy

550 Second Street

Idaho Falls, ID 83401

Attn: C. P. Gertz

Oak Ridge Operations Office

U. S. Department of Energy

P. O. Box E

Oak Ridge, TN 37830

Attn: M. R. Jugan

West Valley Project Office

U. S. Department of Energy

P. 0. Box 191

West Valley, NY 14171-0191

Attn: W. H. Hannum

3 Office of Technical and Scientific Information

P. 0. Box 62

Oak Ridge, TN 37830

\section{DOE CONTRACTORS}

Argonne National Laboratory 9700 South Cass Avenue

Argonne, IL 60439

Attn: S. S. Borys

Battel le Project Management Division

505 King Avenue

Col umbus, $\mathrm{OH} 43201$

Attn: P. L. Hofmann 
No. of

Copies

EG\&G Idaho, Inc.

P. 0. Box 1625

Idaho Fal1s, ID 83415

Attn: E. A. Jennrich

Los Al amos National Laboratory

P. O. Box 1663

Los Alamos, NM 87545

Attn: D. T. Oak1ey, MS-F671

Lawrence Livermore National Laboratory

University of Cal ifornia

P. 0. Box 808

Livermore, CA 94550

Attn: L. D. Ramspott, L-204

2 Oak Ridge National Laboratory

P. O. Box $X$

Oak Ridge, TN 37831

Attn: L. J. Mezga,

B1dg. 1505/106

J. G. Stradley,

B1dg. 7601, MS 002

Joint Integration Office

2201 San Pedro N.E.

Bldg. 3, Floor 2

Albuquerque, NM 87110

Attn: P. G. Hagan

3 Sandia National Laboratories

P. 0. Box 5800

Albuquerque, NM 87185

Attn: J, F. Ney

Technical Library

R. W. Lynch, Bldg. 823,

Dept. 6300

Savannah River Laboratory

E. I. du Pont

Aiken, SC 29808-0001

Attn: E. J. Hennel1y, 773-41A

Weston

2301 Research Boulevard

Rockv111e, MD 20850

Attn: J. F. Strah1
No. of

Copies

West Valley Nuclear Services Inc. P. O. Box 191

West Valley, NY 14171-0191

Attn: J. L. Knabenschuh

\section{EEDERAL AGENCIES}

U. S. Mission to OECD

c/o U. S. Embassy - Paris, FR

APO New York, NY 09777

Attn: A. W. Reynolds

2 Environmental Protection Agency

Office of Radiation Programs

401 M Street, S. W.

Washington, DC 20460

Attn: R. S. Dyer, MC ANR-461

S. Meyers, MC ANR-458

U. S. Nucl ear Regulatory Commission

Office of Inspection and Enforcement

Washington, DC 20555

Attn: D. M. Rohrer, MS $359 \mathrm{EW} / \mathrm{W}$

U. S. Nuclear Regulatory Commission

Office of Nuclear Regulatory Research

Division of Health, Siting, and Waste Management

Washington, DC 20555

Attn: J. L. M. Cortez, MS 1130 SS

\section{EOREIGN AGENCIES}

International Atomic Energy Agency

Wagramerstrasse 5 ,

P. O. Box 100

A-1400 Vienna, Austria

Attn: D. E. Saire 
No. of

Copies

\section{LOCAL OPERATIONS}

3 DOE-Richland Operations Office
P. A. Craig
C. E. Miller
J. D. White

21 Pacific Northwest Laberatory

W. F. Bonner

J. M. Davidson

K. M. Harmon (10)

A. B. Johnson, Jr

L. T. Lakey

I. W. Leigh

D. R. Oden

K. J. Schneider

Publishing Coordination (2)

Technical Information (2)

UNC Nuclear Industries

R. A. Paasch

Westinghouse Hanford Corporation

J. D. Watrous

3

Rockwell Hanford Operations

D. D. Wodrich

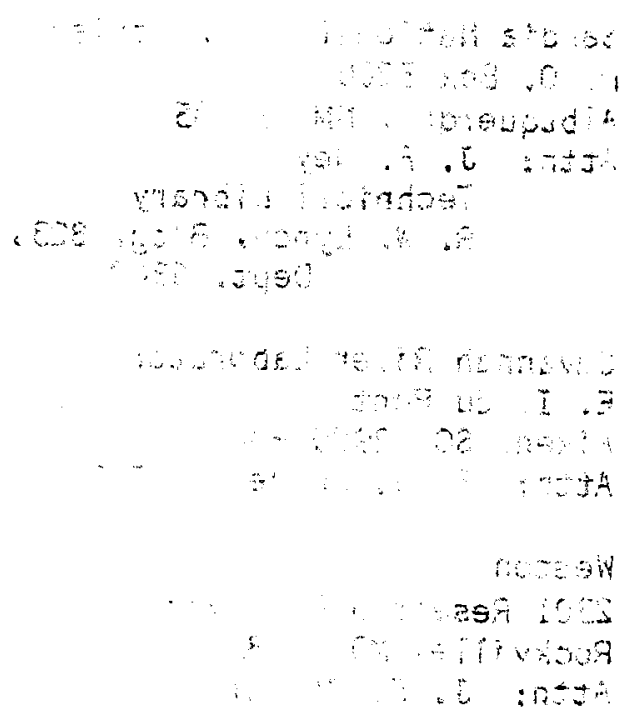


